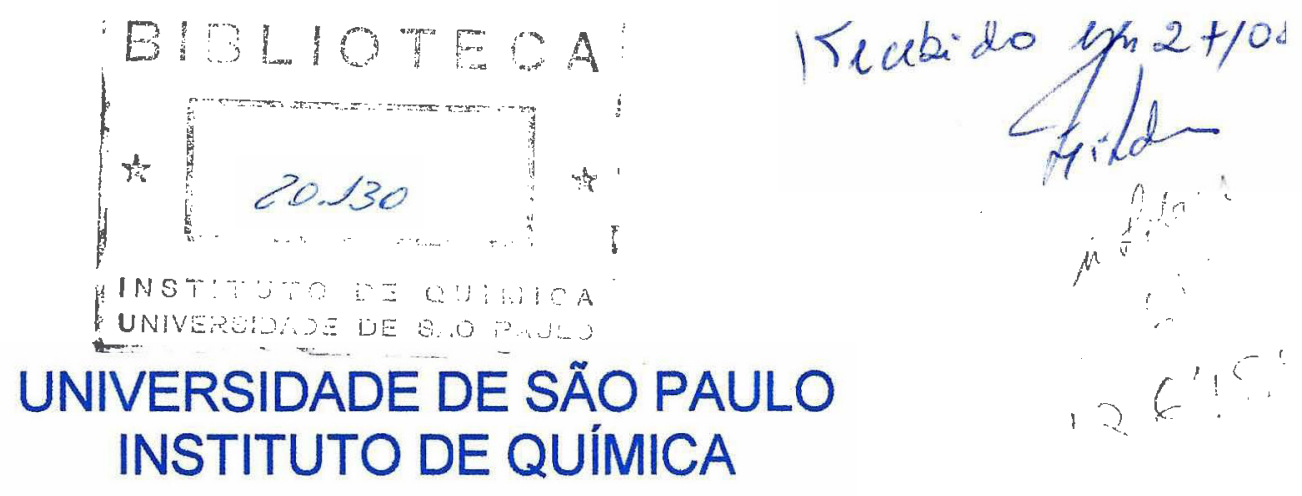

\title{
PRODUÇÃO DE COPOLÍMEROS DE ESTIRENO COM TEMPO DE VIDA CONTROLADO
}

\section{Paulo Cezar Frangiosa}

Tese de Doutorado

Orientador: Prof. Dr. Luiz Henrique Catalani
São Paulo 2002 


\section{"Produção de Copolímeros de Estireno com Tempo de Vida Controlado"}

\section{PALLO CEZAR FRANGIOZA}

Tese de Doutorado submetida ao Instituto de Química da Universidade de São Paulo como parte dos requisitos necessários à obtenção do grau de Doutor em Química Área: Química Orgânica.

Aprovado por:

Prof. Dr. LUIZ HENRIQUE CATALANI

IQ - USP

(Orientador e Presidente)

\begin{tabular}{c}
\hline Prof. Dr. YOSHIO KAWANO \\
IQ - USP \\
\hline Profa. Dra. VERA LUCIA PARDINI \\
IQ - USP
\end{tabular}

\section{Prof. Dr. HELIO WIEBECK}

EP - USP

Prof. Dr. SEBASTIĀO VICENTE CANEVAROLO JUNIOR

UFSCar

SÃO PAULO

29 DE MAIO 2002. 
Ao meu orientador, por me guiar nos momentos de dúvida.

Aos meus amigos, por me incentivarem nos momentos de angústia.

Aos meus pais, por me acalentarem nos momentos de solidão.

Ao meu irmão (in memoriam), por me proteger nos momentos de perigo.

À minfia avó, por me ensinar mais do que qualquer livro.

A Deus, por tê-fos colocado em meu caminfio. 


\section{Agradecimentos}

Ao Lique, pela orientação, amizade e sobretudo por ter acreditado em mim.

À professora Carmem, pela indicação; ao professor Omar, pela ajuda nos primeiros passos; à professora Vera Lúcia, pela confiança depositada.

Ao professor Canevarolo da UFSCar, pela amizade e inestimável contribuição no tratamento dos dados relativos às medidas de cisão e função distribuição cisão de cadeia dos polímeros.

Ao professor Hélio Wiebeck, da Escola Politécnica, pela amizade e importantes sugestões nos ensaios mecânicos dos polímeros.

Ao professor Yoshio Kawano, pela participação e paciência com que norteou nossas discussões.

Aos professores Kachan, Maria Elisa e Dantas, da Universidade de Mogi das Cruzes, pela amizade sincera e pelo apoio recebido durante toda esta jornada.

À professora lara Garcia, pelo primor com que corrigiu este trabalho, e pela delicadeza com que sempre me atendeu.

À Patrícia, Lílian e Décio, pela paciência, pela grande ajuda na construção deste trabalho e, principalmente, pela amizade sincera e incondicional durante todos os dias em que estivemos juntos, ou não.

Ao pessoal do laboratório: Valdecir, Janaína, Sandra, Sascha, Érick, Gabriel, Chien, Xud's, Willi, Daisy, Ivan, Sílvia e Bete, pelos momentos de descontração e inestimável ajuda.

Ao pessoal da Central Analítica e da Secção de Pós-Graduação, em especial à Cibele, pela competência e gentileza com que sempre me atenderam.

Aos meus amigos: Will Cezar, Leny, Luis Pinheiro, Reinaldo, Magali, Cardoso, Gerson, Sônia Nan, Hernandes, Nanci, Ana Maria, Luiz Fernando, Rose, João Coragem, Lorene, João Victor, Maria Júlia e a todos que, injustamente, esqueci.

À Universidade de Mogi das Cruzes, pelo apoio financeiro e, sobretudo, por me confiar seu mais precioso tesouro: os alunos. 
1. Resumo 1

2. Abstract 3

3. Introdução 5

3.1. A Natureza é o Negócio da Década 5

3.2. Plásticos Degradáveis: uma Revisão Crítica 7

3.2.1. O Interesse $\quad 7$

$\begin{array}{lr}\text { 3.2.2. As Aplicações } & 10\end{array}$

3.2.3. Definições e Metodologias 13

$\begin{array}{lr}\text { 3.2.4. Mecanismos para Degradar Plásticos } & 14\end{array}$

A - Fotodegradação $\quad 14$

B-Biodegradação $\quad 17$

$\begin{array}{lr}\text { 3.3. Poliestireno } & 19\end{array}$

3.3.1. Produção 19

3.3.2. Propriedades e Aplicações 21

3.3.3. Degradação $\quad 24$

A - Degradação Térmica $\quad 24$

B - Degradação Térmica-Oxidativa 25

C - Degradação por Radiação lonizante 26

D-Fotodegradação $\quad 27$

3.4. Copolímeros Cetônicos

$\begin{array}{ll}\text { 3.5. Princípios Fotoquímicos } & 37\end{array}$

3.6. Cisão de Cadeia e Função Distribuição Cisão de Cadeia 40

3.7. Considerações Sobre Algumas Técnicas Analíticas Utilizadas 43

3.7.1. Espalhamento de Luz Estático Dependente do Tempo (TDSLS)

3.7.2. Cromatografia por Exclusão de Tamanho (SEC) 49

3.7.3. Análise Térmica (DSC e TG) 51

4. Objetivos 53 
5.1. Sintese e Caracterização do Poliestireno e Copolímeros de Estireno e Butadienos Substituídos

5.1.1. Introdução

5.1.2. A Sintese

5.1.3. Determinação dos Teores de Incorporação dos Comonômeros

5.1.4. Análise Estrutural

5.1.5. Comportamento Térmico

5.1.6. Determinação das Massas Molares

5.1.7. Estudos Cinéticos Através da Equação do Copolímero

5.1.8. Estudos de Superfície por Microscopia Eletrônica de Varredura

5.2. Estudo do Efeito da Radiação UV na Estrutura Química dos Polímeros

5.2.1. Estudo da Cinética de Degradação Absoluta no Ultravioleta dos Polímeros em Solução

5.2.4. Medidas de Cisão de Cadeia e Função de Distribuição Cisão de Cadela

5.3. Estudo do Efeito do Envelhecimento Acelerado no Comportamento Mecânico dos Polímeros

5.3.2. Definições Importantes 102

5.3.3. Ensaios de Tração

\section{Experimental}

7.1. Materiais e Métodos

7.1.1. Reagentes

7.1.2. Solventes

7.1.3. Aparelhagem

7.1.3.1. Espectroscopia de Ressonância Magnética Nuclear

7.1.3.2. Espectroscopia de Infravermelho

7.1.3.3. Espectrometria de Massa

7.1.3.4. Cromatografia Gasosa

7.1.3.5. Cromatografia em Camada Delgada Preparativa

7.1.3.6. Cromatografia de Exclusão por Tamanho

7.1.3.7. Espalhamento de Luz Estático Dependente do Tempo 117

7.1.3.8. Análise Elementar

7.1.3.9. Microscopia Eletrônica de Varredura

7.1.3.10.Calorimetria Exploratória Diferencial 120 
$\begin{array}{ll}\text { 7.1.3.12. Envelhecimento Acelerado } & 120\end{array}$

7.1.3.13. Resistência à Tração 121

7.2. Preparação dos Comonômeros $\quad 121$

7.2.1. Preparação do 2-Trimetilsililóxi-1,3-butadieno (TSB) 121

7.2.2. Preparação do 2-Metóxi-1,3-butadieno (MEB) 124

7.2.2.1. Preparação do 1,3,3-Trimetóxibutano 124

7.2.2.2. Preparação do 2-Metóxi-1,3-butadieno (MEB) 125

$\begin{array}{ll}\text { 7.2.3. Preparação do 2-Etóxi-1,3-butadieno (ETB) } & 127\end{array}$

7.2.3.1. Preparação do 1,3,3-Trietóxibutano 127

7.2.3.2. Preparação do 2-Etóxi-1,3-butadieno (ETB) 129

7.3. Síntese e Purificação do Poliestireno e Copolímeros de Estireno

e Butadienos Substituídos

130

7.3.1. Série TSB: 2-Trimetilsililóxi-1,3-butadieno (MEB) 132

$\begin{array}{ll}\text { 7.3.2. Série MEB: 2-Metóxi-1,3-butadieno (MEB) } & 134\end{array}$

$\begin{array}{ll}\text { 7.3.3. Série ETB: .2-Etóxi-1,3-butadieno (ETB) } & 136\end{array}$

7.4. Hidrólise dos Copolímeros de Estireno e Butadienos Substituídos 138

7.5. Cálculo do Percentual de Incorporação da Carbonila no Homopolímero 139

7.6. Determinação do Fator " $d n / d c$ " para as Soluções Poliméricas 140

7.7. Fotólise do PS e seus Copolímeros

8. Anexos 143

$\begin{array}{ll}\text { 8.1. Espectros } & 143\end{array}$

$\begin{array}{ll}\text { 8.2. Curriculum Vitae } & 156\end{array}$ 


\section{Abreviaturas}

fragmentos finais dos produtos de degradação

ângulo de espalhamento

$\lambda$

comprimento de onda da luz

constante de velocidade

constante de velocidade de degradação inicial

rendimento quântico da clivagem de ligações

$A_{2}$ segundo coeficiente virial copolímero acrilonitrila-butadieno-estireno

2,2'-azobis-iso-butironitrila clorofluorcarbono

DMF dimetifformamida

dn/dc variação do índice de refração em função da concentração

DSC calorimetria exploratória diferencial

ETB 2-etóxi-1,3-butadieno

ETB5 copoli(estireno-co-ETB) $5 \%$ fração molar de ETB

ETB10 copoli(estireno-co-ETB) 10\% fração molar de ETB

ETB15 copoli(estireno-co-ETB) 15\% fração molar de ETB

GC/MS espectrometria de massa acoplada a cromatografia gasosa

HIPS poliestireno de alto impacto

${ }^{1} \mathrm{H}-\mathrm{NMR}$ ressonância magnética nuclear protônica

HPLC cromatografia líquida de alta performance

$I(\phi)$ intensidade de luz espalhada de cada molécula no ângulo (ø) de espalhamento

IR espectroscopia de infravermelho

$K c d I(t) \quad$ razão de espalhamento Rayleigh

LRMS espectrometria de massa de baixa resolução

MEB 2-metóxi-1,3-butadieno 


\section{Abreviaturas}

\begin{tabular}{ll} 
MEB5 & copoli(estireno-co-MEB) $5 \%$ fração molar de MEB \\
MEB10 & copoli(estireno-co-MEB) 10\% fração molar de MEB \\
MEB15 & copoli(estireno-co-MEB) 15\% fração molar de MEB \\
MEV & microscopia eletrônica de varredura \\
$\bar{M}_{n}$ & massa molar média numérica \\
$\bar{M}_{w}$ & massa molar média ponderal \\
$\bar{M}_{\text {w }} / \bar{M}_{n}$ & indice de polidispersidade \\
MVK & metil-vinil-cetona \\
MWD & distribuição de massa molar \\
ONU & Organização das Nações Unidas \\
PE & polietileno \\
PET & poli(tereftalato de etileno) \\
PHB & poli(hidróxi-butirato) \\
PHV & poli(hidróxi-valerato) \\
PP & polipropileno \\
PS & poliestireno \\
$R_{g}$ & raio de giração \\
SAN & copolimero de estireno e acrilonitrila \\
SEC & cromatografia de exclusão por tamanho \\
ST & estireno \\
TBAF & fluoreto de tetrabutilamônio \\
TDSLS & espalhamento de luz estático dependente do tempo \\
TEA & trietilamina \\
TG & termogravimetria \\
$T_{g}$ & temperatura de transição vítrea \\
$T_{m}$ & temperatura de fusão cristalina \\
THF & tetrahidrofurano \\
TLC & cromatografia em camada delgada \\
TMS & tetrametilsilano \\
& \\
\hline
\end{tabular}


TSB 2-trimetilsililóxi-1,3-butadieno

TSB5 copoli(estireno-co-TSB) 5\% fração molar de TSB

TSB10 copoli(estireno-co-TSB) 10\% fração molar de TSB

TSB15 copoli(estireno-co-TSB) 15\% fração molar de TSB

UV radiação no ultravioleta

VR relaxação vibracional 


\section{Resumo}

Este trabalho é direcionado ao estudo dos efeitos da radiação UV sobre amostras de poliestireno (PS) e de copolímeros de estireno com proporções variáveis de 2-trimetilsililóxi-1,3-butadieno (TSB, I), 2-metóxi-1,3-butadieno (MEB, II) e 2-etóxi-1,3-butadieno (ETB, III), em solução aerada, visando principalmente à amplificação da degradação ambiental do PS quando exposto a condições de intemperismo natural.

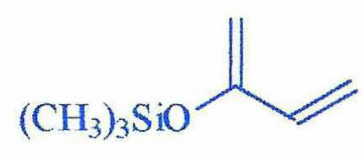

(I)

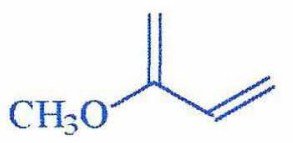

(II)

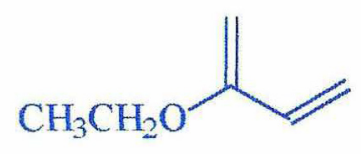

(III)

Os polímeros foram sintetizados via polimerização radicalar em solução, resultando em uma massa molar ponderal média $\left(M_{w}\right)$ de cerca de $30,0 \mathrm{~kg} / \mathrm{mol}$ para o homo e copolímeros.

Estes produtos, após serem submetidos a um processo de hidrólise na presença de fluoreto de tetrabutilamônio (série TSB) ou $\mathrm{HCl}$ aquoso (séries MEB e ETB), resultaram em PS contendo grupos carbonila na cadeia principal sendo, a seguir, isolados e caracterizados por meio de técnicas analíticas como espectroscopia de infravermelho (IR), análise elementar, cromatografia de exclusão por tamanho (SEC), espalhamento de luz estático dependente do tempo (TDSLS), análise térmica (TG e DSC) e microscopia eletrônica de varredura (MEV).

As soluções poliméricas foram irradiadas com lâmpada de mercúrio de baixa pressão (99,5\% de emissão a $254 \mathrm{~nm}$ ), na presença de ar e à temperatura ambiente, por um periodo de dez horas. As alterações sofridas pelos polímeros foram acompanhadas por meio de medidas de IR, TDSLS e SEC. 
Os espectros no infravermelho mostraram um aumento contínuo da intensidade de algumas bandas: na região entre $3800-3000 \mathrm{~cm}^{-1}$, houve um alargamento das bandas que pode ser atribuído à formação de grupos hidroxila e/ou hidroperóxido; na região de $1900-1500 \mathrm{~cm}^{-1}$, observou-se o aparecimento de um ombro em $1712 \mathrm{~cm}^{-1}$, que pode ser atribuído à formação de grupos cetona e aldeído como funções terminais na cadeia do polímero e, na região entre 1500 $1000 \mathrm{~cm}^{-1}, \mathrm{o}$ alargamento das bandas foi atribuído à formação de grupos anidrido.

Os estudos realizados por TDSLS revelaram claramente que os copolimeros degradam com mais rapidez que o PS puro, e as taxas de degradação aumentam proporcionalmente ao aumento no teor de carbonilas incorporadas ao polímero. Tal observação tem suporte nas massas molares ponderais médias obtidas via SEC $\left(\overline{\mathrm{M}}_{\mathrm{w}}\right)$ dos fragmentos resultantes da fotólise, com valores cada vez menores com o aumento dos efeitos da fotodegradação, iniciando com cerca de 34,0 kg/mol (TSB5), por exemplo, e decrescendo a valores de $\bar{M}_{w}$ tão baixos quanto $4,8 \mathrm{~kg} / \mathrm{mol}$ (TSB15).

Para finalizar, tentou-se verificar o comportamento dos polímeros quando expostos a condições reais de utilização, submetendo-se corpos de prova a um envelhecimento acelerado em câmara de intemperismo artificial e avaliando seu comportamento mecânico. Os resultados mostraram que, para homo e copolímeros, houve uma redução na resistência à tração com o aumento do tempo de exposição ( 0 a 600 horas), sendo este efeito muito mais acentuado para os copolímeros. 


\section{Abstract}

This work was directed to the study of the UV radiation effects upon samples of polystyrene (PS) and copolymers of styrene with different fractions of 2trimethylsililoxy-1,3-butadiene (TSB, I), 2-methoxy-1,3-butadiene (MEB, II) and 2ethoxy-1,3-butadiene (ETB, III), in normally aerated solution, aiming at the optimization of the PS degradation when exposed to weathering conditions.<smiles>C=CC(=C)OCC</smiles>

(I)<smiles>C=CC(=C)OC</smiles>

(II)<smiles>C=CC(=C)OCC</smiles>

(III)

The polymers were prepared by free-radical polymerization in solution, resulting in average molecular weight $\left(M_{w}\right)$ of about $30.0 \mathrm{~kg} / \mathrm{mol}$ for the homo and copolymers.

The resulting polymers were submitted to hydrolysis in the presence of tetrabutylamonium fluoride (TSB series) or aqueous $\mathrm{HCl}$ (MEB and ETB series), resulting in PS containing carbonyls inserted in its backbone. The polymers were isolated and characterized by infrared spectroscopy (IR), elemental analysis, size exclusion chromatography (SEC), time dependent static light scattering (TDSLS), thermal analysis (TG and DSC) and scanning electron microscopy (SEM).

The polymeric solutions were irradiated with a low pressure mercury lamp $(99.5 \%$ emission at $254 \mathrm{~nm})$, in the presence of air at room temperature, for a period of 10 hours. The polymer changes were followed by IR, TDSLS and SEC.

The infrared spectra showed a continuous increase in the intensity of some bands: the broad band in the region of $3800-3000 \mathrm{~cm}^{-1}$ was assigned to the formation of hydroxides or hydroperoxides groups; the band at $1900-1500 \mathrm{~cm}^{-1}$ with a shoulder at $1712 \mathrm{~cm}^{-1}$ can be assigned to ketones or aldehydes, which 
appear as chain termination groups and the band at $1500-1000 \mathrm{~cm}^{-1}$ was attributed to the formation of anhydrides.

The TDSLS studies clearly showed that the copolymers degradated much faster than the pure PS, and the degradation rates were directly related to the increase in the TSB, MEB and ETB contents of the polymer. This observation is supported by the decreasing molecular weight values obtained by SEC $\left(\bar{M}_{w}\right)$ for the resulting fragments from photolysis, when the carbonylic content of the polymer increased, starting at around $34.0 \mathrm{~kg} / \mathrm{mol}$ (TSB5), for instance, decreasing to $\overline{\mathrm{M}}_{w}$ values as low as $4.8 \mathrm{~kg} / \mathrm{mol}$ (TSB15).

Finally, we tried to found out the polymer behavior when exposed to the real outdoor conditions of use, by submitting samples to an accelerated aging process in a Weather-o-Meter chamber and evaluating its mechanical behavior afterwards. The results showed that for both, homo and copolymers, there was a reduction in the tensile strength with increasing in the exposition time ( 0 to 600 hours). This behavior is much stronger in the copolymers. 


\section{Introdução}

\subsection{A Natureza é o Negócio da Década}

Os poetas sempre a louvaram em seus versos, sempre se inspiraram nela para produzir rimas idílicas, mas na vida real a natureza foi, ao longo dos tempos, impiedosamente castigada pelos homens. Humilhada. Desprezada. Foram tempos - décadas, séculos - em que poluição e progresso pareceram irmãos siameses. Florestas destruidas, rios contaminados, $\mathrm{o}$ ar das cidades escurecido por nuvens de fumaça. Isso tudo foi sempre considerado o preço a pagar pelo desenvolvimento. Não mais. Primeiro foi a devastação, depois a indignação, e agora é a ação. É como se a humanidade tivesse despertado para o óbvio: não adianta acumular riquezas, erigir um super-PIB ou construir megalópoles se não há ar puro para respirar nem água limpa para beber. O divórcio do século, no limite, não é o que afasta a classe operária do comunismo -é o que separa a poluição do progresso. O capital torna-se cada dia mais verde.

Aos mais céticos, recomenda-se observar os movimentos dos capitães de indústria. Numa recente reunião do World Economic Forum, 650 empresários e executivos das maiores companhias do mundo elegeram o meio ambiente como $o$ desafio número 1 para os negócios nos anos 90. A matriz da Monsanto anunciou investimentos de 600 milhões de dólares até 1992 para reduzir as emissões tóxicas de suas fábricas. Os chefes mundiais da DuPont separaram 1 bithão de dólares para investir num substituto para o clorofluorcarbono, CFC, apontado como destruidor da camada de ozônio. No Brasil, sete grandes empresas anunciaram a criação da Fundação Brasileira para o Desenvolvimento Sustentável, um marco a ser celebrado no calendário ecológico do país. Por desenvolvimento sustentável entenda-se um avanço que não espanque a natureza'.

O Brasil aproxima-se da luz, é verdade, mas com algum atraso e em marcha lenta, tendo em vista o que se passa no Primeiro Mundo. Uma recente 
pesquisa EXAME/Harvard Business Review foi reveladora. $O$ meio ambiente foi sagrado prioridade absoluta para as empresas por apenas $9 \%$ dos respondentes brasileiros - empresários e executivos. O índice entre os japoneses: $44 \%$. Entre os alemães:36\%. Mas que há um avanço no Brasil, isso é inegável. Por muito tempo viveu-se uma espécie de faroeste no país em matéria de meio ambiente, com muitos bandidos e poucos mocinhos. Cada um impunha a sua lei. Madeireiras e fábricas de papel devastavam florestas e não plantavam uma só árvore no lugar das abatidas. A Amazônia foi, aí, palco privilegiado entre 1980 e 1990, em que foram devastados 415.000 quilômetros quadrados de florestas, o equivalente aos territórios de países como Itália, Áustria e Bélgica somados. Mineradores sujavam os rios e igarapés com mercúrio, matavam os peixes, empesteavam as águas. Nas cidades, chaminés expeliam gases venenosos que provocavam doenças respiratórias na população.

Há vários - e animadores - sinais de que um número crescente de empresas brasileiras está sintonizado com os novos tempos:

- o mais notável é a Fundação Brasileira para o Desenvolvimento Sustentável, que será uma espécie de xerife incumbido de vedar as torneiras de financiamentos para projetos que agridam o meio ambiente;

- Cubatão deixou de ser o "Vale da Morte". Embora ainda exista muito a ser feito, a região recebeu da ONU a honraria - inimaginável até há bem pouco tempo - de ser considerada um exemplo de programa de controle ambiental bemsucedido. De 1984 até agora, as indústrias investiram na cidade cerca de 350 milhões de dólares em equipamentos antipoluição;

- a Riocell, do Rio Grande do Sul, investiu 70 milhões de dólares para reduzir mau cheiro que saía de sua fábrica de celulose e eliminar os dejetos despejados no Rio Guaíba. Os resíduos resultantes do processo de produção são convertidos agora em adubos orgânicos e em corretivos para a agricultura;

- a subsidiária brasileira da Colgate-Palmolive iniciou um programa de substituição de suas embalagens plásticas. Até o fim de 2002, o PVC empregado dará lugar a materiais mais facilmente recicláveis;

\footnotetext{
${ }^{1}$ Revista Exame. “A Natureza é o Negócio da Década”, julho (1991).
} 
- em companhias como Ripasa, Fibra, Rhodia e MBR, um novo executivo freqüenta as reuniões da diretoria: é o homem incumbido das questões de meio ambiente. Com o cargo de gerente ou diretor, ele responde diretamente à presidência da empresa. Em casos de emergência, tem autoridade para paralisar a produção.

A Du Pont simboliza os novos tempos. Sua matriz está desativando um negócio de 750 milhões de dólares ao ano apenas porque suspeita de que ele possa trazer danos para a atmosfera. Gestos como esse mostram que estão longe os dias em que a coluna de lucros era o que importava às empresas. As mais avançadas já perceberam que convém esticar os olhos para fora e espiar a paisagem onde operam. Uma natureza devastada hoje é sinônimo de lucros devastados amanhã.

\subsection{Plásticos Degradáveis: uma Revisão Crítica}

\subsubsection{O Interesse}

O interesse em plásticos degradáveis tem crescido muito, por um lado, como resultado do aumento no volume de resíduo sólido municipal e, por outro, da diminuição da capacidade dos aterros para depositá-lo. Além disso, os produtos plásticos estão entre as formas mais visíveis de lixo $0^{2,3,4}$.

O lixo plástico tem causado doenças e morte entre os pássaros, peixes e outras criaturas marinhas. Os problemas dos resíduos sólidos e do lixo em nossas cidades e na zona rural, e especialmente no meio ambiente marinho, têm gerado uma crescente pressão a favor dos plásticos degradáveis, uma das esperanças para amenizar tal situação.

A maioria dos polímeros sólidos (plásticos) são usados como revestimentos, peças estruturais e embalagens sendo, portanto, concebidos e

\footnotetext{
${ }^{2}$ Huang, S.J., Polym.Mater.Sci.Eng., 63 (1990) 633.

${ }^{3}$ Tallman, J., Waste Age, 18 (1987) 141.

${ }^{4}$ Wessling, B., Kunstoffe, 83 (1993) 7.
} 
produzidos para resistir à degradação provocada pelo meio ambiente, incluindo a biodegradação.

Uma vez que os plásticos são, do ponto de vista dos custos de produção, consumo de energia e água, economicamente mais viáveis que os metais, madeiras e vidros, e por provocarem, na maioria dos casos, danos menores ao meio ambiente, sua utilização vem aumentando a passos largos. Esse fato torna o gerenciamento de resíduos poliméricos um problema urgente, demandando soluções compatíveis e amigáveis ao meio ambiente, a curto e médio prazos. Reciclagem, incineração e produção de polímeros degradáveis despontam como possivveis soluções.

Entre os países desenvolvidos destaca-se, de longe, o Japão, que tem feito muitos progressos, tanto em termos de políticas nacionais como na prática; na Europa, a Alemanha está se dedicando ativamente ao desenvolvimento de métodos de reciclagem mecânica; nos Estados Unidos, devido à ausência de uma política nacional, pouco tem sido feito em termos de gerenciamento dos resíduos poliméricos a não ser dispô-los em aterros, atitude que já está se tornando impraticável ${ }^{5}$; no Brasil, mais especificamente na cidade de São Paulo, $87 \%$ do lixo seguem para aterros, $10 \%$ sofrem compostagem e apenas $3 \%$ são incinerados. Os plásticos perfazem $6 \%$ em massa ( $17 \%$ em volume) deste total ${ }^{6}$.

Atualmente, cerca de $50 \%$ dos vidros, $40 \%$ dos papéis e alumínio e apenas $2 \%$ dos plásticos são reciclados. Esta discrepância pode ser explicada por uma série de fatores: elevado custo em coletar, lavar e separar as diversas classes de material plástico antes da reciclagem; baixa qualidade do material coletado; o processo não é eficiente para misturas de plásticos e embalagens alimentícias; freqüentemente há perda das propriedades mecânicas, como resistência ao impacto e/ou ruptura e, finalmente, porque apenas adia o problema do resíduo, uma vez que o processo não leva a um destino final ${ }^{7}$.

\footnotetext{
${ }^{5}$ Huang, S.J., Pure Appl.Chem,. A32 (1995) 593.

${ }^{6}$ Folha de São Paulo. Suplemento Ciência, (1991).

${ }^{7}$ Röper, H.and Koch, H., Starch/Stärke, 42 (1990) 123.
} 
A reciclagem química é potencialmente útil para certos tipos de polímeros. Hoje, somente o poli(tereftalato de etileno), PET, tem sido reciclado na prática ${ }^{8}$.

A incineração dos resíduos em geral é um processo comum. O Japão espera tratar até $70 \%$ dos seus resíduos sólidos por meio da incineração neste século $X X l^{9}$. Nos Estados Unidos, Connecticut é o único estado em que entre $40 \%$ e $60 \%$ dos seus resíduos sólidos municipais são incinerados. Entretanto, uma vez que tais resíduos não são devidamente classificados, cerca de $40 \%$ acabam como cinzas, de difícil descarte ${ }^{10}$.

Uma separação mais criteriosa dos resíduos poliméricos será necessária no futuro. Uma vez que a combustão de poliolefinas relativamente puras gera uma quantidade de calor muito elevada para os fornos tradicionais, novos fomos cerâmicos para altíssimas temperaturas estão sendo requeridos. Isto irá aumentar de maneira significativa os já elevados custos dos incineradores nos dias de hoje utilizados para tal finalidade. Coleta, classificação e transporte são os custos envolvidos antes do processo de incineração propriamente dito.

A geração de $\mathrm{CO}_{2}$ durante a incineração, e os problemas que o mesmo pode causar ao meio ambiente, têm originado muitas barreiras políticas à construção de novos incineradores pelo mundo.

Várias formas de degradação podem ser usadas para o tratamento de resíduos sólidos. O processo mais amigável do ponto de vista do meio ambiente é a biodegradação, ou um processo que leve o polímero a se tornar biodegradável. Além do forte apelo ecológico e do fato de não haver limitação de escala, este projeto apresenta dois grandes desafios: desenvolvimento de novos produtos e a criação de um novo conceito para a sociedade ${ }^{11,12}$.

\footnotetext{
${ }^{8}$ Calendiene, R., Palmer, M. And von Bramiers, Mfod. Plast., (1980) 64.

${ }^{9}$ Plastic Wastes. Disposal and Recycling, Past, Present and Future in Japan, Plastic Waste Management Institute, Tokyo, 1992.

${ }^{10}$ Johnson,K., New York Times, p.Bl (30 de Janeiro de 1989).

${ }^{11}$ Albertsson, ${ }^{2} \mathrm{C}$. and Karlsson, S., in Comprehensive Polymer Science, First Supplement (G.A.Allen, S.L.Agarwal and S.Russo, Eds.), Pergamon Press, London, 1993, p.285

${ }^{12}$ Potts, J.E., Clendinning, R. ${ }^{\text {a }}$, Ackaart, W.B. and Niegisch,W.D., in Polymers and Ecological Problems (J.Guillet, Ed.), Plenum Press, New York, 1973, p.61.
} 


\subsubsection{As Aplicações}

Plásticos degradáveis apresentam uma gama de usos significativamente diferente uns dos outros. Alguns usos como material para suturas em procedimentos cirúrgicos, levando a sua auto-degradação sem necessidade de nova intervenção, por exemplo, têm solucionado com sucesso muitos dos problemas relativos a infecções que ocomiam com freqüência.

O crescente interesse sobre os plásticos degradáveis reside principalmente nos problemas acarretados pelo acúmulo de lixo e na quantidade, cada vez maior, de resíduos sólidos municipais que, de uma forma ou de outra, precisam de um destino. Entretanto, os plásticos degradáveis são também de interesse na agricultura, como materiais de recobrimento e proteção para raízes, em países assolados pela neve, e em recipientes para o plantio de mudas. O processo de compostagem também deve ser destacado, uma vez que possibilita que os plásticos degradáveis sejam combinados com outros materiais biodegradáveis e convertidos a nutrientes para o solo ${ }^{13}$.

\section{- Embalagens e produtos descartáveis}

Uma boa dose da pressão que recai sobre os plásticos degradáveis emerge da infindável quantidade de lixo proveniente de embalagens e produtos descartáveis, atirados na natureza sem qualquer tipo de cuidado. Seja na terra ou na água, o descarte de tais produtos pode causar doença e morte de animais, como pássaros, peixes e outras criaturas terrestres e marinhas que tenham ingerido ou entrado em contato com o lixo. Estudos cuidadosos sobre animais que entraram em contato com artigos plásticos, no lixo e aterros atingidos pelo mar na vizinhança de praias, estão levando os cientistas a perceberem a gravidade das conseqüências do descarte indiscriminado desses materiais ${ }^{14}$.

\footnotetext{
${ }^{13}$ Klemchuk.P.P., Polymer Degradation and Stability 27 (1990) 183.

${ }^{14}$ Cox,M.K., Pure Appl. Chem. A32(4) (1995) 607.
} 
O crescente interesse na manufatura de embalagens e outros produtos descartáveis como plásticos degradáveis já resultou em alguns avanços: copolímeros $(E / C O)^{15,16}$ de etileno com monóxido de carbono (usualmente $1 \%$ de CO) sofrem fotodegradação quando expostos à luz do sol por tempos relativamente curtos (alguns dias), e já estão sendo utilizados pelo comércio em embalagens de latas de cerveja ("six pack rings").

Além dos copolímeros, produtos baseados na incorporação de aditivos já estão disponíveis, incluindo-se $\circ$ uso de compostos férricos ${ }^{17}$, de níquel ${ }^{18,19}$, benzofenonas e também misturas de benzofenonas substituídas ${ }^{20}$ e quelatos de titânio ou zircônio, como agentes sensibilizantes à fotodegradação.

Outra classe que desponta no setor de polímeros degradáveis para a indústria de descartáveis é aquela que contempla a incorporação física de amido granular ou derivados de amido, como aditivos funcionais e cargas para poliolefinas durante o processo de polimerização (extrusão, injeção ou sopro de filmes). Teores variando entre $6-20 \%$ de amido podem ser incorporados no polietileno, por exemplo, de forma que os grãos de amido são uniformemente dispersos na matriz polimérica, sem qualquer tipo de interação química. Tais produtos são encontrados comercialmente sob as marcas BIOPLAST ${ }^{T M}(U K)$ e ECOSTAR $^{\text {TM }}$ (Can). Em filmes de baixa espessura, o amido causa degradação na medida em que propicia o ataque de enzimas: o filme plástico toma-se poroso e, assim, susceptível à degradação oxidativa ${ }^{21}$.

\section{- Revestimento de proteção para raízes ("agricultural mulches")}

Os plásticos degradáveis encontraram um nicho de mercado muito promissor na agricultura, como revestimento de proteção para raízes de plantas.

\footnotetext{
${ }^{15}$ USPat.2.495.286, Du Pont (24/01/50).

${ }^{16}$ GerPat.863.711, Bayer (27/08/41).

${ }^{17}$ USPat.4.121.025, G.Scott (17/10/78).

${ }^{18}$ USPat.4.461.853, Scott-Gilcad (24/07/84).

${ }^{19}$ USPat.4.519.161, Scott-Gilcad (28/05/85).

${ }^{20}$ USPat.4.495.31 1, Princeton Polymer Laboratories, Inc (22/01/85).

${ }^{21}$ Griffin,G.J.L., Biodegradable Fillers in Thermoplastics. Adv.Chem.Ser. 134 (1974) 159.
} 
Tais materiais permitem que os agricultores utilizem o filme plástico para ajudar no crescimento das mesmas e então fotodegradem nos campos, evitando os custos de sua remoção. Tais filmes são desejáveis pois conservam a umidade, reduzem o aparecimento de ervas daninhas e aumentam a temperatura do solo, acelerando a taxa de crescimento.

Os plásticos empregados para esse fim em geral contém aditivos fotosensibilizantes que induzem a fotodegradação. Um sistema particularmente interessante consiste em uma mistura de dibutil-ditiocarbamatos de ferro ou níquel, em proporções tais que a degradação seja iniciada quando a estação de crescimento das plantas está no seu final. Combinações de benzofenonas substituídas com quelatos de zircônio ou titânio também são utilizadas para este fim.

\section{- Recipientes para mudas}

Um pequeno, porém em crescimento, nicho de mercado para os plásticos degradáveis está no uso de policaprolactona na manufatura de pequenos recipientes para mudas depositadas no solo por máquinas de plantio automatizadas. $O$ interessante é que este tipo de polímero é biodegadável dentro de um curto período de tempo: em até 6 meses no solo, a policaprolactona sofre uma biodegradação significativa, resultando em uma perda de massa de cerca de $48 \%$, subindo a $95 \%$ em um período de um ano ${ }^{11}$.

\section{- Compostagem}

A compostagem tem sido alvo das atenções quanto ao destino dos resíduos sólidos por se tratar de uma maneira natural de descarte de lixo biodegradável. Assim, o lixo orgânico, resíduos de jardins e grama despontam como candidatos para a compostagem. Infelizmente, a maior parte das embalagens poliméricas 
comerciais não são adequadas à compostagem, uma vez que sua biodegradação é muito lenta.

Embora atrativo, este método não deve ser considerado uma solução a curto prazo para os problemas do destino dos resíduos plásticos. Compostagem de plásticos biodegradáveis deve ser pensada como uma solução para o futuro ${ }^{22}$.

\subsubsection{Definições e Metodologias}

Polímeros degradados por intempéries são geralmente classificados em quatro diferentes categorias que descrevem o modo pelo qual os mesmos sofrem degradação: biodegradação, degradação hidrolítica, fotodegradação e degradação oxidativa. Estes termos têm sido exaustivamente empregados em várias publicações e de formas muito diferentes. As definições estabelecidas pela American Society of Testing and Materials (ASTM) para plásticos ${ }^{23}$ parecem ser as mais adequadas, sendo bem aceitas no meio acadêmico e industrial.

Um polímero degradável é concebido com a finalidade de sofrer alterações significativas em sua estrutura química sob condições ambientais específicas, acarretando em uma perda variável de suas propriedades, que pode ser quantificada através de ensaios específicos por meio de métodos apropriados ao polímero, por periodos de tempo que determinam sua classificação.

Um polímero biodegradável é um polímero que sofre degradação como resultado da ação de microorganismos presentes no solo e na água, como bactérias, fungos e algas.

Um polímero hidroliticamente degradável é um polímero que se degrada como resultado de um processo de hidrólise.

Um polímero oxidativo é um polímero degradável como resultado da oxidação.

Um polímero fotodegradável é um polímero que sofre degradação por meio da ação da luz solar natural.

\footnotetext{
${ }^{22}$ Graham.S.,Pure Appl.Chem., A32(4) (1995) 641.

${ }^{23}$ ASTM Standards on Environmentally Degradable Plastics, ASTM Publication Code Number (PCN):1993,\#003-420093-19.
} 
Tais definições para polímeros degradáveis referem-se apenas ao processo de degradação e não a um resultado final. São todos parte de um processo que objetiva estabelecer o destino e os efeitos que os polímeros provocam ao meio ambiente, que é o verdadeiro e único interesse para o ambiente, independente dos mecanismos envolvidos na degradação.

\subsubsection{Mecanismos para Degradar Plásticos}

Dois mecanismos genéricos são usualmente considerados para plásticos degradáveis: fotodegradação e biodegradação. Lamenta-se o fato de nenhum cuidado ser tomado para definir que tipo de mecanismo específico está envolvido em um processo particular e ambos são empregados indistintamente. Há uma tendência em se presumir que os plásticos degradam por completo pela biodegradação. Entretanto, na maioria das vezes, a fotodegradação é o processo iniciador.

\section{A - Fotodegradação}

A fotodegradação é um processo de transformações químicas e alterações físicas dos polímeros decorrente da ação da luz ultravioleta (UV) ou visível. Os polímeros absorvem tais radiações por meio de grupos cromóforos que fazem parte de sua estrutura ou estão presentes na forma de impurezas. Tais radiações podem provocar ruptura de ligações químicas dando origem a radicais livres, e a maneira como esses radicais reagem determina a natureza global do processo degradativo. De uma forma ou de outra, ocorre uma redução na massa molecular da matriz polimérica, de modo que os artefatos plásticos se tornam mais quebradiços e desintegram-se.

Há dois mecanismos principais envolvidos na fotodegradação de plásticos. Um deles é a foto-oxidação, processo composto por etapas sucessivas de iniciação, propagação e terminação (Esquema 1). Praticamente todos os plásticos 
disponíveis no comércio são sensiveis à foto-oxidação quando expostos à luz solar, eventualmente perdendo suas propriedades físicas iniciais.

\section{INICIAÇÃO}

$$
\begin{aligned}
\mathrm{IN} \stackrel{\mathrm{h} v}{\longrightarrow} & \mathrm{IN}^{*} \\
\mathrm{IN}^{*}+\mathrm{RH} & \longrightarrow \mathrm{R}^{\circ}
\end{aligned}
$$

PROPAGAÇÃo

$$
\begin{aligned}
& \mathrm{R} \cdot+\mathrm{O}_{2} \longrightarrow \mathrm{RO}_{2} \cdot \\
& \mathrm{RH}+\mathrm{RO}_{2}^{*} \longrightarrow \mathrm{R}^{*}+\mathrm{RO}_{2} \mathrm{H} \\
& \mathrm{RO}_{2} \mathrm{H} \stackrel{\mathrm{hv}}{\longrightarrow \mathrm{RO}_{+} \cdot{ }^{\cdot} \mathrm{OH}} \\
& \mathrm{RH}_{+} \cdot \mathrm{OH} \longrightarrow \mathrm{RH}_{+}+\mathrm{H}_{2} \mathrm{O} \\
& \mathrm{RH}+\mathrm{RO}_{+} \longrightarrow \mathrm{ROH}_{+} \mathrm{ROH}
\end{aligned}
$$

\section{TERMINAÇĀO}

$$
\begin{aligned}
& \mathrm{R}_{s e c} \mathrm{O}_{2}^{\cdot}+\mathrm{R}_{s e c} \mathrm{O}_{2}^{\cdot} \longrightarrow \mathrm{R}_{s e c} \mathrm{OH}+\mathrm{R}^{\prime \prime} \mathrm{CR}^{\prime \prime}+\mathrm{O}_{2} \\
& \mathrm{R}_{\text {tert }} \mathrm{O}_{2}^{\circ}+\mathrm{R}_{\text {tert }} \mathrm{O}_{2}^{\cdot} \longrightarrow[\mathrm{ROOOOR}] \\
& {[\mathrm{ROOOOR}] \longrightarrow \mathrm{R}_{\text {tert }} \mathrm{OOR}_{\text {tert }}+\mathrm{O}_{2}} \\
& {[\mathrm{ROOOOR}] \longrightarrow 2 \mathrm{R}_{\text {tert }} \mathrm{O}^{\cdot}+\mathrm{O}_{2}} \\
& \mathrm{R}_{\text {tert }} \mathrm{O} \cdot \stackrel{\mathrm{O}}{\longrightarrow} \mathrm{R}^{\prime} \mathrm{CR}^{\prime \prime}+\mathrm{R}^{\prime \prime}
\end{aligned}
$$

Esquema 1: Decomposição fotoquímica de polímeros: foto-oxidação.

O segundo mecanismo envolvido na fotodegradação de plásticos é a fotólise de cetonas, que ocorre por meio de duas reações principais denominadas Norrish I e Norrish II (Esquema 2). Esses processos levam, invariavelmente, à cisão da cadeia principal. Estudos demonstraram que grupos cetônicos presentes 
em materiais poliméricos sofrem o mesmo tipo de reações fotoquímicas que as pequenas moléculas de cetonas ${ }^{24,25}$.

Tipo 1<smiles>CCCCCCCCCCCCC[CH][CH+]C(=O)CCCCCCCCCCCCCCCCCC</smiles>

Tipo II<smiles>CCCCC=C=C[CH-]C(=O)CCCCCCCCCCCCCC(=O)CCCCC</smiles>

Esquema 2: Decomposição fotoquímica de polímeros: fotólise de cetonas.

Quando expostos à luz, tais grupos cetônicos absorvem fótons, ocorrendo a cisão subseqüente da cadeia principal do polímero. Nas reações Norrish tipo I, a ligação C - C é quebrada e dois radicais são formados. Freqüentemente monóxido de carbono é eliminado do radical carbonila e dois radicais livres de carbono terminais são gerados, reagindo prontamente com oxigênio, propagandose, desta forma, a foto-oxidação.

O ponto mais importante, entretanto, é que a cadeia principal do polímero é quebrada. Este fato é crucial, uma vez que polímeros dependem da presença de moléculas de tamanho relativamente grandes para manterem suas propriedades físicas. Quando as moléculas grandes são fragmentadas, as moléculas menores resultantes não contribuem efetivamente para a manutenção das propriedades físicas do material e, assim, o mesmo sofre uma perda de resistência, traduzida em um material mais quebradiço e frágil ${ }^{26,27}$.

Pesquisas realizadas por Alexandru e Guillet $(1976)^{28}$ com copolímeros de poli(tereftalato de etileno) contendo teores de 0-5\% em dimetil- $\gamma$-cetopimelato (DMKP), dietil acetil succinato (DEAS) e dietil butiril succinato (DEBS), forneceram

\footnotetext{
${ }^{24}$ Guillet,J.E., Dhanraj,J., Golemba,F.J., and Hartley,G.H., Advan.Chem.Ser., 85 (1968) 272.

${ }^{25}$ Heskins,M., and Guillet.J.E., Macromolecules, 1 (1968) 97.

${ }^{26}$ Scott, G., Atnospheric Oxidation and Antioxidants, Elsevier; (1965) 272.

${ }^{27}$ Scott,G., Developments in Polym.Degradation, 1 ed., N.Grassie.App1.Sci.Pub. (1977) 205.

${ }^{28}$ Alexandru.L., and Guillet,J.E., Joumal of Polymer Science, 14 (1976) 2791.
} 
poliésteres contendo grupos cetônicos na cadeia principal e, quando submetidos à luz UV $(\lambda=313 \mathrm{~nm})$ sofreram fotólise através do mecanismo Norrish tipo I. Li e Guillet $(1980)^{29}$ estudaram o comportamento fotoquímico de copolímeros de etileno com monóxido de carbono (CO), metil-vinil-cetona (MVK) e metilisopropenil-cetona (MIPK) em filmes sólidos, confirmando os mecanismos de Norrish tipos I e II para os fotoprodutos obtidos.

Apesar das consideráveis vantagens apresentadas pelos copolímeros carbonílicos fotodegradáveis, os mesmos são substancialmente mais caros do que os polímeros convencionais utilizados atualmente nas indústrias de embalagens e descartáveis, sendo estas extremamente resistentes a um aumento em seus custos de produção. Conseqüentemente, outras rotas para obtenção de polímeros fotodegradáveis têm sido exploradas, particularmente aquelas que se baseiam na incorporação de aditivos para acelerar a foto-oxidação.

Neste sentido, destacam-se trabalhos que utilizam compostos com metais de transição não-tóxicos (acetil-acetonatos de Fe e Co aditivados em uma matriz de PE, por exemplo $)^{30}$, ou outras combinações como estearato de ferro(III), trimetilol propano dialil éter, dialil ftalato, etil-p-(dimetil-amino) benzoato, entre outros, em LDPE e LLDPE ${ }^{31}$.

\section{B - Biodegradação}

A biodegradação é um processo em que bactérias, fungos, leveduras e suas enzimas (carboidrases, proteases e estearases) consomem uma substância como fonte de alimento. O resultado final é a completa perda da integridade estrutural como conseqüência da redução drástica na massa molecular.

Uma vez que os plásticos têm, por definição, uma massa molecular elevadíssima e são inerentemente inertes, é possível sintetizar novos materiais que degradem de forma extensiva em curtos períodos de tempo.

\footnotetext{
${ }^{29}$ Li,S.K.L., and Guillet,J.E., J.Polym.Sci., 13 (1980) 483.

${ }^{30}$ Amim,M.U., and Scott,G., Eur.Pohm.J., 10 (1974) 1019.

${ }^{31}$ David,C.,Trojan,M., and Daro,A., Polym. Degrad. and Stab., 37 (1992) 233.
} 
Sob condições de umidade, temperatura $\left(20\right.$ a $\left.60^{\circ} \mathrm{C}\right)$, dependendo do tipo de microorganismo, $\mathrm{pH}$ (6 a 8, preferencialmente) e disponibilidade de oxigênio, o processo de biodegradação é relativamente rápido (2 a 3 anos) ${ }^{32}$.

A primeira geração de materiais biodegradáveis consistiu em blendas de polímeros, contendo fontes naturais de alimentos como o amido. A segunda tentativa se concentrou na inserção de grupos funcionais susceptíveis a uma ação microbial, tais como ligações tipo éster, na cadeia principal do polímero ${ }^{33}$. o terceiro caminho foi o desenvolvimento de polímeros sintetizados naturalmente tais como o PHB (poli-hidroxi-butirato), PHV (poli-hidroxi-valerato), ou copolímeros PHBV. O processo envolve a inoculação da bactéria com uma quantidade específica de fonte de carbono, sendo um excesso de nutrientes fornecido para seu crescimento. Em seguida, o suprimento de um nutriente essencial é cortado, limitando o crescimento da célula e ao mesmo tempo estimulando o organismo a converter todo o excesso de carbono em reserva química, ou seja, $\mathrm{PHB}$, por exemplo. Neste estágio, o nível de PHB na célula aumenta de $10 \%$ para $80 \%$ em peso seco. Após evaporação da água e congelamento (ou "spray-drying"), o PHB é extraído com solventes como o clorofórmio ${ }^{34}$. Tal produto é fabricado atualmente pela $\mathrm{ICI}(\mathrm{UK})$ sob o nome comercial $\mathrm{BIOPOL}^{35}$.

O PHB é um poliéster termoplástico com alta cristalinidade (70\%-90\%) e altamente estereoregular, com propriedades físicas comparáveis ao polipropileno, porém um pouco mais quebradiço.

De grande importância para a biodegradabilidade de plásticos foi a descoberta de que hidrocarbonetos de cadeia linear são biodegradáveis somente até uma massa molecular de cerca de $500 \mathrm{u}^{36}$. Acima desse valor a cadeia não é susceptivel ao crescimento de fungos. Não menos importante foi a confirmação do

\footnotetext{
${ }^{32}$ Huang,J.C., Shetty,A.S., and Wang, M.S., Advances in Polyner Technology, 10 (1) (1990) 23.

${ }^{33}$ Bailey, W.J., and Gapud,B, Pohymer Stabilization and Degradation, P.P.Klemchuk ed., ACS Symp.Ser.No.280, Am.Chem.Soc.Washington, DC, 1985, p.423.

${ }^{34}$ Holmes,P. ${ }^{\text {a }}$ Collins,S.H., and Wright,L.F., USPat. 4.477.654 (1984).

${ }^{35}$ Scott, G., Polym. Degrad. and Stab., 29 (1990) 135.

${ }^{36}$ Klemchuck,P.P.Potym.Degrad.and Stab, 27 (1990) 183.
} 
fato de que hidrocarbonetos ramificados também não sofrem ataque de microorganismos ${ }^{37}$.

Uma vez que os polímeros são compostos por moléculas de massas moleculares não idênticas, mas por uma distribuição de massas moleculares, não é surpresa que, mesmo em polímeros com massa molecular média de $2000 \mathrm{u}$ a 3000 u, seja observado o crescimento de fungos. Provavelmente, neste caso, alguns fragmentos com massas moleculares em torno de 500u fazem parte da distribuição de massa molecular do polímero em questão.

Estudos mostraram que hidrocarbonetos lineares com longas cadeias sofrem uma oxidação enzimática apenas nas suas extremidades.

Comumente, a degradabilidade microbial de polímeros sintéticos é estudada por testes de crescimento em meio agar ${ }^{38}$ : fungos elou bactérias são inoculados juntamente com o material polimérico (na forma de filmes, grânulos, placas ou pó). O meio agar contém todos os nutrientes necessários ao crescimento microbial, menos a fonte de carbono. As taxas de crescimento são classificadas de acordo com a fração da superfície do gel recoberta pelas colônias: 0 , quando não ocorre crescimento algum; 1 , para até $10 \%$ de recobrimento; $2,20-30 \% ; 3,30-60 \%$ e 4 para $60-100 \%$ de recobrimento por microorganismos. O PS apresenta uma classificação "1", ou seja, menos de $10 \%$ de recobrimento.

\subsection{Poliestireno}

\subsubsection{Produção}

Entre a descoberta e a comercialização, o estireno foi encontrado casualmente como impureza em diversos processos químicos comerciais e foi preparado em pequenas quantidades por diversas rotas. Isso ocorreu até a descoberta, por Bayer, do craqueamento do etil-benzeno e o desenvolvimento

\footnotetext{
${ }^{37}$ Potts,J.E., "Biodegradation" in H.H.G.Jellinek ed., "Aspects of Degradation and stabilization of Polymers", Elsevier, Amsterdam (1978).
} 
bem sucedido de inibidores de polimerização, quando então o estireno, e conseqüentemente o PS, tornaram-se comerciais.

A primeira tentativa (porém mal sucedida) de processo comercial para a produção do monômero estireno foi feita em 1925, pela "Naugatuk Chemical Company" nos EUA. Quase ao mesmo tempo, a I.G. Farbenindustrie começou a desenvolver um estudo na Alemanha, o qual resultou num processo comercial bem sucedido. Em 1930, a "Dow Chemical Company" entrou na área do estireno com o "cracking" do etil-benzeno e, em 1938, tomou-se a primeira companhia nos EUA a comercializar o poliestireno (PS) ${ }^{39}$.

Com o desenvolvimento de inibidores, necessários para evitar perdas devido à polimerização durante a destilação do etil-benzeno, permitindo a estocagem segura sem formação de polímero, outros processos de síntese foram desenvolvidos, porém o processo de "cracking" do etil-benzeno provou-se tão simples e eficiente que continua sendo a maior rota para a produção do monômero do estireno.

Hoje, o PS é preparado industrialmente pela polimerização radicalar do estireno, utilizando quatro diferentes técnicas:

- em massa: quando o monômero é polimerizado em um reator apropriado, somente em presença de catalisador e aditivos especiais, obtendo-se - polímero sólido. A polimerização em massa para o PS diminuiu quando o mercado evoluiu para produtos residuais mais baixos que o requerido na etapa de desvolatilização. Devido a pequenas quantidades de etil-benzeno presentes no monômetro estireno, desvolatilização e reciclagem levam à produção de etilbenzeno que efetivamente converte qualquer processo em massa, contínuo, em um processo em solução;

- em solução: quando é adicionado um solvente orgânico do PS, obtendose uma solução viscosa do polimero. Esse é o principal processo para o PS,

\footnotetext{
${ }^{38}$ ASTM-D-1924-63 e ASTM-D-2676T.

${ }^{39}$ Whitehead,D. "The Dow Story.McGraw-Hill Book,Co., New York, 1968, 145 (abstract).
} 
devido a sua alta pureza, baixo teor de monômero residual e baixo custo. O PS cristal é produzido atualmente por polimerização em solução por processo contínuo, consistindo de um ou mais reatores (normalmente em série), seguido de remoção completa dos voláteis a altas temperaturas e alto vácuo. O polímero fundido é, então, resfriado e granulado ou peletizado;

- em suspensão: processo caracterizado por se utilizar um solvente que dissolve o monômero, mas não o polímero, como um hidrocarboneto alifático, o que implica em uma polimerização em fase heterogênea, em que o polímero precipita à medida que vai se formando;

- em emulsão: quando o monômero é polimerizado em presença de água, emulsificado por intermédio de agentes especiais, obtendo-se uma dispersão de partículas sólidas em água.

\subsubsection{Propriedades e Aplicações}

Embora o PS seja freqüentemente chamado de PS cristal, esta designação refere-se somente à transparência da resina e não a sua ordem molecular. $O$ sucesso comercial do PS é enorme devido a sua transparência, ausência de cor, facilidade de fabricação, estabilidade térmica, baixa densidade, excelentes propriedades elétricas e baixo custo.

O PS produzido industrialmente é um polímero termoplástico e atáctico (não estereoespecífico), isto é, os grupos laterais estão distribuídos aleatoriamente. Sua natureza amorfa resulta na claridade da resina e na facilidade de fabricação.

PS é solúvel em solventes aromáticos, cetonas, ésteres e hidrocarbonetos clorados, sendo também solúvel em THF, dissulfeto de carbono, tetralina, dioxano, piridina, ciclo-hexano, dimetiltetra-hidrofurano, dietilftalato, dimetilftalato, nitropropano e N,N-dimetilformamida. É insolúvel em álcoois superiores, etanol, metanol e hidrocarbonetos alifáticos e propiolactonas. 
A temperatura de transição vítrea $\left(T_{g}\right)$ do PS depende da massa molar, dos diluentes, variando entre 90 e $100^{\circ} \mathrm{C}$. Abaixo da temperatura $T_{g_{1}}$ o PS possui boa resistência mecânica, permitindo sua utilização em centenas de situações que exigem tolerância à aplicação de cargas. Acima de $T_{g}$ é fluído o suficiente para ser facilmente moldado em formatos adequados.

A sua densidade, a temperaturas de $25^{\circ} \mathrm{C}$, varia entre 1,04 a $1,065 \mathrm{~g} / \mathrm{cm}^{3}$.

$O$ formato da curva de distribuição de massa molar e a magnitude da massa molar média têm uma grande influência nas propriedades térmicas, mecânicas e reológicas do PS. Ainda que a massa molar média, a esteroregularidade e as quantidades e tipos de aditivos sejam mantidos constantes, as propriedades inerentes do PS cristal podem ser alteradas pela simples mudança na forma da curva de distribuição de massa molar, sendo difícil prever quantitativamente os efeitos sobre as propriedades do polímero.

O PS puro, conhecido como resina PS cristal, é adequado para várias aplicações, especialmente onde a transparência é solicitada. Aplicações típicas incluem produtos de embalagens (containers, tampas, garrafas), artigos médicos descartáveis, brinquedos, copos descartáveis, talheres, bobinas de fitas, janelas, peças eletrônicas e algumas aplicações para espuma - cartela de ovos e bandejas para embalagens de carnes.

Equipamentos modernos de processamento utilizam orientação controlada para produzir peças mais resistentes. A resistência à tração pode dobrar e o alongamento à ruptura aumenta em até duas ordens de grandeza, resultando em uma considerável expansão da resistência. $O$ enrijecimento por orientação contribuiu para o sucesso de espumas de PS utilizadas como isolante e como mantas de espuma em embalagens alimentícias.

Popularmente conhecido como isopor ${ }^{\mathrm{TM}}$, o PS expandido foi desenvolvido pela empresa BASF, por meio de cápsulas de estireno ( 0,4 a 2,5 mm de diâmetro) expandidas em até 50 vezes seu tamanho original, em câmaras hermeticamente fechadas e aquecidas à vácuo. O resultado são esferas expandidas aderidas umas às outras, com $97 \%$ de seu volume constituído por ar. 
O ST copolimeriza facilmente com outros monômeros, sendo os copolímeros industriais mais conhecidos: copolímero de ST e butadieno (SBR), que é uma borracha sintética; copolímero de ST e acrilonitrila (SAN), resistente a solventes e rígida; copolímero de ST, acrilonitrila e butadieno (ABS); copolímero de ST, butadieno e metacrilato de metila (MBS) e copolímero de ST, butadieno, acrilonitrila e acrilato de alquila (ASA).

As principais aplicações do PS são encontradas nas indústrias de embalagens, primariamente devido ao seu baixo custo e a sua facilidade de fabricação em altas velocidades. Estes fatores permitem a produção de recipientes atraentes e funcionais a baixo custo, sendo o PS de alto impacto e o cristal os mais usados na indústria de embalagens. Além disso, o tremendo crescimento das indústrias alimentícias tem aumentado a demanda pelo PS. Melhoramentos no odor, na propriedade de transferência de sabor dos "grades" de PS usados para embalagens e sua resistência à radiação gama na faixa de 20 a $30 \mathrm{kGy}$ (2 a 3 Mrad) usada para esterilização, têm contribuído para sua aceitação nesta área.

$\mathrm{Na}$ indústria automobilística, o crescimento do consumo (primariamente ABS e SAN) foi impulsionado pela necessidade de se produzirem veículos mais leves e mais energéticos. O custo para produzir muitas dessas peças e os requisitos para montá-las são consideravelmente menores do que o de algumas das peças que eles substituem.

O crescimento do consumo no mercado de eletrônica origina-se na produção de novos aparelhos, tais como computadores, fitas de videocassetes e novos equipamentos de telecomunicações.

Devido ao seu interesse comercial, sua facilidade de polimerização e sua estrutura linear relativamente simples, o PS é um dos sistemas poliméricos mais intensamente estudados no mundo. A tendência do crescimento futuro para o PS continuará sendo em aplicações em embalagens médicas e eletrônicas. Na área de embalagens, as duas principais áreas de crescimento serão em containers, produzidos a partir de laminados de PS orientados e laminados de espuma. 
Aplicações médicas continuarão a crescer quando mais exames diagnósticos automatizados forem desenvolvidos.

\subsubsection{Degradação}

Dentre os modos de degradação ambiental possivveis para as poliolefinas, destacam-se aqueles que se referem à adição de grupos carbonílicos na cadeia principal ou próximos a ela, seja pela copolimerização com compostos vinilcetônicos ou monóxido de carbono em porcentagens variáveis, pela produção de blendas a partir de homopolímeros contendo grupos carbonílicos, ou ainda pela produção de polímeros enxertados e de bloco ${ }^{40}$.

Como resultado, a carbonila pode estar situada na cadeia principal do polímero e, neste caso, as reações de fotodegradação necessariamente devem gerar polímeros de massa molar menor. Caso a carbonila seja adicionada em cadeia lateral, a clivagem fotoquímica pode originar fotoprodutos idênticos aos anteriores ou não, dependendo do tipo de mecanismo envolvido: Norrish tipo I ou II.

Muito mais abrangente do que a degradação foto-oxidativa é o conceito de auto-oxidação de polímeros. Uma vez que radicais livres podem ser gerados em um vasto número de reações de iniciação, a subseqüente adição de oxigênio molecular aos mesmos é um fenômeno bastante geral. No PS, os modos de iniciação podem ser pela ação do calor, energia mecânica ou ultrassônica, luz, radiação de alta energia, produtos químicos ou meios biológicos.

\section{A - Degradação Térmica}

A degradação térmica do PS ocorre por mecanismo radicalar, envolvendo as etapas de iniciação, propagação (durante a qual transferências de cadeia inter e intramoleculares ocorrem) e terminação de $1^{a}$ ordem $^{41}$. No vácuo, o PS começa

\footnotetext{
${ }^{40}$ Guillet,J.E., Polymers and Ecological Problems, J.E.Guillet ed.,Plenum Press, New York, 1973

${ }^{41}$ Guyot,A.,Polym.Degrad. and Stab., 15 (1986) 219.
} 
a apresentar perda de massa a cerca de $300^{\circ} \mathrm{C}$, porém, redução da massa molar pelas quebras de cadeia pode ser observada em temperaturas mais baixas. CAMERON et al. [1984] ${ }^{42}$ verificaram que as velocidades de degradação dependem da técnica pela qual o polímero foi sintetizado.

\section{B - Degradação Térmica-Oxidativa}

Quando o PS é submetido à radiação UV na presença de ar, ele sofre um rápido amarelamento, tornando-se gradualmente mais quebradiço. Do ponto de vista industrial, descoloração constitui um importante efeito adverso de envelhecimento do PS quando exposto às intempéries.

As teorias mais aceitas atualmente para a oxidação de polímeros são baseadas em mecanismos via radicais livres para a oxidação térmica de hidrocarbonetos, propostas por BOLLAND \& GEE $^{43,44,45,46}$ : há a formação de um grupo peróxi e, a partir deste, o mecanismo de degradação passa pelas etapas de iniciação, propagação, ramificação radicalar da cadeia e terminação $47,48,49$.

DICKENS [1980] ${ }^{50}$ estudou as energias de ativação para a degradação térmica do PS acima de $350^{\circ} \mathrm{C}$ na ausência e presença de oxigênio, utilizando termogravimetria. No vácuo ou em atmosfera de nitrogênio, a energia de ativação é $188 \mathrm{~kJ} / \mathrm{mol}(44,9 \mathrm{kcal} / \mathrm{mol})$, mas, com excesso de oxigênio, decresce para $90 \mathrm{~kJ} / \mathrm{mol}(21,5 \mathrm{kcal} / \mathrm{mol})$.

KAMYUA \& NIK $[1978]^{51}$ sugeriram que as etapas para a degradação radicalar do PS na presença de oxigênio fossem muito similares àquelas da fotodegradação. De início, o radical poliestireno, gerado termicamente, reage com

\footnotetext{
${ }^{42}$ Cameron,G.G.;Bryce,W.A.J.;McWalter,I.T ,Eur.Polym.J., 20(6) (1984) 563.

${ }^{43}$ Bolland,J.L., Quart. Yer., 3 (1949) 1.

${ }^{44}$ Bolland,J.L.. and Cooper,H.R., Proc.Roy.Soc., 225 (1954) 405

${ }^{45}$ Bolland,J.L., and Gee,G., Trans.Faraday.Soc., 42 (1946) 236.

${ }^{46}$ Bolland,J.L., and Gee,G., Trans.Faraday Soc., 42 (1946) 244.

${ }^{47}$ Rabek,J.F., in Comprehensive Chemical Kinctics, (Ed. C.H.Bamford and C.F.Tipper). Elsevicr, Amsterdam, 14 (1974) 425.

${ }^{48}$ Guillet,J.E., Pure and Appl.Chem., 30 (1972) 135.

${ }^{49}$ Ranby,B., and Lucki,J., Pure \& Appl. Chem., 52 (1980) 295.

${ }^{50}$ Dickens,B., Polym.Degrad.and Stab., 2 (1980) 249.

${ }^{51}$ Kamiya,Y.;Niki,E.H.H.G., Jellinek ed., em Aspects of Degradation and Stabilization of Polymers, Elsevier Science Publishing Co.,Inc., New York, 1978, p.79.
} 
dez vezes mais rapidez com uma molécula de oxigênio do que com uma molécula de PS. O radical peroxila resultante abstrai rapidamente um hidrogênio terciário, formando um hidroperóxido-poliestireno. Esta etapa de propagação é repetida enquanto existir oxigênio. A decomposição térmica do hidroperóxido pode produzir diversas espécies oxigenadas. VU DUC \& HUYNH [1986] ${ }^{52}$ identificaram os produtos termo-oxidativos do PS como benzaldeído, ácido benzóico, acetofenona, fenol, álcool benzílico, cinamaldeido, estireno dímero e trímero do estireno. Em um trabalho posterior, estudaram a degradação do PS aniônico aquecido a $225^{\circ} \mathrm{C} \mathrm{em}$ ampolas seladas, sob quantidades controladas de pressão de ar, para identificar os produtos de degradação e determinar como suas concentrações dependem da concentração de oxigênio presente. Os produtos em maior quantidade foram estireno, trímero estireno e benzaldeido, os produtos minoritários foram dímero estireno, acetofenona e $\alpha$-metilestireno. Tanto a identificação como as análises quantitativas foram feitas por cromatografia gasosa.

\section{C - Degradação por Radiação lonizante}

O PS é altamente resistente à degradação por radiação ionizante, em particular sob vácuo ou em atmosferas inertes. Esta notável estabilidade é devido à presença de grupos fenila, os quais exercem um efeito protetor em PS (e polímeros aromáticos similares) por meio da dissipação da energia de excitação sem decomposição ${ }^{53}$.

Quando placas de PS são expostas a doses relativamente altas de radiação gama, ao ar, sua resistência mecânica decresce rapidamente, porém não é afetada pela irradiação sob vácuo ${ }^{54}$. Radicais poliméricos reagem originando ligações cruzadas sob vácuo, ou reagindo com oxigênio do ar para formar peróxidos, que levariam a reações de cisão oxidativa da cadeia ${ }^{55}$. A difusão de oxigênio, doses de irradiação e espessura da amostra têm um efeito significativo.

\footnotetext{
${ }^{52}$ Vu Duc, T.and Huynh,C.K., Trav.Chim.Aliment.Hyg., 76 (1986) 48.

${ }_{53}^{53}$ Chapiro,A. Radiation Chem istry of Polymeric Systems, Interscience Publishers, London, 1962, p.446.

${ }^{54}$ Nichol,J.M.J.Polym.Sci.,Polym.Chem.Ed.,15 (1977) 2919.

${ }^{55}$ Bowmer,T.N., J.Appl.Polym.Sci., 24 (1979) 425.
} 
Quando corpos de prova de PS para o ensaio de tração foram expostos à radiação gama, ao ar, a cisão de cadeia predominou na superfície, enquanto ligações cruzadas predominaram no interior da amostra. Cisão da cadeia na superfície é o fator principal na perda das propriedades mecânicas, quando o PS é irradiado em presença do ar.

\section{D - Fotodegradação}

Os mecanismos de foto-oxidação do PS em comprimentos de onda curtos e longos não devem ser considerados como definitivamente estabelecidos. Um número razoável de diferentes fotoprodutos são formados, e uma larga gama de mecanismos podem ser propostos. A formação de hidroperóxidos como fotoprodutos primários já está bem estabelecida, enquanto que vários tipos de reações secundárias são reportadas e envolvem: fotólise direta; decomposição por transferência de energia e decomposição intramolecular de peróxidos, levando à formação de compostos carbonílicos e hidroxilas $56,57,58,59,60$.

WANDELT et al.[1980] ${ }^{61}$ estudaram a degradação foto-oxidativa do PS na forma de filmes, utilizando luz a $254 \mathrm{~nm}$, desde a temperatura ambiente até temperaturas próximas à sua $T_{g}\left(92^{\circ} \mathrm{C}\right)$. Observou-se que a fotodegradação é mais rápida quanto mais alta a temperatura de exposição dos filmes, e os valores de $M_{w}$ e $M_{n}$ decaem consideravelmente nas amostras irradiadas a altas temperaturas por curtos períodos de tempo. Para longos períodos de irradiação, entretanto,não foram observadas diferenças significativas nos valores de massas molares, independentemente da temperatura da irradiação.

A variável mais importante na fotodegradação do PS é o comprimento de onda da radiação incidente. O espectro de absorção no ultravioleta (UV) do PS

\footnotetext{
${ }^{56}$ Dulog,L., and David.K., Makromol.Chem., 145 (1971) 67.

${ }^{57}$ Geuskens,G.,Baeyens-Volant,D., Delaunois,G., Lu-Vinh, Q., Piret,W., and David,C., Eur.Polym.J., 14 (1978) 291.

${ }^{58}$ Geuskens, G.,Baeyens-Volant,D., Delaunois,G., Lu-Vinh, Q., Piret,W., and David,C., Eur.Pohym.J., 14 (1978) 299.

${ }^{59}$ Khalil,Z., Michaille,S., and Lemaire,J., Makromol.Chem., 188 (1987) 1743.

${ }^{60}$ Lucas,P.C., and Porter,R.S., Potym.Deg.Stab., 261 (1989) 203.

${ }^{61}$ Wandelt,B., Brzezinski,J., and Kryszewski, M., Eur.Polym.J., 16 (1980) 583.
} 
(Figura 1) ${ }^{62}$ mostra que o polímero absorve fortemente em comprimentos de onda menores que $290 \mathrm{~nm}$. Embora a luz solar que atinge a terra não contenha esses comprimentos de onda e, portanto, não seja absorvida pelo $P S$, muitos pesquisadores optaram por estudar a fotodegradação do PS quando irradiado a $254 \mathrm{~nm}$. A radiação UV neste comprimento de onda é facilmente gerada e é absorvida fortemente pelo polímero, resultando em alterações marcantes em um tempo relativamente curto ${ }^{63}$. Assim sendo, as fotodegradações sob condições de baixos e altos comprimentos de onda e de intemperismo natural serão consideradas, neste texto, separadamente.

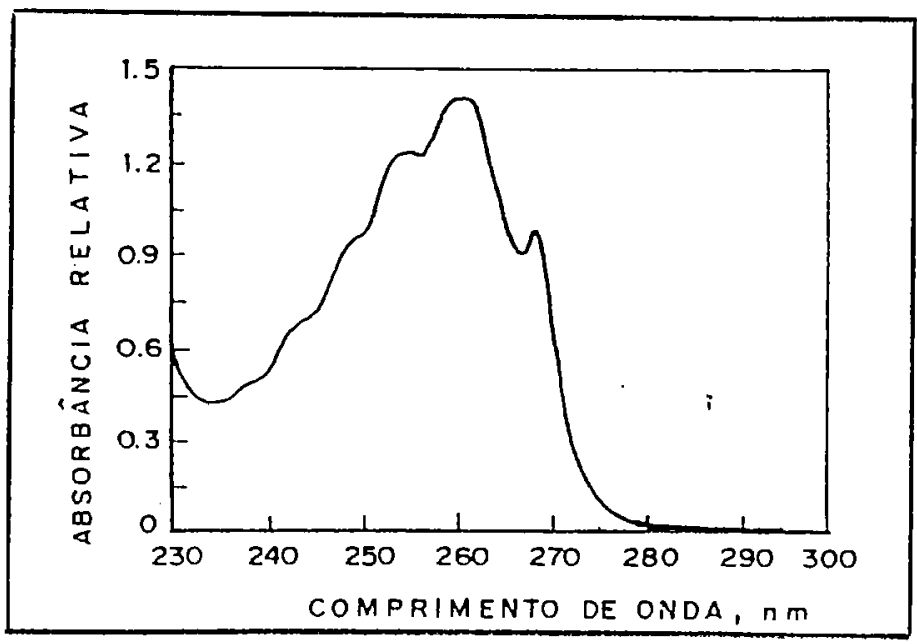

Figura 1: Espectro de absorção no ultravioleta do PS (em THF) ${ }^{62}$.

\footnotetext{
${ }^{62}$ Maecker.N.,The Dow Chemical Company, Midland. Mich..1987.

${ }^{63}$ Weir.N.A.. New Trends Photochem.Polym., 11 (1985) 169.
} 
O mecanismo de fotooxidação do PS em comprimentos de onda curtos e longos não pode ser considerado como estabelecido definitivamente. Vários fotoprodutos são formados e uma grande variedade de mecanismos pode ser proposta, sendo a formação de hidroperóxidos como fotoproduto primário bem estabelecida.

WEIR \& WHITING [1989] $]^{64}$ verificaram diversos tipos de reações secundárias, envolvendo a fotólise direta, decomposição por transferência de energia e decomposição intramolecular de hidroperóxidos, levando à formação de compostos carbonilícos e hidroxilados. Cetonas aromáticas, formadas pela decomposição de hidroperóxidos terciários, também foram observadas. Cetonas alifáticas seriam formadas pela oxidação do átomo de carbono secundário da cadeia principal do polímero. Peroxiésteres, resultantes da formação de cetonas alifáticas, foram detectados nos espectros de infravermelho do PS foto-oxidado. Produtos voláteis como água, dióxido de carbono, benzaldeido e acetofenona também foram detectados e identificados.

GARDETTE et al.[1995] ${ }^{65}$ realizaram um estudo geral dos mecanismos de foto-oxidação do PS, pela identificação dos produtos da fotólise por absorção no infravermelho, utilizando vários tratamentos físicos e químicos de filmes fotooxidados em comprimentos de onda longos $(\lambda \geq 300 \mathrm{~nm})$ e curtos $(\lambda=253,7 \mathrm{~nm})$. A partir destes resultados propuseram um mecanismo geral para explicar a fotodegradação do PS (Esquema 3).

Exceto para os estágios iniciais, como apresentado no Esquema 3, este mecanismo descreve as foto-oxidações em comprimentos de onda longos e curtos. Os mesmos fotoprodutos são observados em ambas as condições, diferindo nas concentrações e na forma de algumas bandas de absorção no infravermelho.

\footnotetext{
${ }^{64}$ Weir,N.A. and Whiting,K.,Eur:Polym.J., 3 (1989) 291.

${ }^{65}$ Gardette,J.: Mailhot.B.; Lemaire,J., Pohm.Degrad and Stab., 48 (1995) 457.
} 
GARDETTE et al. [1995] mostraram que os fotoprodutos de oxidação a comprimentos de onda curtos são formados em camadas altamente superficiais, sendo estas, portanto, muito oxidadas e os diferentes fotoprodutos alcançaram concentrações locais muito altas. Medidas por espectroscopia na região do infravermelho revelaram uma contribuição fraca de grupos livres. Em contraste, irradiação em comprimentos de onda longos levam a uma distribuição homogênea de fotoprodutos, através de matriz oxidada. As concentrações locais são, então, bastante baixas e grupos hidroxilas livres podem ser observados.

As análises das camadas superficiais (aproximadamente $2 \mu \mathrm{m}$ de espessura cada) de amostras foto-oxidadas a $254 \mathrm{~nm}$ confirmam que os fotoprodutos de oxidação apresentam uma distribuição heterogênea, ainda que nos $15 \mu \mathrm{m}$, onde ocorre a foto-oxidação. Esta heterogeneidade resulta de menores concentrações de fotoprodutos de baixa massa molar próximos à superfície.

Um dos pontos mais notáveis da oxidação fotoquímica do PS é que muitos fotoprodutos formados são compostos de baixa massa molar. A maioria deles foi identificada: benzaldeido, ácido benzóico, acetofenona, ácido fórmico, ácido acético, anidrido benzóico e benzeno. Dependendo das condições da irradiação, alguns de tais produtos se volatilizam e a análise no infravermelho revela diferenças aparentes de estequiometria, que podem ser confundidas com efeitos de comprimento de onda. 


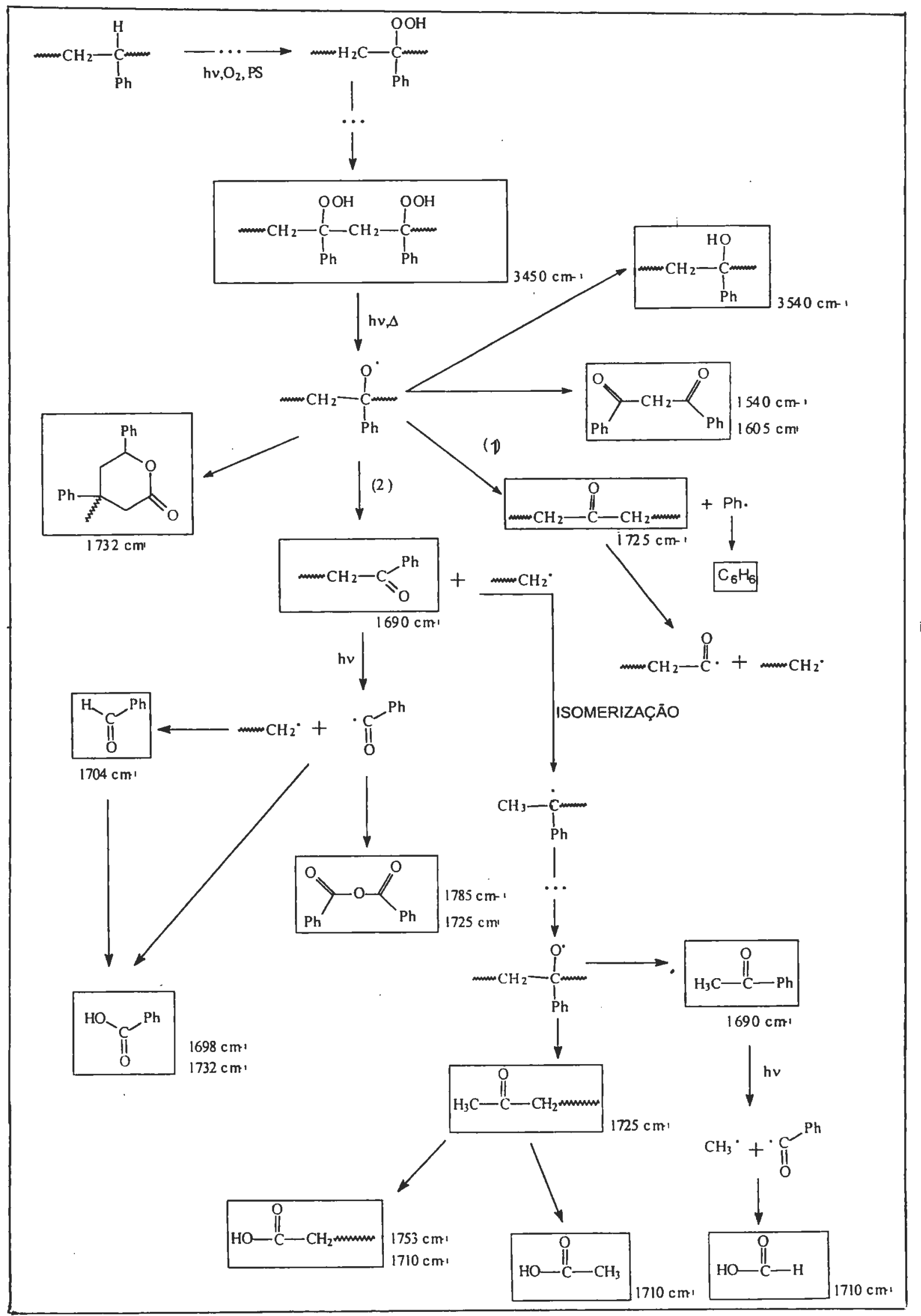

Esquema 3: Proposta para a fotodegradação do PS. 
As reações predominantes no PS exposto a condições de intemperismo natural são: quebra da cadeia, amarelamento e formação de estruturas oxigenadas $^{66}$.

Diversos trabalhos de vários pesquisadores constataram que o polímero puro não absorve comprimentos de onda presentes na luz solar, e que a iniciação seria atribuída à presença de impurezas cromóforas formadas durante a polimerização e processamento ${ }^{67,68,69,70,71,72}$. Tais impurezas incluem peróxidos iniciadores, resíduos de monômero, hidroperóxidos e grupos terminais acetofenona. Iniciadores peróxidos são formados no PS preparado em processo radicalar por copolimerização com traços de oxigênio, enquanto hidroperóxidos e grupos acetofenona são formados por oxidação térmica durante o processo de fusão. A iniciação por peróxidos e hidroperóxidos é devida a radicais formados por homólise da ligação O-O. Uma vez iniciada a degradação, ocorre a formação de radicais poliestireno por abstração de hidrogênio. Os radicais poliestireno podem reagir com oxigênio e outras moléculas de PS, numa reação de propagação de cadeia. A seqüência de reações normalmente acompanha certas etapas, em que IN é o iniciador e $\mathbf{P}$ é a molécula de polímero, conforme mostrado no Esquema 4.

\footnotetext{
${ }^{66}$ Davis,A.and Sims,D. Styrene Polymers, em Encyclopedia of Polymer Science and Technology,Ed.H.F.Mark,N.G.Gaylord;N.M.Bikales, John Wiley \& Sons, New York, 1971.

${ }^{67}$ Lawrence,J.B. and Weir,N.A.. J.Polym.Sci.Chem.Ed, 11 (1973) 105.

${ }^{68}$ George,G.A.and Hodgeman,D.K.C., Eur.Polym.J., 13 (1977) 63.

${ }^{69}$ Ranby,B.and Lucki,J., J.Pure Appl.Chem., 52 (1980) 295.

${ }^{70}$ Chiantore,O.; Camino, G.; Costa,L and Grassie,N., Pohm.Deg.Stab., 3 (1981) 209.

${ }^{71}$ Geuskens,G., Polym.Degrad.and Stab., 3 (1981) 295.

${ }^{72}$ Weir,N.A., Developments in Polymers Photodegradation, $4^{\text {a }}$ Ed., N.Grassie, Applied Science Publishers, London, 143, 1982.
} 


$$
\begin{array}{rl}
\mathrm{IN} & \stackrel{h v}{\longrightarrow} \mathrm{IN}^{\cdot} \\
\mathrm{N} \cdot+\mathrm{PH} & \longrightarrow \mathrm{P} \cdot \\
\mathrm{P} \cdot+\mathrm{O}_{2} & \longrightarrow \mathrm{POO} \cdot \\
\mathrm{POO} \cdot+\mathrm{PH} & \longrightarrow \mathrm{POOH}+\mathrm{P} \cdot \\
\mathrm{POOH} & \mathrm{hv} \\
\mathrm{PO} \cdot+\mathrm{PH} & \longrightarrow{ }^{\circ}+{ }^{\circ} \mathrm{H} \\
\cdot \mathrm{OH}+\mathrm{PH} & \longrightarrow \mathrm{PH}^{+\mathrm{P} \cdot}
\end{array}
$$

Esquema 4: Formação de radicais PS.

WEIR \& GRASSIE [1982] ${ }^{73}$ estudaram a fotólise iniciada por hidroperóxidos e verificaram que os radicais alcoxila podem sofrer quebra da ligação $C-C \beta$ ao centro radicalar, para formar grupos terminais acetofenona (Esquema 5).<smiles>CCC(C[C+]([O-])c1ccccc1)C(=O)CCCCCC([O-])c1ccccc1</smiles>

Esquema 5: Formação de grupos terminais acetofenona.

As reações levando à formação de polienos conjugados, como na fotólise a baixo comprimento de onda, são menos prováveis durante o intemperismo natural, devido a reações oxidativas competitivas. WEIR \& GRASSIE [1982] ${ }^{72}$ propuseram que estruturas oxigenadas tais como cetonas $\alpha, \beta$-insaturadas podem também contribuir para o amarelamento. 


\subsection{Copolímeros Cetônicos}

Em 1950, NORRISH e GUILLET descobriram que, sob irradiação por luz UV, poli(metil-vinil-cetona) sofre as mesmas reações de clivagem fotoquímica que as pequenas moléculas de cetonas.

Estudos realizados por WISSBRUM $[1959]^{74}$ e LINDENAU et al. [1977] ${ }^{75}$ revelaram que, no caso da poli(metil-vinil-cetona), o processo Norrish tipo I envolve clivagem do grupo acila lateral, gerando um radical polimérico e um radical acila, enquanto o mecanismo Norrish tipo II resulta em ruptura da cadeia para gerar ligações duplas terminais e unidades cetona. Outros copolímeros de cetonas, tais como poli(metil-isopropenil-cetona) ${ }^{76}$, poli(fenil-vinil-cetona) ${ }^{77}$ e poli(metacrilato de metila) copolimerizado com vinil-cetonas ${ }^{78}$ também passam por processos similares de fotodegradação.

RANBY \& RABEK [1975] ${ }^{79}$ e GEUSKENS \& DAVID [1975] ${ }^{80}$ desenvolveram um método de fotodegradação baseado na adição de cetonas aromáticas (como benzofenonas, por exemplo) na cadeia do PS, facilitando a geração de radicais poliméricos oxidáveis. RABEK $[1987]^{81}$ realizou ensaios com incorporação de cetonas por meio da síntese de PS com grupos laterais foto-lábeis ou em segmentos da cadeia principal. Em ambos os métodos, a cetona absorve luz, elevando-se a um estado excitado e, subseqüentemente, reage por abstração de hidrogênio e/ou clivagem da ligação.

DAN \& GUILLET [1973] ${ }^{82}$ mostraram que os estados singlete de mais baixa energia e triplete são estados tipo $n-\pi^{*}$ em dialquil e alquil-fenil-cetonas. Assim,

\footnotetext{
${ }^{73}$ Weir,N.A. and Grassie, N., Eds., Dev .Polym.Deg., 4 (1982) 143.

${ }^{74}$ Wissbrum,K.F., J.Am.Chem.Soc., 81 (1959) 58

${ }^{75}$ Lindenau,D.; Beavan,S.W.; Beck, G.; Schnabel,W., Eur:Pohm.J., 13 (1977) 819.

${ }^{76}$ Bargon,J., J.Polym.Sci., Polym.Chem.Ed., 16 (1978) 2747.

${ }^{77}$ Encinas,M.V.; Funabashi,K.; Scaiano, J.C., Macromolecules, 6 (1979) 1167.

${ }^{78}$ Bond,S.G. and Ebdon,J.R., Polymer Commun., 32 (1991) 290.

${ }^{79}$ Ranby,B. and Rabek,J.F., Photodegradation, Photooxidation and Photostabilization of Polymers, Interscience Publishers, New York, 1975.

${ }^{80}$ Geuskens, G. and David,C., em Degradation and Stabilization of Polymers, Ed.G.Genskens, Applied Science Publishers, London, 113, 1975.

${ }^{81}$ Rabek, J.F., Mechanisms of Photophysical Process and Photochemical Reactions in Polymers, John Wilew and Sons, New York, capítulo 14, 1987.

${ }^{82}$ Dan,E., and Guillet,J.E., Macromolecules, 6 (1973) 230.
} 
uma excitação com radiação UV leva à promoção de um elétron não-ligante para um estado singlete anti-ligante $\pi^{*}$. Devido à rápida relaxação vibracional (VR) ao nível vibracional de mais baixa energia, mesmo a baixas temperaturas, todos os processos subseqüentes ocorrem no nível vibracional fundamental do estado singlete excitado $n-\pi^{*}$.

Uma série de polímeros com fotodegradabilidade amplificada foram preparados por meio da copolimerização do estireno. Os copolímeros com metilvinil-cetonas (MVK) foram estudados por KATO \& YONESHIGE [1973] $]^{83}$, SHIMURA [1978] $]^{84}$, NENKOV et al. [1983] ${ }^{85}$, STOYANOV \& NENKOV [1992] ${ }^{86}$, KNITTEL \& KILP [1983] ${ }^{87}$ e GOLEMBA \& GUILLET [1972] ${ }^{88}$. A copolimerização do estireno com fenil-vinil-cetonas teve seu desenvovimento baseado nos trabalhos de KATO \& YONESHIGE $[1973]^{82}$, LUKAC et al. [1972] ${ }^{89}$, DAN \& GUILLET $[1973]^{90}$ e NENKOV et al. [1980] ${ }^{91}$, tendo estes últimos também desenvolvido trabalhos com metil-isopropenil-cetonas. As terc-butil-vinil-cetonas foram estudadas por TANAKA \& OTSU [1977] ${ }^{92}$, enquanto SENO et al. [1975 $]^{93}$, HRDLOVIC et al. [1980] $]^{94}$ e SHIRAISHI et al. [1976] ${ }^{95}$ pesquisaram a copolimerização do estireno com benzalacetona e benzala-acetofenona.

GUILLET $^{96,97}$ patenteou artigos fabricados a partir de resinas estireno-vinilcetonas. Concentrados de copolímeros estireno-metil-isopropenil-cetona são vendidos usualmente como aditivos para PS fotodegradáveis, sob o nome comercial ECOLYTE ${ }^{\text {TM }}$, sendo recomendadas aditivações da ordem de $5-10 \%$ em

\footnotetext{
${ }^{83}$ Kato,M. and Yoneshige,Y,, Die Makrom.Chem., 164 (1973) 159.

${ }^{84}$ Shimura,Y., J.Appl.Polym.Sci., 22 (1978) 1491.

${ }^{85}$ Nenkov,G.; Bogdanzaliev, T.; Stoyanov,A.; Kabaivanov,W., Angew. Makromol.Chem., 114 (1983) 25.

${ }^{86}$ Stoyanov,A. and Nenkov,G., Polym.Degrad.and Stab., 36 (1992) 121.

${ }^{87}$ Knittel,T.W. and Kilp,T., J.Polym.Sci., Pohy.Chem.Ed., 21 (1983) 3209.

${ }^{88}$ Grolenba,F.J. and Guillet,J.E., Macromolecules, 5 (1972) 212.

${ }^{89}$ Lukac,I,; Zvara,I.; Hrdlovic,P.; Manasek,Z., Chem.Zvesti, 26 (1972) 404.

${ }^{90}$ Dan.E.; Somersall, A.C. and Guillet, J.E., Macromolecules, 6 (1973) 228.

${ }^{91}$ Nenkov,G.; Georgieva,T.; Stoyanov,A.; Kabaivanov,V., Angew Makromol.Chem., 91 (1980) 69.

${ }^{92}$ Tanaka,H. and Otsu.T., J. Polym.Sci.,Poly.Chem.Ed., 15 (1977) 2613.

${ }_{93}^{93}$ Seno,M.; Shiraishi,S.;Ishili,M.; Asahara,T., Nippon Kagaku Kaishi, 5 (1975) 904.

${ }_{94}^{94}$ Hrdlovic,P; Lukac,I.; Zvara,I.; Kulickova,M.; Berek,D., Eur.Polym.J., 16 (1980) 651.

${ }^{95}$ Shiraishi,S.; Seno,M.; Ishii,M.; Asahara,T., J.Appl.Pohm.Sci., 20 (1976) 2429.

${ }^{96}$ Guillet,J.E., US.Pat. 375.39.52, 1 August 1973.

${ }^{97}$ Guillet,J.E.. US.Pat. 386.05.38, 4 January 1975.
} 
peso. Nesta área, HANNER et al. $[1993]^{98}$ prepararam blendas de PS com concentrados de copolímeros vinil-cetonas (ECOLYTE ${ }^{\text {TM }}$ ) e copolímeros MVK, ambos contendo entre 0,25-10\% em fração molar de cetonas.

RABELLO ${ }^{99}$ estudou o efeito da radiação U.V. (com lâmpada de $\mathrm{Hg}$ de baixa pressão a $254 \mathrm{~nm}$ ) sobre amostras de PS ( $M_{W}$ em torno de $100.000 \mathrm{~g} / \mathrm{mol}$ ) e de copolímeros de estireno $\left(M_{w}\right.$ em torno de $\left.40.000 \mathrm{~g} / \mathrm{mol}\right)$ contendo $6 \%, 12 \%$ e $14 \%$ de MVK (Figura 2), em solução aerada, sendo as alterações sofridas acompanhadas por meio de IR, TDSLS e GPC. O estudo da degradação fotooxidativa desses polímeros foi expandido por meio da análise dos efeitos de aditivos metálicos, como sais de ferro III e seus complexos, nas soluções poliméricas, observando-se um efeito inibidor sobre a degradação, em relação às soluções puras.<smiles>C=Cc1ccccc1</smiles>

ST<smiles>C=CC(C)=O</smiles>

MVK

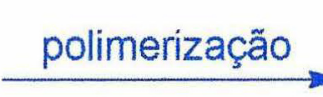

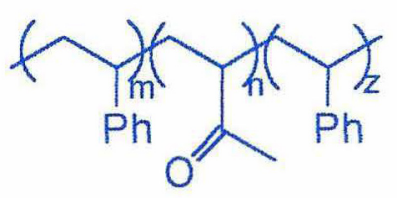

Figura 2: Estrutura geral dos copolímeros de estireno e MVK.

\footnotetext{
${ }^{98}$ Hanner,M.J.; McKelvy,M.L.; Sikkema,K.; Priddy, D.B., Polym.Degrad.and Stab., 39 (1993) 235.

${ }^{99}$ Rabello de A.,A.M.,"Estudo da Degradação Foto-Oxidativa de Copolímeros de Estircno c Vinil Cetonas"Dissertação de Mestrado, IQ, USP, 1997.
} 


\subsection{Princípios Fotoquímicos}

Fotoquímica é o estudo de processos químicos que são exclusivamente efetuados pela interação da luz com a matéria. Quando um quantum de energia luminosa é absorvido por um cromóforo (átomo ou grupo de átomos responsável pela absorção eletrônica) a molécula passa para um estado eletronicamente excitado (Figura 3).

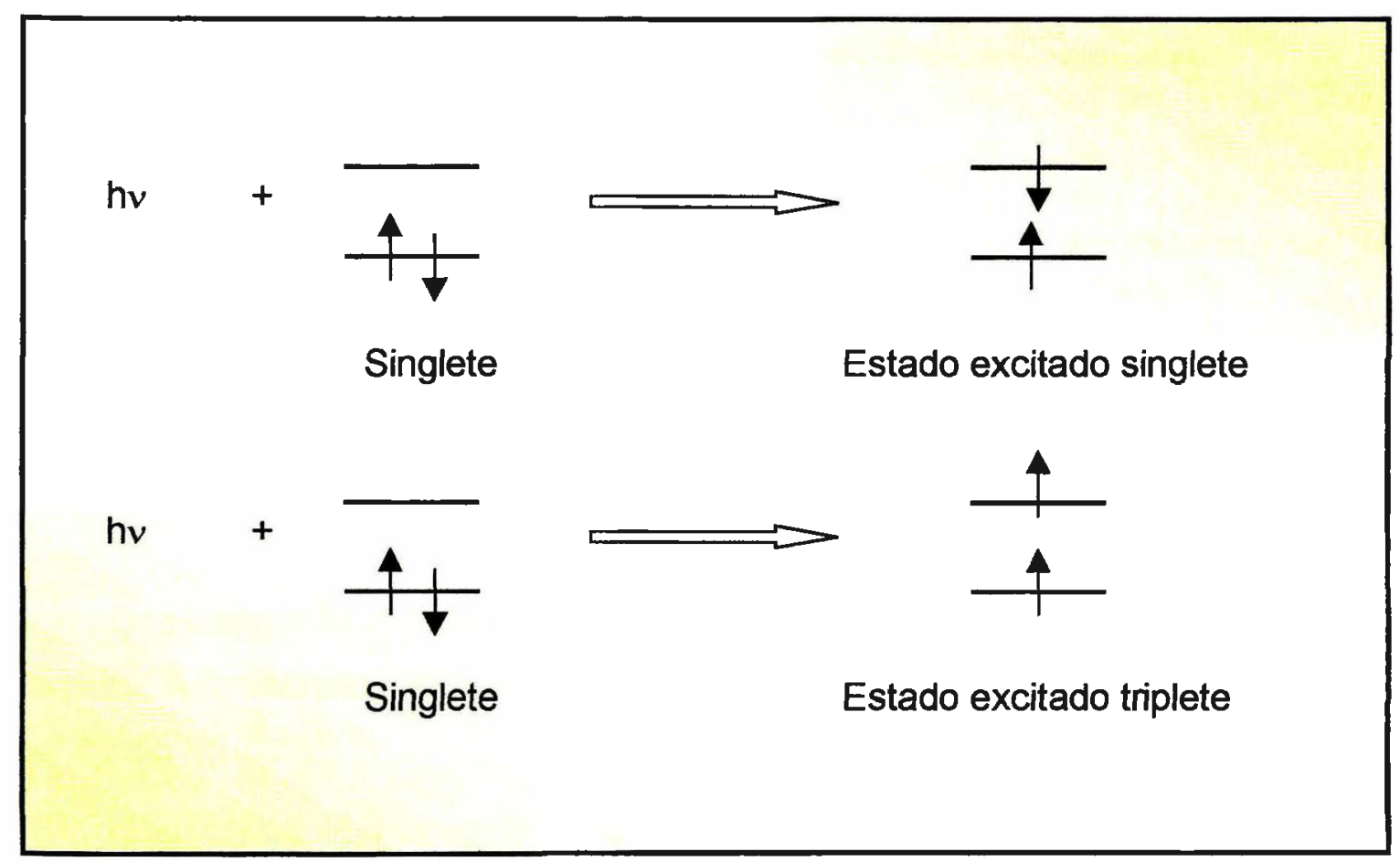

Figura 3: Estados excitados.

Após absorção de luz e subseqüente formação de um estado eletronicamente excitado, a molécula decai ao estado fundamental. $O$ decaimento pode ser radiativo ou não-radiativo através de processos fotofísicos (Figura 4). 


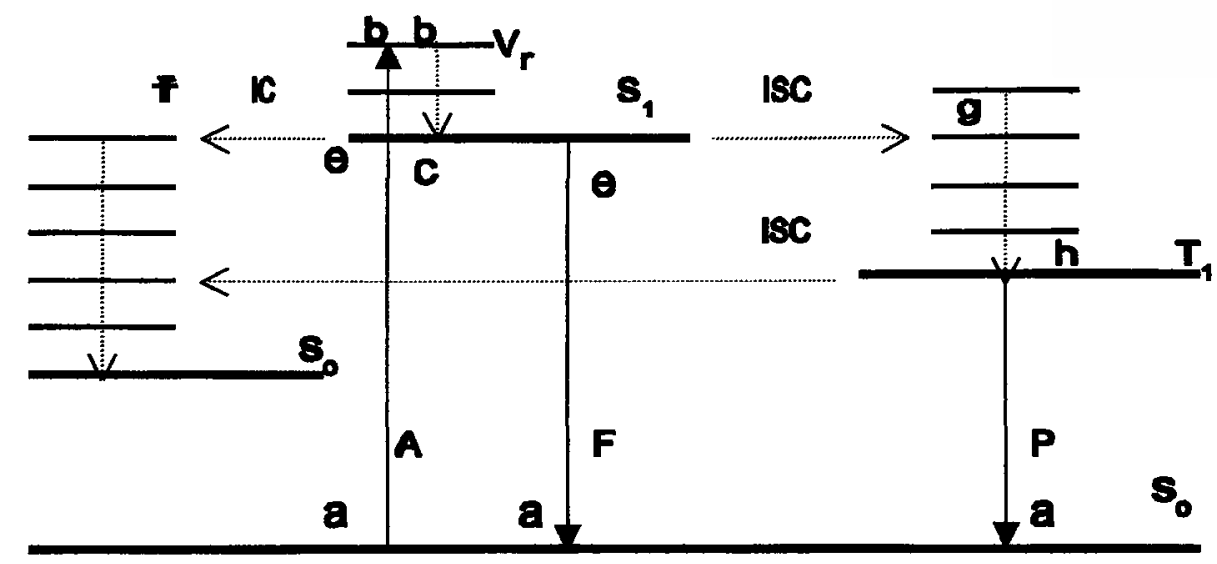

Transições radiativas

Transições não-radiativas

$A$ : absorção - $F$ : fluorescência - $P$ : fosforescência - IC : conversão interna

ISC : cruzamento intersistema - Vr : relaxamento vibracional

Figura 4: Diagrama de Jablonski.

O decaimento radiativo é um processo fotofísico em que não há reação química. A molécula eletronicamente excitada volta ao estado fundamental reemitindo luz.

$O$ decaimento não-radiativo pode ser um processo fotofísico em que a molécula eletronicamente excitada volta ao estado fundamental, cedendo calor ao meio ambiente ou fotoquímico, quando a molécula excitada fornece um produto no estado fundamental e calor ao meio ambiente. Nesse caso, ocorre uma reação fotoquímica. A molécula excitada após absorção de um fóton pode sofrer uma série de processos descritos por meio do diagrama de Jablonski (Figura 4) ${ }^{100}$.

\footnotetext{
${ }^{100}$ Turro,N.J., Molecular Photochemistry, W.A.Benjamin, Inc., New York, 1967.
} 
A molécula, ao absorver um fóton de energia, passa do estado fundamental $\left(S_{0}\right)$ para um estado eletronicamente excitado $\left(S_{1}\right)(a \rightarrow b)$ b 0 excesso de energia vibracional de $S_{1}$ é dissipado na solução por meio de um processo nãoradiativo $(b \rightarrow c)$. $O$ estado excitado $S_{1}$ pode, então, sofrer um processo de conversão interna não-radiativa. A molécula no estado excitado $S_{1}$ pode decair por três processos fundamentais:

(1) Fluorescência $(e \rightarrow a)$. A molécula no estado excitado $S_{1}$ retorna ao estado fundamental $S_{o}$ emitindo luz.

(2) Reação química $(e \rightarrow f)$. Formação de produto.

(3) Cruzamento intersistema ( $\rightarrow$ g). A molécula no estado excitado $S_{1}$ passa para o estado excitado $T_{1}$ envolvendo inversão de spin.

A molécula agora no estado excitado $T_{1}$ decai por:

(1) Fosforescência $\left(h \rightarrow\right.$ a). A molécula no estado excitado $T_{1}$ volta ao estado fundamental $S_{o}$ emitindo luz.

(2) Reação química. Formação do produto.

(3) Transferência de energia triplete. A energia do estado excitado triplete, $\left(T_{1}\right)$, é transferida para outra molécula no estado fundamental $\left(S_{0}{ }^{\prime}\right)$.

$$
\mathrm{T}_{1}+\mathrm{S}_{\mathrm{o}}^{\prime} \rightarrow \mathrm{S}_{\mathrm{o}}+\mathrm{T}_{1}{ }^{\prime}
$$

\section{Equação1}




\subsection{Cisão de Cadeia e Função Distribuição Cisão de Cadeia}

O número de cisões que ocorrem na cadeia polimérica durante um processo de degradação termo-mecânico é função da estrutura química do polímero (e, portanto, de seu mecanismo de degradação), e das condições de processamento, tais como os perfis de temperatura e o grau de cisalhamento.

A curva de distribuição de massa molar (MWD) de um polímero desloca-se de sua posição original de acordo com o tipo e a extensão da degradação. Em geral, se a degradação ocorre preferencialmente por meio de cisões das cadeias, a curva desloca-se para a região de massas molares menores.

CANEVAROLO ${ }^{101}$ desenvolveu uma metodologia para cálculo do número de cisão de cadeias em função da massa molar inicial. Esses dados foram obtidos a partir do deslocamento de curvas de distribuição de massas molares, entre uma referência (normalmente uma amostra não degradada), e seu análogo degradado. Partiu-se da definição do número de cisões ao longo de uma cadeia polimérica $\left(n_{R}\right)$ expresso pela Equação $2^{102}$.

$$
\mathrm{n}_{\mathrm{R}}=\frac{\overline{\mathrm{M}}_{\mathrm{n} 0}}{\overline{\mathrm{M}}_{\mathrm{nf}}}-1
$$

\section{Equação 2}

$\bar{M}_{n 0}$ é a massa molar numérica média para a amostra não degradada, e $\overline{\mathrm{M}}_{\mathrm{nf}}$ é a massa molar numérica média após sua degradação. Tal equação pode ser ampliada considerando-se toda a curva de distribuição de massas molares, $N_{R}$ :

$$
N_{R}=\frac{M W D_{i}}{M W D_{f}}-1
$$

\section{Equação 3}

\footnotetext{
${ }^{101}$ Canevarolo, S.V., Polym. Degrad. Stab., 709 (2000) 71.

${ }^{102}$ David C., Trojan, M., Daro.A., Demarteau W., Polym.Degrad.Stab., 37(3) (1992) 233.
} 
em que $M W D_{i}$ e $M W D_{f}$ correspondem, respectivamente, às curvas de distribuição de massas molares da amostra antes e após o processo degradativo.

Pode-se definir uma Função Distribuição de Cisão de Cadeia (CSDF), que corresponde ao deslocamento de cada valor de massa molar da curva de distribuição de massas molares da amostra em relação a sua referência, conforme exemplificado na Figura 5.

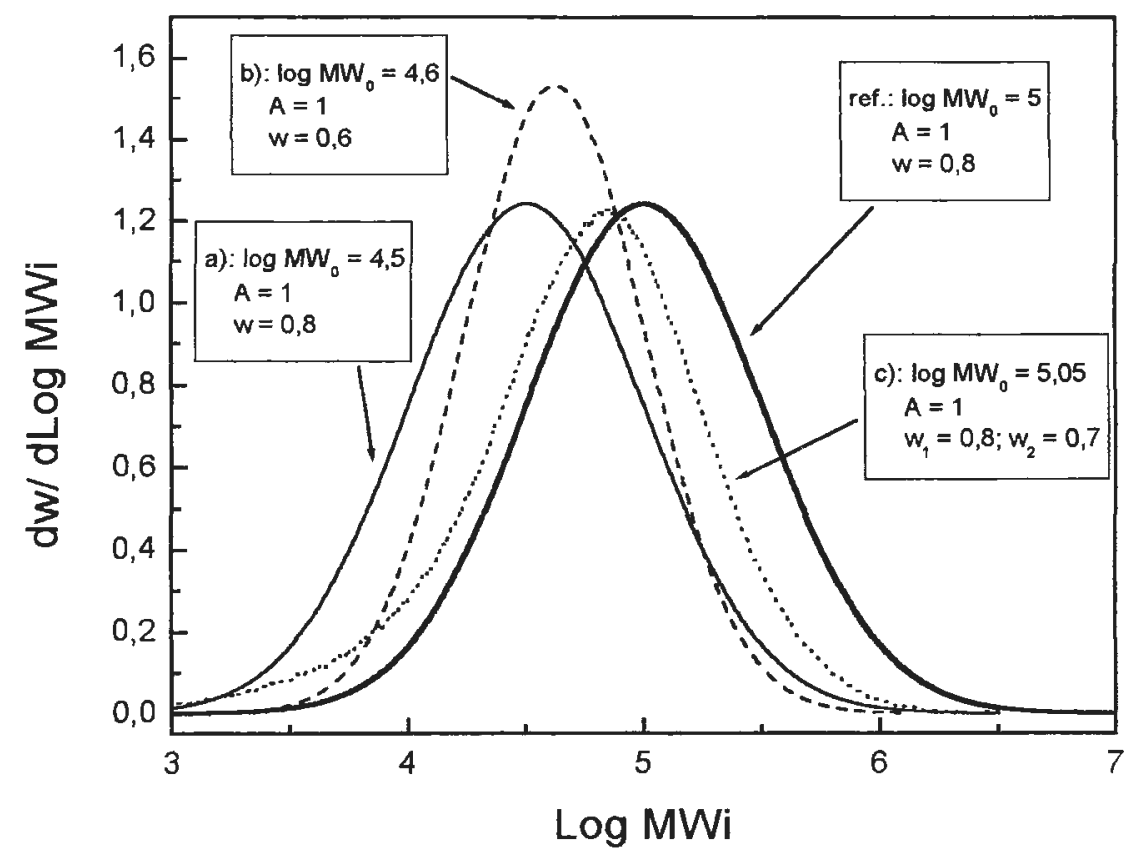

Figura 5: Simulação de diferentes curvas de distribuição de massas molares Gaussianas.

A função distribuição de cisão de cadeia pode ser calculado pela Equação 4, obtida por meio de simulação, em computador PC, via software Excel. Todas as curvas de GPC $[\log (\mathrm{MW}), \mathrm{dw} / \mathrm{d}(\log M W)]$ foram transportadas como 
matrizes ASCII, do software Millenium, para planilhas do Excel. Uma vez obtidos os valores correspondentes de $M W_{f}$ para cada $M W_{i}$, os valores de $N_{R}$ podem ser calculados aplicando-se a equação 4. Procedendo-se desse modo para todo o intervalo de MW, uma curva CSDF [Como CSDF= $\log \left(N_{R}+1\right)$ ] pode ser calculada e apresentada como função dos valores de MW originais.

$$
\operatorname{CSDF}=\log \left(N_{R}+1\right)=\log M W_{i}-{\log M W_{f}}
$$

\section{Equação 4}

De forma simplificada pode-se obter três comportamentos característicos da função da distribuição de massas molares iniciais, conforme ilustrado na Figura 6:

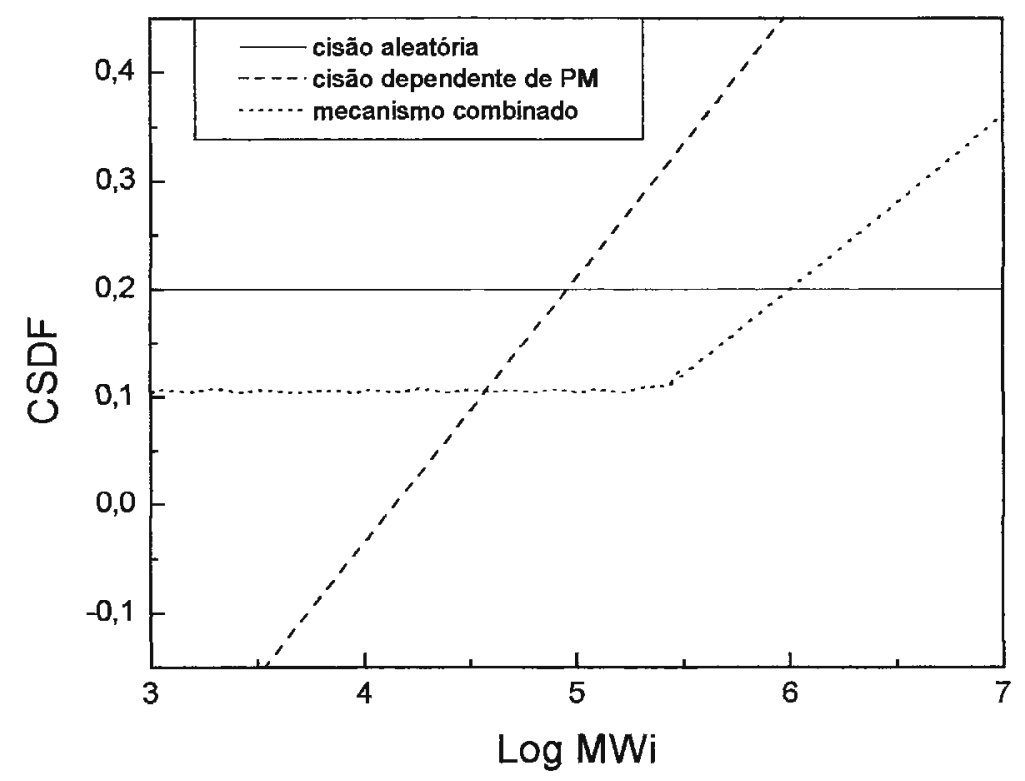

Figura 6: Tipos característicos de cisões de cadeia definidos pela variável CSDF.

i. No primeiro caso, as duas curvas de MWD, referência e amostra, possuem a mesma forma, estando a curva da amostra apenas 
deslocada para valores de $\bar{M}_{W}$ menores do que a referência (curva "_-" da Figura 6). Se o mecanismo for independente do valor da massa molar inicial, então tem-se cisão aleatória das cadeias;

ii. Se a forma da curva de MWD da amostra é diferente da curva de referência, então o número de cisões de cadeia é dependente do valor da massa molar inicial. Para o caso da largura da curva final se estreitar (como para a curva "---.-." da Figura 6), então teremos maior probabilidade de cisão de cadeia quanto maior for a massa molar;

iii. O mecanismo de cisão pode, finalmente, ser misto, ou seja, a curva MWD da amostra é assimétrica (curva "........" da Figura 6). Neste caso, a curva de CSDF se divide em duas partes: a primeira ( $\bar{M}_{W}$ baixos), representando o processo de cisão aleatória, ou seja, independente da massa molar; e a segunda ( $\bar{M}_{W}$ elevados), onde tem-se a dependência com a massa molar inicial.

\subsection{Considerações Sobre Algumas Técnicas Analíticas Utilizadas}

\subsubsection{Espalhamento de Luz Estático Dependente do Tempo (TDSLS)}

Qualquer interação da radiação eletromagnética com a matéria resulta em espalhamento dessa radiação. Se a radiação incidente tem um comprimento de onda na faixa na qual é chamada luz, o fenômeno de espalhamento é referido como espalhamento de luz. Mesmo nesse intervalo restrito de comprimento de onda, o fenômeno de espalhamento de luz assume várias formas dependendo da relação entre o tamanho do objeto espalhador e o comprimento de onda da luz, do comportamento de fase espalhada, da multiplicidade potencial do processo de espallhamento e do balanço energético do mecanismo de interação. 
A técnica de espalhamento de luz fornece um método absoluto de determinação da massa molar de substâncias macromoleculares, sem necessidade de utilização de padrões de calibração. ZIMM [1948] ${ }^{103}$ estudou o espalhamento de luz de soluções diluídas de novelos aleatórios Gaussianos e propôs um método (o gráfico de Zimm) de determinação da Massa Molar Média $\left(\bar{M}_{w}\right)$, do Raio de Giração $\left(R_{g}^{2}\right)$ e do Segundo Coeficiente Virial $\left(A_{2}\right)$ do sistema sob investigação, sendo:

- Segundo Coeficiente Virial $\left(A_{2}\right)$ : quantidade característica da interação termodinâmica entre soluto e solvente, resultante de qualquer experimento clássico de espalhamento de luz. Valores de $A_{2}$ maiores que zero, implica que o contato solvente-polímero é favorecido, sendo um bom solvente para o polímero.

- Raio de Giração $\left(R_{g}\right)$ : parâmetro que caracteriza as dimensões da partícula, independente de sua forma, baseado nas distâncias dos elementos de massa, e também entre os pares de elementos de massa dentro da partícula. Matematicamente, é definido como a raiz quadrada da média distância ao quadrado de um elemento de massa ao centro de massa:

$$
R_{g}=\left(1 / \sigma r^{2} i\right)^{x / 2}
$$

\section{Equação 5}

- Massa molar: fornece a massa molar ponderal média $\left(\bar{M}_{w}\right)$.

A intensidade de luz espalhada por um sistema de partículas independentes é, a uma dada concentração de massa, proporcional a sua massa molar. Portanto, um sistema de macromoléculas independentes espalha luz duas ou quatro ordens de grandeza mais intensamente do que um sistema contendo igual massa de moléculas independentes de uma substância de baixa massa molar.

Um sistema de macromoléculas mutuamente independentes pode ser comparado a uma solução infinitamente diluída, sendo que a intensidade de luz

${ }^{103}$ Zimm,B.H., J.Chem.Phys., 16 (1948) 1093. 
espalhada por essa solução consiste de duas contribuições: (i) intensidade correspondente à flutuação de densidade do solvente, (ii) intensidade devida ao espalhamento próprio das macromoléculas. Portanto, duas intensidades, a da solução e a do solvente puro devem ser medidas. A diferença entre esses valores é a contribuição devida às macromoléculas dissolvidas para a intensidade global do espalhamento da solução. Esta contribuição ao espalhamento pelas macromoléculas é conhecida como espalhamento em excesso.

O espalhamento de luz de uma população monodispersa diluída de moléculas tipo novelos é descrito pela função forma de espalhamento.

$$
P(\theta, r)=\left(\frac{2}{u^{2}}\right)\left(e^{-u}-1+u\right)
$$

\section{Equação 6}

em que:

$$
\boldsymbol{u}=\boldsymbol{q}^{2}\left\langle\boldsymbol{R}_{g}^{2}\right\rangle
$$

\section{Equação 7}

$$
q=\left(\frac{4 \pi n}{\lambda}\right) \operatorname{sen} \theta
$$

\section{Equação 8}

$R_{g}$ é o raio de giração dos novelos aleatórios, $q$ é a magnitude do vetor espalhamento, $n$ é o índice de refração do solvente puro, $\lambda$ o comprimento de onda do laser no vácuo e $\theta$ o ângulo do espalhamento.

REED \& REED $[1989,1990]^{104,105,106}$ demonstraram que, quando uma população ideal de novelos aleatórios inicialmente monodispersa na condição $\theta$ (ideal) sofre cisão aleatória, é possível, pelo monitoramento das mudanças na intensidade da luz espalhada, determinar a cinética de degradação utilizando a

\footnotetext{
${ }^{104}$ Reed,C.E. and Reed,W.F., J.Chem.Phys., 91 (1989) 11.

${ }^{105}$ Reed,C.E. and Reed,W.F., J.Chem.Phys., 93 (1990) 12.
} 
técnica do espalhamento de luz dependente do tempo, mantendo-se a função forma de espalhamento. Isto é, se um número médio de cortes aleatórios ré feito por molécula original do polímero, a função espalhamento $P(\theta)$ pode ser descrita como função Debye $D(u)$, no qual o argumento $u=R_{g}^{2} q^{2}$ é acrescido de $r$.

$$
P(q, r)=D(u)=\left(\frac{2}{u^{2}}\right)\left(e^{-u}-1+u\right), u=q^{2}\left\langle R_{g}^{2}\right\rangle+r
$$

\section{Equação 9}

Para tornar válida a teoria e conseqüentemente sua utilidade, foram necessárias aproximaçōes menos restritivas, ou seja, adaptar condições ideais da teoria à prática, pelas aproximações que permitam que a cisão seja monitorada, sem o conhecimento preciso das propriedades moleculares dos polímeros ou da polidispersão inicial. As principais aproximações estão resumidas abaixo:

- Espalhamento Rayleigh em excesso é definido como a intensidade de luz espalhada pelas moléculas do polímero dissolvidas num único solvente;

- As moléculas dos polímeros sejam constituídas de diferentes números de subunidades monoméricas idênticas (n), considerando-as como pontos opticamente isotrópicos espalhadores, conectados por ligações idênticas as quais estão sujeitas à cisão;

- A luz espalhada de cada molécula é dependente de $\theta$ (ângulo de espalhamento). A dependência angular de $I_{I}(\theta)$, por sua vez, depende da polarização do feixe incidente;

- A luz incidente seja verticalmente polarizada, monocromática e essencialmente paralela ao plano do espalhamento;

- Todas as dimensões do volume de espalhamento sejam grandes em comparação ao comprimento de onda de luz incidente e ao tamanho da maior molécula polimérica;

\footnotetext{
${ }^{106}$ Reed,W.F.; Reed,C.E.and Byers,L.D., Biopolymers, 30 (1990) 1073.
} 
- O processo de cisão é aleatório. Cisão aleatória de ligações significa que todas as ligações têm igual probabilidade de serem cortadas quando um corte é feito na população inteira;

- Interações entre moléculas diferentes são tratadas somente como de primeira ordem (contato único) e interações intramoleculares são ignoradas;

Com base nas hipóteses de que (i) duas moléculas aleatórias fazem contato somente numa posição, ignorando interações intramoleculares, (ii) que $A_{2}$ não depende da massa molar para incluir a polidispersão, e (iii) que a distribuição de comprimentos de ligações e direções entre unidades monoméricas adjacentes é Gaussiana, o tratamento clássico de Zimm gera a equação abaixo para uma população inicialmente polidispersa de polímeros:

$$
\frac{K c_{0}}{I}(q, r)=\frac{c_{0}}{\int_{0}^{\infty} M c_{0}(M) P(q, r(M)) d M}+2 A_{2} c_{0}
$$

\section{Equação 10}

em que:

- $C_{o}(M) d M$ é a concentração inicial do polímero, dentro do intervalo de massa $M$ a $M+d M$;

- $c_{0}$ é a concentração polimérica inicial do polímero em $\mathrm{g} / \mathrm{cm}^{3}$;

- $q$ é o vetor espalhamento;

- ré o número médio de cortes feitos no polímero original;

- $P(q, r)$ é o fator forma de espalhamento, o qual é uma função do vetor de espalhamento $q$ e do número de cortes $r$ feitos por polímero. Este fator relaciona a intensidade de luz espalhada com o número médio de cortes feito por polímero original $r$;

-K é uma constante óptica de valor: 


$$
K=\frac{4 \pi^{2} n_{0}^{2}(d n / d c)^{2}}{\lambda^{4} N_{A}}
$$

Equação 11

$n_{0}$ é o índice de refração do solvente para o comprimento de onda da radiação incidente no vácuo, $\lambda$ é o comprimento de onda da radiação incidente no vácuo, expressa em nanômetros, $N_{A}$ é o número de Avogrado e $d n / d c$ é o incremento diferencial do índice de refração pela mudança na concentração do soluto;

- $A_{2}$ é o segundo coeficiente virial $\left(\mathrm{cm}^{3} \cdot \mathrm{mol} \cdot \mathrm{g}^{-2}\right)$. Os efeitos de uma mudança de $A_{2}$ sobre o espalhamento de luz em polímeros lineares foram considerados por GHOSH \& REED [1995] ${ }^{107}$. Foi observado que as curvas de $K c / I(q, t)$ vs $t$ para diferentes $C_{0}$, sobrepõem-se por uma constante aditiva igual a $2 A_{2} C_{0}$, que justifica este último termo como independente do tempo.

Uma vez considerada a aproximação de que a cisão aleatória de ligações signifique que todas as ligações tenham igual probabilidade de serem cortadas, quando um corte é feito na população inteira o número esperado de cortes $r(m, t)$ por molécula original é proporcional à massa original da molécula,

$$
r(m)=\beta m t
$$

Equação 12

Aqui $\beta$ é o número de cortes por unidade de tempo por unidade de massa do polímero (isto é, uma constante de velocidade). Portanto, a determinação experimental de $\beta$ permite expressar a velocidade inicial em ligações molares quebradas por segundo como:

\footnotetext{
${ }^{107}$ Ghosh,S. and Reed,W.F., Biopolymers, 35 (1995) 435.
} 


$$
v=\beta c
$$

\section{Equação 13}

em que $c$ é expresso em $\mathrm{mg} / \mathrm{mL}$.

REED et al. [1990] ${ }^{105}$ mostraram que, se o mecanismo da despolimerização é semelhante à cisão aleatória de espirais aleatórias, e se $\beta$ for constante, então $\mathrm{Kc} / I_{R}(t)$ aumenta linearmente com o tempo. Assumindo que $A_{2}$ é independente da massa, isto é, não muda, pelo menos durante a fase inicial da despolimerização, tem-se:

$$
\beta=2 K c \frac{d\left[1 / I_{R}(t)\right]}{d t}
$$

Equação 14

\subsubsection{Cromatografia de Exclusão por Tamanho (SEC)}

A cromatografia de exclusão por tamanho (SEC) é um dos métodos comumente empregados para se determinar a massa molar e a distribuição de massa molar de polímeros, sendo que a importância na determinação destes parâmetros está relacionada ao fato de influenciarem fortemente as propriedades térmicas, mecânicas e reológicas de alguns polímeros. As propriedades inerentes ao PS cristal podem ser alteradas por simples modificação do formato da curva de distribuição da massa molar ${ }^{108}$. McCORMICK et al. [1959] ${ }^{109}$ sugeriram que as médias de massa molar entre $\bar{M}_{n}$ e $\bar{M}_{w}$ podem ser parâmetros a serem usados para prever as propriedades mecânicas.

\footnotetext{
${ }^{108}$ Rudin,A. and Chee,K.K., Macromolecules, 6 (1973) 613.

${ }^{109}$ McCormick,II.W.; Browmer,F.M. and Kin,L., J.Polym.Sci., 39 (1959) 87.
} 
Trata-se de um método rápido, relativo, conhecido há cerca de 30 anos, aplicado também em controle de qualidade e em controle de processos, como um parâmetro a partir do qual é possivel comparar o material de partida com o material processado, detectar degradação do polímero, ramificação, oxidação, efeito térmico, fracionamento de polímeros polidispersos etc. A separação é realizada de acordo com o tamanho da macromolécula, sendo que moléculas maiores são eluídas no início, pois o caminho médio da partícula maior é menor, ou seja, ocorre permeação seletiva. O tempo de retenção da molécula, definido como o tempo decorrido entre o início da injeção e o máximo do pico, é inversamente proporcional à massa molar.

Nessa técnica, o polímero em estudo é dissolvido em um solvente adequado, inicialmente deaerado, e submetido a um procedimento de filtração adequado. Em seguida, a solução polimérica é injetada em fluxo contínuo de solvente, que é bombeado para as colunas cromatográficas colocadas em série, cada uma com fase estacionária com o diâmetro médio dos poros, variando geralmente entre 50 e $10^{6}$ angstrons. Os sistemas de detecção mais comuns utilizam detectores de índice de refração diferencial e espectroscopia UV que, por sua vez, encaminha informações para o sistema de coleta e tratamento de dados.

O método de determinação de massa molar de polímeros por SEC é um método relativo, no qual se mede a propriedade que depende da estrutura química, física e da interação solvente-soluto, requerendo para tal uma curva de calibração entre a quantidade a ser medida e a massa molar. Embora a massa molar média determinada por SEC seja apenas um valor relativo e não um parâmetro físico-químico, os valores de $\bar{M}_{n}$ e $\bar{M}_{w}$, através da curva de calibração e da correlação com as amostras padrão de PS, podem ser calculados.

Por esta técnica, determina-se a curva de calibração que correlaciona o volume de eluição (ou tempo de retenção) com a massa molar obtida, a partir de padrões de PS, cada um com uma faixa estreita e diferente de massa molar. As massas molares dos polímeros em estudo são calculadas por interpolação, de acordo com o volume de eluição (ou tempo de retenção). 


\subsubsection{Análise Térmica (DSC e TG)}

O termo análise térmica refere-se a um conjunto de técnicas nas quais a variação de alguma propriedade físico-química da amostra é medida em função da temperatura, enquanto a amostra é submetida a uma variação de temperatura controlada. Foram aplicadas duas técnicas de análise térmica: DSC (Calorimetria Exploratória Diferencial) e TG (Análise Termogravimétrica). As propriedades verificadas foram a temperatura de transição vítrea $\left(T_{g}\right)$, temperatura de fusão e perda de massa.

A técnica de DSC mede a diferença de energia entre a amostra e o material de referência em função da temperatura, enquanto a amostra e a referência são submetidas a um programa de variação controlada de temperatura. A partir desta técnica é possivel detectar transições de primeira e segunda ordens em polímeros, tais como: temperatura de fusão $\left(T_{m}\right)$ e temperatura de transição vítrea $\left(T_{g}\right)$, respectivamente. A área sob o pico DSC é uma medida direta do calor de transição (geralmente fusão ou cristalização). Normalmente, o equipamento deve ser calibrado com pelo menos dois padrões, cujos valores de transição tabelados na literatura estejam dentro da faixa de temperatura de análise. Os padrões comumente utilizados são materiais metálicos com altíssima pureza, tais como índio e zinco metálico, com pontos de fusão de $156,6^{\circ} \mathrm{C}$ e $419,5^{\circ} \mathrm{C}$, respectivamente.

Dentre as aplicações desta técnica para polímeros encontram-se: determinação das temperaturas e dos calores relacionados a transições de fase, calor de reação, pureza, diagrama de fase, velocidade de reação, energia de ativação, retenção de solvente, grau de incorporação de uma substância, calor específico, grau de cristalinidade, temperatura de cura e/ou de decomposição térmica dos polímeros, tempo de indução oxidativa (OIT) etc.

A técnica por TG mede a variação de massa de uma amostra em função da temperatura, quando a amostra é submetida a uma variação de temperatura controlada, podendo esta análise ser efetuada para diferentes atmosferas (inerte, oxidante ou redutora). A variação de massa observada pode ser atribuída a um 
dos seguintes fatores: evaporação, sublimação, decomposição, oxidação, redução, dessorção de gás, adsorção de gás etc.

A partir da técnica por TG é possível obterem-se informações sobre: estabilidade térmica da amostra, extensão de cura em polímeros, composição de copolímeros, temperatura de liberação de água de hidratação, estudo da cinética de cura em polímeros etc.

Com relação à temperatura de transição vítrea $\left(T_{g}\right)$ obtida via $\mathrm{DSC}$, convém comentar alguns fatores que afetam os valores de $T_{g}$ no PS: (i) FOX \& FLORY $[1950]^{110}$ obtiveram uma correlação entre a massa molar e a $T_{g}$, expressa como:

$$
T_{g}(K)=373-\left(1,9 \times 10^{5} / \bar{M}_{n}\right)
$$

\section{Equação 15}

em que $\bar{M}_{n}$ é a massa molar média numérica.

Foi observado, ainda, que a influência de $\bar{M}_{n}$ acima de 85.000 sobre $T_{g}$ do PS é pequena; (ii) a substituição na cadeia do PS, dependendo de sua posição e do tipo de substituintes, afeta os valores de $T_{g}$, uma vez que o substituinte restringe os movimentos de cadeia polimérica. Para derivados metila, a substituição na posição $\alpha$ resulta no maior aumento da $T_{g}$, indicando que substituição nesta posição restringe a liberdade de rotação em torno da cadeia principal do polímero. A substituição na posição 2 no anel benzênico também leva a um valor de $T_{g}$ alto, uma vez que restringe o movimento da cadeia do polímero; (iii) copolímeros aleatórios mostram valores de $T_{g}$ que estão relacionados, por um lado, às frações em peso dos monômeros empregados na sua síntese, e por outro, aos valores de $T_{g}$ dos respectivos homopolímeros.

${ }^{110}$ Fox,T.G. and Flory,P.J., J.Appl.Phys., 21 (1950) 581. 


\section{Objetivos}

Polímeros degradáveis por intemperismo, incluindo os biodegradáveis, fotodegradáveis, oxidativa ou hidroliticamente degradáveis passaram a atrair muita atenção nos últimos 20 anos, particularmente "commodities" como poliestireno (PS). Por restrições em sua estrutura, entretanto, os PS não sofrem degradação ambiental significativa, sendo, assim, responsáveis por boa parte do lixo plástico não degradável do momento.

A solução para esse problema parte de um conceito baseado na fotodegradação amplificada de polímeros, principalmente pela adição de grupos carbonílicos na cadeia principal ou próximo a esta ${ }^{111}$.Assim, sob radiação solar, tais polímeros seriam degradados a massas moleculares menores até que a ação de microorganismos fosse possivel.

Dentro deste contexto, este trabalho tem como objetivos o estudo e a comparação dos efeitos da radiação UV sobre o PS puro e seus copolímeros contendo $5 \%, 10 \%$ e $15 \%$ (frações molares) dos seguintes comonômeros: 2trimetilsililóxi-1,3-butadieno (TSB, I); 2-metóxi-1,3-butadieno (MEB, II) e 2-etóxi1,3-butadieno (ETB, III).

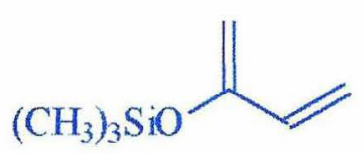

(I)<smiles>C=CC(=C)OC</smiles>

(II)<smiles>C=CC(=C)OCC</smiles>

(III)

Acreditamos que os comonômeros I, II e III, após copolimerização com estireno seguida de hidrólise, sejam capazes de resultar em PS contendo carbonilas inseridas na cadeia principal e apresentem, assim, uma elevada

\footnotetext{
${ }^{111}$ Guillet,J.E., "Polymers and Ecological Problems", Plenum Press, N.Y.(1973).
} 
velocidade de cisão de cadeia, quando expostos à luz solar, em comparação à degradação normal do PS não modificado.

Como primeiro passo, o homo e copolímeros serão sintetizados e caracterizados por técnicas analíticas como IR, ${ }^{1} \mathrm{H}-\mathrm{NMR}$ e Análise Elementar. A seguir, pretendemos monitorar o efeito da radiação UV sobre os mesmos por meio de técnicas como SEC, IR e TDSLS.

Finalmente, serão verificadas as propriedades termo-mecânicas desses materiais pela análise térmica (DSC e TG), e pela manufatura de corpos de prova para envelhecimento acelerado em câmara de intemperismo artificial, seguida por ensaios de resistência à tração. 


\section{Resultados e Discussão}

\subsection{Síntese e Caracterização do PS e Copolímeros de Estireno e Butadienos Substituídos}

\subsubsection{Introdução}

Foram sintetizadas três séries completas de copolímeros de estireno e butadienos 2-substituídos que, após serem submetidos a uma etapa de hidrólise, resultaram em produtos similares estruturalmente e, como conseqüência, com propriedades físicas, químicas, térmicas e mecânicas muito próximas.

Desta forma, para tornar esta parte da discussão mais ágil, optou-se por reunir os resultados experimentais das três séries de copolímeros nas mesmas secções, sendo as diferenças discutidas, em detalhe, assim que forem citadas.

\subsubsection{A Síntese}

O primeiro objetivo do trabalho era a síntese do poliestireno e de copolímeros de estireno com unidades vinil-éster ou vinil-éter que, após hidrólise, gerassem grupos cetônicos como parte da cadeia principal da macromolécula, susceptíveis à ruptura quando expostos a condições de intemperismo natural (Esquema 6). 


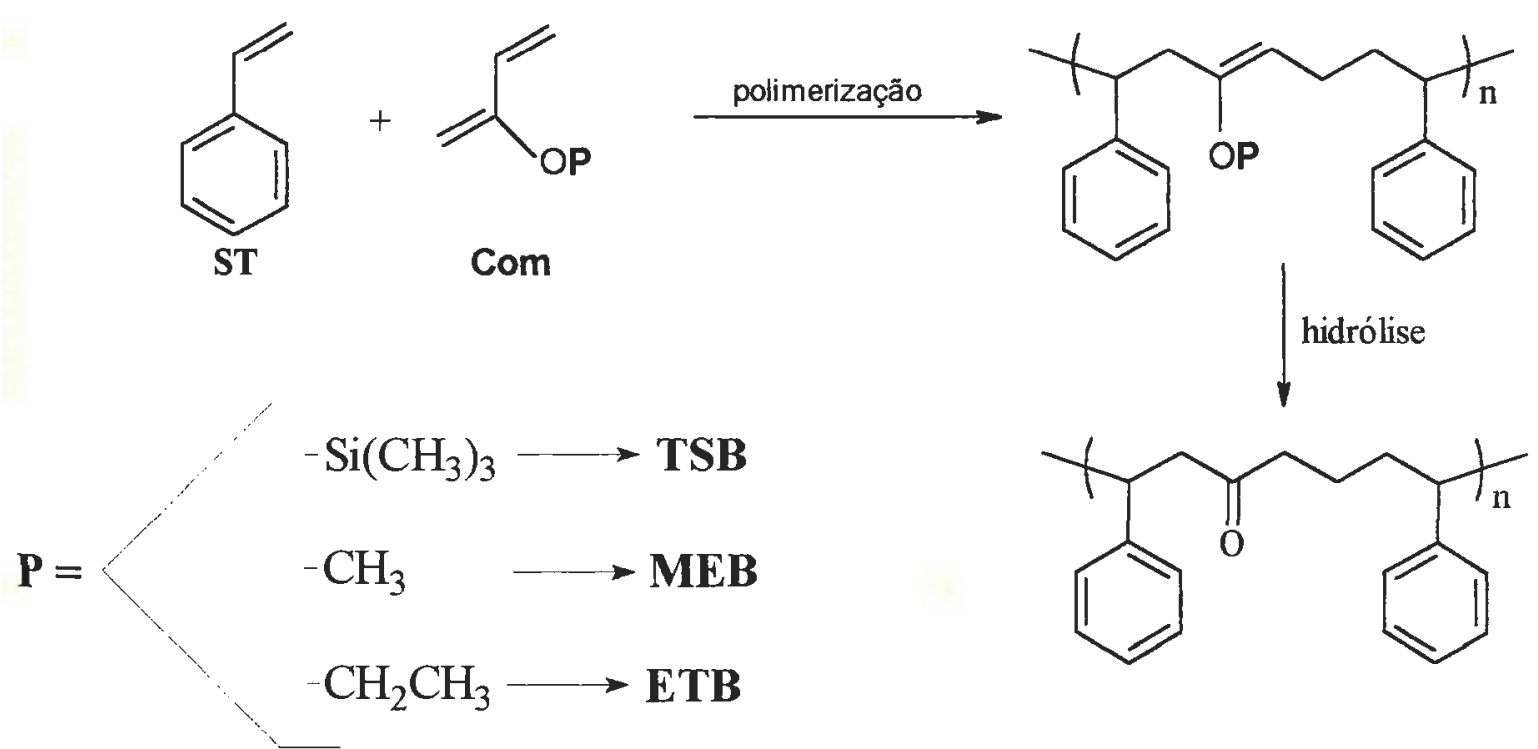

\section{Esquema 6}

O ponto chave era, portanto, selecionar uma série de butadienos 2substituídos cujos grupos P do Esquema 6 que pudessem ser removidos, ou pela ação de nucleófilos tais como iodeto, azida e cianeto ou por uma etapa adicional de hidrólise. De uma forma ou de outra, o copolimero resultante deveria conter grupos carbonila inseridos diretamente na cadeia principal da macromolécula, conferindo uma estrutura somente encontrada no copolímero etileno/monóxido de carbono $(E / C O)^{15,16}$.

Como resultado desta extensa pesquisa, três monômeros foram selecionados e as sinteses dos polimeros efetuadas pelo procedimento descrito por KATO \& YONESHIGE [1973] ${ }^{83}$, SIKKEMA et al. [1992] ${ }^{112}$ e RABELLO[1997] ${ }^{99}$, a partir do estireno e dos monômeros I a III.

\footnotetext{
${ }^{112}$ Sikkema,K.; Hanner,M.J.; Brennan,D.J.; Smith,P.B. and Priddy,D.B., Pohm.Degrad.Stab.,38 (1992) 119.
} 
<smiles>C=CC(=C)O[Sn](C)(C)C</smiles>

(I)<smiles>C=CC(=C)OC</smiles>

(II)<smiles>C=CC(=C)OCC</smiles>

(III)

Vale a pena salientar que o estireno foi escolhido como monômero base devido à facilidade de sua polimerização em solução e manuseio. O controle fino da qualidade da matéria-prima é essencial para uma análise refinada dos diversos fatores envolvidos. Assim, optamos por produzir nossas próprias resinas, facilitando esse controle. Não podemos nos esquecer, ainda, de que o poliestireno é um modelo próximo do polietileno $(\mathrm{PE})$, o grande vilão no que diz respeito à poluição causada por lixo plástico no mundo.

Inicialmente, foram preparados copolímeros de estireno e butadienos substituidos na tentativa de se obterem polímeros com $5 \%, 10 \%, 15 \%$ e $20 \%$ em fração molar de cada um dos comonômeros.

Todavia, as sínteses realizadas com $20 \%$ de TSB, MEB e ETB originaram produtos muito heterogêneos: uma fase predominante líquida, identificada (via CG e IR) como monômero de estireno que não reagiu; uma fase intermediária sólida, infusivel e insolúvel, não identificada, e uma terceira e ínfima fase, em forma de gel, identificada (via IR) como o copolímero de estireno e butadieno substituído. Resultados obtidos via análise elementar para esta última fase revelaram tratar-se de um produto extremamente heterogêneo, com valores de incorporação do comonômero, variando desde aproximadamente $1 \%$ até valores próximos a $10 \%$.

Devido a esses fatos, optou-se por realizar as sínteses com 5\%, 10\% e 15\%, em fração molar, dos comonômeros em relação ao monômero de estireno.

As sínteses dos copolímeros foram realizadas em duplicata, e os resultados obtidos tanto em relação ao rendimento (Tabelas 13-15) quanto em relação aos teores de incorporação dos comonômeros (Tabelas 1-3), revelaram que o 
procedimento adotado apresenta ótima reprodutibilidade para as quantidades de comonômeros escolhidas, conforme veremos um pouco mais a frente.

\subsubsection{Determinação dos Teores de Incorporação dos Comonômeros}

Os valores obtidos experimentalmente por análise elementar estão apresentados na Tabelas 1,2 e 3 para as séries TSB, MEB e ETB, respectivamente. É importante lembrar que os teores de incorporação dos comonômeros foram calculados a partir da equação 16 , e representam os valores médios de dez determinações para cada um deles.

$$
M=\frac{9608,8-10415,2 \% C}{48,04-34,06 \% C}
$$

\section{Equação 16}

Se considerarmos que o valor teórico $\mathbf{T}$ do teor de carbono para o poliestireno é de $92,26 \%$ e que o valor experimental médio E, obtido via análise elementar, foi de $92,12 \%$, o erro relativo, calculado como (T - E)/T, é de 0,15\%. Tal resultado é uma evidência de que os valores médios calculados para a incorporação do TSB, MEB e ETB são confiáveis e apresentam margem de erro relativamente baixa.

RABELLO ${ }^{99}$, utilizando cálculos semelhantes, obteve teores de incorporação de $6 \%, 12 \%$ e $14 \%$, em fração molar de MVK, para os copolímeros com estireno, inicialmente previstos para $5 \%, 10 \%$ e $15 \%$, respectivamente. 
Tabela 1: Valores de incorporação do TSB, calculados a partir dos teores de carbono obtidos via análise elementar.

\begin{tabular}{|c|c|c|c|c|c|c|c|}
\hline \multirow{2}{*}{ Polímeros } & \multicolumn{2}{|c|}{ TSB 5 } & \multicolumn{2}{c|}{ TSB 10 } & \multicolumn{2}{c|}{ TSB 15 } & \multirow{2}{*}{ PS } \\
\cline { 2 - 8 } & $\%$ C & M & $\%$ C & M & $\%$ C & M & \\
\hline \multirow{2}{*}{ Valor Médio } & $\mathbf{9 1 , 3 2}$ & $\mathbf{5 , 7 8}$ & $\mathbf{9 0 , 4 5}$ & 10,91 & $\mathbf{8 9 , 5 9}$ & $\mathbf{1 5 , 8 7}$ & $\mathbf{9 2 , 1 2}$ \\
\hline Desvio Padrão & 0,13 & 0,77 & 0,16 & 0,93 & 0,15 & 0,82 & 0,09 \\
\hline
\end{tabular}

M : porcentual de incorporação da carbonila na cadeia principal do PS; \%C : média aritmética dos teores porcentuais de carbono obtidos experimentalmente.

Tabela 2: Valores de incorporação do MEB, calculados a partir dos teores de carbono obtidos via análise elementar.

\begin{tabular}{|c|c|c|c|c|c|c|c|}
\hline \multirow{2}{*}{ Polimeros } & \multicolumn{2}{|c|}{ MEB 5 } & \multicolumn{2}{c|}{ MEB 10 } & \multicolumn{2}{c|}{ MEB 15 } & \multirow{2}{*}{ PS } \\
\cline { 2 - 8 } & $\%$ C & M & $\%$ C & M & $\%$ C & M & \\
\hline Valor Médio & $\mathbf{9 1 , 4 0}$ & $\mathbf{5 , 2 8}$ & $\mathbf{9 0 , 4 9}$ & 10,69 & $\mathbf{8 9 , 6 6}$ & $\mathbf{1 5 , 4 5}$ & $\mathbf{9 2 , 1 2}$ \\
\hline Desvio Padrão & 0,11 & 0,68 & 0,09 & 0,51 & 0,08 & 0,45 & 0,09 \\
\hline
\end{tabular}

M : porcentual de incorporação da carbonila na cadeia principal do PS; \%C : média aritmética dos teores porcentuais de carbono obtidos experimentalmente. 
Tabela 3: Valores de incorporação do ETB, calculados a partir dos teores de carbono obtidos via análise elementar.

\begin{tabular}{|c|c|c|c|c|c|c|c|}
\hline \multirow{2}{*}{ Polímeros } & \multicolumn{2}{|c|}{ ETB 5 } & \multicolumn{2}{c|}{ ETB 10 } & \multicolumn{2}{c|}{ ETB 15 } & \multirow{2}{*}{ PS } \\
\cline { 2 - 8 } & $\%$ M & M & $\%$ & M & $\%$ M & \\
\hline \multirow{2}{*}{ Valor Médio } & $\mathbf{9 1 , 4 0}$ & $\mathbf{5 , 2 8}$ & $\mathbf{9 0 , 5 0}$ & $\mathbf{1 0 , 6 3}$ & $\mathbf{8 9 , 6 3}$ & $\mathbf{1 5 , 6 2}$ & $\mathbf{9 2 , 1 2}$ \\
\hline Desvio Padrão & 0,07 & 0,41 & 0,06 & 0,40 & 0,08 & 0,46 & 0,09 \\
\hline
\end{tabular}

M : porcentual de incorporação da carbonila na cadeia principal do PS; \%C : média aritmética dos teores porcentuais de carbono obtidos experimentalmente.

\subsubsection{Análise Estrutural}

A séries TSB, MEB e ETB, antes e após hidrólise, foram caracterizadas por meio de espectroscopia de infravermelho (IR), por meio de informações colhidas nos trabalhos realizados por KRIM [1960] ${ }^{113}$, PAINTER \& KOENIG $[1977]^{114}$, SEARS et al. [1981] $]^{115}$, PAINTER et al. [1982] ${ }^{116}$ e RABELLO ${ }^{99}$. Foram feitas atribuições tentativas das vibrações fundamentais do homo e copolímeros, destacando-se a região característica desses compostos $\left(2000 \mathrm{~cm}^{-1}-500 \mathrm{~cm}^{-1}\right)$.

Em relação à série TSB é interessante notar que os espectros obtidos para os copolímeros, antes de serem submetidos à hidrólise, não apresentam as

\footnotetext{
${ }^{113}$ Krim,S., Adv.Polym.Sci., 2 (1960) 51.

${ }^{114}$ Painter,P.C., Koenig,J.L., J.Polym.Sci.Phys.Ed., 15 (1977) 1885.

${ }^{115}$ Sears, W.M., Hunt,J.L, Stevens, J.R., J.Chem.Phys., 75(4) (1981) 1589.

${ }^{116}$ Painter,P.C, Coleman,M.M, Koenig,J.L.,The Theory of Vibracional Spectroscopy and its Applications to

Polymeric Materials, John Wiley \& Sons, Inc., New York, 1982.
} 
bandas características do estiramento normal $\mathrm{C}=\mathrm{O}$ de cetonas, em torno de $1715 \mathrm{~cm}^{-1}$ (Espectros 2-4, anexos). Ao mesmo tempo, uma análise destes mesmos espectros revela a presença de bandas de estiramento do grupo $\mathrm{Si}\left(\mathrm{CH}_{3}\right)_{3}$ a $1252 \mathrm{~cm}^{-1}$, confirmando a necessidade de uma etapa posterior de hidrólise para a regeneração do grupo carbonílico na cadeia polimérica.

Os espectros do PS (Espectro 1, anexo) e dos copolímeros da série TSB hidrolisados (Espectros 5-7, anexos) estão apresentados na Figura 7, enquanto que as freqüências observadas, as intensidades das bandas $e$ as atribuições tentativas encontram-se na Tabela 4.

Observou-se que o espectro obtido para o PS homopolímero é idêntico ao espectro do PS da literatura ${ }^{117}$. Para verificação de alterações na cadeia do homopolímero PS com a incorporação de TSB, foram focadas as seguintes bandas:

- $700 \mathrm{~cm}^{-1}$ anel fenila, deformação $\mathbf{C}-\mathbf{H}$ fora do plano

- $756 \mathrm{~cm}^{-1}$ deformação de $H$ fora do plano em C-H

- 1450,1492 e $1601 \mathrm{~cm}^{-1}$ anel fenila, estiramento de $\mathbf{C}=\mathbf{C}$ no plano

- 2851 e $2923 \mathrm{~cm}^{-1}$ estiramento alifático de $\mathbf{C}$-H

- 3025 e $3060 \mathrm{~cm}^{-1}$ estiramento aromático de $\mathbf{C}-\mathbf{H}$

- $1712 \mathrm{~cm}^{-1}$ estiramento $\mathbf{C}=\mathbf{0}$ de cetonas

Examinando cuidadosamente as bandas em $1712 \mathrm{~cm}^{-1}$ e $1157 \mathrm{~cm}^{-1}$, pôdese perceber que há alterações significativas na estrutura dos copolímeros em relação à estrutura original do PS.

Os espectros dos copolímeros das séries MEB (Espectros 8-10, anexos) e ETB hidrolisados (Espectros 11-13, anexos) são idênticos aos obtidos para a série TSB, como esperado, tornando-se desnecessária, neste ponto, uma análise das bandas de absorção características.

\footnotetext{
${ }^{117}$ The Sadtler Standard Spectra, Sadtler Research Laboratories, Division of Bio-Rad Labs, Inc., Commercial IR, Philadelphia, PA., file:D-7588-K, 1981.
} 
Tabela 4: Freqüências, intensidades e atribuições tentativas do PS e copolímeros da série TSB.

\begin{tabular}{|c|c|c|c|c|c|}
\hline \multirow{2}{*}{$\begin{array}{l}\text { BANDAS } \\
\left(\mathrm{cm}^{-1}\right)\end{array}$} & \multicolumn{4}{|c|}{ INTENSIDADE DAS BANDAS } & \multirow{2}{*}{$\begin{array}{l}\text { ATRIBUIÇÃO } \\
\text { TENTATNA }\end{array}$} \\
\hline & PS & TSB5 & TSB10 & TSB15 & \\
\hline 3452 & $m$ & $\mathrm{~m}$ & $\mathrm{~m}$ & $\mathrm{~m}$ & $V(\mathrm{O}-\mathrm{H})$ \\
\hline 3081 & $\mathrm{~m}$ & $\mathrm{~m}$ & m & $m$ & V (C-H) aromático em fase \\
\hline 3059 & $\mathrm{~m}$ & $\mathrm{~m}$ & m & $\mathrm{m}$ & $\because(\mathrm{C}-\mathrm{H})$ aromático \\
\hline 3025 & $s$ & s & $\mathbf{s}$ & $s$ & $v(\mathrm{C}-\mathrm{H})$ aromático \\
\hline 2921 & s & s & $s$ & s & $(\mathrm{C}-\mathrm{H})$ alifático \\
\hline 2849 & $\mathrm{~m}$ & m & m & $\mathrm{m}$ & V (C-H) alifático \\
\hline 1944 & $m$ & $m$ & $\mathrm{~m}$ & $m$ & $\delta(\mathrm{C}-\mathrm{H})$ no plano (anel fenila) \\
\hline 1871 & $m$ & $\mathrm{~m}$ & m & m & $\therefore(\mathrm{C}-\mathrm{H})$ no plano (anel fenila) \\
\hline 1802 & $m$ & $m$ & $m$ & $\mathrm{~m}$ & $\delta(\mathrm{C}-\mathrm{H})$ no plano (anel fenila) \\
\hline 1746 & $w$ & $w$ & $w$ & $w$ & $\therefore(\mathrm{C}-\mathrm{H})$ no plano (anel fenila) \\
\hline 1712 & - & $w$ & m & vs & $v(C=0)$ cetonas \\
\hline 1601 & s & $s$ & $s$ & vs & $V(C=C)$ no plano (anel fenila) \\
\hline 1493 & 5 & s & $\mathrm{s}$ & vs & I $(\mathrm{C}=\mathrm{C})$ no plano (anel fenila) \\
\hline 1452 & $\mathrm{~s}$ & s & s & $s$ & $\checkmark(C=C)$ no plano (anel fenila) \\
\hline 1368 & $w$ & $w$ & $w$ & - & $\therefore(\mathrm{C}-\mathrm{H})$ alcanos \\
\hline 1352 & - & $w$ & $\mathrm{~m}$ & $s$ & $\therefore\left(\mathrm{CH}_{3} \mathrm{CO}\right)$ \\
\hline 1182 & $\mathrm{~m}$ & $\mathrm{~m}$ & $w$ & $w$ & in (C-H) no plano (anel fenila) \\
\hline 1157 & $w$ & $w$ & $w$ & $\mathrm{~m}$ & $\therefore(\mathrm{C}-\mathrm{H})$ no plano (anel fenila) \\
\hline 1069 & $\mathrm{~m}$ & $\mathrm{~m}$ & $\mathrm{~m}$ & $\mathrm{~m}$ & $i(\mathrm{C}-\mathrm{H})$ no plano (anel fenila) \\
\hline 1029 & $\mathrm{~m}$ & $\mathrm{~m}$ & $m$ & $m$ & $\delta(\mathrm{C}-\mathrm{H})$ no plano (anel fenila) \\
\hline 907 & $\mathrm{~m}$ & $\mathrm{~m}$ & $m$ & $\mathrm{~m}$ & $\delta(\mathrm{C}-\mathrm{H})$ fora do plano (anel fenila) \\
\hline 842 & $w$ & $w$ & $w$ & $w$ & $\delta(\mathrm{C}-\mathrm{H})$ fora do plano (anel fenila) \\
\hline 758 & $\mathbf{s}$ & vs & vs & vs & $\$(\mathrm{C}-\mathrm{H})$ fora do plano (anel fenila) \\
\hline 698 & vs & vs & vs & vs & $\grave{n}(\mathrm{C}+\mathrm{H})$ fora do plano (anel fenila) \\
\hline
\end{tabular}

Onde: $v s$ = banda muito forte; $s$ = banda forte; $m=$ banda média; $w$ = banda fraca; $\mathrm{w} w$ = banda muito fraca; $\delta=$ deformação angular; $v=$ estiramento. 


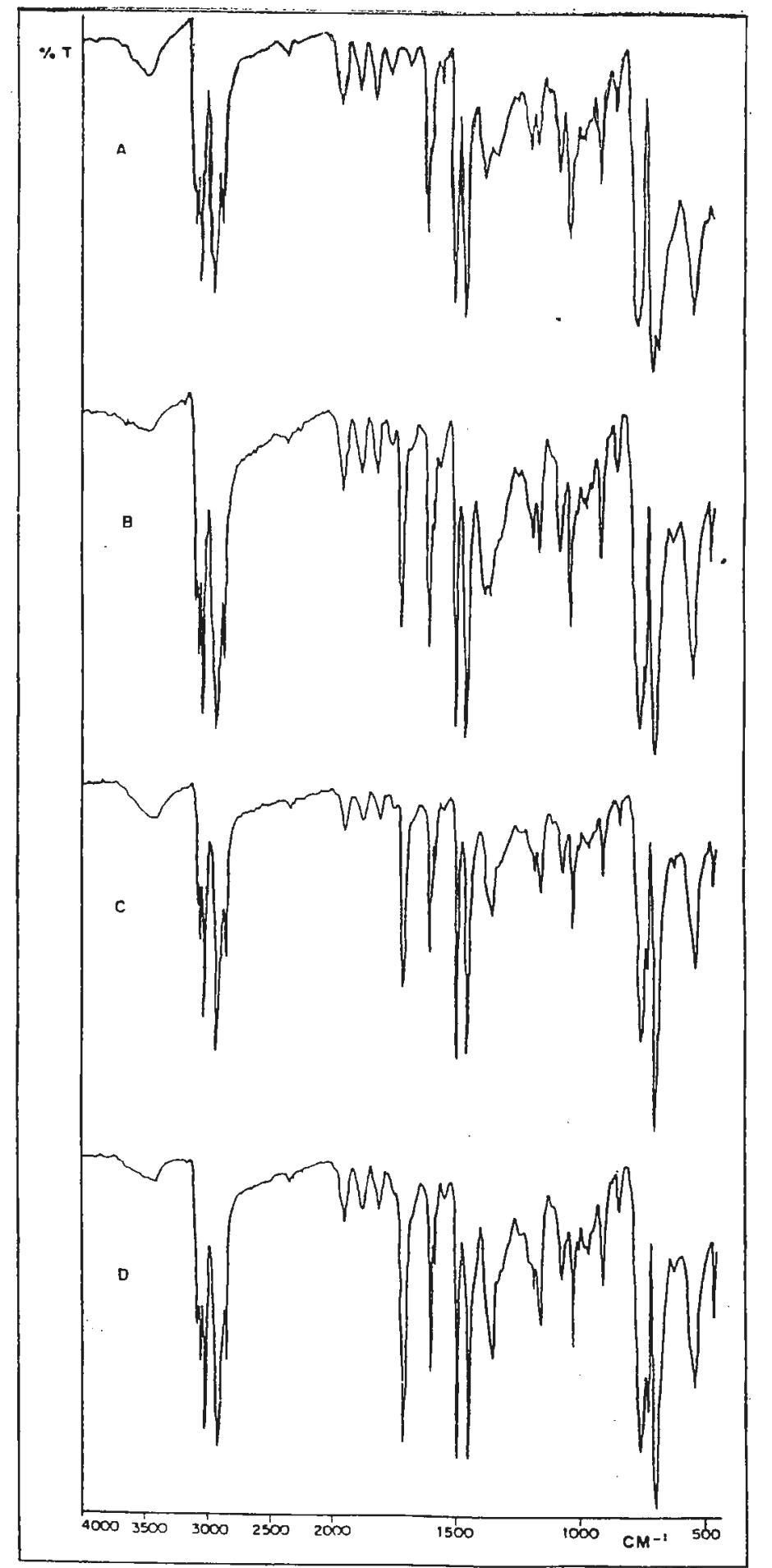

Figura 7: Espectros no IR do PS e copolímeros da série TSB com destaque das bandas a $1712 \mathrm{~cm}^{-1}(\rightarrow)$ sendo: $\mathbf{A}$ : homopolímero; $\mathbf{B}$ : copolímero TSB5; $\mathbf{C}$ : copolímero TSB10 e D: copolímero TSB15. 
As bandas provenientes do estiramento da carbonila em cetonas $\left(1710 \mathrm{~cm}^{-1}\right.$ - $1715 \mathrm{~cm}^{-1}$ ) estão ausentes no espectro obtido para o PS, como esperado, mas surgem nos copolímeros com intensidades relativamente fortes, proporcional ao aumento no teor de incorporação do comonômero (tomando-se a banda de estiramento $\mathbf{C}=\mathbf{C}$ do anel fenila no plano, em $1601 \mathrm{~cm}^{-1}$, como referência).

RABELLO ${ }^{99}$ observou o aparecimento de bandas de absorção dos copolímeros MVK em $1711 \mathrm{~cm}^{-1}$ e $1352 \mathrm{~cm}^{-1}$, provenientes do estiramento da carbonila e da deformação $\mathrm{CH}_{3}$ de cetonas, respectivamente. Além disso, houve um aumento proporcional da intensidade relativa dos picos com o aumento no teor de MVK.

Os espectros obtidos para os copolímeros das séries MEB e ETB antes de serem submetidos à hidrólise, também não apresentam as bandas características do estiramento normal $\mathrm{C}=\mathrm{O}$ de cetonas, em torno de $1715 \mathrm{~cm}^{-1}$. Ao mesmo tempo, uma análise da Figura 8 , relativa à série MEB, revela a presença de bandas características de vinil éter: bandas de alta intensidade relativas ao estiramento assimétrico da ligação $C-O-C\left(1225 \mathrm{~cm}^{-1}-1200 \mathrm{~cm}^{-1}\right)$ e simétrico $\left(1075 \mathrm{~cm}^{-1}\right.$ $\left.1020 \mathrm{~cm}^{-1}\right)$; banda de estiramento da ligação $C=C$ na região de $1660 \mathrm{~cm}^{-1}$ $1600 \mathrm{~cm}^{-1}$. Deve-se ressaltar que a intensidade dessas bandas varia pouco de um copolímero para outro, aumentando discretamente à medida que o teor de incorporação do comonômero na cadeia do PS aumenta. Estiramentos da ligação $\mathrm{C}-\mathrm{H}$ do grupo $-\mathrm{CH}_{3}$ aparecem como bandas fortes em torno de $2920 \mathrm{~cm}^{-1}$ (assimétrica) e $2848 \mathrm{~cm}^{-1}$ (simétrica).

Essas observações são idênticas às obtidas para a série ETB, e confirmam a necessidade de uma etapa posterior de hidrólise para a regeneração dos grupos carbonílicos nas cadeias poliméricas.

Os espectros dos copolímeros da série MEB são apresentados na Figura 8 e as principais freqüências observadas $\left(\mathrm{cm}^{-1}\right)$, as intensidades das bandas, juntamente com as atribuições tentativas de todos os polímeros, encontram-se na Tabela 5. 
Tabela 5: Freqüências, intensidades e atribuições tentativas dos copolímeros da série MEB.

\begin{tabular}{|c|c|c|c|c|}
\hline \multirow{2}{*}{$\begin{array}{l}\text { BANDAS } \\
\left(\mathrm{cm}^{-1}\right)\end{array}$} & \multicolumn{3}{|c|}{ INTENSIDADE DAS BANDAS } & \multirow{2}{*}{$\begin{array}{l}\text { ATRIBUIÇĀO } \\
\text { TENTATNA }\end{array}$} \\
\hline & MEB5 & MEB10 & MEB15 & \\
\hline 3440 & $m$ & $m$ & $m$ & $v(\mathrm{O}-\mathrm{H})$ \\
\hline 2920 & $\mathbf{s}$ & s & s & $v(\mathrm{C}-\mathrm{H})$ alifático \\
\hline 2848 & $m$ & $m$ & $m$ & $v(\mathrm{C}-\mathrm{H})$ alifático \\
\hline 1601 & $m$ & $m$ & $m$ & $v(\mathrm{C}=\mathrm{C})$ no plano (anel fenila) \\
\hline 1492 & $\mathbf{s}$ & $\mathbf{s}$ & s & $v(C=C)$ no plano (anel fenila) \\
\hline 1451 & $\mathbf{s}$ & s & s & $v(\mathrm{C}=\mathrm{C})$ no plano (anel ferila) \\
\hline 1227 & $\mathbf{s}$ & s & vs & $v$ (assimétrico) C-O-C \\
\hline 1068 & $\mathbf{s}$ & $\mathbf{s}$ & vs & $v$ (simétrico) C-O-C \\
\hline 757 & s & $\mathbf{s}$ & s & $\delta(\mathrm{C}-\mathrm{H})$ fora do plano (anel fenila) \\
\hline 697 & vs & vs & vs & $\delta(\mathrm{C}-\mathrm{H})$ fora do plano (anel fenila) \\
\hline
\end{tabular}

Onde: $v s=$ banda muito forte; $s=$ banda forte; $m=$ banda média; $w$ = banda fraca; $u w=$ banda muito fraca; $\delta=$ deformação angular; $v=$ estiramento. 
Transmitância (\%)

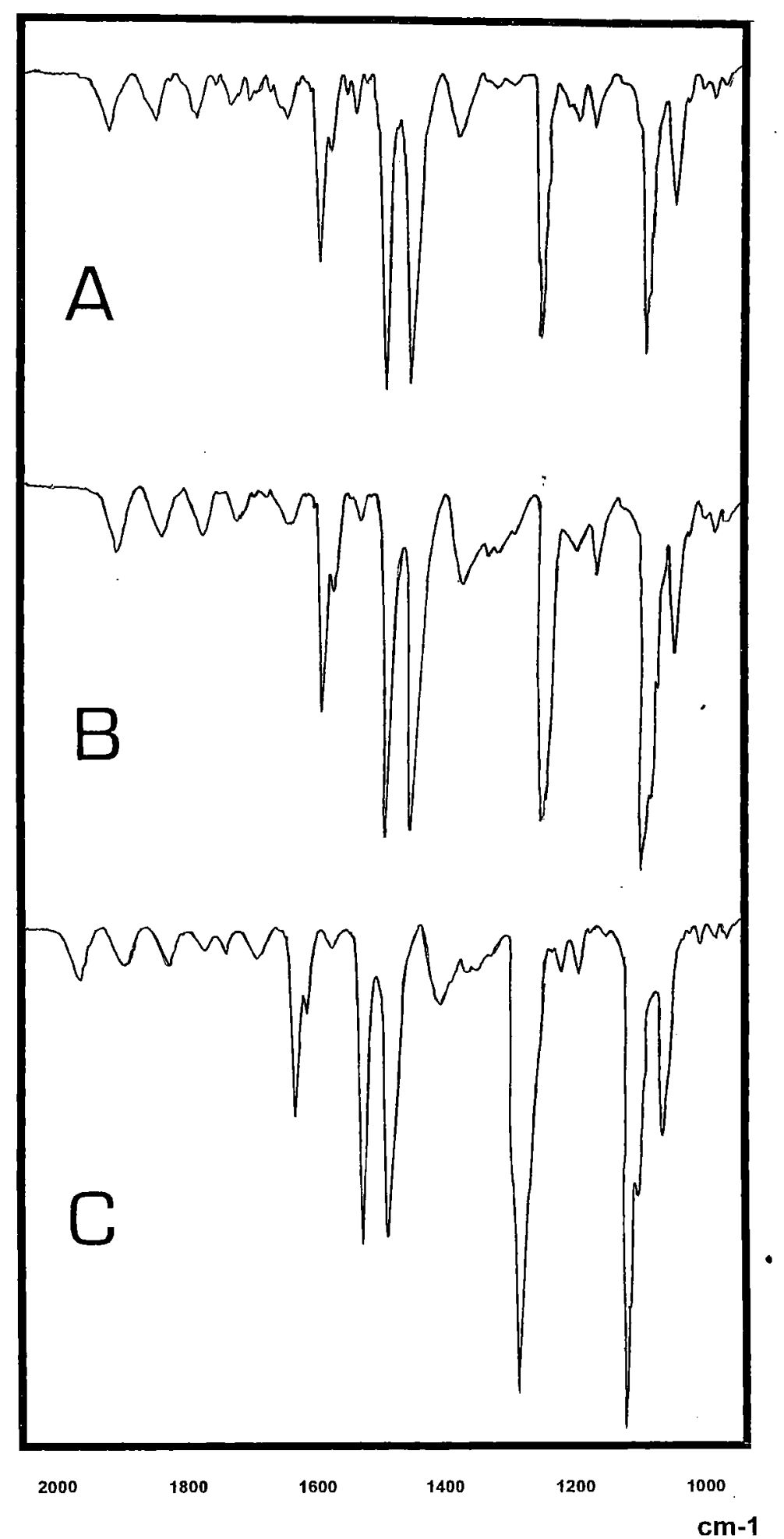

Figura 8: Espectros no IR dos copolímeros da série MEB não hidrolisados com destaque das bandas a $1227 \mathrm{~cm}^{-1}, 1027 \mathrm{~cm}^{-1}$ e $1653 \mathrm{~cm}^{-1}:(\rightarrow)$ sendo: $\mathbf{A}$ : copolímero MEB5; B: copolímero MEB10 e C: copolímero MEB15. 


\subsubsection{Comportamento Térmico}

Como pode ser visto na Figura 9, que representa as curvas obtidas via TG em atmosfera aerada, o processo térmico ocorre em uma única etapa para o PS, com perda de massa total entre $250^{\circ} \mathrm{C}$ a $450^{\circ} \mathrm{C}$; no caso dos copolímeros, tal processo ocorre em duas etapas distintas: (i) entre $25^{\circ} \mathrm{C}$ a $300^{\circ} \mathrm{C}$ verifica-se uma perda de massa que varia de $1 \%$ a $4 \%$ (TSB5, $1 \%$; TSB10, $2 \%$ e TSB15, 4\%), podendo ser atribuída à perda de monômero de estireno que não reagiu e não foi eliminado no processo de purificação, conjuntamente à evaporação do solvente residual adsorvido no polímero e (ii) entre $250^{\circ} \mathrm{C}$ a $450^{\circ} \mathrm{C}$, quando ocorrem quebras generalizadas das ligações covalentes com conseqüente liberação de produtos orgânicos voláteis, até a completa termodecomposição do copolímero, analogamente ao observado para o PS homopolímero.

RABELLO ${ }^{99}$ estudou o comportamento térmico de copolímeros de estireno e MVK, via $T_{g}$, em atmosfera aerada e inerte $\left(\mathrm{N}_{2}\right)$, observando um processo de perda de massa em duas etapas: de $26^{\circ} \mathrm{C}$ a $300^{\circ} \mathrm{C}$, com perda de massa de cerca de $3 \%$; e de $300^{\circ} \mathrm{C}$ a $600^{\circ} \mathrm{C}$, indicando a termodecomposição total.

KAMIYA \& NIKI [1978] ${ }^{118}$ postularam as etapas de degradação por radical livre do PS na presença de oxigênio como sendo muito similares à fotodegradação do PS: inicialmente, o radical PS é gerado termicamente, reagindo cerca de $10^{6}$ vezes mais rápido com uma molécula de oxigênio do que com outra molécula de PS; o radical peroxila resultante abstrai rapidamente um hidrogênio terciário, formando o hidroperóxido PS e PS-radical. Esta etapa de propagação é repetida enquanto houver oxigênio, e a decomposição deste hidroperóxido gera diversas espécies oxigenadas. Assim, benzaldeído, ácido benzóico, acetofenona, fenol, álcool benzílico, cinamaldeído, estireno, dímeros e trímeros de estireno foram

\footnotetext{
${ }^{118}$ Kamiya,Y.,Niki,E.,H.H.G.Jellinek, ed., em Aspects of Degradation and Stabilization of Polymers, Elsevier Science Publishing Co., Inc., New York, (1978) 79.
} 
identificados por VU DUC \& HUYNH [1986 ${ }^{19}$ como produtos termo-oxidativos do PS.

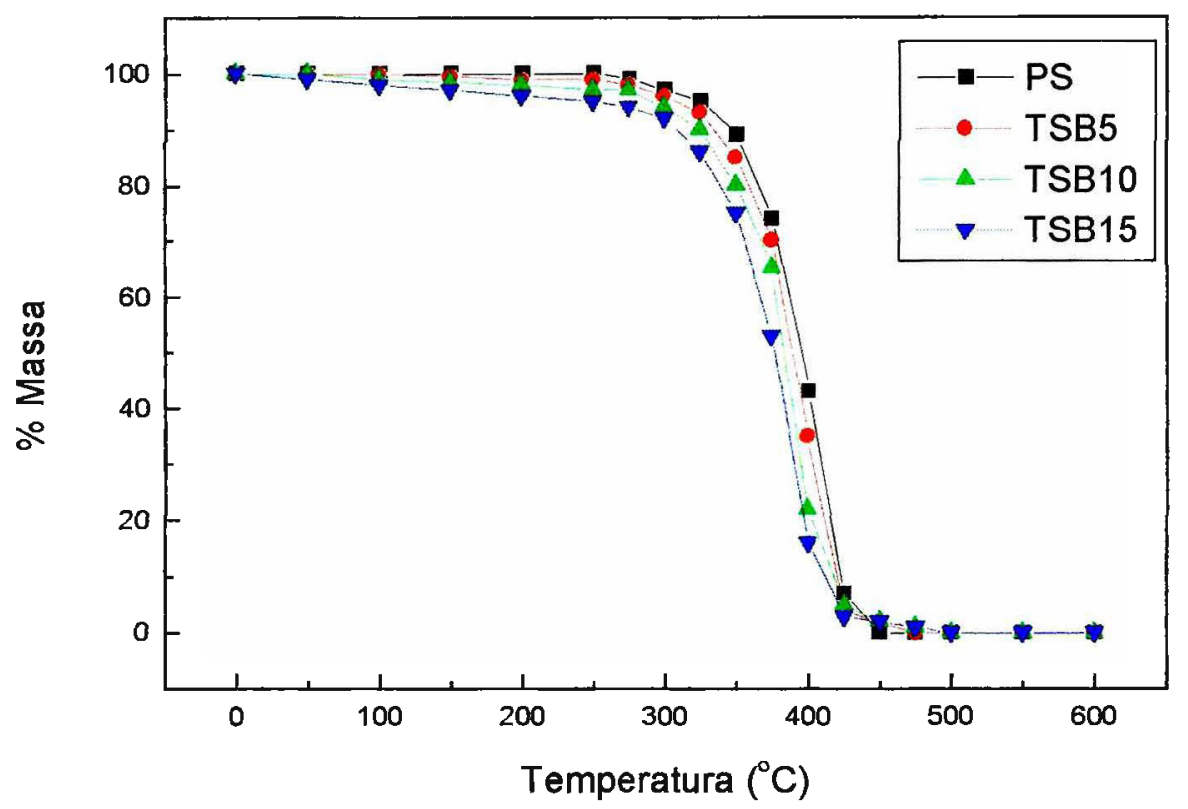

Figura 9: Curvas de TG obtidas para a série TSB em atmosfera de ar.

Com o objetivo de se realizar um estudo comparativo quanto às temperaturas de transição vítrea $\left(T_{g}\right)$ do PS puro e seus copolímeros, realizaramse ensaios via calorimetria exploratória diferencial (DSC) em atmosfera inerte de nitrogênio.

${ }^{119}$ Vu Duk, T., Huynh,C.K., Trav.Chim.Aliment.Hyg., 76 (1986) 48. 


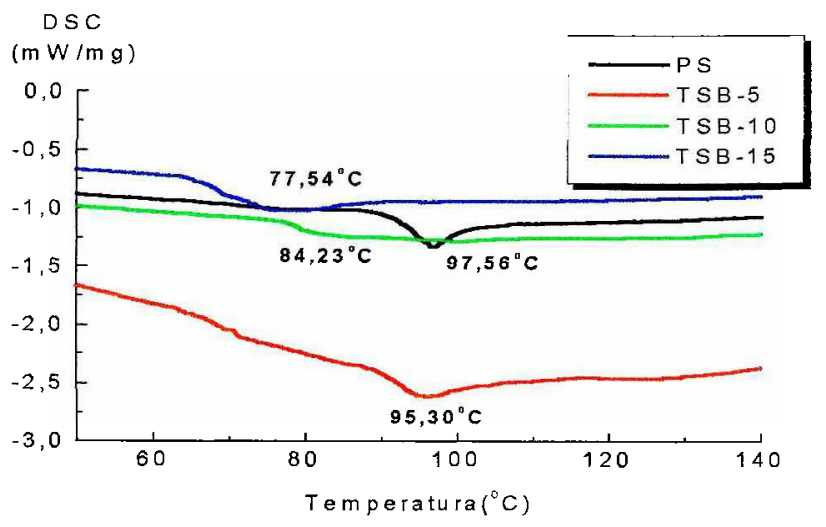

Figura 10: Curvas de DSC obtidas para o PS e a série TSB em atmosfera de $\mathrm{N}_{2}$.

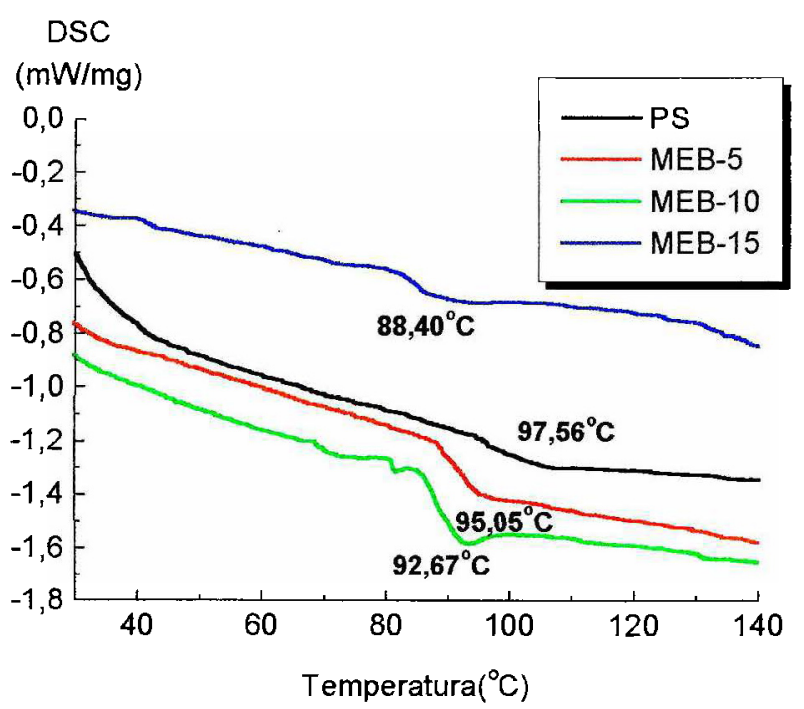

Figura 11: Curvas de DSC obtidas para o PS e a série MEB em atmosfera de $\mathrm{N}_{2}$. 


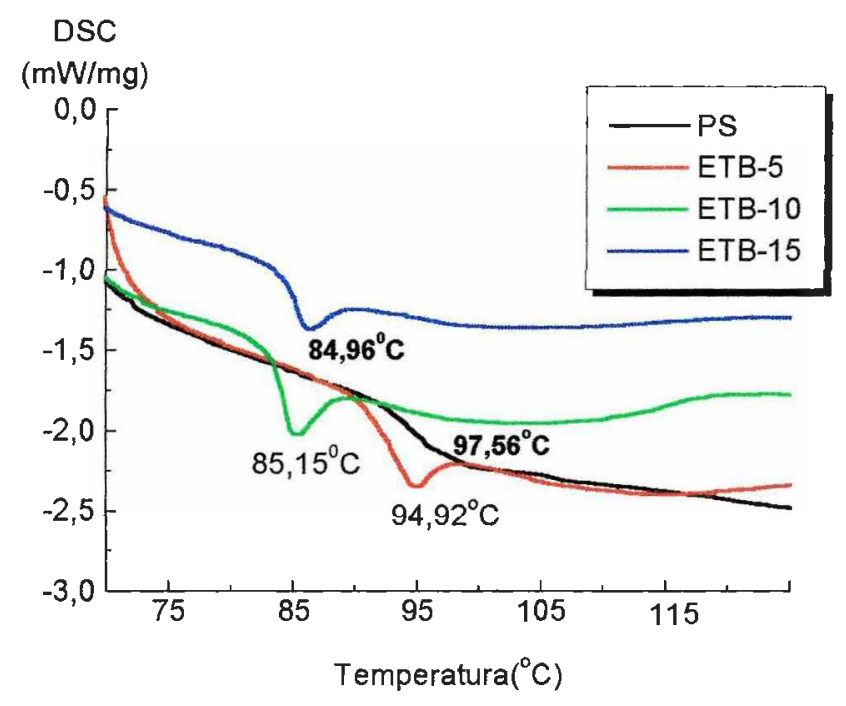

Figura 12: Curvas de DSC obtidas para o PS e a série ETB em atmosfera de $\mathrm{N}_{2}$.

Conforme ilustrado nas Figuras 10, 11 e 12, o processo térmico é evidenciado por variações da linha base no sentido endotérmico entre 80 e $96^{\circ} \mathrm{C}$ (série TSB), 88 e $95^{\circ} \mathrm{C}$ (série MEB) e 85 e $95^{\circ} \mathrm{C}$ (série ETB), características da temperatura de transição vítrea $\left(T_{g}\right)$. Os valores de $T_{g}$, obtidos por DSC, para cada um dos polímeros estudados, estão listados na Tabela 6 , juntamente com os valores de temperatura de decomposição "onset" ( $\left.T_{\text {onset }}\right)$ obtidos via TG.

$\mathrm{Em}$ todos os experimentos realizados, verifica-se que o valor atribuído à $T_{g}$ para o PS preparado é muito próximo ao valor do PS formecido por HUGLIN $[1989]^{120}$, entre 80 a $90^{\circ} \mathrm{C}$.

É interessante notar que os valores atribuídos à $T_{g}$ diminuem com $\circ$ aumento do teor de comonômero na cadeia do PS. Este fato pode estar relacionado à diminuição da tensão estérica da cadeia polimérica, como conseqüência da substituição de anéis fenila por TSB, MEB e ETB, aumentando a

\footnotetext{
${ }^{120}$ Huglin,M.B., em Polymer Handbook, $3^{\text {rd }}$ Ed.Brandrup. J. Immergut,E.H., Eds., John Wiley, New York, VII (1989) 445.
} 
mobilidade da cadeia e, conseqüentemente, diminuindo a temperatura na qual os segmentos da cadeia polimérica começam a mover-se entre si.

Em seus ensaios de $T_{g}$, RABELLO ${ }^{99}$ chegou a conclusões semelhantes, obtendo temperaturas da ordem de $93^{\circ} \mathrm{C}, 72^{\circ} \mathrm{C}, 70^{\circ} \mathrm{C}$ e $61^{\circ} \mathrm{C}$, para as transições vítreas do PS, MVK5, MVK10 e MVK15, respectivamente. A maior variação da $T_{g}$ obtida naquele caso pode estar refletindo uma diferença intrínseca entre os dois tipos de copolimeros: na série estudada por RABELLO ${ }^{99}, 100 \%$ das carbonilas foram incorporadas em grupo lateral da cadeia polimérica (carbonilas "exo"), enquanto os copolímeros descritos na Tabela 6 poderão apresentar grande parte de incorporação de carbonilas na cadeia principal (carbonilas "endo"), com razões endo/exo variáveis.

Tabela 6: $T_{g}$ via DSC em atmosfera de $\mathrm{N}_{2}$ para os copolímeros em estudo.

\begin{tabular}{|c|c|c|}
\hline POLÍMERO & $\mathrm{R}(\%)$ & $\mathrm{T}_{\mathrm{g}}$ via DSC $\left({ }^{\circ} \mathrm{C}\right)$ \\
\hline \multirow{2}{*}{ PS } & 0 & 97,5 \\
& & \\
\hline \multirow{2}{*}{ TSB } & 5 & 95,3 \\
& 10 & 84,2 \\
\hline \multirow{2}{*}{ MEB } & 15 & 77,5 \\
\hline \multirow{2}{*}{ ETB } & 5 & 95,0 \\
& 10 & 92,6 \\
& 15 & 88,4 \\
\hline & 5 & 94,9 \\
& 10 & 84,9 \\
\hline
\end{tabular}

Vale também observar que nenhum grau de cristalinidade pode ser atribuído aos polímeros, já que não se observam eventos endotérmicos característicos de fusão antes da termodecomposição. 
Deve-se mencionar ainda que não há prejuízo nas propriedades térmicas dos copolímeros em relação ao PS puro, uma vez que a termodecomposição ocorre em faixas muito semelhantes de temperatura (entre $250^{\circ} \mathrm{C}$ e $450^{\circ} \mathrm{C}$ ) ou, mais especificamente, em torno de $360^{\circ} \mathrm{C}$ para o PS e seus copolímeros.

\subsubsection{Determinação das Massas Molares}

Para a determinação da massa molar ponderal média $\left(\bar{M}_{w}\right)$, massa molar numérica média $\left(\bar{M}_{n}\right)$ e índice de polidispersividade $\left(\bar{M}_{w} / \bar{M}_{n}\right)$ dos polímeros, utilizou-se a técnica da cromatografia de exclusão por tamanho (SEC), com amostras de poliestireno de massas molares conhecidas e baixa polidispersividade, como padrões de calibração.

Na Tabela 7, encontram-se sumarizados os resultados obtidos para o PS e seus copolímeros TSB, MEB e ETB, calculados a partir das curvas mostradas na Figura 13, todas com polidispersividade em torno de dois.

Tabela 7: Características do PS e seus copolímeros obtidas via SEC.

\begin{tabular}{|c|c|c|c|}
\hline \multirow{2}{*}{ POLÍMERO } & $\mathrm{R}(\%)$ & $\overline{\mathbf{M}}_{\mathrm{w}}(\mathrm{kg} / \mathrm{mol})$ & $\overline{\mathbf{M}}_{\mathrm{w}} / \overline{\mathrm{M}}_{\mathrm{n}}$ \\
\hline \multirow{2}{*}{ PS } & 0 & 34,6 & 2,02 \\
\hline \multirow{2}{*}{ TSB } & 5 & 33,9 & 1,65 \\
\cline { 2 - 4 } & 10 & 27,7 & 2,07 \\
\cline { 2 - 4 } & 15 & 36,8 & 1,83 \\
\hline \multirow{2}{*}{ MEB } & 5 & 31,6 & 1,97 \\
\cline { 2 - 4 } & 10 & 29,0 & 2,10 \\
\hline \multirow{2}{*}{ ETB } & 15 & 30,6 & 1,59 \\
\cline { 2 - 4 } & 5 & 34,9 & 2,15 \\
\cline { 2 - 4 } & 10 & 30,1 & 2,43 \\
\hline
\end{tabular}



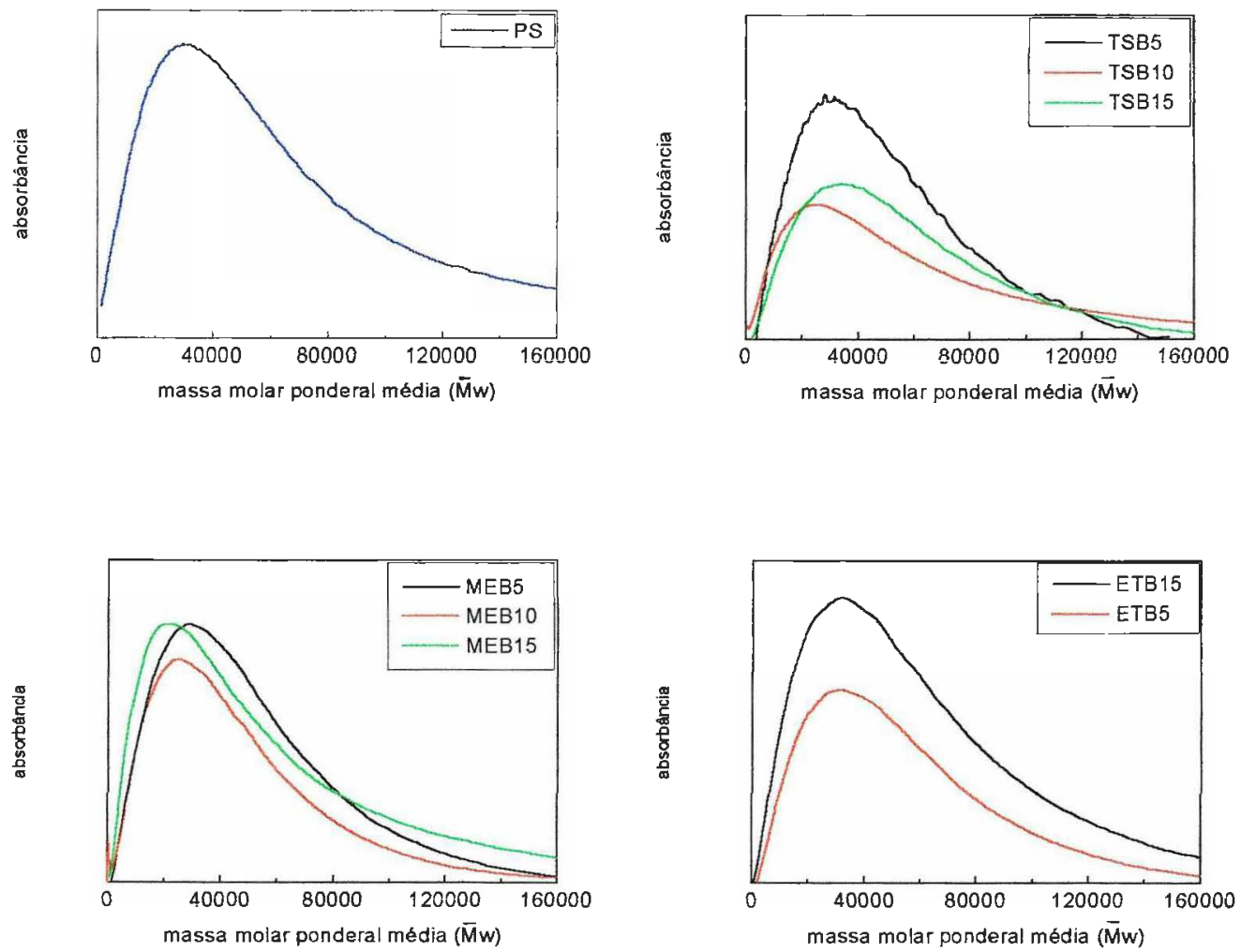

Figura 13: Perfis cromatográficos obtidos via SEC do PS e seus copolímeros.

Uma análise rápida dos perfis de eluição das soluções poliméricas e dos resultados sumarizados, na Tabela 7 , fica claro que, independente do(s) monômero(s) escolhido(s), e de suas frações molares $(5 \%, 10 \%$ ou $15 \%$, no caso dos copolímeros), tanto a homo quanto a copolimerização são, do ponto de vista mecanístico e cinético, fáceis de acontecer, nas condições reacionais escolhidas. Tais observações têm suporte nos valores experimentalmente obtidos para $\bar{M}_{w}$ muito próximos (entre $28,0 \mathrm{~kg} / \mathrm{mol}$ e $35,0 \mathrm{~kg} / \mathrm{mol}$ ) para todos os polímeros estudados.

RABELLO ${ }^{99}$ obteve um $\bar{M}_{w}$ de $81,0 \mathrm{~kg} / \mathrm{mol}$ para o PS, e de cerca de $40,0 \mathrm{~kg} / \mathrm{mol}$ para seus copolímeros com MVK, com índices de polidispersividade de 1,76 para o homopolímero, e de aproximadamente 1,48 para os copolímeros, independente do teor de incorporação de MVK. 


\subsubsection{Estudos Cinéticos Através da Equação do Copolímero}

Conclusões interessantes podem ser obtidas a partir das razões de reatividade " $r$ " dos comonômeros, determinadas por meio da equação do copolímero (Equação 17), levando-se em conta os quatro caminhos possiveis nos quais dois comonômeros, $\left(M_{1}\right.$ e $\left.M_{2}\right)$ e seus respectivos radicais $\left(M_{1}{ }^{\circ}\right.$ e $\left.M_{2}{ }^{*}\right)$ podem adicionar-se ${ }^{121}$ :

\begin{tabular}{ccc}
\hline Reação & Velocidade \\
\hline$M_{1}+M_{1} \rightarrow M_{1} M_{1}^{*}$ & $k_{11}\left[M_{1}\right]\left[M_{1}\right]$ \\
$M_{1}+M_{2} \rightarrow M_{1} M_{2}^{*}$ & $k_{12}\left[M_{1}{ }^{\prime}\right]\left[M_{2}\right]$ \\
$M_{2}+M_{1} \rightarrow M_{2} M_{1}{ }^{*}$ & $k_{21}\left[M_{2}{ }^{\prime}\right]\left[M_{1}\right]$ \\
$M_{2}{ }^{n}+M_{2} \rightarrow M_{2} M_{2}^{*}$ & $k_{22}\left[M_{2}\right]\left[M_{2}\right]$ \\
\hline
\end{tabular}

TURNER ${ }^{122}$, MAYO $^{123}, \mathrm{SIMHA}^{124}$ e WALL ${ }^{125}$ [1944], aplicando a teoria do estado estacionário para cada espécie radicalar separadamente, e considerando que a reatividade da cadeia é determinada pela última unidade que se adicionou (independente do comprimento da cadeia), chegaram à Equação do Copolímero (Equação 17), que especifica qual a proporção de " $\mathrm{M}_{1}$ " e " $\mathrm{M}_{2}$ " adicionada na cadeia em determinado instante da reação:

\footnotetext{
${ }^{121}$ Dostal,H., "A Basis for the Reaction Kimetics of Mixed Polymerization"(in German), Monatsh.Chem.,69 (1936) 424.

${ }^{122}$ Turner,A Jr., and Goldfinger,G., "The Mechanism of Copolymerization", J.Chem.Phys. 12 (1944) 205.

${ }^{123}$ Mayo,F.R., and Lewis,F.M., "Copolymerization .I. A Basis for Comparing the Behavior of Monomers in Copolymerization; The Copolymerization of Styrene and Methyl Methacrylate",JAmer.Chem..Soc. 66 (1944) 1594.

${ }^{124}$ Simha,R,and Branson,H., "Theory of chain Copolymerization Reactions", J.Chem.Phys. 12 (1944) 253.

${ }^{125}$ Wall,F.T.,"The Structure of Copolymers. II.",JAm.Chem.Soc. 66 (1944) 2050.
} 


$$
\frac{d\left[M_{1}\right]}{d\left[M_{2}\right]}=\frac{\left[M_{1}\right]}{\left[M_{2}\right]} \frac{r_{1}\left[M_{1}\right]+\left[M_{2}\right]}{\left[M_{1}\right]+r_{2}\left[M_{2}\right]}
$$

\section{Equação 17}

sendo $r_{1}=k_{11} / k_{12}$ e $r_{2}=k_{22} / k_{21}$ as razões de reatividade de cada espécie reativa $\left(M_{1}{ }^{\circ}\right.$ e $\left.M_{2}{ }^{\circ}\right)$ com relação ao seu próprio monômero e ao outro. Assim, é possível dizer que, se $k_{11}>k_{12}$, então $r_{1}>1$, e o radical $M_{1}$ apresenta maior tendência de homopolimerizar ou formar blocos; por outro lado, se $r_{1}<1$, a reação que leva à copolimerização e à adição alternada é a favorecida.

Como exemplo próximo ao sistema estudado, considerando-se o valor da razão de reatividade do 2 -metil-1,3-butadieno (isopreno, $\left.r_{2}=1,92\right)^{126}$, como referência dos valores reais (não disponiveis na literatura) para os monômeros tipo butadieno 2-substituídos (TSB, MEB e ETB), efetivamente empregados nas copolimerizações, chega-se a alguns resultados muito significativos.

\begin{tabular}{cccc}
\hline$M_{1}$ & $M_{2}$ & $r_{1}$ & $r_{2}$ \\
\hline Estireno & Isopreno & 0,51 & 1,92 \\
\hline & & \multicolumn{2}{c}{ dados obtidos a $60^{\circ}{ }^{126}$}
\end{tabular}

Pode-se dizer que um sistema de copolímeros é dito ideal quando as duas espécies radicalares envolvidas mostram a mesma preferência para se adicionar a um dos comonômeros. Algebricamente: $k_{11} / k_{12}=k_{21} / k_{22}$, ou ainda $r_{1}, r_{2}=1$.

Para o sistema estudado, $r_{1} \cdot r_{2}=0,98$, ou seja, o grupo terminal da cadeia em crescimento não influencia a velocidade de adição e, por conseqüência, os

\footnotetext{
${ }^{126}$ Young,L.J., "Copolymerization Reactivity Ratios", pp.II-105-II386 in J.Brandrup and E.H.Immergut, eds., with the collaboration of W.McDowel, Polymer Handbook, $2^{\text {nd }}$ ed., Wiley-Interscience, New York, 1975.
} 
dois tipos de unidades são adicionados aleatoriamente ao longo da cadeia, em quantidades que dependem apenas das concentrações inicialmente carregadas.

A partir destas observações, pode-se concluir que: (i) uma vez que $r_{1}<1$ e $r_{2}>1$, provavelmente, no início da polimerização, formam-se longas seqüências de comonômero (díades), intercalando poucas unidades de estireno. À medida que a concentração de comonômero diminui, nos estágios mais avançados da reação, surgem longas seqüências de estireno (copolímero "tapered"); (ii) os dois radicais formados tendem a se adicionar ao monômero de 1,3-butadieno-2-substituído e (iii) a copolimerização é considerada de fácil ocorrência, uma vez que $r_{1}$ e $r_{2}$ encontram-se na mesma ordem de grandeza $\left(5,1.10^{-1}\right.$ e $19,2.10^{-1}$, respectivamente).

Tais conclusões dão suporte ao fato das incorporações dos monômeros de TSB, MEB e ETB ao poliestireno terem resultado em valores percentuais muito próximos àqueles inicialmente propostos $(5 \%, 10 \%$ e $15 \%)$, ou seja, a copolimerização foi favorecida e os copolímeros resultantes não apresentaram teores de monômeros livres residuais significativos.

\subsubsection{Estudos de Superfície por Microscopia Eletrônica de Varredura}

Amostras na forma de pó finamente dividido de PS e copolímeros selecionados da série TSB foram submetidas a ensaios de microscopia eletrônica de varredura (MEV). As micrografias obtidas para aumentos de 200 vezes estão mostradas nas Figuras 14-16.

Uma análise cuidadosa destas figuras revela um aumento crescente na rugosidade superficial no sentido $14 \rightarrow 16$, ou seja, da micrografia do PS puro, passando pelo copolímero TSB10 e, finalizando, na micrografia obtida do copolímero TSB15. 


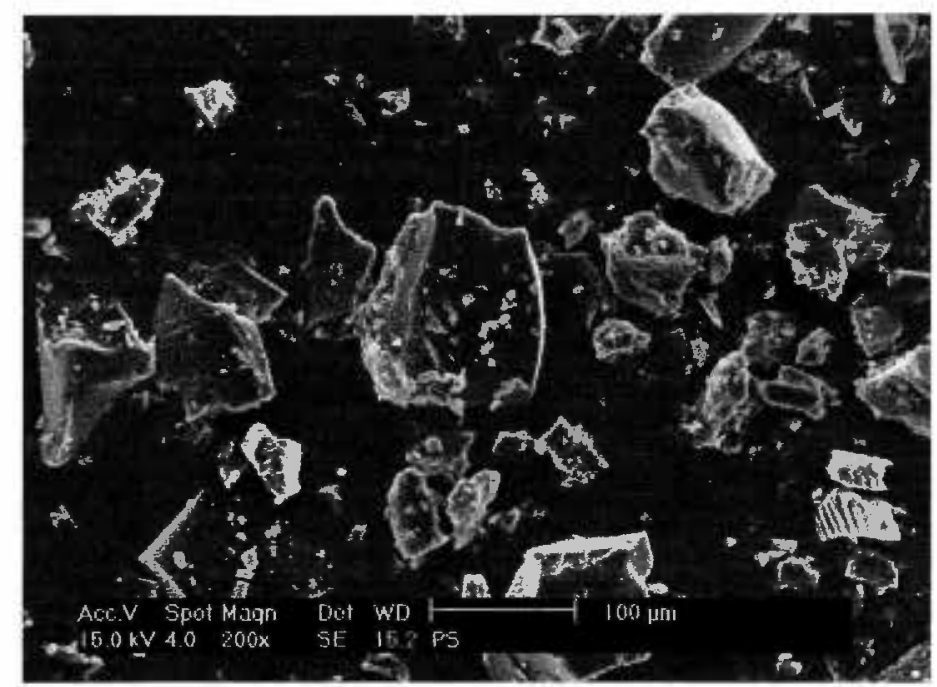

Figura 14: Micrografia do PS (aproximadamente 200X).

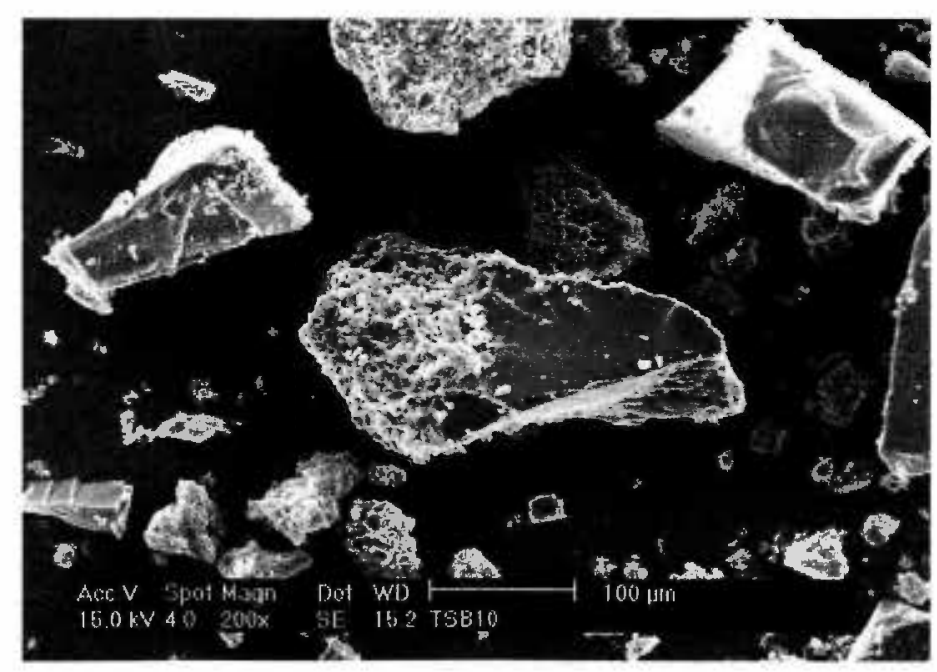

Figura 15: Micrografia do copolímero TSB10 (aproximadamente 200X). 


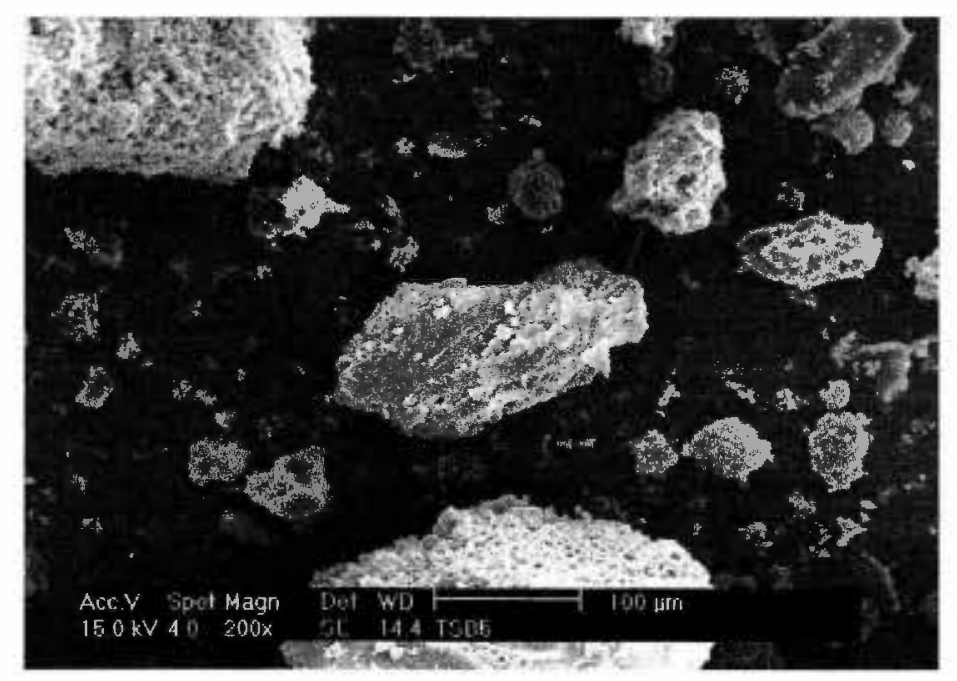

Figura 16: Micrografia do copolímero TSB15 (aproximadamente 200X).

À medida que o teor de carbonilas (grupo polar) aumenta nos copolímeros, suas polaridades aumentam no mesmo sentido, passando de uma situação extrema de $0 \%$ (PS) até o limite de $15 \%$ (TSB).

Esta observação parece sugerir que, durante o tratamento de purificação (precipitação em metanol e redissolução em THF por sucessivas vezes) e secagem (4 dias sob vácuo à temperatura ambiente) dos polímeros, a remoção do metanol não foi completa, sendo mais problemática à medida em que a polaridade do copolímero aumenta, em virtude das interações intermoleculares do tipo dipolodipolo presentes.

Tal fato justifica as alterações superficiais dos polímeros, mais lisas no PS (apolar $\rightarrow$ menor quantidade de metanol residual), por um lado, e mais rugosas no TSB15 (maior teor de carbonilas $\rightarrow$ polaridade aumentada $\rightarrow$ maior retenção de metanol), por outro lado. 


\subsection{Estudo do Efeito da Radiação Ultravioleta na Estrutura Química dos Polímeros}

\subsubsection{Estudo da Cinética de Degradação Absoluta no Ultravioleta dos Polímeros em Solução}

Quando uma cadeia polimérica é quebrada em dois ou mais fragmentos, a intensidade da luz espalhada pelos mesmos será, na maioria dos casos, menor do que aquela resultante do polímero intacto. Assim, a técnica TDSLS procura determinar, em tempo real, como a intensidade da luz espalhada se relaciona ao número de cortes feitos no polímero, ao modo como tais cortes são realizados (aleatoriamente ou não), e à estrutura do polímero.

Soluções poliméricas diluídas em THF $(10 \mathrm{mg} / \mathrm{mL})$ foram irradiadas com luz ultravioleta $(\lambda=254 \mathrm{~nm})$ ao longo de dez horas, $e$ as intensidades de espalhamento originais (obtidas a um ângulo de $90^{\circ}$ ) transformadas em razão de espalhamento Rayleigh dependente do tempo $I(q, t)$, e representadas na forma $K c_{0} / I$ para o PS e os copolímeros da série TSB (Figura 17), série MEB (Figura 18) e série ETB (Figura 19). 


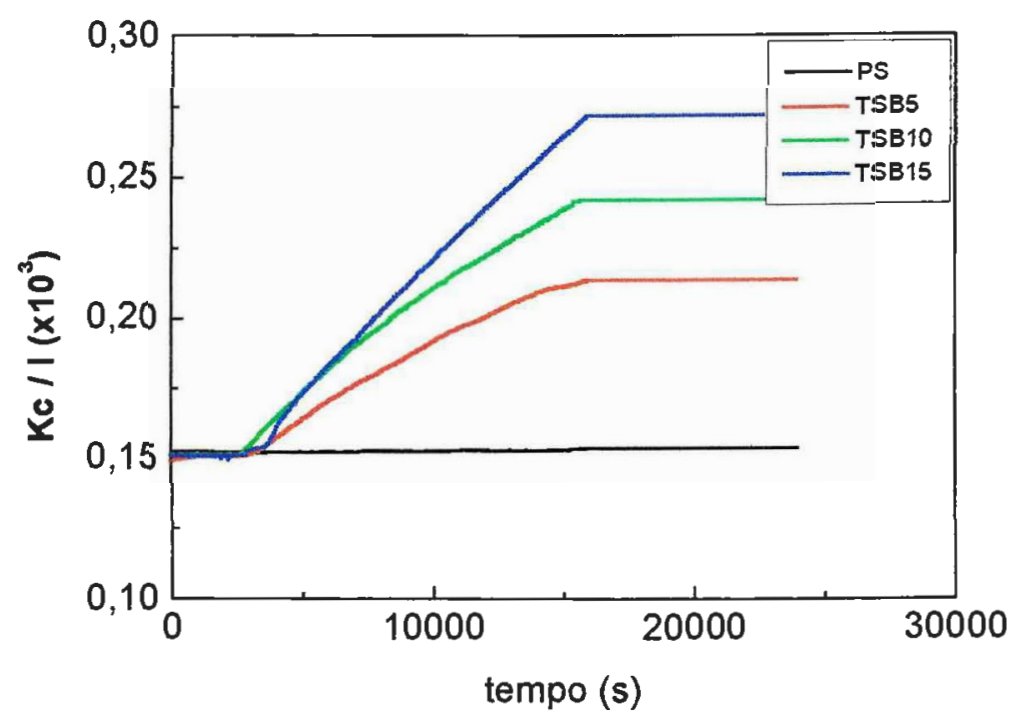

Figura 17: Curvas $K c_{0} / I$ versus tempo para a o PS puro e série TSB

$$
\left(\theta=90^{\circ} \text { e } c_{0}=10 \mathrm{mg} / \mathrm{mL}\right) .
$$

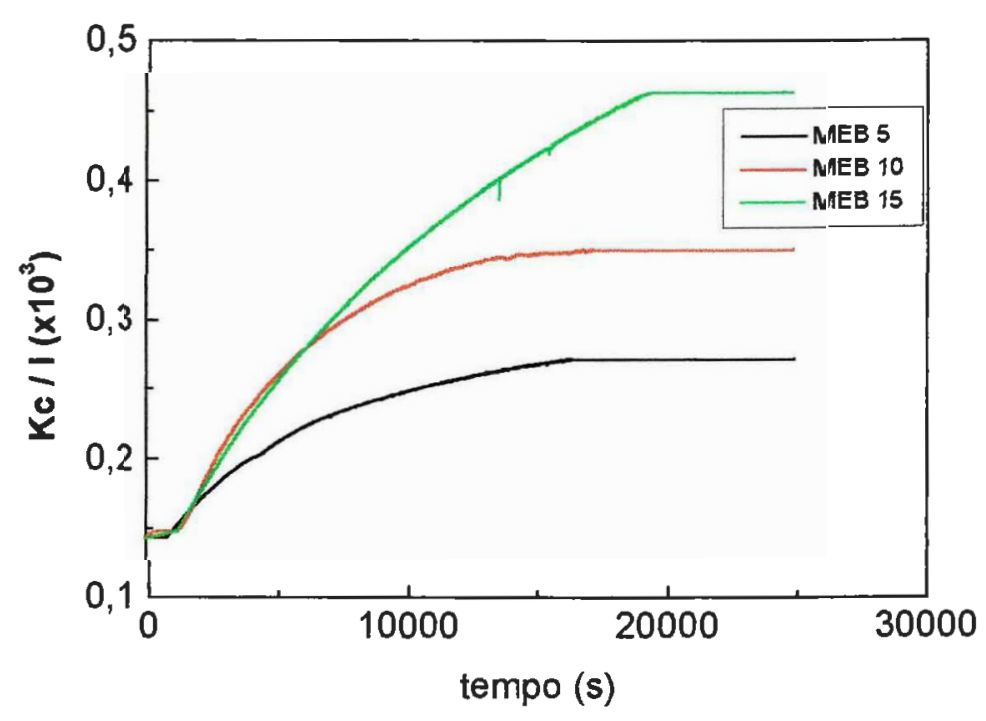

Figura 18: Curvas $K c_{0} / I$ versus tempo para a série MEB

$$
\left(\theta=90^{\circ} \text { e } c_{0}=10 \mathrm{mg} / \mathrm{mL}\right) .
$$




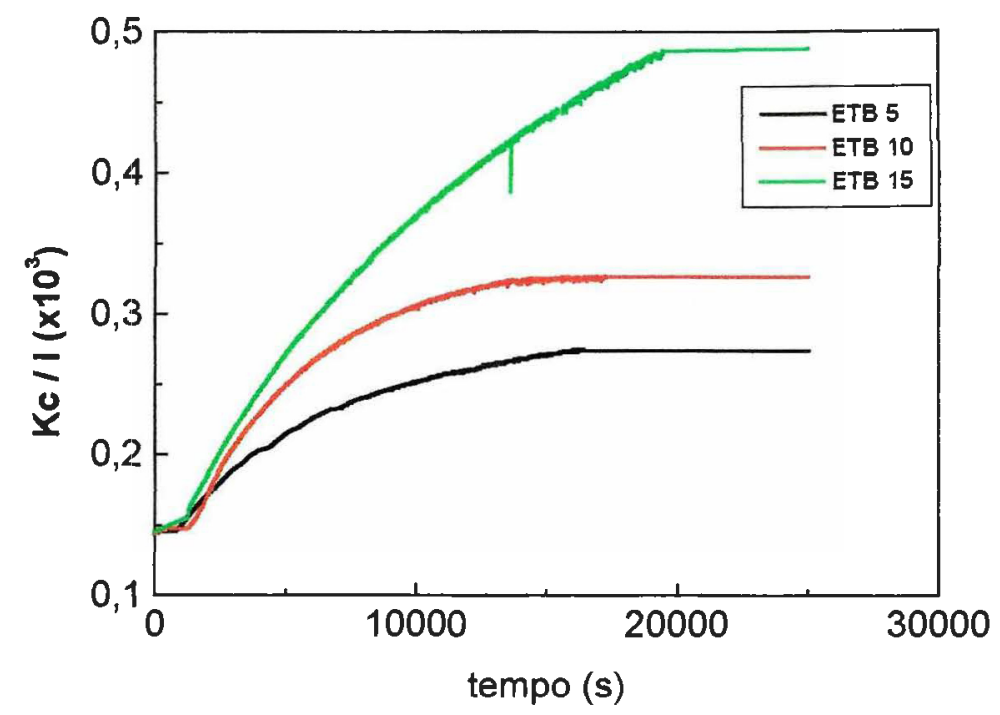

Figura 19: Curvas $K c_{0} / I$ versus tempo para a série ETB

$$
\left(\theta=90^{\circ} \text { e } c_{0}=10 \mathrm{mg} / \mathrm{mL}\right) .
$$

Essas figuras estão representadas por pontos individuais, sem qualquer tipo de correção. Os 1000 segundos iniciais foram mantidos e representam o tempo morto, ou seja, o período que o polímero em degradação leva para alcançar a cela de espalhamento de luz a partir da fonte de irradiação.

É claramente visível que todos os copolímeros sofrem uma degradação mais rápida em comparação ao PS puro, cujo comportamento é o de uma linha praticamente plana na parte inferior da Figura 17. O ponto mais importante observado aqui é que, para todas as séries de copolímeros estudadas, as velocidades de degradação aumentam de modo proporcional ao teor de incorporação dos comonômeros na cadeia do PS. Isso tem suporte nas massas molares ponderais médias $\bar{M}_{w}$ obtidas via SEC para os fragmentos resultantes da fotólise, com valores decrescentes à medida que os efeitos da fotodegradação aumentam.

É evidente, também, que as taxas de degradação são maiores no início da fotólise (até 5000 segundos ou 1hora e 20 minutos), diminuindo gradativamente até aproximadamente 16.000 segundos (cerca de 4 horas e 30 minutos), quando 
as rupturas na cadeia dos copolímeros cessam. Esse comportamento é traduzido em gráficos por linhas planas nas porções finais de cada curva.

CATALANI et al [1997] $]^{127}$ estudaram copolímeros de estireno e MVK sob condições de degradação semelhantes, por períodos de exposição de duas horas e trinta minutos (MVK10 e MVK15), e oito horas (PS e MVK5). Os copolímeros degradaram mais rapidamente em comparação ao PS puro, como esperado.

A Figura 20 apresenta a porção inicial, linear, de cada curva da Figura 19, para a série ETB. O tempo morto não foi eliminado das curvas, observando-se que pouco ruído estava presente.

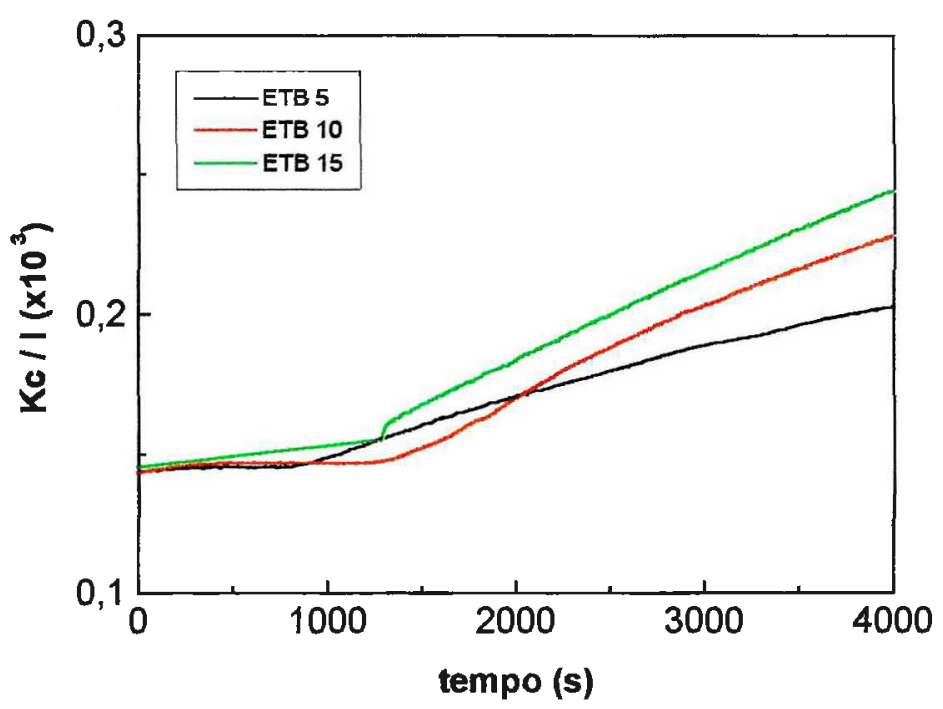

Figura 20: Comportamento das curvas $K c_{0} / I$ versus tempo para a série ETB, para intervalos de tempo curtos.

As inclinações iniciais são proporcionais às velocidades de ruptura iniciais da cadeia polimérica. A Tabela 8 quantifica tais inclinações ("tga"), comparativamente aos respectivos valores obtidos para os copolímeros de

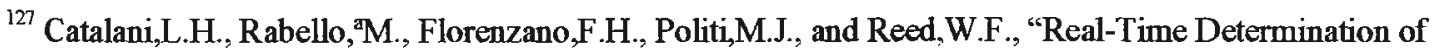
Ultraviolet Degradation Kinetics of Polymers in Solution", Int.J.Polym.Anal.Charact. 3 (1997) 231.
} 
estireno e $\mathrm{MVK}^{127}$. Esses dados revelam que os copolímeros da série ETB sofreram rupturas em suas cadeias com velocidades de cerca de duas a três vezes maiores do que seus análogos da série MVK. Tal comportamento é explicado com base nos mecanismos de fotodegradação envolvidos em cada um dos casos:

Tabela 8: Parâmetros indicativos das velocidades de ruptura iniciais de copolímeros ETB versus MVK.

\begin{tabular}{|c|c|c|c|c|c|c|}
\hline COPOLÍMERO & \multicolumn{3}{|c|}{ E T B } & \multicolumn{3}{c|}{ M V K } \\
\hline $\begin{array}{c}\text { COMONÔMERO } \\
(\%)\end{array}$ & 5 & 10 & 15 & 5 & 10 & 15 \\
\hline $\operatorname{tga}\left(\mathbf{s}^{-1}\right)$ & $1,67.10^{-2}$ & $3,00.10^{-2}$ & $3,20.10^{-2}$ & $6,25.10^{-3}$ & $1,00.10^{-2}$ & $1,40.10^{-2}$ \\
\hline
\end{tabular}

i) na série ETB, as carbonilas encontram-se principalmente distribuídas ao longo da cadeia principal dos copolímeros, possibilitando sua fragmentação por meio dos mecanismos de Norrish Tipos I e II e, como conseqüência, as velocidades de ruptura são elevadas;

ii) na série MVK, as carbonilas encontram-se distribuídas em grupos laterais dos copolímeros, permitindo a fragmentação da cadeia principal apenas por meio do mecanismo de Norrish Tipo II, levando a velocidades de ruptura relativamente inferiores. 


\subsubsection{Alterações nos Parâmetros Relativos às Massas Molares}

Decorrido o período de dez horas de fotólise, as soluções poliméricas foram recuperadas e armazenadas em recipientes escuros, no freezer $\left(\mathrm{a}-18^{\circ} \mathrm{C}\right)$, ao abrigo da luz.

Os resultados obtidos para as massas molares médias ponderais $\left(\bar{M}_{w}\right)$ e índices de polidispersividade $\left(\bar{M}_{w} / \bar{M}_{n}\right)$ do PS puro e das três séries de copolímeros, antes e após serem irradiados, foram obtidos por meio da interpretação dos perfis de eluição mostrados nas Figuras 21-24, e estão resumidos na Tabela 9.

Com o intuito de realizar uma comparação visual direta e facilitar a interpretação dos resultados, os perfis de eluição e os valores das massas molares médias, obtidos antes da fotólise, estão sendo reapresentados.

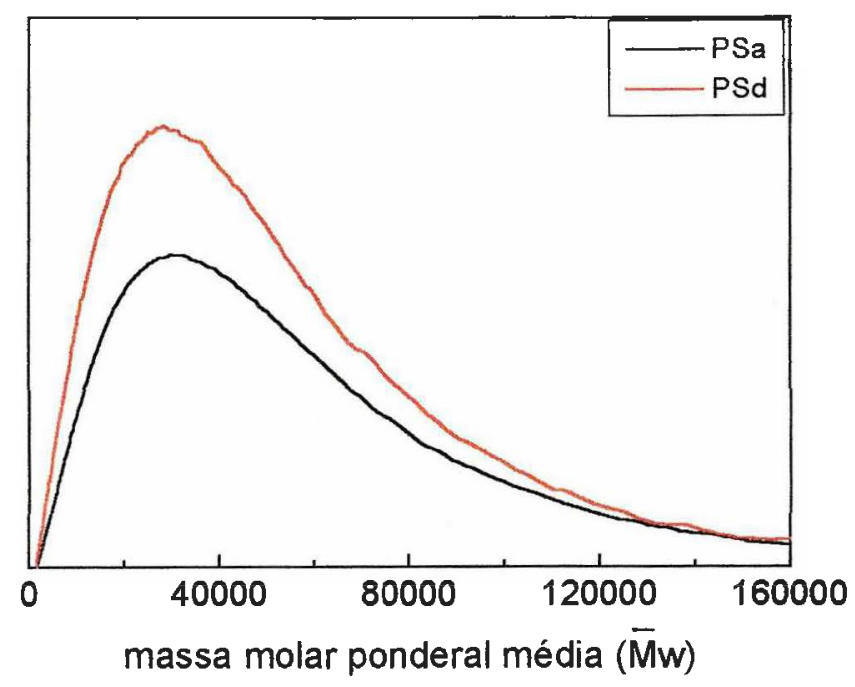

Figura 21: Massa molar média ponderal via SEC para o PS.

$$
\text { ( } \mathbf{a}=\text { antes; } \mathbf{d}=\text { depois da fotólise) }
$$




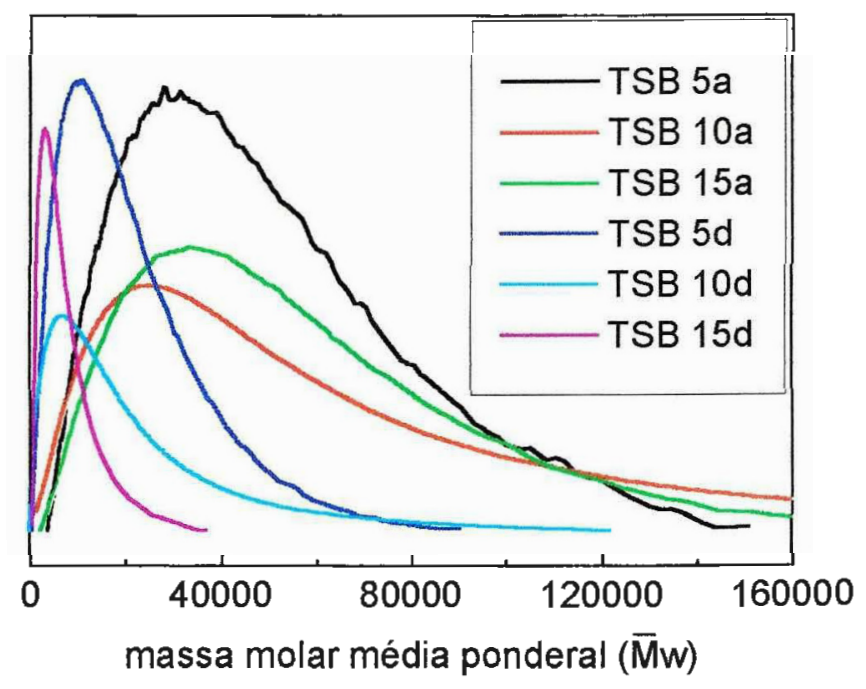

Figura 22: Massa molar média ponderal via SEC para a série TSB.

$$
\text { ( } \mathbf{a}=\text { antes; } \mathbf{d}=\text { depois da fotólise) }
$$

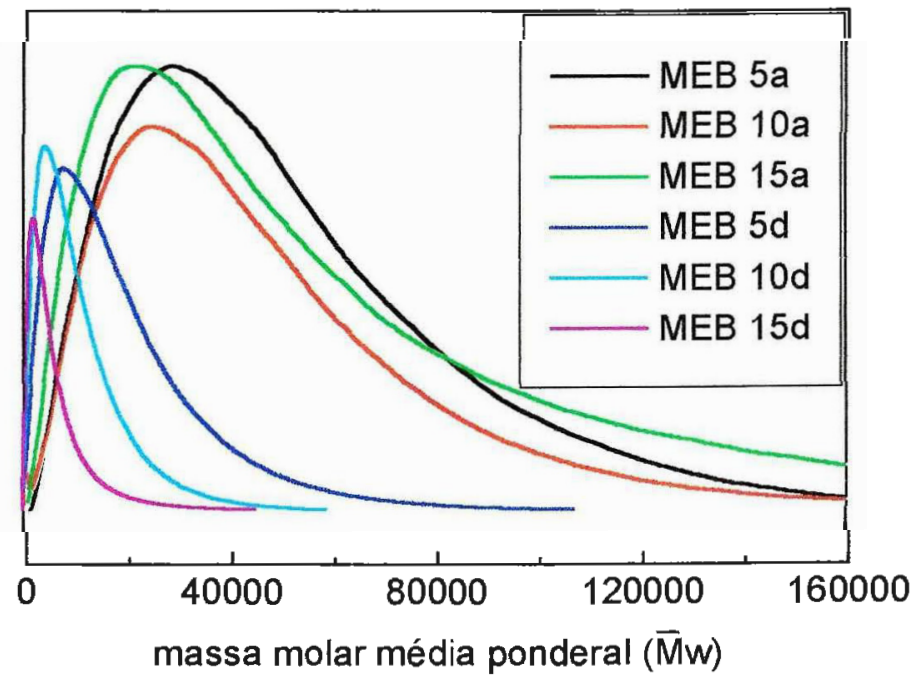

Figura 23: Massa molar média ponderal via SEC para a série MEB.

( $\mathbf{a}=$ antes; $\mathbf{d}=$ depois da fotólise) 


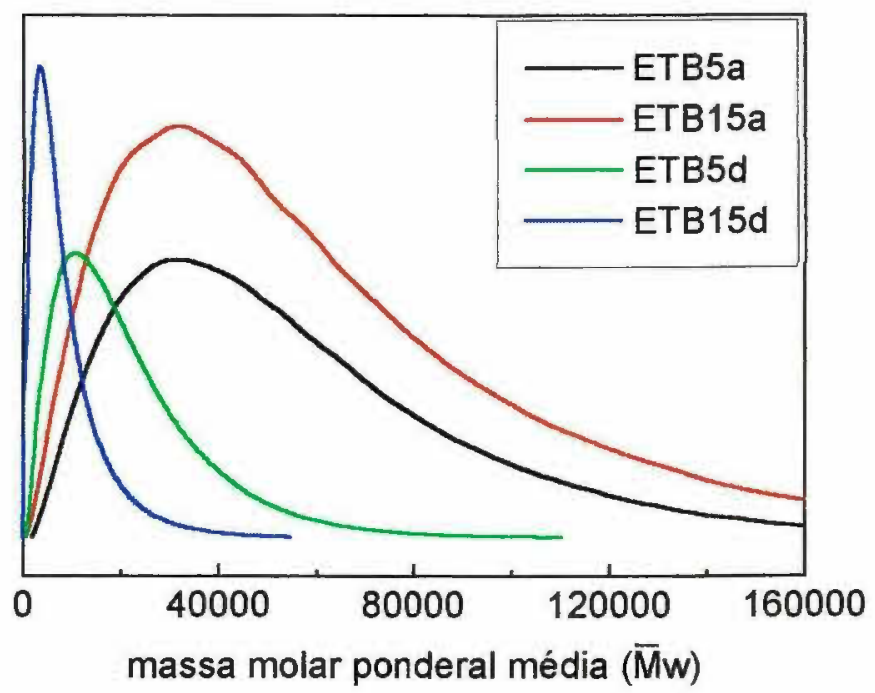

Figura 24: Massa molar média ponderal via SEC para a série ETB.

$$
\text { ( } \mathbf{a}=\text { antes; } \mathbf{d}=\text { depois da fotólise) }
$$

Tabela 9: Resultados das análises elementares e das massas molares médias ponderais $\bar{M}_{\mathrm{w}}(\mathrm{kg} / \mathrm{mol})$, e polidispersividade $\left(\bar{M}_{\mathrm{w}} / \bar{M}_{n}\right)$ dos copolímeros.

\begin{tabular}{|c|c|c|c|c|c|c|}
\hline POLÍMERO & $\mathbf{R}(\%)$ & $M(\%)$ & $\bar{M}_{w}(\mathrm{af})$ & $\bar{M}_{w}(d f)$ & $\bar{M}_{w} / \bar{M}_{n}$ (af) & $\bar{M}_{w} / \bar{M}_{n}(d f)$ \\
\hline PS & 0 & 0,00 & 34,6 & 32,8 & 2,02 & 2,09 \\
\hline \multirow{3}{*}{ TSB } & 5 & 5,78 & 33,9 & 12,5 & 1,65 & 2,17 \\
\hline & 10 & 10,91 & 27,7 & 10,3 & 2,07 & 2,48 \\
\hline & 15 & 15,87 & 36,8 & 4,8 & 1,83 & 1,69 \\
\hline \multirow{3}{*}{ MEB } & 5 & 5,28 & 31,6 & 10,0 & 1,97 & 3,14 \\
\hline & 10 & 10,69 & 29,0 & 5,5 & 2,10 & 2,77 \\
\hline & 15 & 15,45 & 30,6 & 3,0 & 2,59 & 2,24 \\
\hline \multirow{3}{*}{ ETB } & 5 & 5,28 & 34,9 & 12,7 & 1,89 & 2,81 \\
\hline & 10 & 10,63 & 30,1 & 9,5 & 2,15 & 2,68 \\
\hline & 15 & 15,62 & 35,4 & 4,0 & 2,43 & 3,83 \\
\hline
\end{tabular}

$\mathrm{R}=\mathrm{Com} / \mathrm{ST}$ antes da polimerização (\%); M = Com / ST após a polimerização (\%);

$\bar{M}_{w}=$ Massa molar média ponderal $(\mathrm{kg} / \mathrm{mol})$ antes (af) e depois (df) de $10 \mathrm{~h}$ de fotólise. 
Os resultados obtidos mostram decréscimos nos valores de $\bar{M}_{w}$ após a fotólise, sendo mais acentuados quanto maiores os teores de incorporação dos comonômeros na cadeia do poliestireno, começando em torno de $34,0 \mathrm{~kg} / \mathrm{mol}$ (TSB5 não fotolisado), por exemplo, e decaindo para valores de $\bar{M}_{w}$ tão baixos quanto $3,0 \mathrm{~kg} / \mathrm{mol}$ (MEB15 fotolisado).

No estudo da variação de $\bar{M}_{w}$ em função do tempo de fotólise, para copolímeros de estireno e MVK feito por RABELLO ${ }^{99}$, observou-se que, a partir de $\bar{M}_{w}$ iniciais de cerca de $40,0 \mathrm{~kg} / \mathrm{mol}$, atingiu-se valores de 15,0kg/mol (MVK5) e 10,0kg/mol (MVK10 e MVK15), aproximadamente, quando não se observou alterações significativas posteriores.

Os valores de polidispersividade dos copolímeros fotolisados, em contrapartida, aumentam em relação aos seus respectivos não-fotolisados, conforme observado experimentalmente também por HRDLOVIC et al. [1980] ${ }^{94}$, para filmes de copolímeros de estireno e benzalacetofenona submetidos à radiação de $313 \mathrm{~nm}$ por períodos de até 123 horas, e por WANDELT et al. [1980] $]^{61}$, para filmes de PS atáctico irradiados a $254 \mathrm{~nm}$ por até 600 minutos a várias temperaturas $\left(25^{\circ} \mathrm{C}\right.$ a $\left.92^{\circ} \mathrm{C}\right)$.

Tal constatação pode ser atribuída ao fato de que, mesmo após um longo período de degradação, há uma considerável contribuição da fração residual de elevada massa molar (frações com caráter de homopolímero), e o máximo das curvas de distribuição desloca-se para valores de massa molar numérica média, $\bar{M}_{n}$, menores, acarretando aumentos nos valores de polidispersividade.

Um estudo paralelo de acompanhamento da fragmentação do PS e copolímeros durante a fotólise foi feito, coletando-se amostras em intervalos de uma hora (de 0 a 10 horas), nas mesmas condições de irradiação anteriormente descritas. Essas amostras foram analisadas individualmente, via SEC, e os resultados obtidos para $\bar{M}_{w}$ foram apresentados na Tabela 10 e nas Figuras 25-27.

Como indicado pelos gráficos, os copolímeros degradam rapidamente durante as duas primeiras horas de irradiação, e mais lentamente a seguir, não ocorrendo alterações significativas de $\bar{M}_{w}$ após 5 horas. Esse padrão de 
comportamento já era esperado, diante dos resultados de espalhamento de luz estático dependente do tempo (TDSLS), apresentados anteriormente.

Tabela 10: Valores das massas molares médias ponderais $\left(\bar{M}_{w}\right)$ ao longo de dez horas de fotólise (soluções a $10 \mathrm{mg} / \mathrm{mL}$ em THF; $\lambda=254 \mathrm{~nm}$ ).

\begin{tabular}{|c|c|c|c|c|c|c|c|c|c|c|c|c|}
\hline \multirow{2}{*}{\multicolumn{2}{|c|}{ Polímero }} & \multicolumn{11}{|c|}{$\begin{array}{l}\text { Valores de } \overline{\mathrm{M}}_{*}(\mathrm{~kg} / \mathrm{mol}) \text { ao longo de } 10 \text { horas de irradiaça } \\
\text { Tempo (h) }\end{array}$} \\
\hline & & 0 & 1 & 2 & 3 & 4 & 5 & 6 & 7 & 8 & 9 & 10 \\
\hline \multicolumn{2}{|c|}{ PS } & 34,6 & 35,2 & 35,3 & 35,1 & 35,0 & 34,0 & 33,9 & 33,2 & 33,1 & 33,0 & 32,8 \\
\hline \multirow{3}{*}{$\begin{array}{l}T \\
\text { S } \\
\text { B }\end{array}$} & 5 & 33,9 & 25,3 & 17,5 & 15,0 & 13,5 & 13,2 & 13,0 & 12,9 & 12,8 & 12,6 & 12,5 \\
\hline & 10 & 27,7 & 20,1 & 15,2 & 12,3 & 11,2 & 11,0 & 11,3 & 10,9 & 10,8 & 10,5 & 10,3 \\
\hline & 15 & 36,8 & 17,5 & 12,0 & 8,6 & 7,6 & 6,0 & 5,7 & 5,2 & 5,0 & 4,9 & 4,8 \\
\hline \multirow{3}{*}{$\begin{array}{l}\mathbf{M} \\
\mathbf{E} \\
\mathbf{B}\end{array}$} & \multirow[b]{2}{*}{10} & 31,6 & 23,1 & 15,6 & 12,8 & 11,2 & 10,8 & 10,9 & 10,5 & 10,2 & 10,2 & 10,0 \\
\hline & & 29,0 & 19,2 & 11,8 & 9,0 & 7,9 & 7,5 & 7,0 & 6,7 & 6,1 & 5,7 & 5,5 \\
\hline & 15 & 30,6 & 17,5 & 10,1 & 7,6 & 6,2 & 5,1 & 4,3 & 4,0 & 3,7 & 3,4 & 3,0 \\
\hline \multirow{3}{*}{$\begin{array}{l}\mathbf{E} \\
\mathbf{T} \\
\mathbf{B}\end{array}$} & \multirow{2}{*}{10} & 34,9 & 27,5 & 20,1 & 17,0 & 15,0 & 14,8 & 14,1 & 13,6 & 13,2 & 12,9 & 12,7 \\
\hline & & 30,1 & 20,2 & 15,3 & 13,0 & 11,9 & 11,1 & 10,4 & 10,2 & 9,8 & 9,7 & 9,5 \\
\hline & 15 & 35,4 & 16,1 & 10,3 & 8,5 & 7,5 & 6,3 & 5,7 & 5,0 & 4,7 & 4,2 & 4,0 \\
\hline
\end{tabular}




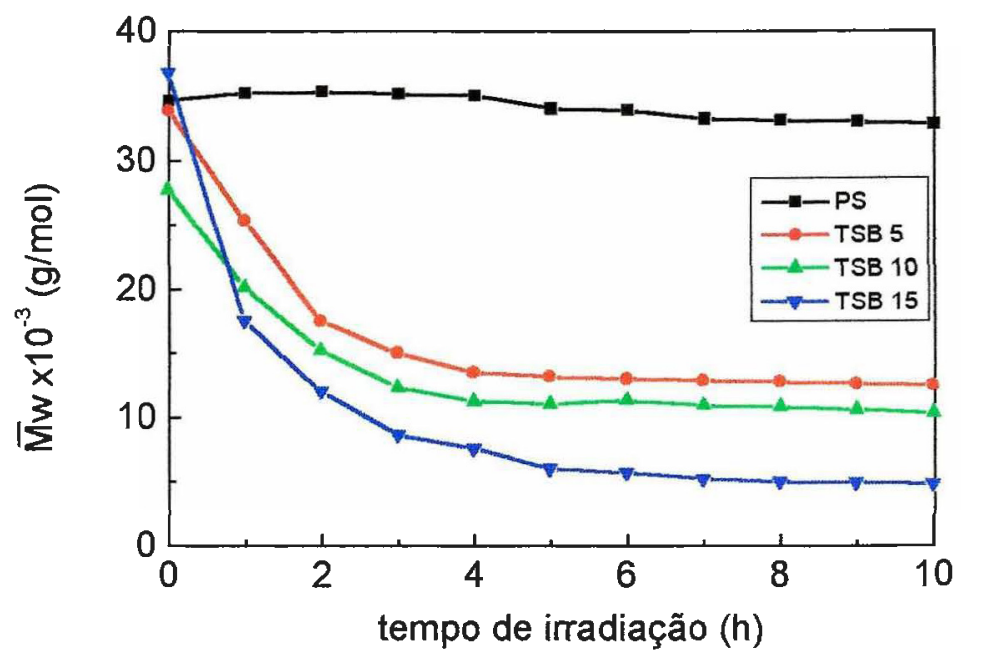

Figura 25: Comportamento de $\bar{M}_{\mathrm{w}}$ do PS e copolímeros da série TSB ao longo de dez horas de fotólise (soluções a $10 \mathrm{mg} / \mathrm{mL}$ em THF; $\lambda=254 \mathrm{~nm}$ ).

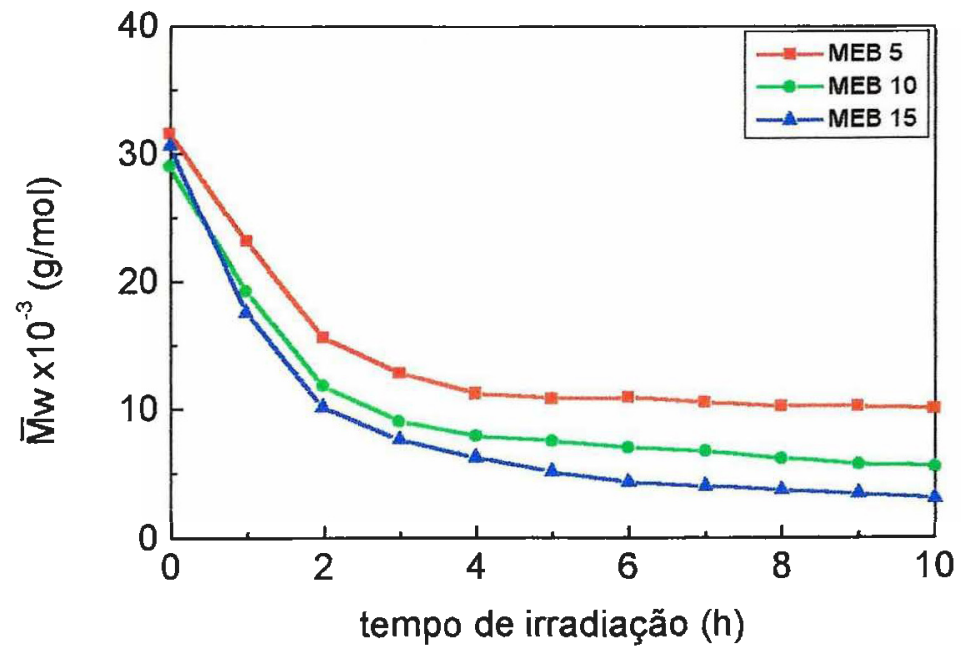

Figura 26: Comportamento de $\bar{M}_{\mathrm{W}}$ dos copolímeros da série MEB ao longo de dez horas de fotólise (soluções a $10 \mathrm{mg} / \mathrm{mL}$ em THF; $\lambda=254 \mathrm{~nm}$ ). 


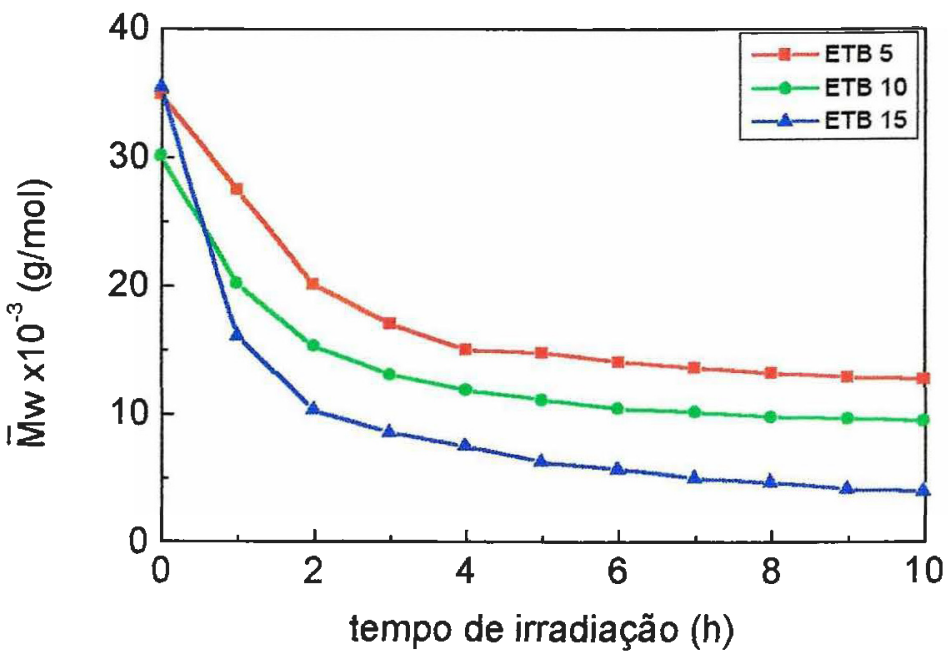

Figura 27: Comportamento de $\bar{M}_{w}$ dos copolímeros da série ETB ao longo de dez horas de fotólise (soluções a $10 \mathrm{mg} / \mathrm{mL}$ em THF; $\lambda=254 \mathrm{~nm}$ ). 


\subsubsection{Alterações nos Espectros de Infravermelho}

Estudos espectroscópicos dos efeitos provocados pela radiação UV foram realizados para a série TSB, como sendo representativa de todos os polímeros sintetizados. Os ensaios foram feitos, tomando-se os copolímeros TSB10 e TSB15 antes e após dez horas de irradiação, na presença de ar e a temperatura ambiente.

Analisando-se os espectros obtidos dos copolímeros antes e após a fotólise (Figuras 28 e 29), observou-se um aumento contínuo da intensidade das bandas na região entre 3800 - $3000 \mathrm{~cm}^{-1}$, alargamento da banda centralizada em $1712 \mathrm{~cm}^{-1}$, na região entre $1900-1500 \mathrm{~cm}^{-1}$ e o surgimento de uma banda larga de absorção na região de $1500-1000 \mathrm{~cm}^{-1}$.

KATO \& YONESHIGE $[1973]^{83}$ obtiveram resultados semelhantes para filmes de copolímeros de estireno com 3\% (em fração molar) de fenil vinil cetona (PVK), irradiados por até doze horas em benzeno, a $290 \mathrm{~nm}$. Eles verificaram o aparecimento de novas bandas de absorção em torno de 1750 e $3500 \mathrm{~cm}^{-1}$, e atribuíram tais absorções aos grupos carbonila e hidroxila, respectivamente, sugerindo ter ocorrido uma reação de fotooxidação por meio de um mecanismo Norrish tipo I (Esquema 7).

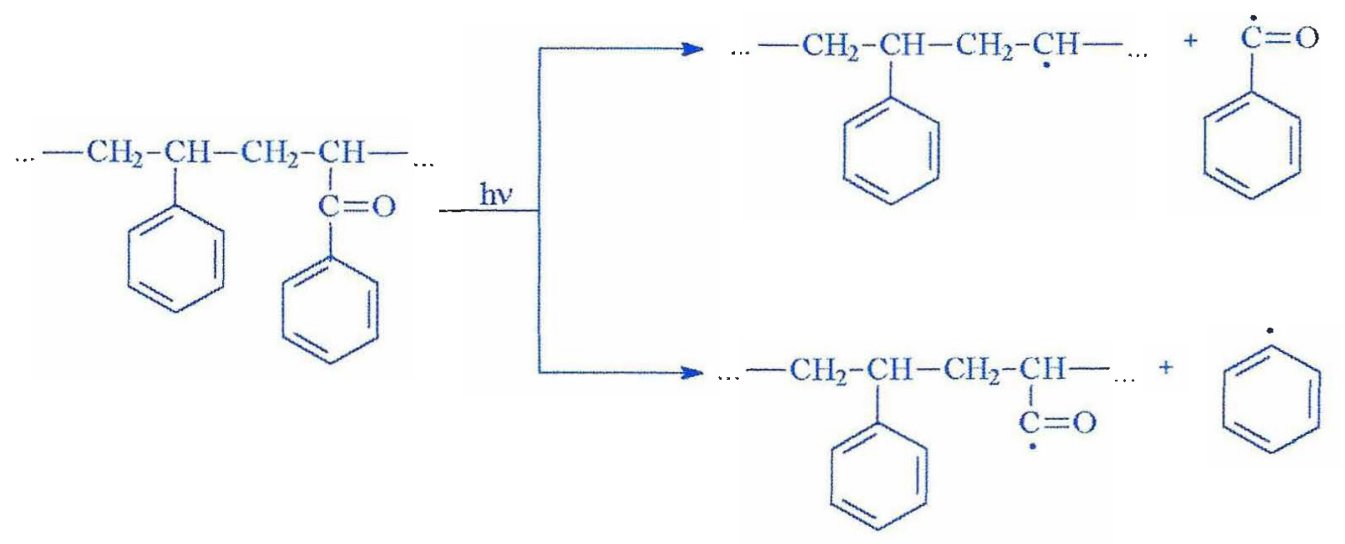

Esquema 7: Mecanismo Norrish tipo I para copolímeros de estireno e PVK. 

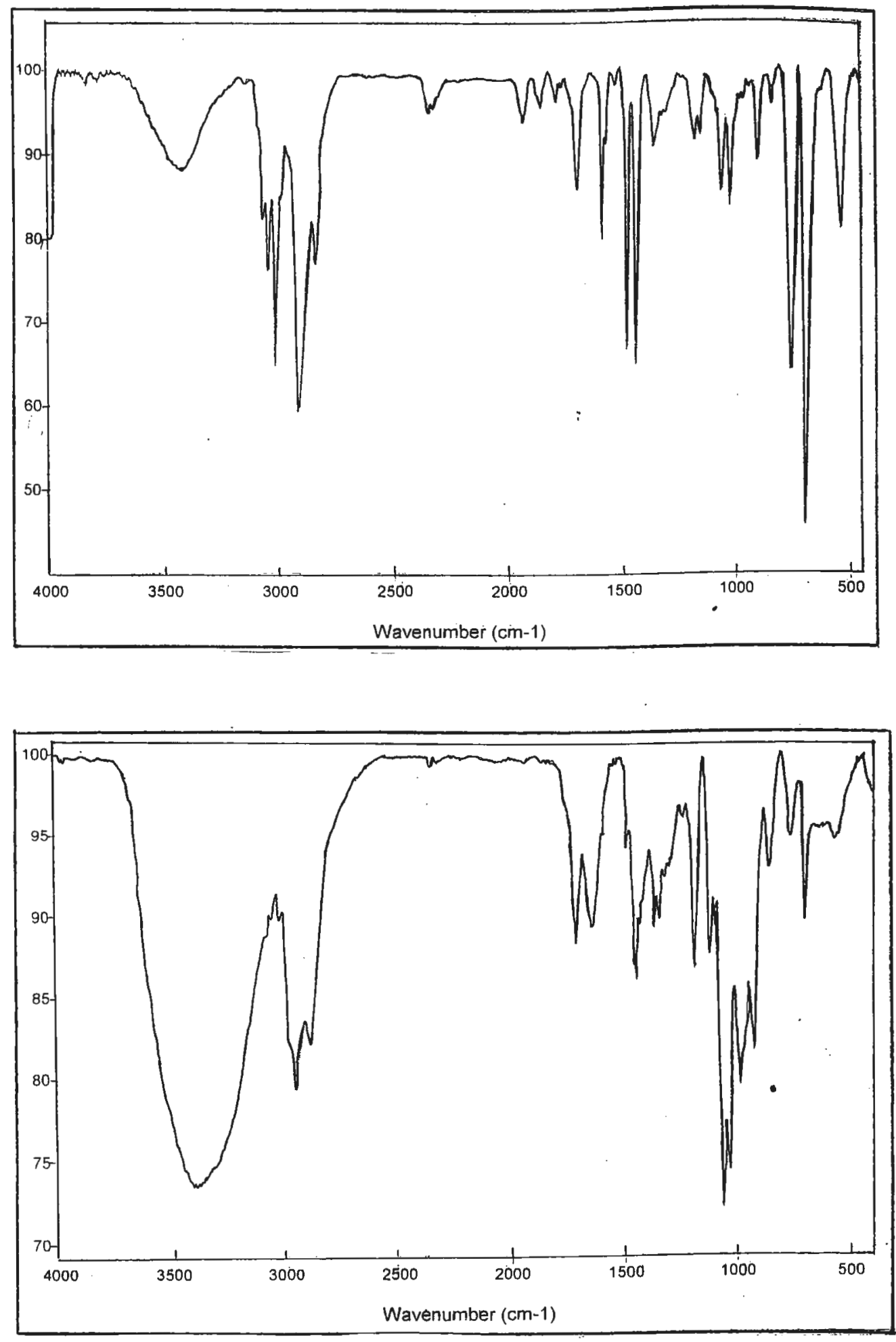

Figura 28: Espectros de IR do copolímero TSB10, antes e após dez horas de fotólise $\left(\lambda=254 \mathrm{~nm} ; 10 \mathrm{mg} / \mathrm{mL}\right.$ em THF; $\left.25^{\circ} \mathrm{C}\right)$. 

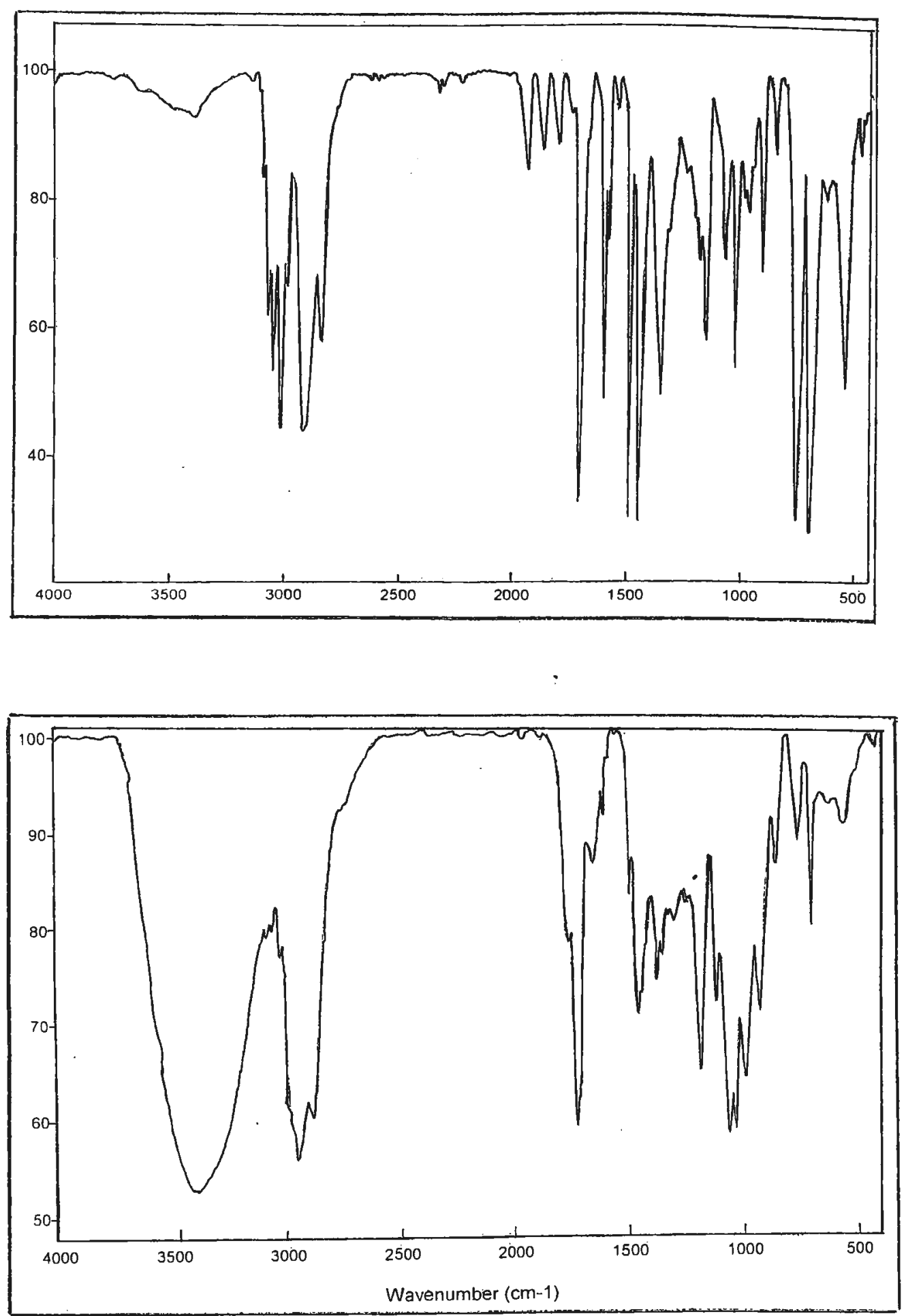

Figura 29: Espectros de IR do copolímero TSB15, antes e após dez horas de fotólise $\left(\lambda=254 \mathrm{~nm} ; 10 \mathrm{mg} / \mathrm{mL}\right.$ em THF; $\left.25^{\circ} \mathrm{C}\right)$. 
HRDLOVIC et al. [1980] ${ }^{94}$ analisaram por IR filmes de copolimeros de estireno e porcentagens variáveis de benzalacetofenona e benzalacetona a $313 \mathrm{~nm}$, irradiados por até 500 minutos. Eles verificaram a formação de estruturas contendo oxigênio com absorção em torno de $3580 \mathrm{~cm}^{-1}$ e um alargamento da banda original da carbonila a 1680 ou $1700 \mathrm{~cm}^{-1}$.

GARDETTE et al. [1995] ${ }^{128}$ realizaram estudos com filmes de PS a $30^{\circ} \mathrm{C}$ irradiados a $254 \mathrm{~nm}$, e observaram, também, a formação de duas bandas largas de absorção: uma a $1710 \mathrm{~cm}^{-1}$, apresentando diversos ombros e outra na região de $3800-3000 \mathrm{~cm}^{-1}$, com o máximo não localizado facilmente.

Utilizando-se de medidas via HPLC, Gardette extraiu, com metanol, alguns fotoprodutos, identificando-os no UV-VIS como sendo ácido benzóico, acetofenona, benzaldeído, benzoato de metila , monômero de estireno e outros produtos não aromáticos, com absorção abaixo de $200 \mathrm{~nm}$, de difícil identificação. Um tratamento de termólise a $100^{\circ} \mathrm{C}$, sob vácuo, revelou a presença de monômeros e dímeros dos ácidos fórmico e acético, identificados por infravermelho.

O Esquema 8 ilustra as etapas prováveis de geração de macro-radicais terciários e secundários via abstração radicalar de átomos de hidrogênio da cadeia polimérica, irradiada a $254 \mathrm{~nm}$. Uma vez formados, tais radicais podem se adicionar ao oxigênio e formar radicais peroxila (I) e grupos hidroperóxidos (II), também identificados por COZZENS \& MONIZ [1968 $]^{129}$.

\footnotetext{
${ }^{128}$ Gardette J., Mailhot,B., Lemaire,J., Polym.Deg.Stab., 48 (1995) 457.

${ }^{129}$ Cozzens,R.F., Moniz,W.B., J.Chem.Phys., 48 (1968) 581.
} 


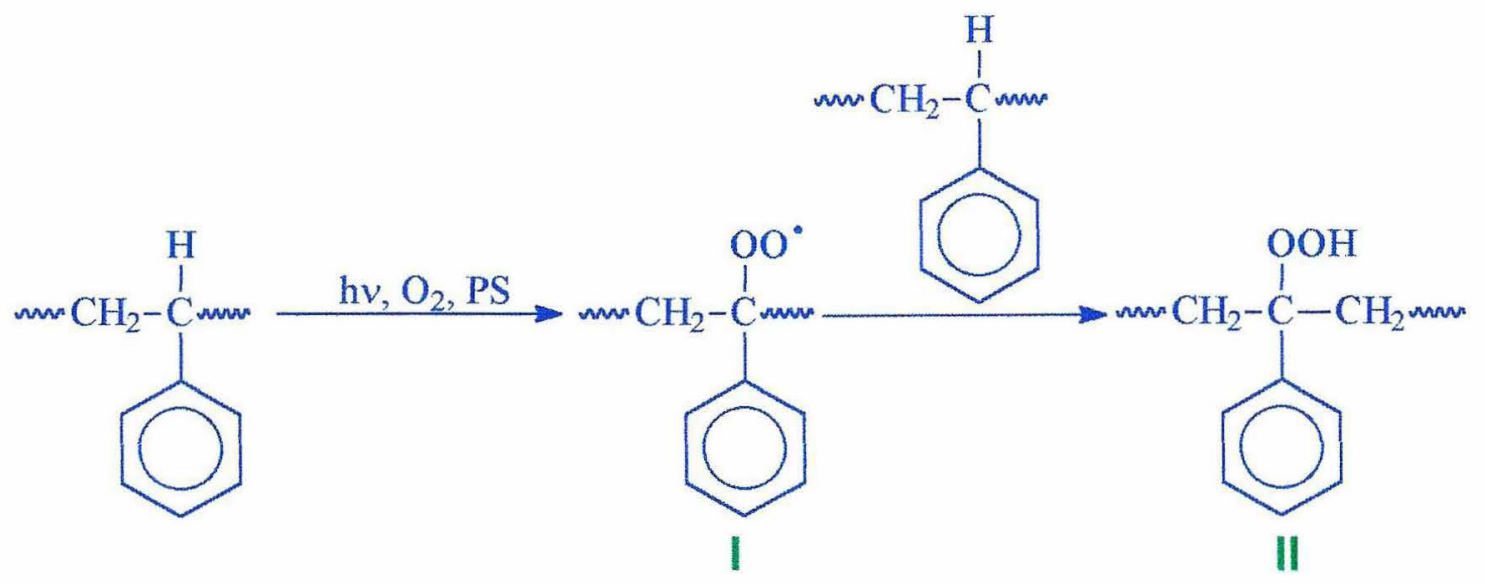

Esquema 8

A fotólise dos copolímeros TSB10 e TSB15, no presente trabalho, originou fotoprodutos semelhantes aos apresentados nos Esquemas 7 e 8 . Uma proposta de mecanismo para a foto-degradação dos copolímeros de estireno e butadienos 2-substituídos, baseada nas reações Norrish tipos I e II, está apresentada no Esquema 9.

No mecanismo Norrish tipo I (primário), dois tipos de macro-radicais podem ser formados:

i)

macro-radical carbonílico (I) que, por decarbonilação e posterior abstração de um átomo de hidrogênio da cadeia polimérica, gera um polímero de massa molar reduzida (II) ou, por oxidação, origina uma estrutura com grupo terminal carboxílico (III);

ii) macro-radical primário (IV) que, abstraindo um átomo de hidrogênio da cadeia polimérica, resulta em um polímero de massa molar reduzida $(\mathbf{V})$, semelhante à estrutura II. 


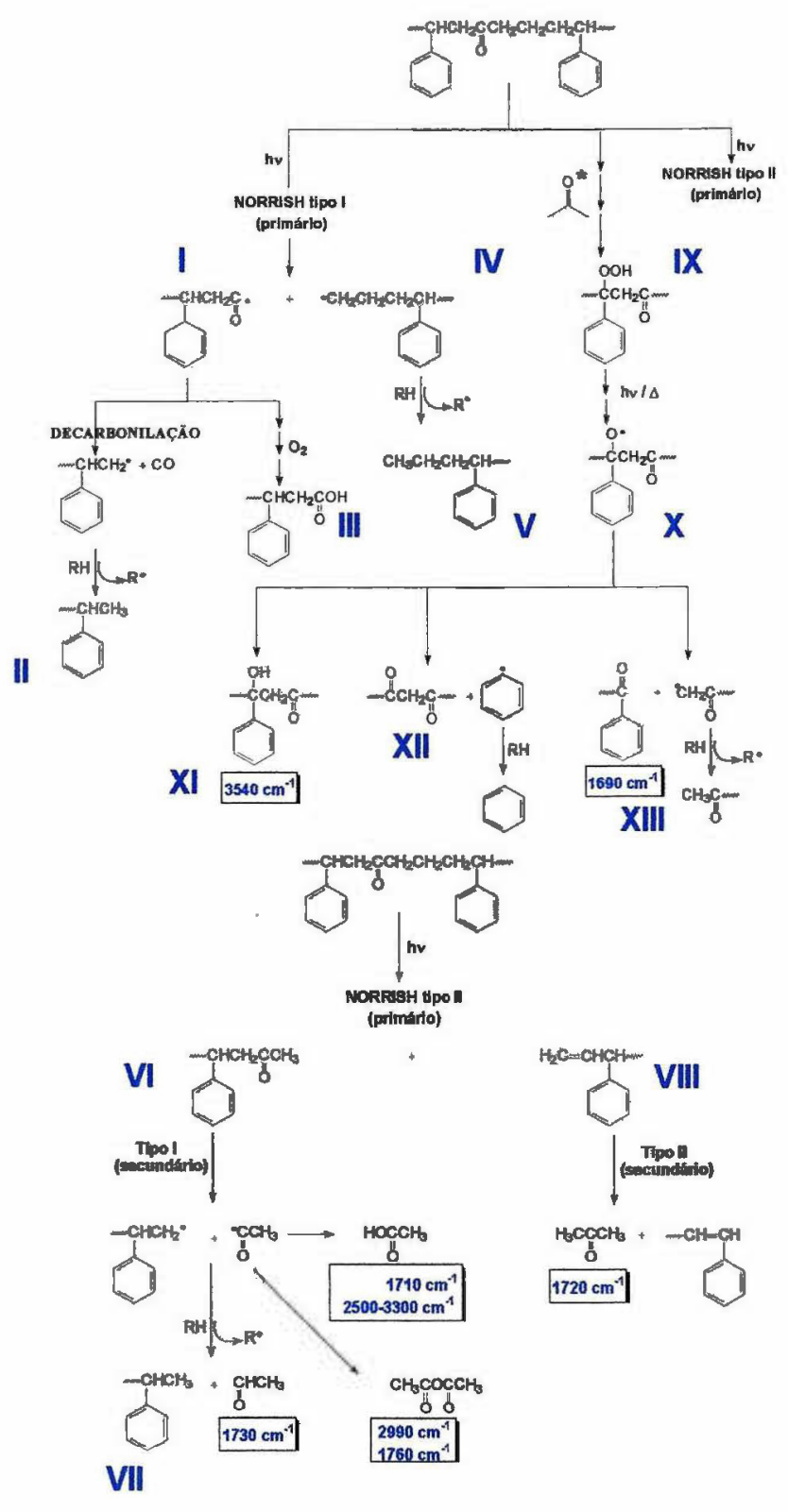

Esquema 9: Proposta de mecanismo via reações Norrish tipos I e II para os copolímeros de estireno e butadienos 2-substituídos. 
Pelo mecanismo Norrish tipo II (primário), dois tipos de cadeias macromoleculares podem ser originadas:

i) macromolécula acetílica (VI) que, por um mecanismo Norrish tipo I secundário e posterior oxidação, pode formar ácido acético (identificado a $1710 \mathrm{~cm}^{1}$ e $2500-3300 \mathrm{~cm}^{-1}$ ) e anidrido acético $\left(1760\right.$ e $2990 \mathrm{~cm}^{-1}$ ) ou ainda, por abstração de um átomo de hidrogênio da cadeia polimérica, resultar em um polímero de massa molar reduzida (VII) idêntica a estrutura II e anidrido acético $\left(1730 \mathrm{~cm}^{-1}\right)$;

ii) macromolécula etilênica (VIII) que por um mecanismo Norrish tipo II secundário leva à acetona $\left(1720 \mathrm{~cm}^{-1}\right)$.

A carbonila excitada pode gerar radicais terciários tipo poli-estiril que, por sua vez, podem se adicionar a oxigênio formando radicais peroxila (identificados espectroscopicamente por TORIKAl et al. [1983 ${ }^{130}$ ) e, com posterior abstração de um átomo de hidrogênio da cadeia macromolecular, levam à formação de grupos hidroperóxido (IX). Estes, quando irradiados, levam a macro-radicais alcoxila (X) que, sofrendo uma ruptura- $\beta$, podem gerar:

i) cadeias com grupos cetona exclusivamente (XII) e/ou hidroxila (identificadas a $3540 \mathrm{~cm}^{-1}$ ) e cetona (XI), e ainda moléculas de benzeno (observado como bandas alargadas a $1600-1400 \mathrm{~cm}^{1}$ );

ii) cadeias com grupos acetofenona terminais (identificados a $1690 \mathrm{~cm}^{-1}$, estrutura XIII).

É importante salientar que, apesar dos muitos artigos publicados sobre o tópico, ainda é difícil a compreensão completa dos mecanismos que levam à fotooxidação do PS e seus copolímeros, uma vez que tanto as amostras quanto as condições experimentais empregadas variam muito, e nenhuma correlação quantitativa é possível entre os resultados obtidos por diferentes pesquisadores. Desta forma, a foto-oxidação do PS e seus copolímeros não pode ser considerada como definitivamente estabelecida.

${ }^{130}$ Torikai,A., Takenchi,T., and Fucki,K., Polym.Photochem., 3 (1983) 307. 


\subsubsection{Medidas de Cisão de Cadeia e Função de Distribuição Cisão de Cadeia}

Partindo-se das curvas MWD, e aplicando-se a metodologia de CANEVAROLO ${ }^{101}$, descrita em detalhes na secção 3.6, calculou-se, para a série MEB, o número de cisões de cadeia $\left(N_{R}\right)$, e sua respectiva função de distribuição (CSDF). As curvas utilizadas como referência foram aquelas relativas aos copolímeros não degradados. As Figuras 30, 31 e 32 trazem as curvas de $N_{R}$ e CSDF para os copolímeros MEB5, MEB10 e MEB15, respectivamente.
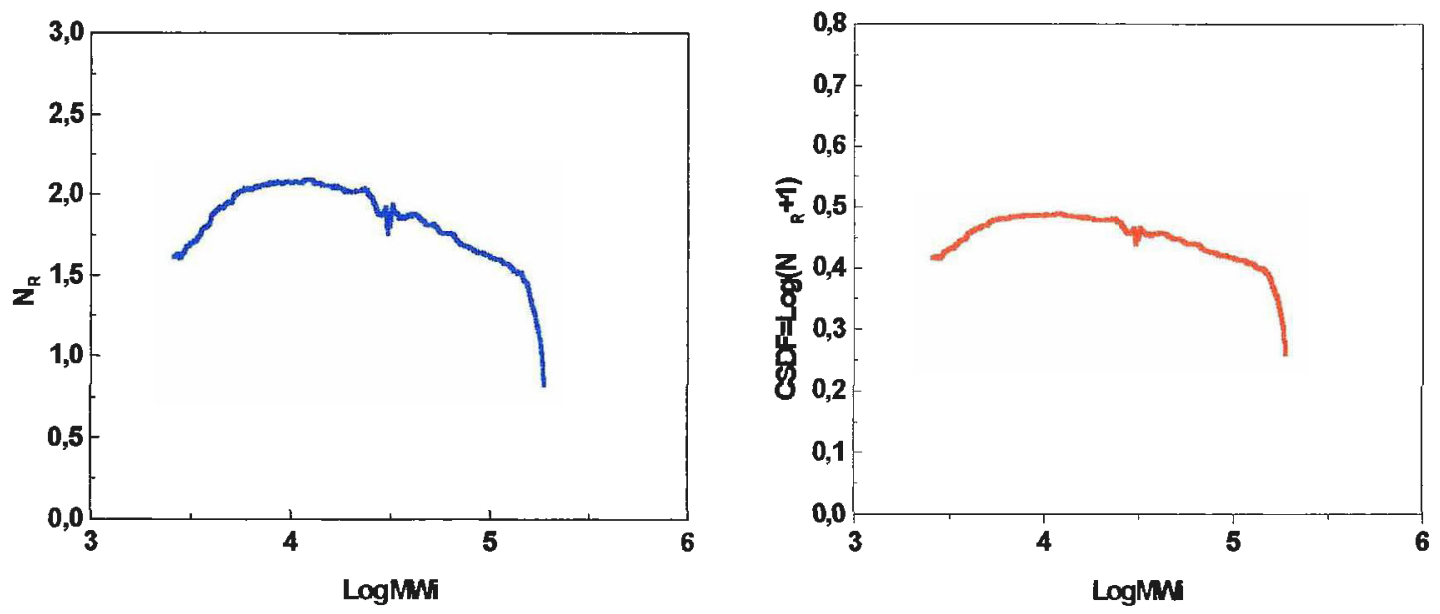

Figura 30: Perfis de $\mathrm{N}_{\mathrm{R}}$ e CSDF para o copolímero MEB5.
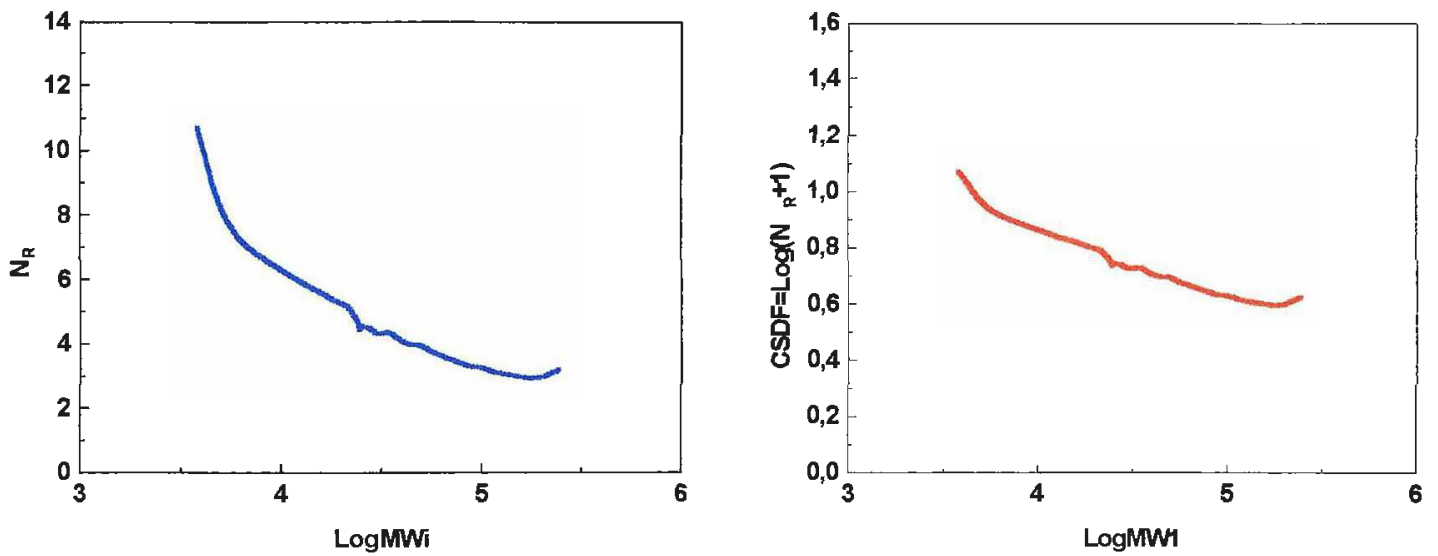

Figura 31: Perfis de $N_{R}$ e CSDF para o copolímero MEB10. 

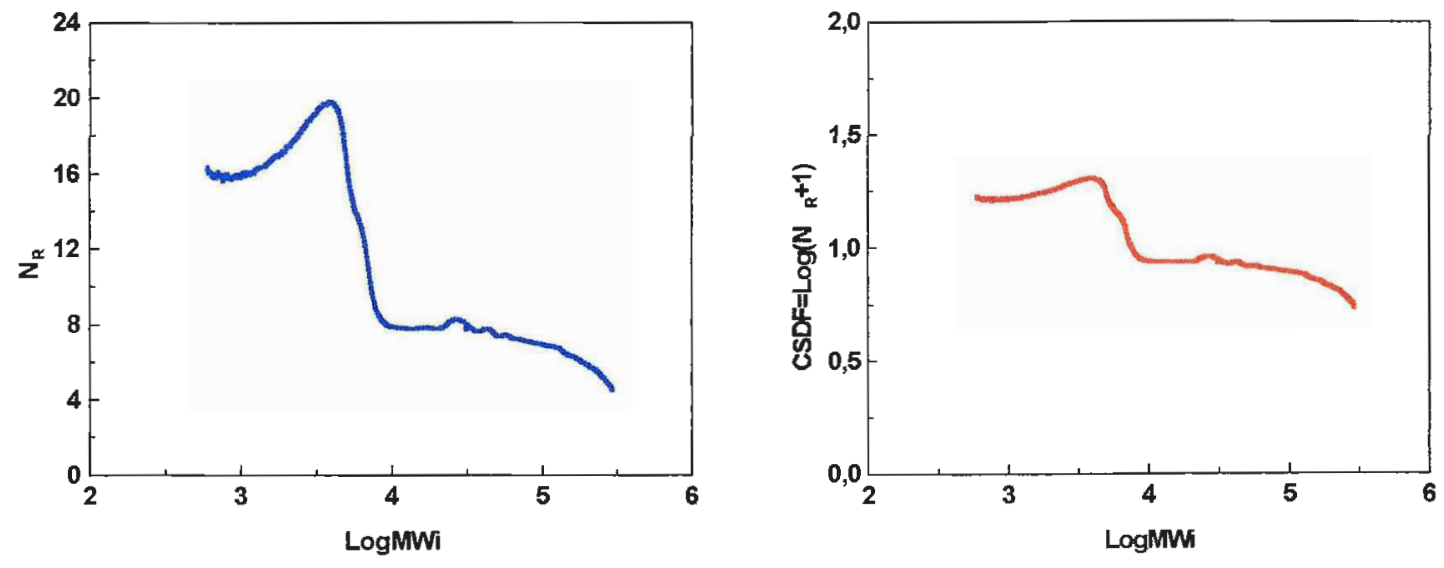

Figura 32: Perfis de $N_{R}$ e CSDF para o copolímero MEB15.

A Função Distribuição de Cisão de Cadeia (CSDF) revelou, para a série completa de copolímeros MEB, que as cisões ocorrem de forma dependente das massas molares dos mesmos, porém, com diferenças significativas:

i) no caso do copolímero MEB5, o número de cisões por cadeia $\left(N_{R}\right)$ iniciou em torno de 1,5, para cadeias de $\bar{M}_{w}$ de cerca de $1.000 u$, atingindo o máximo de 2 cortes para cadeias de $\bar{M}_{W}$ com aproximadamente $10.000 \mathrm{u}$. Com o aumento de $\bar{M}_{W}, \mathrm{~N}_{\mathrm{R}}$ voltou a cair de modo proporcional, até atingir novamente valores da ordem de 1,5 , para copolímeros de $\bar{M}_{W}$ de $100.000 \mathrm{u}$. $O \mathrm{~N}_{\mathrm{R}}$ médio de cortes por cadeia, para o copolímero MEB5, foi de 2;

ii) $\quad \mathrm{N}_{\mathrm{R}}$ atingiu seu máximo em torno de 10, para cadeias do copolímero MEB10 de $\bar{M}_{W}$ aproximado de 5.000u, decrescendo, de forma proporcional, com o aumento da massa molar, até valores de cerca de 2, para cadeias com $\bar{M}_{W}$ de 100.000 u. $O N_{R}$ médio foi de 4 cortes/cadeia; 
iii) Para o copolímero MEB15, $N_{R}$ iniciou em tomo de 16, para cadeias de $\bar{M}_{W}$ de cerca de $1.000 \mathrm{u}$, atingindo o máximo de 20 cortes para cadeias com $\bar{M}_{W}$ de aproximadamente $5.000 \mathrm{u}$. Com o aumento de $\bar{M}_{W}, N_{R}$ caiu de forma brusca, atingindo valores de cerca de 8 , para copolímeros de $\bar{M}_{W}$ de 10.000 u. A queda continuou, de forma menos acentuada, para um valor de 4, para cadeias com $\bar{M}_{W}$ de cerca de $100.000 \mathrm{u}$. $O \mathrm{~N}_{\mathrm{R}}$ médio foi de 12 cortes/cadeia.

A interpretação para os valores de $\mathrm{N}_{\mathrm{R}}$ pode ser feita em termos da estrutura química dos copolímeros sintetizados. Conforme proposto na secção 5.1.7, os estudos cinéticos, a partir das razões de reatividade " $r$ " dos comonômeros, apontaram para a possibilidade de formaçăo de copolímeros "tapered", contendo longas seqüências do comonômero no início das cadeias, intercaladas a poucas unidades de estireno, seguidas por longas seqüências de estireno, intercaladas a poucas unidades do comonômero. Dessa forma, cadeias menores apresentariam uma maior concentração relativa de carbonilas, e o número de cisãoes/cadeia é elevado. Com o aumento de $\bar{M}_{W}$, entretanto, $N_{R}$ decrece, uma vez que a proporção carbonila/estireno diminui, atingindo valores mínimos para cadeias com as maiores massas molares, $\bar{M}_{W}$.

A análise conjunta dos resultados obtidos para $N_{R}$ e SEC (secção 5.2.2), antes e após a fotólise dos copolímeros, revelou que a utilização da CSDF é aplicável aos copolímeros estudados neste trabalho, auxiliando em sua análise. Aplicando-se os valores de $N_{R}$ médios obtidos, às respectivas massas molares médias ponderais por SEC, antes da fotólise, $\bar{M}_{W}$ (af), para cada um dos copolímeros da série estudada, chegou-se a valores muito próximos às massas molares médias ponderais após a fotólise, $\bar{M}_{W}$ (df), conforme ilustrado na Tabela 11. 
Tabela 11: Resultados comparativos de $\bar{M}_{W}(\mathrm{~kg} / \mathrm{mol})$ obtidos por SEC e $N_{R}$.

\begin{tabular}{|c|c|c|c|c|}
\hline POLÍMERO & $\begin{array}{c}\overline{\mathbf{M}}_{W} \text { (af) } \\
\text { por SEC }\end{array}$ & $\mathbf{N}_{\mathrm{R}}$ & $\begin{array}{c}\overline{\mathbf{M}}_{W}(\mathbf{d f}) \\
\text { por SEC }\end{array}$ & $\begin{array}{c}\overline{\boldsymbol{M}}_{W}(\mathrm{df}) \\
\text { por } \mathbf{N}_{\mathrm{R}}\end{array}$ \\
\hline MEB5 & 31,6 & 2 & 10,0 & 10,5 \\
\hline MEB10 & 29,0 & 4 & 5,5 & 5,8 \\
\hline & 30,6 & 12 & 3,0 & 2,4 \\
\hline
\end{tabular}

Relativamente, os valores de $N_{R}$ deixaram claro que, à medida que se aumentou o teor de carbonilas na cadeia principal do PS, as cisões também aumentaram, de forma proporcional, atingindo máximos de 2,10 e 20 cortes/cadeia, para os copolímeros MEB5, MEB10 e MEB15, respectivamente.

\subsection{Estudo do Efeito do Envelhecimento Acelerado no Comportamento Mecânico dos Polímeros}

\subsubsection{Aspectos Gerais}

Os ensaios de tração proporcionam informações sobre a resistência e a ductilidade dos materiais quando submetidos a tensões uniaxiais de tração. Esta informação é muito útil para a comparação do desempenho de materiais, 
desenvolvimento de novas blendas ou ainda no controle da qualidade dos mesmos.

Tais ensaios consistem em se submeter um corpo de prova de geometria normalizada a esforços de tração uniaxial, em geral, até a ocorrência da fratura, sendo as cargas aplicadas gradualmente. Sob a ação dessas cargas, o corpo de prova se alonga na direção em que são aplicados os esforços e, assim, a resultante da carga é obrigada a coincidir com o eixo longitudinal do corpo de prova, obtendo-se, deste modo, uma série de informações sobre as propriedades mecânicas do material.

Hoje, mais do que nunca, o ensaio realizado com modelos é muito utilizado, pelo simples fato de permitir que se chegue rapidamente a uma série de conclusões importantes. Sua validez é inconteste, desde que determinadas precauções, relativas à experimentação e interpretação de resultados, sejam tomadas.

\subsubsection{Definições Importantes ${ }^{131}$}

A fim de tornar mais ágil e clara a discussão dos resultados obtidos, tornase importante definir alguns conceitos básicos pertinentes à avaliação das propriedades mecânicas dos polímeros.

- Propriedades Mecânicas: são as propriedades que estão diretamente associadas à reação elástica e inelástica quando uma força é aplicada ao material, ou que envolvam a relação tensão-deformação.

- Comprimento Inicial: comprimento original daquela porção do corpo de prova sobre o qual a deformação ou variação no comprimento é definida.

- Regime Plástico: as propriedades de um material à tração no regime plástico são aquelas que definem a habilidade do material em resistir a cargas e deformações sem se romper; as deformações sofridas não são mais recuperáveis.

\footnotetext{
${ }^{131}$ Rodrigues, Raul dos Santos, Testes de Materiais, $1{ }^{\text {a }}$ Edição, Mogi das Cruzes, SP, 1990.
} 
- Regime Elástico: as cargas são proporcionais aos alongamentos; refere-se à fase inicial dos ensaios, quando as deformações são recuperáveis.

- Zona de Escoamento: região no gráfico Carga X Alongamento com grande deformação plástica, sem aumento considerável da carga.

- Tensão Normal de Tração: é a intensidade, em um ponto de um corpo, das forças internas ou componentes de forças que atuam em um dado plano, dirigida para fora do corpo.

- Tensão de Escoamento: é a carga máxima que um corpo pode suportar, antes de entrar em regime plástico.

- Elongação à Ruptura: ou elongação máxima, é um parâmetro obtido por meio de ensaios de tração, que mede quanto o material pode deformar até sofrer ruptura total.

- Alongamento: aumento do comprimento calibrado original de um corpo de prova submetido à tração.

- Ductilidade: habilidade do material em se deformar plasticamente antes de se romper.

- Módulo de Elasticidade: relação entre a tensão e a deformação, antes do limite elástico (que é a maior tensão suportada pelo material sem que sofra qualquer deformação plástica).

- Resistência à Tração: máxima tensão de tração que o material pode suportar, calculada a partir da carga máxima aplicada, levando em conta a área da secção reta original do corpo de prova.

\subsubsection{Ensaios de Tração}

Foram injetados corpos de prova de PS homopolímero e do copolímero TSB15, sendo submetidos a um processo de envelhecimento acelerado em câmara de intemperismo artificial Weather-o-Meter, conforme descrito em detalhes na Parte Experimental, por 100, 300 e 600 horas em cada uma das faces. 
A seguir, os corpos de prova envelhecidos foram avaliados por ensaios de tração. Todos os resultados apresentados nesta secção referem-se às médias obtidas para 5 (cinco) corpos de prova ensaiados.

A Figura 33 mostra a Tensão de Escoamento (kgf) em função do tempo de envelhecimento, para todas as amostras analisadas. Observou-se que há um decréscimo acentuado na carga máxima suportada pelos materiais nas primeiras 300 horas de envelhecimento, mantendo-se praticamente inalterada a seguir. É interessante notar que não houve diferenças significativas entre o PS e o copolímero, indicando que ambos suportaram aproximadamente as mesmas cargas antes de começarem a escoar, ou seja, antes de entrarem em regime plástico.

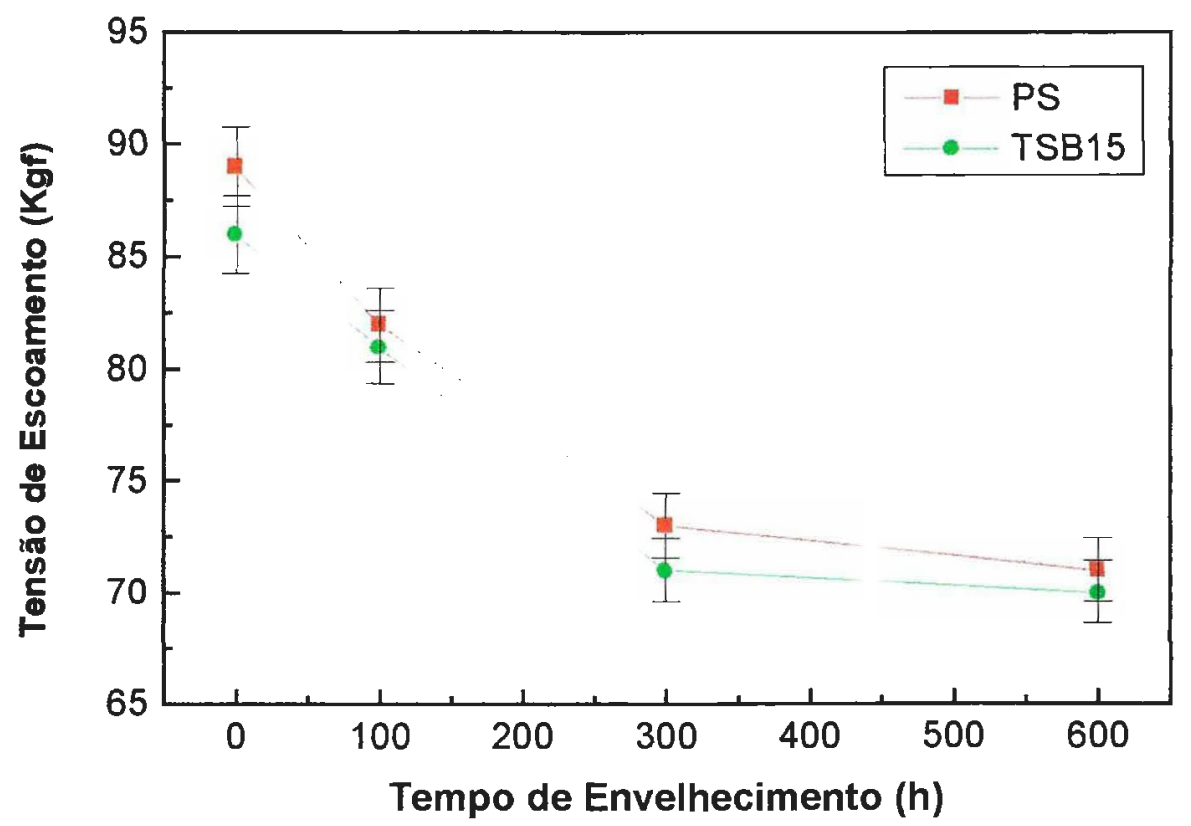

Figura 33: Avaliação da Tensão de Escoamento em função do Tempo de Envelhecimento. 
As Figuras 34 e 35 ilustram as curvas Carga (kgf) X Alongamento (mm) obtidas para o PS homopolímero e copolímeros TSB15, respectivamente, antes e depois de serem submetidos ao envelhecimento acelerado.

A análise da Figura 34 revela, para o PS, com o aumento do tempo de envelhecimento:

i) discreta diminuição da carga máxima suportada pelo polímero antes de começar a escoar (tensão de escoamento);

ii) discreta diminuição da rigidez do material, ou seja, pequeno aumento da deformação na região elástica, para a mesma carga aplicada;

iii) comportamento de material dúctil, apresentando redução significativa da deformação plástica na zona de escoamento $(31,27,25$ e $23 \mathrm{~mm}$, respectivamente para 0,100, 300 e 600 horas de envelhecimento), indicando leve tendência à perda da ductilidade.

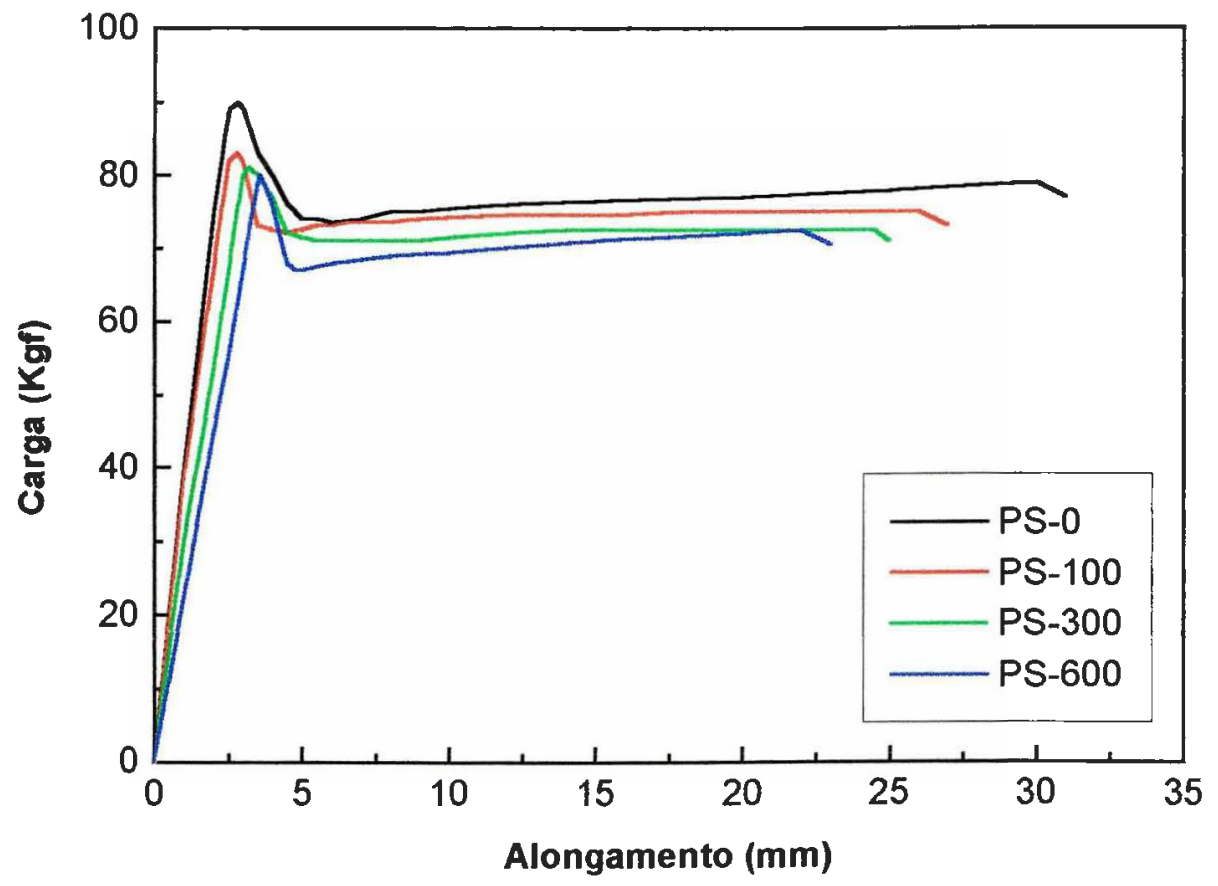

Figura 34: Avaliação da Carga em função do Alongamento para amostras de PS. 
Uma avaliação da Figura 35 para o copolímero TSB15 mostra, também com o aumento do tempo de envelhecimento:

i) discreta diminuição da carga máxima suportada pelo polímero antes de começar a escoar (tensão de escoamento), com valores muito próximos aos obtidos para os respectivos tempos de envelhecimento das amostras de PS;

ii) não houve variação significativa de deformação na região elástica, ou seja, a rigidez do material foi mantida com o envelhecimento;

iii) comportamento de material frágil, isto é, aceitou deformações reduzidas antes de se romper, apresentando diminuição bastante significativa da deformação plástica na zona de escoamento $(27,5,15,10$ e $5 \mathrm{~mm}$, respectivamente para $0,100,300$ e 600 horas de envelhecimento), indicando que o material se tornou progressivamente mais frágil.

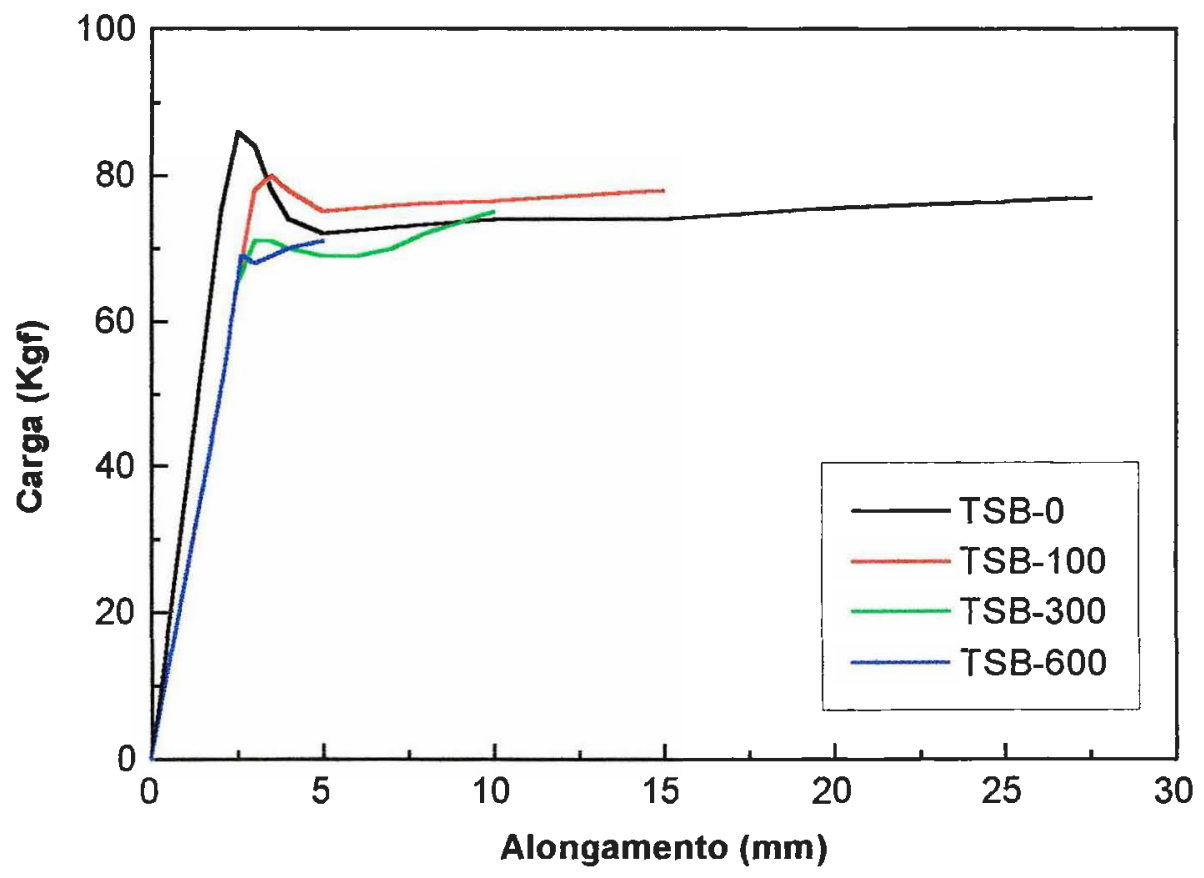

Figura 35: Avaliação da Carga em função do Alongamento para amostras do copolímero TSB15. 
Resultados muito importantes são mostrados na Figura 36, que representa a Elongação à Ruptura (\%) em função do Tempo de Envelhecimento, de forma comparativa, para homo e copolímero.

Ambos, PS e TSB15, demonstraram valores muito próximos de elongação à ruptura (56\% e 53\%, respectivamente), quando não são submetidos ao envelhecimento. Entretanto, à medida que o envelhecimento é acelerado, observou-se uma acentuada redução na elongação à ruptura para o copolímero (que estabilizou em torno de 2,5\% a partir de 100 horas de envelhecimento), diferentemente do PS, cujos valores de elongação decresceram, porém com taxas muito mais discretas, finalizando em $22 \%$ após 600 horas de envelhecimento.

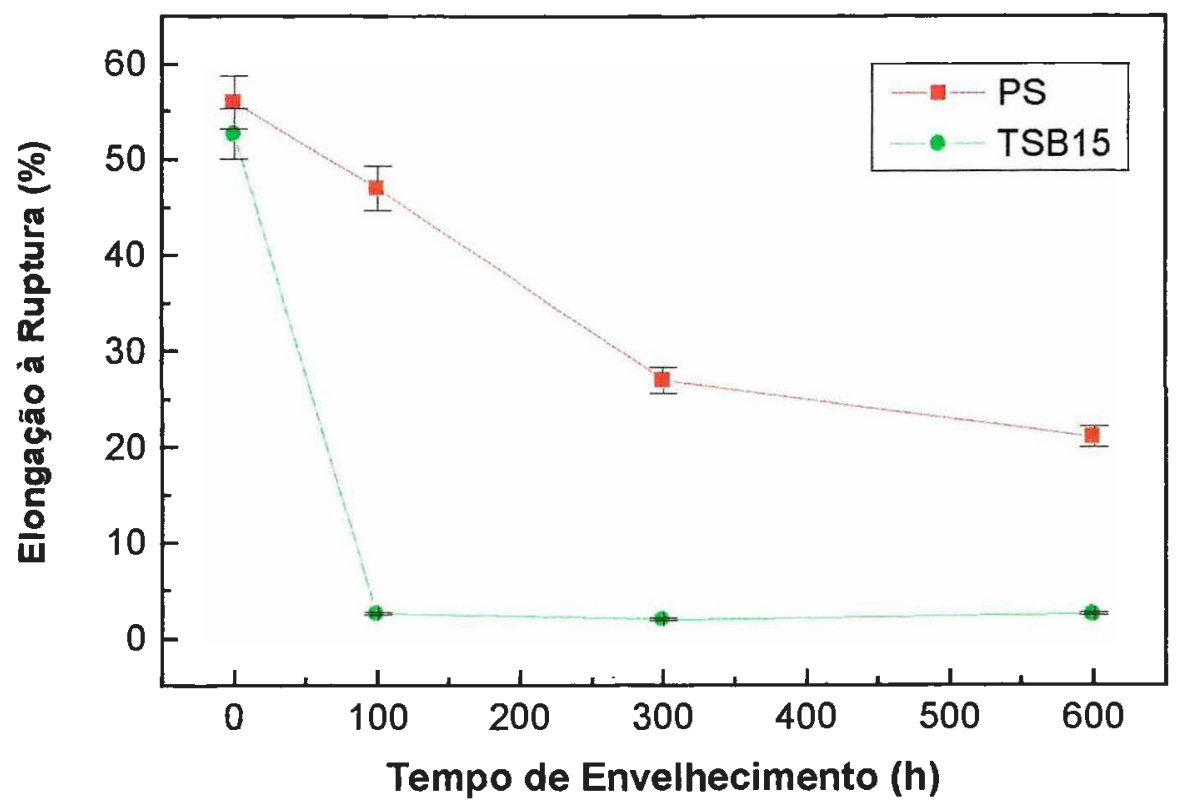

Figura 36: Avaliação da Elongação à Ruptura em função do Tempo de Envelhecimento.

É importante apontar que os resultados dos ensaios de resistência à tração sobre corpos de prova injetados para dimensões padronizadas, a partir de regiões selecionadas, podem não representar totalmente as propriedades de resistência e 
ductilidade de todo o produto acabado ou seu comportamento em serviço, sob condições ambientais distintas daquelas empregadas nos ensaios, mas sem dúvida despontam como uma razoável previsão de seu comportamento. 


\section{Conclusões}

Nesse trabalho foram preparados e caracterizados, por ${ }^{1} \mathrm{H}-\mathrm{NMR}, \mathrm{GC} / \mathrm{MS}$ e IR, os monômeros 2-trimetil-sililóxi-1,3-butadieno, 2-metóxi-1,3-butadieno e 2etóxi-1,3-butadieno, a partir dos quais foram sintetizadas três séries de copolímeros de estireno, via radicais livres, designadas por TSB, MEB e ETB, respectivamente, em proporções de 5\%,10\% e 15\% destes monômeros.

Os copolímeros das séries TSB, MEB e ETB, após uma etapa obrigatória de hidrólise, foram caracterizados por diferentes técnicas analíticas, verificandose:

- concentrações controladas de grupos carbonila na cadeia do PS foram obtidas, conforme observado por IR, pelo aparecimento de bandas características da carbonila $\mathrm{C}=\mathrm{O} \mathrm{em} 1712 \mathrm{~cm}^{-1}$, sendo mais intensas quanto maiores os teores de incorporação dos comonômeros;

- os valores finais de incorporação dos comonômeros na cadeia de PS, calculados a partir dos teores de carbono e hidrogênio obtidos por análise elementar, estão em torno de 5, 10 e $15 \%$ em fração molar de cetona, conforme previsto inicialmente, para as três séries sintetizadas;

- o comportamento térmico sofre a influência da modificação estrutural do polímero, evidenciado pelas alterações nos valores de $T_{g}$ para os copolímeros, iniciando-se em $97^{\circ} \mathrm{C}$ para o PS homopolímero, e decrescendo a valores médios de $95^{\circ} \mathrm{C}, 87^{\circ} \mathrm{C}$ e $83^{\circ} \mathrm{C}$ para 5,10 e $15 \%$ de incorporação de comonômero, respectivamente;

- os valores obtidos para as massas molares médias ponderais $\left(M_{w}\right)$ por SEC para o PS e seus copolímeros não variam consideravelmente, independente da composição do polímero, e giram em torno de 30 a $35 \mathrm{~kg} / \mathrm{mol}$, evidenciando processos de polimerização adequados e reprodutivos, com fácil copolimerização; 
Após dez horas de fotólise em fluxo contínuo na presença de ar $(\lambda=254 \mathrm{~nm}$, $10 \mathrm{mg} / \mathrm{mL}$ em THF, a $25^{\circ} \mathrm{C}$ ), as soluções de copolímeros sofreram alterações muito significativas em relação ao do PS puro:

- rupturas da cadeia polimérica resultantes de mecanismos de fotodegradação Norrish tipos I e II, monitoradas por duas técnicas distintas: (i) SEC, comprovadas pela diminuição das massas molares médias ponderais $\left(M_{w}\right)$, iniciando em cerca de $35 \mathrm{~kg} / \mathrm{mol}$ (ETB5), por exemplo, e decrescendo para valores tão baixos quanto $3 \mathrm{~kg} / \mathrm{mol}$ (MEB15) e (ii) IR, com formação de grupos terminais e micromoléculas, conforme observado por aumento contínuo da intensidade, alargamento e surgimento de bandas caracteristicas de aldeídos, ácidos, cetonas e anidridos nos espectros.

- velocidades de degradação muito maiores do que a apresentada pelo PS puro, com taxas de degradação crescentes e diretamente proporcionais ao aumento do teor de comonômeros no polímero, conforme observado através do TDSLS;

- em relação aos copolímeros de estireno e MVK, que apresentam carbonilas distribuídas em cadeias laterais, os copolímeros das séries TSB, MEB e ETB apresentam velocidades de ruptura iniciais da cadeia de duas a três vezes maiores;

- para a série MEB, o número de cisões de cadeia, $\mathrm{N}_{R}$, deixou claro que, à medida que se aumentou o teor de carbonilas na cadeia principal do PS, as cisões também aumentaram, de forma proporcional, atingindo máximos de 2, 10 e 20 cortes/cadeia, para os copolímeros MEB5, MEB10 e MEB15, respectivamente.

Os ensaios de envelhecimento no intemperismo acelerado realizados com PS não modificado e copolímero TSB15, revelam que há um decréscimo acentuado na carga máxima suportada por todos os polímeros com 0 envelhecimento, sem diferenças significativas entre eles. Entretanto, ○ PS apresenta um comportamento típico de material dúctil, com leve tendência a perda da ductilidade com o envelhecimento, enquanto o copolímero TSB15 mostra um comportamento de material frágil, tornando-se progressivamente mais frágil com 0 
envelhecimento. O ponto mais importante é o fato de que os corpos de prova dos copolimeros apresentam uma queda muito mais acentuada na Elongação à Ruptura, com o envelhecimento, em comparação ao PS não modificado.

Finalmente, é preciso lembrar que não se pode considerar como definitivas as propostas mecanísticas para a fotodegradação do PS e seus copolímeros, nem tão pouco esgotadas as possibilidades de processos de reciclagem e "construção" de plásticos degradáveis em condições ambientais. De fato, os processos industriais atualmente utilizados para degradação de plásticos descartáveis focam, quase sem exceção, a aceleração dos processos de oxidação natural, de forma controlada, visando a tornar o material biodegradável.

Em nosso projeto, em particular, os resultados obtidos são bastante promissores, mas há um longo caminho ainda a ser percorrido. E de preferência sob o sol. Bem forte. 


\section{Experimental}

\subsection{Materiais e Métodos}

Para a concentração das soluções, bem como para a eliminação do solvente, foi utilizado um evaporador rotativo Büchler, operando a pressão reduzida (na faixa de 20 a $30 \mathrm{mmHg}$ ).

As destilações de pequenos volumes foram realizadas em um destilador tipo Kugelrohr Buchi GHR-51 (destilações bulbo a bulbo).

\subsubsection{Reagentes}

Ácido p-tolueno-sulfônico monohidratado $\mathrm{C}_{7} \mathrm{H}_{8} \mathrm{SO}_{3} . \mathrm{H}_{2} \mathrm{O}$ (APTS) : foi adquirido da Acros Organics a 97,5\%, com grau analítico, e utilizado sem nenhuma purificação adicional.

2,2'-azobis-iso-butironitrila $\mathrm{C}_{8} \mathrm{H}_{12} \mathrm{~N}_{4}$ (AIBN): foi utilizado como iniciador da polimerização via radicais livres, sendo purificado por recristalização em metanol, seco à temperatura ambiente e armazenado a $-18^{\circ} \mathrm{C}$, ao abrigo da luz.

Clorotrimetilsilano $\left(\mathrm{CH}_{3}\right)_{3} \mathrm{SiCl}$ : foi adquirido da Aldrich Chemical Co. e destilado à pressão atmosférica sob argônio, recolhendo-se a fração que destilou entre $56,5-57,5^{\circ} \mathrm{C}$. O reagente foi armazenado à temperatura ambiente, sob atmosfera de argônio, ao abrigo da luz e calor.

Estireno $\mathrm{C}_{8} \mathrm{H}_{8}$ : o monômero de estireno foi adquirido da Arco Química do Brasil Ltda a 99,96\% (em peso via GLC), com teor de polímeros abaixo de $1 \mathrm{ppm}$ e inibidor Terc-Butil-Catecol (TBC) a $20 \mathrm{ppm}$. O processo de purificação utilizado foi a extração do inibidor com cinco lavagens sucessivas com solução de hidróxido de sódio aquoso a $5 \%$ (em peso), seguidas por cinco lavagens sucessivas com 
solução saturada de cloreto de sódio. Em ambas as extrações, a proporção solução extratora/estireno foi 1:5, v/v. A seguir, o estireno foi seco por duas horas em sulfato de magnésio e destilado, sob pressão reduzida, imediatamente antes do uso.

Etil-ortoformato $\mathrm{C}_{7} \mathrm{H}_{16} \mathrm{O}_{3}$ : foi adquirido da Acros Organics a 98\%, com grau analítico, e utilizado sem nenhuma purificação adicional.

Fluoreto de Tetrabutilamônio $\mathrm{C}_{16} \mathrm{H}_{36} \mathrm{NF}$ (TBAF) : foi adquirido da Aldrich Chemical Co. a 98\%, com grau analítico, e utilizado sem nenhum tipo de tratamento adicional.

Metil-ortoformato $\mathrm{C}_{4} \mathrm{H}_{10} \mathrm{O}_{3}$ : foi adquirido da Acros Organics a $98 \%$, com grau analítico, e utilizado sem nenhuma purificação adicional.

Metil-vinil-cetona $\mathrm{C}_{4} \mathrm{H}_{6} \mathrm{O}$ : foi adquirido da Aldrich Chemical Co a $99 \%$ e submetido à secagem sob carbonato de potássio anidro durante 24 horas, filtração e destilação à pressão reduzida imediatamente antes do uso.

Trietilamina $\left(\mathrm{C}_{2} \mathrm{H}_{5}\right)_{3} \mathrm{~N}$ (TEA): foi adquirido da Quimesp e aquecido a refluxo na presença de hidróxido de potássio $(\mathrm{KOH})$ por cerca de 3 horas $(100 \mathrm{~mL}$ TEA/10g KOH) e, então, destilado, recolhendo-se a fração que destilou entre 87 $88^{\circ} \mathrm{C}$. O produto puro foi armazenado em recipiente escuro sobre $\mathrm{KOH}$, sob atmosfera de argônio, à temperatura ambiente, ao abrigo da luz e calor.

\subsubsection{Solventes}

Dimetilformamida $\mathrm{HCON}\left(\mathrm{CH}_{3}\right)_{2}$ (DMF): o solvente adquirido da F.Maia S.A., com grau analítico, foi deixado por cerca de 4 horas sob agitação magnética na presença de hidreto de cálcio $\left(\mathrm{CaH}_{2}\right)$, aquecido a refluxo por 2 horas e, em 
seguida, destilado à pressão atmosférica, recolhendo-se a fração obtida entre 151 $152^{\circ} \mathrm{C}$. Armazenou-se ao abrigo da luz e calor.

Etanol absoluto $\mathrm{C}_{2} \mathrm{H}_{5} \mathrm{OH}$ : o solvente foi adquirido da Merck, grau analítico (99,9\% via CG), e utilizado sem nenhuma purificação adicional.

Metanol absoluto $\mathrm{CH}_{3} \mathrm{OH}$ : o solvente foi adquirido da Merck, grau analítico (99,9\% via CG), e utilizado sem nenhuma purificação adicional.

Tetra-hidrofurano $\mathrm{C}_{4} \mathrm{H}_{8} \mathrm{O} \quad$ (THF): 0 solvente adquirido da Merck, grau analítico, foi destilado via coluna de vigreux e, ao destilado, foram adicionados fios de sódio e uma ponta de espátula de benzofenona. Antes do uso, o solvente foi aquecido a refluxo até apresentar coloração azul e, em seguida, destilou-se a quantidade necessária. O THF utilizado nos ensaios de Espalhamento de Luz Estático Dependente do Tempo (TDSLS) e Cromatografia de Exclusão por Tamanho (SEC), por outro lado, era Mallinckrodt, grau cromatográfico $(99,99 \%$ via CG), e foi utilizado sem nenhuma purificação adicional.

Tolueno $\mathrm{C}_{6} \mathrm{H}_{5} \mathrm{CH}_{3}$ : o solvente foi adquirido da Aldrich Chemical Co, grau cromatográfico $(99,8 \%$ via $C G)$, foi aquecido a refluxo na presença de sódio metálico por cerca de 4 horas e, em seguida, destilado via coluna de vigreux.

Os demais solventes usados, todos de grau analítico, não foram submetidos a nenhum tipo de tratamento. 


\subsubsection{Aparelhagem}

\subsubsection{Espectroscopia de Ressonância Magnética Nuclear}

Os espectros de ressonância magnética nuclear foram registrados em um espectrômetro Brucker modelo DMX-300 (300MHz) e em um espectrômetro Brucker modelo AC-200 (200MHz), pertencentes à Central Analítica do IQ-USP.

Os deslocamentos químicos ( $\delta$ ) dos espectros obtidos estão relatados em partes por milhão (ppm) em relação ao sinal do tetrametilsilano (TMS), utilizado como padrão interno em todas as amostras $(0,03 \%$ em massa).

\subsubsection{Espectroscopia de Infravermelho}

Os espectros de absorção na região do infravermelho foram obtidos entre os números de onda de 4.000 a $450 \mathrm{~cm}^{-1}$, com resolução de $4 \mathrm{~cm}^{-1}$, utilizando-se os espectrômetros FT-IR da Perkin-Elmer, modelo 1750 e o FT-IR da Nicolet, modelo 510. As amostras sólidas foram preparadas na forma de pastilhas de $\mathrm{KBr}$ para o homo e copolímeros intactos, e na forma de filmes aplicados sobre cristais de $\mathrm{NaCl}$, para os fotoprodutos

\subsubsection{Espectrometria de Massa}

Os espectros de massa de baixa resolução (LRMS) foram registrados em um espectrômetro de massa Shimadzu modelo GC/MS-QP5000, conectado a um cromatógrafo a gás Shimadzu modelo GC-17A (equipado com uma coluna SPB-5 de 30m), ou GC/MS - Hewlet Packard modelo 5988A, conectado a um cromatógrafo HP 5890. 


\subsubsection{Cromatografia Gasosa}

O acompanhamento das reações por meio de consumo de reagentes e/ou aparecimento dos produtos foi feito via um cromatógrafo a gás Shimadzu modelo GC-14A, através de uma coluna capilar apolar CBP-1 (poli-dimetil-silicone) de $0,25 \mathrm{~mm}$ de diâmetro interno e detector de ionização de chama, acoplado a um integrador/registrador Shimadzu modelo GC-14A, utilizando-se hélio como gás de arraste em um fluxo de $1,6 \mathrm{~mL} / \mathrm{min}$. Os cromatogramas foram obtidos nas seguintes condições: $40^{\circ} \mathrm{C}$ durante 4 minutos, aumento de $10^{\circ} \mathrm{C}$ por minuto até $240^{\circ} \mathrm{C}$, mantendo-se nesta temperatura por 5 minutos; injetor a $200^{\circ} \mathrm{C}$; detector a $250^{\circ} \mathrm{C}$.

\subsubsection{Cromatografia em Camada Delgada Preparativa}

Os ensaios de cromatografia em camada delgada (TLC) preparativa foram feitos em placas de vidro, cobertas com uma camada de $1 \mathrm{~mm}$ de espessura de Kieselgel $60 \mathrm{~F}_{254}$ (sílica com indicador de fluorescência). A eluição foi efetuada à temperatura ambiente e a revelação das placas foi feita sob luz ultravioleta.

\subsubsection{Cromatografia de Exclusão por Tamanho}

As análises de cromatografia de exclusão por tamanho (SEC) foram realizadas em um cromatógrafo líquido de alta eficiência Shimadzu modelo CLASS-LC10, dotado de três colunas Supelco Progel TSK-HXL (1xG5000 + $1 \times G 4000$ + 1xG3000, em série), detectores de UV-VIS e índice de refração diferencial. Todas as análises foram obtidas nas seguintes condições: temperatura do forno, $45^{\circ} \mathrm{C}$; fluxo de THF, $1 \mathrm{~mL} / \mathrm{min}$; volume de injeção, $25 \mu \mathrm{L}$. Os valores de $\bar{M}_{w}$ e $\bar{M}_{w} / \bar{M}_{n}$ dos polímeros foram calculados com base na calibração com padrões de poliestireno da Aldrich com diferentes massas molares $(2.500,5.000$, $17.500,30.000,50.000,95.800$ e $184.200 \mathrm{~g} / \mathrm{mol})$. 


\subsubsection{Espalhamento de Luz Estático Dependente do Tempo}

A determinação do tempo real de degradação no ultravioleta foi realizada utilizando-se medidas de espalhamento de luz estático dependente do tempo (TDSLS), obtidos de um fotômetro de espalhamento de luz Wyatt Technology Dawn-F DSP (Sta.Bárbara, Ca.), através de cela de fluxo, possibilitando a leitura simultânea de 18 ângulos $\left(22,5^{\circ}\right.$ a $\left.147^{\circ}\right)$. Os dados foram transferidos de uma linha RS-232c a um microcomputador, e um software desenvolvido por W.F.Reed ${ }^{132}$ (Tulane University) efetuou a análise e aquisição dos dados.

- Laser

A fonte de luz para o sistema é um laser He-Ne linearmente polarizado de $5 \mathrm{~mW}$, posicionado de maneira que o feixe incidente seja verticalmente polarizado.

\section{- Detectores}

Uma série de 18 detectores capta os sinais de espalhamento medidos em relação à direção do feixe do laser, para um determinado ângulo específico. Uma vez que os ângulos observados mudam com o índice de refração do solvente, medidas em ângulo de espalhamentos baixos são possíveis (Tabela 12). Os sinais dos fotodiodos foram normalizados com uma solução de poliestireno (massa molar $=5,0 \mathrm{~kg} / \mathrm{mol}$ ) em THF, e tolueno foi usado como padrão de espalhamento de luz. Os valores de $d n / d c$ foram calculados para cada solução polimérica (item 7.6).

\footnotetext{
${ }^{132}$ Reed, W.F., J.Chem.Phys., 103, (1995) 7576.
} 
Tabela 12: Posições dos detectores relativas ao feixe de luz incidente ( $\theta$ = ângulos do detector fixados).

\begin{tabular}{|c|c|c|c|c|c|c|c|c|c|c|c|c|c|c|c|c|c|c|}
\hline CANAL & 1 & 2 & 3 & 4 & 5 & 6 & 7 & 8 & 9 & 10 & 11 & 12 & 13 & 14 & 15 & 16 & 17 & 18 \\
\hline$\theta(\%)$ & 22,5 & 28 & 32 & 38 & 44 & 50 & 57 & 64 & 72 & 81 & 90 & 99 & 108 & 117 & 126 & 134 & 141 & 147 \\
\hline
\end{tabular}

- Celas de fluxo

O desenho da cela de fluxo foi feito de tal forma que somente o espalhamento da amostra e não da cela (interfaces ar/vidro/solvente) seja medido (Figura 37). Os detectores são ajustados para detectar luz a um ângulo $\theta \mathrm{e}$ colimados para serem localizados no centro aparente da cela; como resultado da refração, a luz detectada é a luz espalhada pelo ângulo.

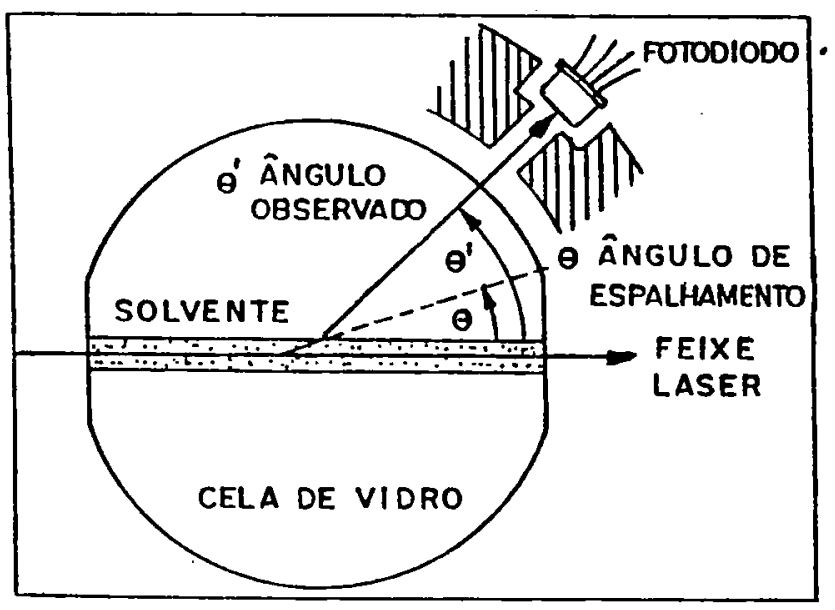

Figura 37: Detalhe da interface líquido/vidro e refraçōes da cela te fluxo. 


\section{- Amplificador}

O instrumento Dawn DSP converte cada uma das 18 voltagens do detector para o formato digital e as transmite para o computador, juntamente com o sinal do monitor do laser.

O amplificador possibilita o processamento e a resolução dos sinais, amplificando a potência útil de cada fotodiodo por 1, 21 ou 100 vezes em relação ao sinal original. Todas as determinações foram feitas utilizando-se o sinal amplificado 21 vezes.

\subsubsection{Análise Elementar}

Os ensaios de análise elementar foram realizados em equipamento Elemental Analyser CHN Perkin Elmer modelo 2400, utilizando-se dez amostras de cada um dos produtos em estudo.

\subsubsection{Microscopia Eletrônica de Varredura}

Os ensaios de microscopia eletrônica de varredura (MEV) foram feitos em um Microscópio Eletrônico de Varredura Philips modelo XL-30, no Instituto de Pesquisas Energéticas e Nucleares (IPEN). Amostras hidrolisadas de PS e copolímeros selecionados da série TSB (TSB10 e TSB15), após um processo de secagem (em dessecador à temperatura ambiente, sob vácuo) ao longo de quatro dias, e posterior trituração, foram analisadas. As micrografias foram obtidas, em porta-amostras de aço inoxidável, com aumento de 200 vezes. 


\subsubsection{Calorimetria Exploratória Diferencial}

As curvas de calorimetria exploratória diferencial (DSC) foram obtidas em um equipamento para análise térmica Shimadzu modelo DSC-50, acoplado a um microcomputador dotado de um sistema de aquisição e tratamento de dados TA 2000. Foram utilizadas massas de aproximadamente $2 \mathrm{mg}$ das amostras, acondicionadas em cápsulas de alumínio aberta; atmosfera dinâmica de nitrogênio com fluxo de $50 \mathrm{~mL} / \mathrm{min}$; razão de aquecimento de $10^{\circ} \mathrm{C} / \mathrm{min}$; intervalo de temperatura de $25^{\circ} \mathrm{C}$ a $600^{\circ} \mathrm{C}$. O equipamento foi calibrado com índio metálico de $99,99 \%$ de pureza.

\subsubsection{Termogravimetria}

As curvas de termogravimetria (TGA) foram obtidas em uma Termobalança modelo TGA-7 série Delta da Perkin-Elmer, acoplada a um microcomputador dotado de um sistema de aquisição e tratamento de dados TA 2000. Foram utilizadas massas de cerca de $5 \mathrm{mg}$ das amostras, acondicionadas em cadinho de platina; atmosfera dinâmica de ar com fluxo de $50 \mathrm{~mL} / \mathrm{min}$; razão de aquecimento de $10^{\circ} \mathrm{C} / \mathrm{min}$; intervalo de temperatura de 25 a $600^{\circ} \mathrm{C}$. O equipamento foi calibrado a partir da obtenção das curvas de uma amostra padrão de carbonato de cálcio.

\subsubsection{Envelhecimento Acelerado}

O copolímero TSB15 foi injetado em molde usual para ensaios de tração em injetora ARBURG com força de fechamento de 30 toneladas, no Laboratório de Ensaios Mecânicos do Departamento de Engenharia de Materiais (DEMa) da Universidade Federal de São Carlos (UFSCar), e os corpos de prova foram submetidos a envelhecimento acelerado em câmara de intemperismo artificial Weather-o-Meter WOM-001 modelo 65 WRC, no Laboratório de Aplicações Tecnológicas (LAT) da Reichold-Resana S.A. em Mogi das Cruzes, S.P. Utilizou- 
se a norma ASTM D 5071-91 ${ }^{133}$ e as seguintes condições de ensaio: lâmpada tipo arco-xenônio $6.500 \mathrm{~W}$ com filtros interno e extemo de vidro borosilicato; temperatura no corpo-negro, $63+/-3^{\circ} \mathrm{C}$; tipo de radiação: luz natural (do dia); condições de exposição: ciclos alternados de 102 minutos de luz e 18 minutos de luz com aspersão de água; tempos de exposição: 0, 100, 300 e 600 horas em cada uma das faces.

\subsubsection{Resistência à Tração}

Os corpos de prova envelhecidos do copolímero TSB15 foram avaliados no Laboratório de Ensaios Mecânicos do Departamento de Metalurgia do Instituto de Pesquisas Energéticas e Nucleares (IPEN), de acordo com norma ASTM D 638$98^{134}$ em uma máquina universal de ensaios Instron modelo $4400 \mathrm{R}$, nas seguintes condições de ensaio: corpos de prova tipo I (largura de $13 \mathrm{~mm}$ e espessura de $3,20 \mathrm{~mm}$ ); velocidade de separação das garras, 0,5 a $10 \mathrm{~mm} / \mathrm{min}$; cela de carga, $500 \mathrm{~kg}$; espaço entre garras, $105 \mathrm{~mm}$ e comprimento Gauge, $50 \mathrm{~mm}$.

\subsection{Preparação dos Comonômeros}

\subsubsection{Preparação do 2-Trimetilsililóxi-1,3-butadieno $(\mathrm{TSB})^{135}$}<smiles>C=CC(=C)O[Mg]C(C)(C)C(CCC)N(C)C(C)(C)C</smiles>

\footnotetext{
${ }^{133}$ ASTM D 5071-91 "Standard Practice for Operating Xenon-Arc-Type Exposure Apparatus with Water for Exposure of Photodegradable Plastics".

${ }_{134}$ ASTM D 638-98 "Tensile Properties of Plastics"(DQ-LAPB-PE-01 1).

${ }^{135}$ Jung, M.E. and McCombs, C.A., Organic Syntheses, 58 (1978) 163.
} 
Em um balão de três bocas de $500 \mathrm{~mL}$ acoplado a 2 funis de adição de $100 \mathrm{~mL}$ com equalizadores de pressão (acoplados a tubos secantes), uma entrada de $\mathrm{N}_{2}$ seco e agitação mecânica, foram colocados 40,5 g (0,40 mol) de TEA dissolvidos em cerca de $200 \mathrm{~mL}$ de DMF. A solução, sob agitação, foi aquecida a $50-60^{\circ} \mathrm{C}$ em banho de óleo mineral, sendo então adicionados simultaneamente, pelos funis de adição, $25 \mathrm{~g}$ (0,36 mol) de MVK dissolvidos em $25 \mathrm{~mL}$ de DMF e $43,4 \mathrm{~g}(0,40 \mathrm{~mol})$ de clorotrimetilsilano dissolvidos em $25 \mathrm{~mL}$ de DMF, respectivamente. A adição foi feita ao longo de 40 minutos.

Ao término das adições, elevou-se a temperatura do sistema para 80 $90^{\circ} \mathrm{C}$, mantendo-se por 15 horas.

A mistura reacional foi, então, resfriada à temperatura ambiente e filtrada (primeiramente sobre algodão e, em seguida, através de uma coluna de $10 \mathrm{~cm}$ preenchida com lã de vidro) para um funil de separação de $2 \mathrm{~L}$ contendo $300 \mathrm{~mL}$ de n-pentano gelado. A esta solução adicionou-se $1 \mathrm{~L}$ de $\mathrm{NaHCO}_{3}$ (solução aquosa gelada a $5 \%$ ) para facilitar a separação das fases.

Após sucessivas etapas de agitação vigorosa ( 10 a 20 segundos) seguida por descompressão, separou-se a fase orgânica (superior) e a fase aquosa (inferior) foi extraída outras duas vezes com porções de $300 \mathrm{~mL}$ de n-pentano gelado.

As três porções de n-pentano foram combinadas e então lavadas com $200 \mathrm{~mL}$ de água destilada gelada: a fase aquosa foi rapidamente extraída em funil de separação; a fase orgânica foi armazenada sobre $\mathrm{Na}_{2} \mathrm{SO}_{4}$ anidro e agitada pernoite.

A remoção do n-pentano e outros voláteis foi feita por um sistema de destilação fracionada sob atmosfera de $\mathrm{N}_{2}$, em um banho de óleo a $70^{\circ} \mathrm{C} \mathrm{e}$ peneira molecular ativada (4⿱⺈) no recipiente coletor.

O produto bruto foi destilado em sistema tipo Kugelrohr Buchi à pressão reduzida $\left(\sim 50 \mathrm{mmHg}\right.$ ), resultando em $31,5 \mathrm{~g}$ do dieno, que foi identificado por ${ }^{1} \mathrm{H}$ NMR (Espectro 14, anexo), GC/MS (Espectro 15, anexo) e IR (Espectro 16, anexo). 
Rendimento : $62 \%(31,51 \mathrm{~g} / 0,221 \mathrm{~mol})$

Pureza: $99 \%(G C)$

Ponto de ebulição: $50-55^{\circ} \mathrm{C}(\sim 50 \mathrm{mmHg})$

Rf: 0,58 (hexano / acetato de etila - 9:1 v/v em $\mathrm{SiO}_{2}$ )

${ }^{1} \mathrm{H}-\mathrm{NMR}\left(\mathrm{CDCl}_{3}, 300 \mathrm{MHz}\right): \delta=0,4$ (singleto, $9 \mathrm{H}, \mathrm{Si}\left(\mathrm{CH}_{3}\right)_{3}$ )

$\delta=4,4$ (singleto, $2 \mathrm{H}, \mathrm{CH}_{2}=\mathrm{CH}$-)

$\delta=5,1$ (dubleto, $1 \mathrm{H},-\mathrm{CH}=$ )

$\delta=5,5$ (dubleto de dubletos, $1 \mathrm{H}, \mathrm{CH}_{2}=$ )

$\delta=6,3$ (multipleto, $1 \mathrm{H}, \mathrm{CH}_{2}=$ )

GC/MS(70eV):

$$
\begin{aligned}
& \mathrm{m} / \mathrm{z}(\%)=142\left(24, \mathrm{M}^{+}\right) \\
& \mathrm{m} / \mathrm{z}(\%)=127\left(100, \mathrm{M}^{+}-\mathrm{CH}_{3}\right) \\
& \mathrm{m} / \mathrm{z}(\%)=75\left(81, \mathrm{HOSi}\left(\mathrm{CH}_{3}\right)_{3}-\mathrm{CH}_{3}\right)
\end{aligned}
$$

IR (filme): $2957 \mathrm{~cm}^{-1}, \quad 2926 \mathrm{~cm}^{-1}, \quad 2851 \mathrm{~cm}^{-1}, \quad 2361 \mathrm{~cm}^{-1}, \quad 2340 \mathrm{~cm}^{-1}, 1712 \mathrm{~cm}^{-1}$, $1671 \mathrm{~cm}^{-1}, 1633 \mathrm{~cm}^{-1}, 1448 \mathrm{~cm}^{-1}, 1424 \mathrm{~cm}^{-1}, 1366 \mathrm{~cm}^{-1}, 1253 \mathrm{~cm}^{-1}$, $1186 \mathrm{~cm}^{-1}, 878 \mathrm{~cm}^{-1}, 846 \mathrm{~cm}^{-1}$. 


\subsubsection{Preparação do 2-Metóxi-1,3-butadieno (MEB) ${ }^{136}$}

\subsubsection{Preparação do 1,3,3-Trimetóxibutano}

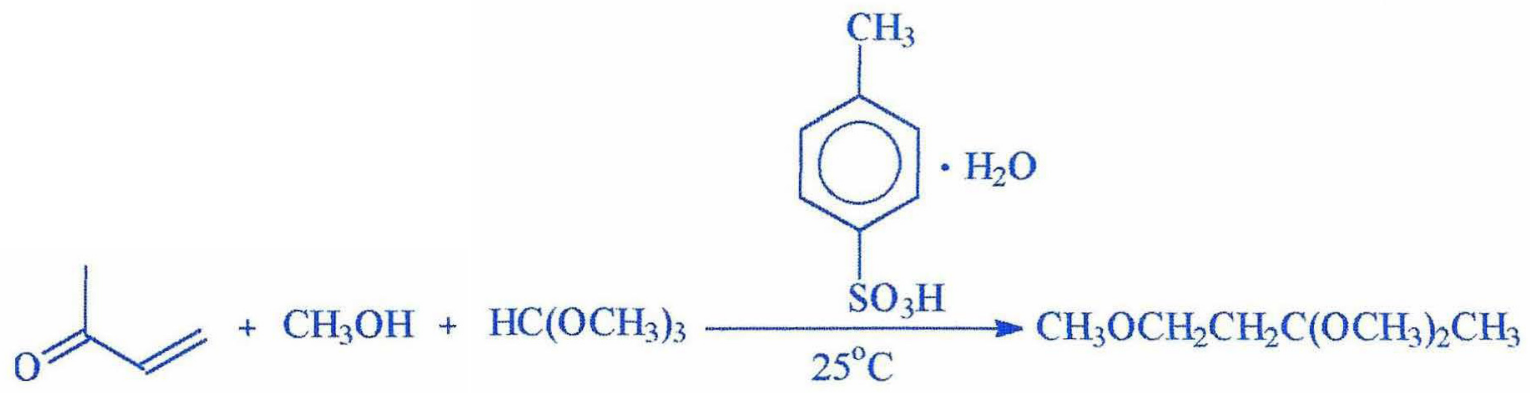

Em um frasco Erlenmeyer de $250 \mathrm{~mL}$, contendo $35,0 \mathrm{~g}(0,50 \mathrm{~mol})$ de $\mathrm{MVK}$, $88,4 \mathrm{~g}(0,83 \mathrm{~mol})$ de formiato de metila e $48,0 \mathrm{~g}(1,5 \mathrm{~mol})$ de metanol anidro, foram adicionados, sob agitação vigorosa, $0,21 \mathrm{~g}$ de APTS mono-hidratado.

Após um período de sete minutos de indução, a reação tornou-se altamente exotérmica e a solução adquiriu uma coloração avermelhada. Cessada a exotermia, o frasco foi fechado com tubo secante e mantido em repouso por doze dias, em ambiente escuro, à temperatura ambiente.

À solução verde-escuro resultante, foi adicionado $1,0 \mathrm{~g}$ de $\mathrm{Na}_{2} \mathrm{CO}_{3}$ anidro, mantendo-se sob agitação magnética por três dias.

Finalmente, a solução foi filtrada e destilada à pressão atmosférica até $70^{\circ} \mathrm{C}$, eliminando-se 0 excesso de metanol e formiato de metila (destilados 78 $\mathrm{mL})$. O produto bruto $(\sim 100 \mathrm{~g})$ foi novamente filtrado e, posteriormente, destilado em sistema tipo Kugelrohr Buchi à pressão reduzida $(\sim 50 \mathrm{mmHg})$, resultando em $62,90 \mathrm{~g}$ de produto puro, um líquido incolor, que foi identificado por ${ }^{1} \mathrm{H}$-NMR (Espectro 17, anexo), GC/MS (Espectro 18, anexo), e IR (Espectro 19, anexo).

Rendimento : $85 \%(62,90 \mathrm{~g} / 0,425 \mathrm{~mol})$

${ }^{136}$ Dolby, L.J., and Marshall, K.S., Org.Prep. and Procedures, 1(4), (1969). 
Pureza: $99 \%(G C)$

Ponto de ebulição: 62 - $64^{\circ} \mathrm{C}(\sim 50 \mathrm{mmHg})$

$\mathrm{n}_{\mathrm{D}}{ }^{20}=1,4110\left(1,4112^{137}\right)$

${ }^{1} \mathrm{H}-\mathrm{NMR}\left(\mathrm{CDCl}_{3}, 300 \mathrm{MHz}\right): \delta=1,31$ (singleto, $3 \mathrm{H}, \mathrm{CH}_{3}$ )

$\delta=1,97$ (tripleto, $\left.2 \mathrm{H}, \mathrm{CH}_{3} \mathrm{OCH}_{2} \mathrm{CH}_{2} \mathrm{C}\left(\mathrm{OCH}_{3}\right)_{2} \mathrm{CH}_{3}\right)$

$\delta=3,26$ (singleto, $6 \mathrm{H}, \mathrm{C}\left(\mathrm{OCH}_{3}\right)_{2}$ )

$\delta=3,35$ (singleto, $3 \mathrm{H}, \mathrm{CH}_{3} \mathrm{O}$ )

$\delta=3,54$ (tripleto, $2 \mathrm{H}, \mathrm{CH}_{3} \mathrm{OCH}_{2}$ )

GC/MS(70eV):

$$
\begin{aligned}
& \mathrm{m} / \mathrm{z}(\%)=148\left(17, \mathrm{M}^{+}\right) \\
& \mathrm{m} / \mathrm{z}(\%)=133\left(100, \mathrm{M}^{+}-\mathrm{CH}_{3}\right) \\
& \mathrm{m} / \mathrm{z}(\%)=103\left(66, \mathrm{M}^{+}-\mathrm{CH}_{3} \mathrm{OCH}_{2}\right)
\end{aligned}
$$

IR (filme): $2987 \mathrm{~cm}^{-1}, 2946 \mathrm{~cm}^{-1}, 2892 \mathrm{~cm}^{-1}, 2829 \mathrm{~cm}^{-1}, 2811 \mathrm{~cm}^{-1}, 1458 \mathrm{~cm}^{-1}$, $1379 \mathrm{~cm}^{-1}, 1200 \mathrm{~cm}^{-1}, 1173 \mathrm{~cm}^{-1}, 1117 \mathrm{~cm}^{-1}, 1081 \mathrm{~cm}^{-1}, 1055 \mathrm{~cm}^{-1}$, $857 \mathrm{~cm}^{-1}$.

\subsubsection{Preparação do 2-Metóxi-1,3-butadieno (MEB)}

$\mathrm{CH}_{3} \mathrm{OCH}_{2} \mathrm{CH}_{2} \mathrm{C}\left(\mathrm{OCH}_{3}\right)_{2} \mathrm{CH}_{3} \underset{145-150^{\circ} \mathrm{C}}{\stackrel{\mathrm{KHSO}_{4}}{\longrightarrow}} \mathrm{CH}_{3} \mathrm{O}+2 \mathrm{CH}_{3} \mathrm{OH}$

Em um balão de três bocas de $125 \mathrm{ml}$ contendo $10,0 \mathrm{~g}(0,07 \mathrm{~mol})$ de 1,3,3trimetóxibutano e cerca de $6 \mathrm{mg}$ de sulfato ácido de potássio, foram adaptados um agitador magnético, uma coluna de Vigreux acoplada a um sistema de

${ }^{137}$ Dykstra, H.B., J.Am.Chem.Soc., 57 (1935) 2255. 
condensador e um funil de adição de $25 \mathrm{~mL}$ com equalizador de pressão, conectado a uma linha de argônio.

A solução, sob agitação, foi aquecida a $145-150^{\circ} \mathrm{C}$ em banho de glicerina, sendo então adicionados, pelo funil de adição, $30,0 \mathrm{~g}(0,2 \mathrm{~mol})$ de 1,3,3trimetóxibutano. A adição foi feita ao longo de cinco horas, durante as quais destilou-se cerca de $35 \mathrm{~g}$ de um líquido incolor (recolhido em um balão coletor de $50 \mathrm{~mL}$ imerso em um banho, contendo gelo seco e acetona).

O produto bruto foi destilado em sistema tipo Kugelrohr Buchi à pressão atmosférica, sob $N_{2}$, resultando em $20,2 \mathrm{~g}$ de um líquido incolor, que foi identificado por ${ }^{1} \mathrm{H}-\mathrm{NMR}$ (Espectro 20, anexo), GC/MS (Espectro 21, anexo) e IR (Espectro 22, anexo).

Rendimento : $89 \%(20,20 \mathrm{~g} / 0,240 \mathrm{~mol})$

Pureza: $99 \%$ (GC)

Ponto de ebulição: $74-75^{\circ} \mathrm{C}\left(75^{\circ} \mathrm{C}^{137}\right)$

$n_{D}^{20}=1,4440\left(1,4442^{136}\right)$

${ }^{1} \mathrm{H}-\mathrm{NMR}\left(\mathrm{CDCl}_{3}, 300 \mathrm{MHz}\right): \delta=3,55$ (singleto, $3 \mathrm{H}$ )

$\delta=4,08$ (singleto, $2 \mathrm{H}$ )

$\delta=4,83$ a 6,38 (multipleto, $3 \mathrm{H}$ )

GC/MS(70eV):

$$
\begin{aligned}
& \mathrm{m} / \mathrm{z}(\%)=84\left(39, \mathbf{M}^{+}\right) \\
& \mathrm{m} / \mathrm{z}(\%)=69\left(100, \mathrm{M}^{+}-\mathrm{CH}_{3}\right) \\
& \mathrm{m} / \mathrm{z}(\%)=53\left(42, \mathrm{M}^{+}-\mathrm{OCH}_{3}\right)
\end{aligned}
$$

IR (filme): $2983 \mathrm{~cm}^{-1}, 2894 \mathrm{~cm}^{-1}, 2830 \mathrm{~cm}^{-1}, 1719 \mathrm{~cm}^{-1}, 1659 \mathrm{~cm}^{-1}, 1613 \mathrm{~cm}^{-1}$, $1464 \mathrm{~cm}^{-1}, 1452 \mathrm{~cm}^{-1}, 1381 \mathrm{~cm}^{-1}, 1314 \mathrm{~cm}^{-1}, 1116 \mathrm{~cm}^{-1}, 1079 \mathrm{~cm}^{-1}$ $1051 \mathrm{~cm}^{-1}, 994 \mathrm{~cm}^{-1}, 936 \mathrm{~cm}^{-1}, 912 \mathrm{~cm}^{-1}, 862 \mathrm{~cm}^{-1}, 802 \mathrm{~cm}^{-1}$. 


\subsubsection{Preparação do 2-Etóxi-1,3-butadieno (ETB) ${ }^{136}$}

\subsubsection{Preparação do 1,3,3-Trietóxibutano}

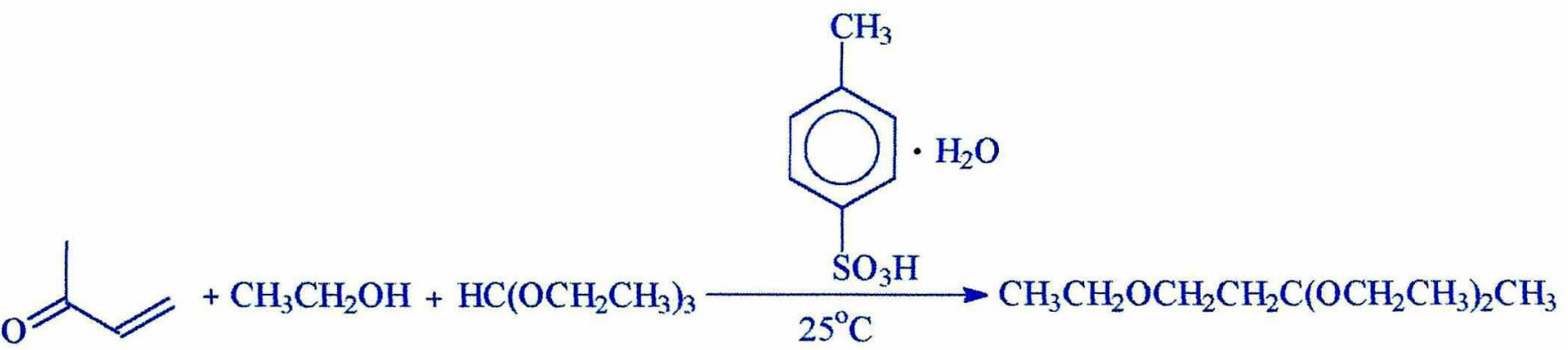

Em um frasco Erlenmeyer de $500 \mathrm{~mL}$, contendo $52,5 \mathrm{~g}(0,75 \mathrm{~mol})$ de $\mathrm{MVK}$, $185,2 \mathrm{~g}(1,25 \mathrm{~mol})$ de formiato de etila e 103,5g ( 2,25 mols) de etanol absoluto, foram adicionados, sob agitação vigorosa, $0,21 \mathrm{~g}$ de APTS mono-hidratado.

Após um período de cinco minutos de indução, a reação tornou-se altamente exotérmica e a solução adquiriu uma coloração marrom-avermelhada. Cessada a exotermia, o frasco foi fechado com tubo secante e mantido em repouso por doze dias, em ambiente escuro, à temperatura ambiente.

À solução verde-escuro resultante, foi adicionado $1,5 \mathrm{~g} \mathrm{de} \mathrm{Na}_{2} \mathrm{CO}_{3}$ anidro, mantendo-se sob agitação magnética por três dias.

Finalmente, a solução foi filtrada e destilada à pressão atmosférica até $80^{\circ} \mathrm{C}$, eliminando-se o excesso de etanol e formiato de etila (destilados $155 \mathrm{~mL}$ ). $O$ produto bruto $(\sim 200 \mathrm{~g})$ foi novamente filtrado e posteriormente destilado em sistema tipo Kugelrohr Buchi a pressão reduzida $(\sim 50 \mathrm{mmHg})$, resultando em $111,80 \mathrm{~g}$ de produto puro, um líquido incolor, que foi identificado por ${ }^{1} \mathrm{H}-\mathrm{NMR}$, GC/MS, e IR. 
Rendimento : $78,5 \%(111,80 \mathrm{~g} / 0,588 \mathrm{~mol})$

Pureza: $99 \%(G C)$

Ponto de ebulição: $75-78^{\circ} \mathrm{C}(\sim 50 \mathrm{mmHg})$

$n_{D}^{20}=1,4110\left(1,4112^{138}\right)$

${ }^{1} \mathrm{H}-\mathrm{NMR}\left(\mathrm{CDCl}_{3}, 300 \mathrm{MHz}\right): \delta=1,31$ (singleto, $3 \mathrm{H}, \mathrm{CH}_{3}$ )

$\delta=1,96$ (tripleto, $2 \mathrm{H}, \mathrm{CH}_{3} \mathrm{CH}_{2} \mathrm{OCH}_{2} \mathrm{CH}_{2} \mathrm{C}$-)

$\delta=2,87$ (tripleto, $6 \mathrm{H}, \mathrm{C}\left(\mathrm{OCH}_{2} \mathrm{CH}_{3}\right)_{2}$ )

$\delta=2,97$ (quadrupleto, $4 \mathrm{H}, \mathrm{C}\left(\mathrm{OCH}_{2} \mathrm{CH}_{3}\right)_{2}$ )

$\delta=3,12$ (tripleto, $3 \mathrm{H}, \mathrm{CH}_{3} \mathrm{CH}_{2} \mathrm{O}-$ )

$\delta=3,33$ (quadrupleto, $2 \mathrm{H}, \mathrm{CH}_{3} \mathrm{CH}_{2} \mathrm{O}$-)

$\delta=3,55$ (tripleto, $2 \mathrm{H}, \mathrm{CH}_{3} \mathrm{CH}_{2} \mathrm{OCH}_{2}$ )

GC/MS(70eV):

$$
\begin{aligned}
& \mathrm{m} / \mathrm{z}(\%)=190\left(36, \mathbf{M}^{+}\right) \\
& \mathrm{m} / \mathrm{z}(\%)=161\left(100, \mathrm{M}^{+}-\mathrm{CH}_{2} \mathrm{CH}_{3}\right) \\
& \mathrm{m} / \mathrm{z}(\%)=46\left(42, \mathrm{HOCH}_{2} \mathrm{CH}_{3}\right)
\end{aligned}
$$

IR (filme): $2985 \mathrm{~cm}^{-1}, 2946 \mathrm{~cm}^{-1}, 2890 \mathrm{~cm}^{-1}, 2829 \mathrm{~cm}^{-1}, 2809 \mathrm{~cm}^{-1}, 1458 \mathrm{~cm}^{-1}$, $1369 \mathrm{~cm}^{-1}, 1200 \mathrm{~cm}^{-1}, 1175 \mathrm{~cm}^{-1}, 1116 \mathrm{~cm}^{-1}, 1080 \mathrm{~cm}^{-1}, 1055 \mathrm{~cm}^{-1}$, $855 \mathrm{~cm}^{-1}$.

${ }^{138}$ Dykstra, H.B., J.Am.Chem.Soc., 57 (1935) 2255. 
7.2.3.2. Preparação do 2-Etóxi-1,3-butadieno (ETB)

$\mathrm{CH}_{3} \mathrm{CH}_{2} \mathrm{OCH}_{2} \mathrm{CH}_{2} \mathrm{C}\left(\mathrm{OCH}_{2} \mathrm{CH}_{3}\right)_{2} \mathrm{CH}_{3} \frac{\mathrm{KHSO}_{4}}{145-150^{\circ} \mathrm{C}} \rightarrow \mathrm{CH}_{3} \mathrm{CH}_{2} \mathrm{O}^{2}+2 \mathrm{CH}_{3} \mathrm{CH}_{2} \mathrm{OH}$

Em um balão de três bocas de $125 \mathrm{ml}$ contendo $10,0 \mathrm{~g}(0,05 \mathrm{~mol})$ de 1,3,3trietóxibutano e cerca de $6 \mathrm{mg}$ de sulfato ácido de potássio, foram adaptados um agitador magnético, uma coluna de vigreux acoplada a um sistema de condensador e um funil de adição de $25 \mathrm{~mL}$ com equalizador de pressão, conectado a uma linha de argônio.

A solução, sob agitação, foi aquecida a $145^{\circ} \mathrm{C}-150^{\circ} \mathrm{C}$ em banho de glicerina, sendo então adicionados, pelo funil de adição, $30,0 \mathrm{~g}(0,16 \mathrm{~mol})$ de $1,3,3-$ trimetóxibutano. A adição foi feita ao longo de cinco horas, durante as quais destilou-se cerca de $32 \mathrm{~g}$ de um líquido incolor (recolhido em um balão coletor de $50 \mathrm{~mL}$ imerso em um banho contendo gelo seco e acetona).

O produto bruto foi destilado em sistema tipo Kugelrohr Buchi à pressão atmosférica, sob $\mathrm{N}_{2}$, resultando em $19,8 \mathrm{~g}$ de um líquido incolor, que foi identificado por ${ }^{1} \mathrm{H}-\mathrm{NMR}$ (Espectro 23, anexo), GC/MS (Espectro 24, anexo) e IR (Espectro 25, anexo).

Rendimento : $96 \%(19,80 \mathrm{~g} / 0,202 \mathrm{~mol})$

Pureza: 99\% (GC)

Ponto de ebulição: $95-96^{\circ} \mathrm{C}\left(96,5^{\circ} \mathrm{C}^{137}\right)$

$n_{D}^{20}=1,4399\left(1,4401^{138}\right)$ 
${ }^{1} \mathrm{H}-\mathrm{NMR}\left(\mathrm{CDCl}_{3}, 300 \mathrm{MHz}\right): \delta=1,10-1,81$ (multipleto, $5 \mathrm{H}$ )

$\delta=2,14-2,26$ (multipleto, $2 \mathrm{H}$ )

$\delta=3,42-3,71$ (multipleto, $3 \mathrm{H}$ )

GC/MS(70eV):

$$
\begin{aligned}
& \mathrm{m} / \mathrm{z}(\%)=98\left(22, \mathbf{M}^{+}\right) \\
& \mathrm{m} / \mathrm{z}(\%)=69\left(100, \mathrm{M}^{+}-\mathrm{CH}_{2} \mathrm{CH}_{3}\right) \\
& \mathrm{m} / \mathrm{z}(\%)=53\left(12, \mathrm{M}^{+}-\mathrm{OCH}_{2} \mathrm{CH}_{3}\right) \\
& \mathrm{m} / \mathrm{z}(\%)=46\left(37, \mathrm{HOCH}_{2} \mathrm{CH}_{3}\right)
\end{aligned}
$$

IR (filme): $2982 \mathrm{~cm}^{-1}, 2894 \mathrm{~cm}^{-1}, 2831 \mathrm{~cm}^{-1}, 1717 \mathrm{~cm}^{-1}, 1659 \mathrm{~cm}^{-1}, 1612 \mathrm{~cm}^{-1}$, $1466 \mathrm{~cm}^{-1}, 1450 \mathrm{~cm}^{-1}, 1381 \mathrm{~cm}^{-1}, 1313 \mathrm{~cm}^{-1}, 1111 \mathrm{~cm}^{-1}, 1079 \mathrm{~cm}^{-1}$, $1050 \mathrm{~cm}^{-1}, 994 \mathrm{~cm}^{-1}, 935 \mathrm{~cm}^{-1}, 911 \mathrm{~cm}^{-1}, 862 \mathrm{~cm}^{-1}, 800 \mathrm{~cm}^{-1}$.

\subsection{Síntese e Purificação do Poliestireno e Copolímeros de Estireno e Butadienos Substituídos ${ }^{139,140}$}

Os copolímeros de estireno e butadienos substituídos foram preparados via polimerização radicalar, partindo-se de 5\%, 10\% e 15\% em fração molar de cada um dos monômeros (TSB, MEB e ETB), resultando em três séries de copolímeros: TSB5, TSB10, TSB15; MEB5, MEB10, MEB15 e ETB5, ETB10, ETB15, respectivamente (Esquema 10).

\footnotetext{
${ }^{139}$ Kato, M. and Yoneshige, Y., Makromol.Chem., 164 (1973) 159.

${ }^{140}$ Sikkema, K.H., Brennan, M.J., Smitth. D.J. and Priddy, D.B., Polym.Degrad.Stab. 38 (1992) 119.
} 
<smiles>C=Cc1ccccc1</smiles>

ST<smiles>C=CC(=C)[OH2+]</smiles>

Com

Esquema 10: Reação geral de síntese dos copolímeros de estireno e butadienos 2-substituídos.

Os monômeros, solvente e iniciador, nas quantidades indicadas nas Tabelas 13, 14 e 15, foram carregados em ampolas de vidro de $50 \mathrm{~mL}$, submetidas a quatro ciclos de degasamento sucessivos de dez minutos cada (sob vácuo, com congelamento em gelo seco e acetona), e seladas a vácuo.

As ampolas seladas foram aquecidas em banho de óleo de silicone a $70^{\circ} \mathrm{C}$, ao longo de 48 horas, na ausência de luz.

O material obtido, um líquido xaroposo incolor, foi dissolvido em THF e isolado por precipitação em metanol. A solução sobrenadante resultante foi separada por decantação, e a massa de polímero obtida foi dissolvida na menor quantidade possivel de THF ( cerca de $4 \mathrm{~mL} / \mathrm{g}$ ).

A purificação foi feita por etapas de precipitação em metanol e redissolução em THF, repetidas três vezes, sendo o material obtido submetido à secagem (em dessecador à temperatura ambiente, sob vácuo) ao longo de quatro dias, quando obteve-se massa constante.

O sólido seco foi triturado brandamente em almofariz de porcelana, obtendo-se um pó branco finamente dividido, armazenado em dessecador sob atmosfera de $\mathrm{N}_{2}$, no escuro. 


\subsubsection{Série TSB: 2-Trimetilsililóxi-1,3-butadieno}

Observou-se que a copolimerização com 10\% e 15\% do comonômero originou um produto extremamente viscoso, contendo porções de material insolúvel na forma de gel.

As sínteses foram efetuadas em duplicata com o objetivo de se estudar a reprodutibilidade do processo, bem como a obtenção de uma quantidade satisfatória de produto. 


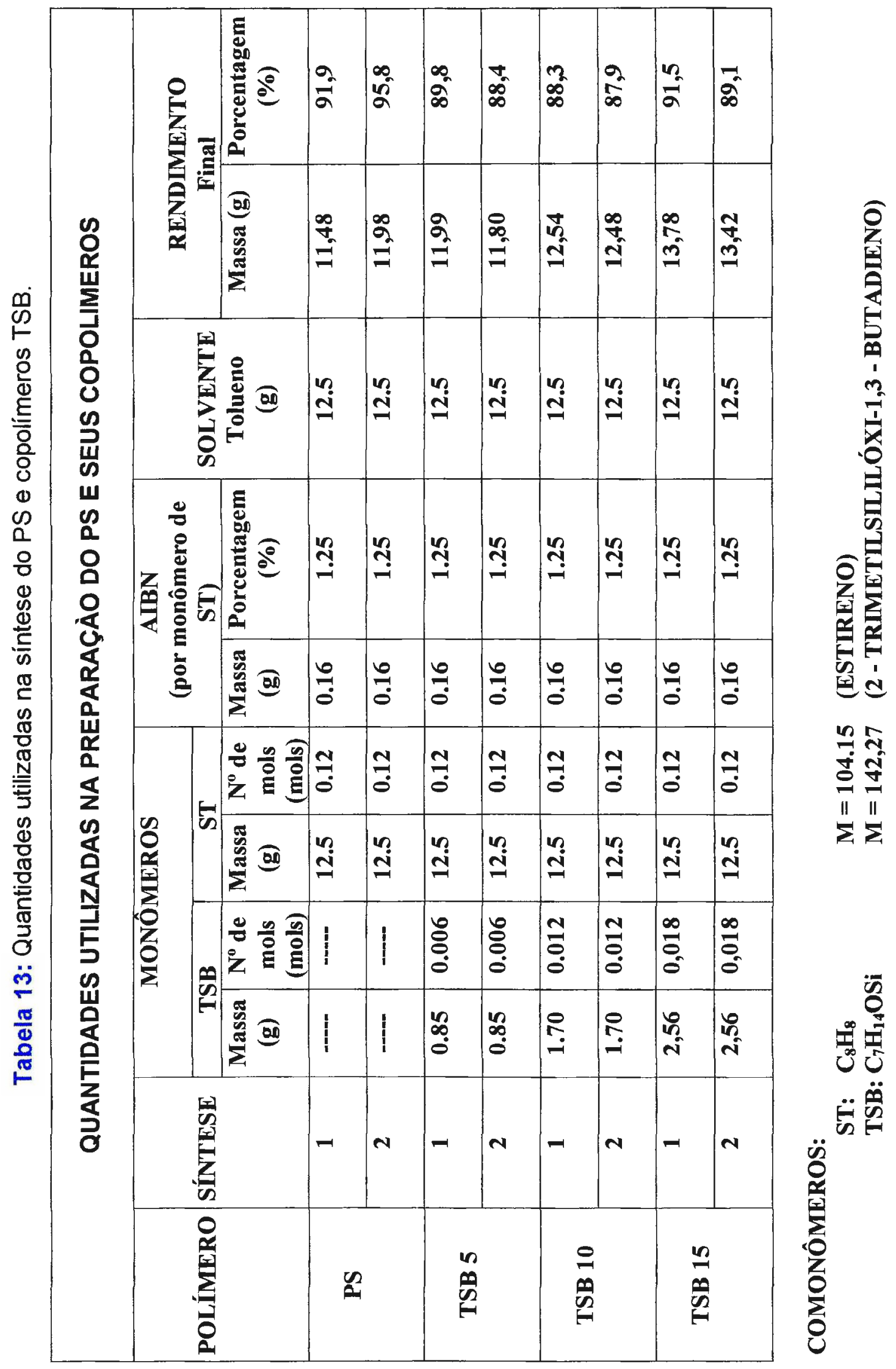


Os copolímeros resultantes foram submetidos à hidrólise (item 7.4), resultando em PS, contendo carbonilas inseridas na cadeia principal, conforme observado por IR (Espectros 5-7, anexos) e Análise Elementar (Tabela 1), com teores da ordem de $6 \%, 11 \%$ e $16 \%$, respectivamente.

\subsubsection{Série MEB: 2-Metóxi-1,3-butadieno}

Observou-se que a copolimerização com $15 \%$ do comonômero originou um produto extremamente viscoso, contendo porções de material insolúvel na forma de gel.

As sinteses foram efetuadas em duplicata. 


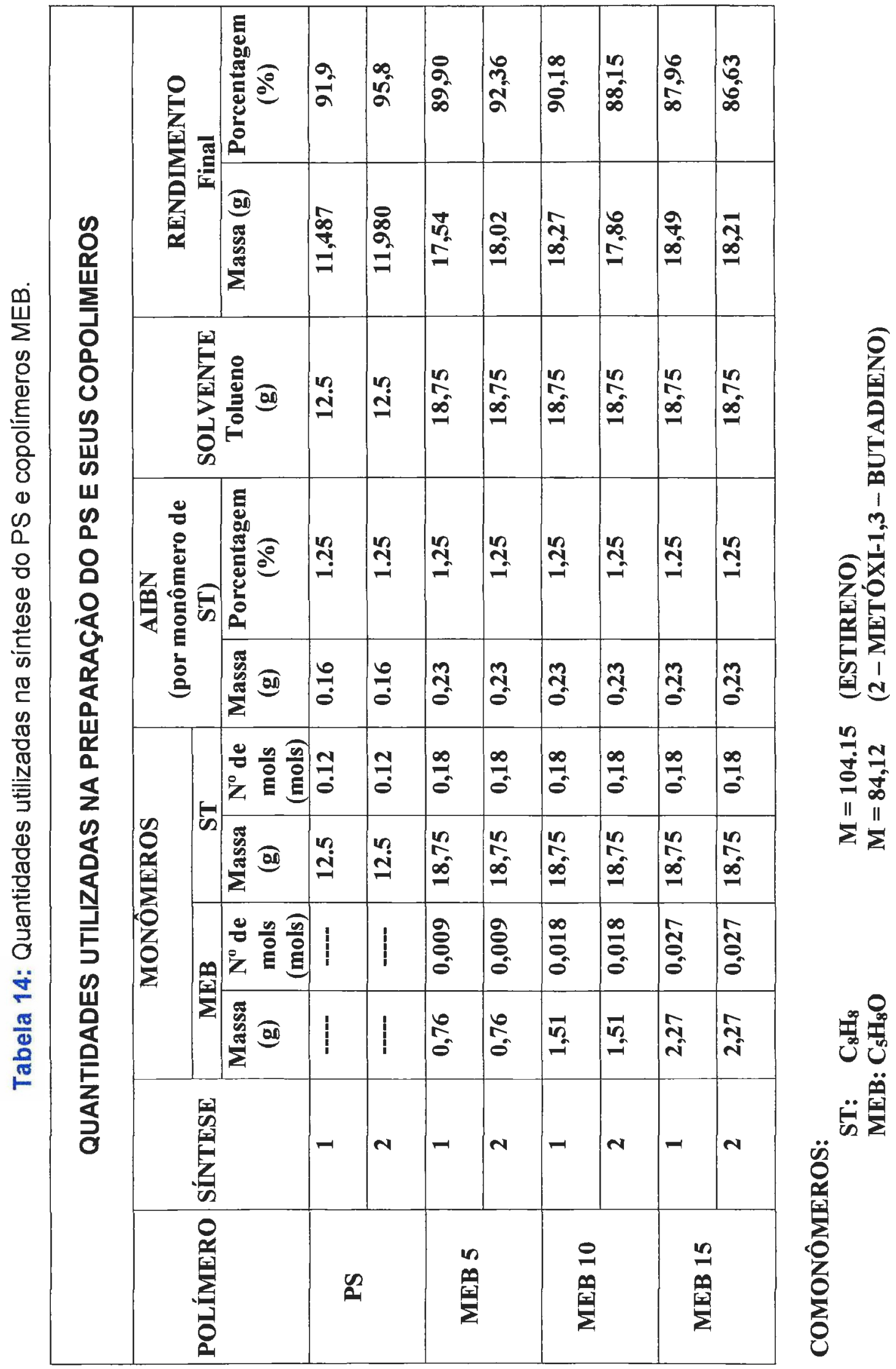


Os copolímeros resultantes foram submetidos à hidrólise (item 7.4), resultando em PS, contendo carbonilas inseridas na cadeia principal, conforme observado por IR (Espectros 8-10) e Análise Elementar (Tabela 2), com teores da ordem de $5 \%, 11 \%$ e $15 \%$, respectivamente.

\subsubsection{Série ETB: 2-Etóxi-1,3-butadieno}

Observou-se que a copolimerização com $15 \%$ do comonômero originou um produto extremamente viscoso, contendo porções de material insolúvel na forma de gel.

As sínteses foram efetuadas em duplicata.

Os copolímeros resultantes foram submetidos à hidrólise (item 7.4), resultando em PS, contendo carbonilas inseridas na cadeia principal, conforme observado por IR (Espectros 11-13) e Análise Elementar (Tabela 3), com teores da ordem de $5 \%, 11 \%$ e $16 \%$, respectivamente. 


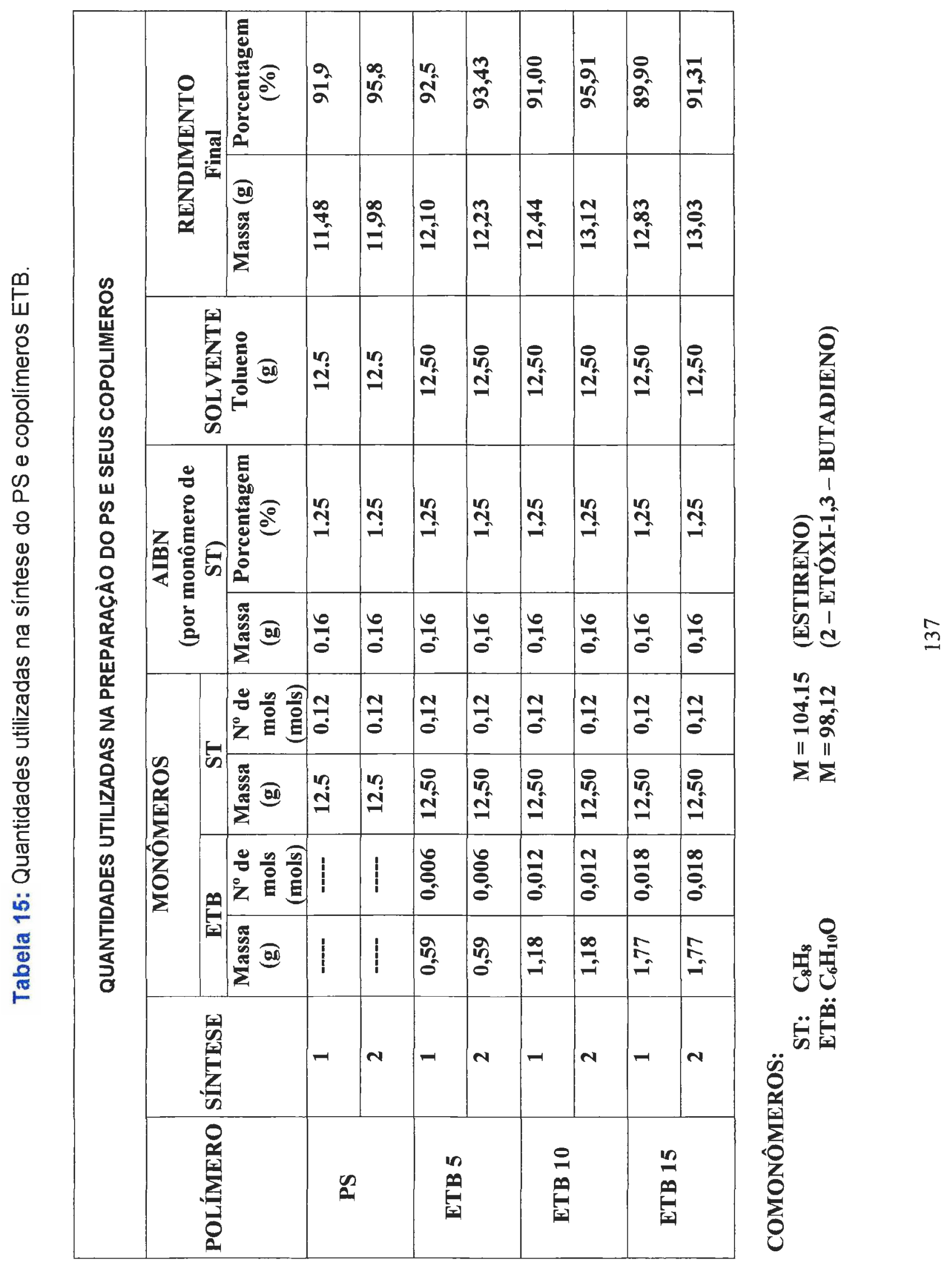




\subsection{Hidrólise dos Copolímeros de Estireno e Butadienos Substituídos}

A análise dos espectros de $\mathrm{IR}$ em torno de $1710 \mathrm{~cm}^{-1}$ evidenciou que não ocorreu a hidrólise dos grupos $-\mathrm{OSi}\left(\mathrm{CH}_{3}\right)_{3}, \quad-\mathrm{OCH}_{3}$ e $-\mathrm{OCH}_{2} \mathrm{CH}_{3}$ nos copolímeros das séries TSB, MEB e ETB, respectivamente, tornando-se necessária uma etapa de sua desproteção (Esquema 11).

Assim, para os copolímeros da série TSB, em um frasco tipo Erlenmeyer de $125 \mathrm{~mL}$, foram adicionados cerca de $6 \mathrm{~g}$ de copolímero, $25 \mathrm{~mL}$ de THF seco e quantidade suficiente de fluoreto de tetrabutilamônio (2mols de TBAF/mol de comonômero incorporado na cadeia de PS), mantendo-se sob agitação magnética por 48 horas em atmosfera aerada.

Para os copolímeros das séries MEB e ETB, em um frasco tipo Erlenmeyer de $125 \mathrm{~mL}$, foram adicionados cerca de $5 \mathrm{~g}$ de copolímero, $30 \mathrm{~mL}$ de THF, $10 \mathrm{~mL}$ de água e 10 gotas de $\mathrm{HCl}$ concentrado, mantendo-se o sistema sob agitação magnética por 48 horas em atmosfera aerada.

O processo de separação, purificação e secagem dos copolímeros foi idêntico ao anteriormente descrito no item 7.3.<smiles>CC(C)(C)C(CCCC(=O)CC(c1ccccc1)C(C)(C)C)c1ccccc1</smiles>

Esquema11: Reação geral de hidrólise dos copolímeros de estireno e butadienos 2-substituídos. 
7.5. Cálculo do Percentual de Incorporação da Carbonila no Homopolímero

O cálculo do teor de carbonila incorporado à cadeia de PS foi feito a partir dos dados obtidos por análise elementar, utilizando-se a equação 16 , deduzida a seguir.

$$
\begin{aligned}
& \left(\mathrm{C}_{8} \mathrm{H}_{8}\right)_{100-\mathrm{M}}\left(\mathrm{C}_{4} \mathrm{H}_{6} \mathrm{O}_{1}\right)_{\mathrm{M}} \\
& \text { ou } \\
& \mathrm{C}_{(100-\mathrm{M}) 8+(\mathrm{M} 4)} \mathrm{H}_{(100-\mathrm{M}) 8+\mathrm{M}_{6} \mathrm{O}_{M 1}} \\
& \text { ou } \\
& \mathrm{C}_{800-4 M} \mathrm{H}_{800-2 M} \mathrm{O}_{M} \\
& \% C=\frac{(800-4 M) C}{(800-4 M) C+(800-2 M) H+M O} \\
& \% C=\frac{800 C-4 M C}{800 C-4 M C+800 H-2 M H+M O} \\
& 800 C \% C-4 M C \% C+800 H \% C-2 M H \% C+M O \% C=800 C-4 M C \\
& 4 M C-4 M C \% C-2 M H \% C+M O \% C=800 C-800 C \% C-800 H \% C \\
& M=\frac{800 C-(800 C+800 H) \% C}{4 C-(4 C+2 H-0) \% C} \\
& M=\frac{9608,8-10415,2 \% C}{48,04-34,06 \% C}
\end{aligned}
$$

Equação 16 
em que:

M : porcentual de incorporação da carbonila na cadeia principal do PS;

\% C: a média aritmética dos teores percentuais de carbono obtidos experimentalmente (Tabelas 1, 2 e 3);

C, $\mathrm{H}$ e O : massas molares de carbono, hidrogênio e oxigênio, respectivamente.

\subsection{Determinação do Fator " $d n / d c "$ para as Soluções Poliméricas ${ }^{141}$}

Soluções poliméricas em THF filtrado com concentrações conhecidas $\left(2 \times 10^{-4}\right.$ a $\left.1 \times 10^{-3} \mathrm{~g} / \mathrm{mL}\right)$ foram injetadas diretamente no detector de índice de refração do cromatógrafo Shimadzu modelo RID10-A, mantendo-se a temperatura a $20+1-0,5^{\circ} \mathrm{C}$.

As leituras foram obtidas em fluxo (cerca de $1 \mathrm{~mL} / \mathrm{min}$ ) quando da estabilização dos valores mostrados no "display" do aparelho. Foram graficados os valores experimentais de índice de refração, " $n$ ", em função da concentração $(\mathrm{g} / \mathrm{mL})$, sendo os valores de "dn/dc" $\left(\mathrm{mLxg}^{-1}\right)$ obtidos pela tangente das respectivas retas, conforme demonstra a Tabela 16.

${ }^{141}$ Jones, P.H.; Prasad, D.; Heskins, M.; Morgan, M.H.; Guillet, J.E., Env.Sci.Technol., 8 (1974) 919. 
Tabela 16: Fator " $d n / d c^{\prime}$, em THF a $20^{\circ} \mathrm{C}$, como parâmetro dos ensaios de TDSLS.

\begin{tabular}{|c|c|c|c|c|c|c|c|c|c|}
\hline \multirow[t]{2}{*}{$\begin{array}{c}\text { PS } \\
\left(\mathrm{mLxg}^{-1}\right)\end{array}$} & \multicolumn{3}{|c|}{$\begin{array}{c}\text { Série TSB } \\
\qquad\left(\mathrm{mL} \times \mathrm{g}^{-1}\right)\end{array}$} & \multicolumn{3}{|c|}{$\begin{array}{c}\text { Série MEB } \\
\qquad\left(\mathrm{mLxg}{ }^{-1}\right)\end{array}$} & \multicolumn{3}{|c|}{$\begin{array}{c}\text { Série ETB } \\
\left(m \operatorname{mxg}^{-1}\right)\end{array}$} \\
\hline & 5 & 10 & 15 & 5 & 10 & 15 & 5 & 10 & 15 \\
\hline 0,195 & 0,219 & 0,229 & 0,238 & 0,201 & 0,221 & 0,230 & 0,210 & 0,222 & 0,229 \\
\hline
\end{tabular}

\subsection{Fotólise do PS e seus Copolímeros}

Sistema de Irradiação

Foi utilizado um tubo de quartzo, contendo $50 \mathrm{~mL}$ da solução polimérica em $\operatorname{THF}(0,010 \mathrm{~g} / \mathrm{mL})$, previamente filtrada por uma membrana de teflon de $0,22 \mu \mathrm{m}$ (Millipore Corp., Belford, Ma.). A solução foi mantida sob agitação magnética e o tubo posicionado na região central de três lâmpadas circulares de mercúrio de baixa pressão, marca Hanovia (99,5\% de emissão a $254 \mathrm{~nm}$ ) de 18 Watts, inseridas dentro de um cilindro de paredes metalizadas, por um período de dez horas.

Uma bomba HPLC (Shimadzu modelo LC-10AD) forneceu uma taxa de bombeamento contínua de $1 \mathrm{~mL} / \mathrm{min}$. Da cela de reação (fonte de irradiação) a solução foi levada, por uma pré-coluna Phenogel 5 de $2 \mathrm{~cm}$ para SEC $(25 \mu \mathrm{m}$ de 
porosidade; $50 \times 7,8 \mathrm{~mm}$ ) para a cela de fluxo Wyatt Dawn-F DSP e retornou à cela, por um circuito fechado ( Figura 38).

A quantidade de solução circulando pelo sistema exterior à cela de reação foi de cerca de $15 \mathrm{~mL}$, resultando em um tempo morto inicial de aproximadamente 1000 segundos antes do material fotolisado entrar no detector de espalhamento. A solução foi mantida à temperatura de $25+/-1^{\circ} \mathrm{C}$ em sala termostatizada e ventilação forçada.

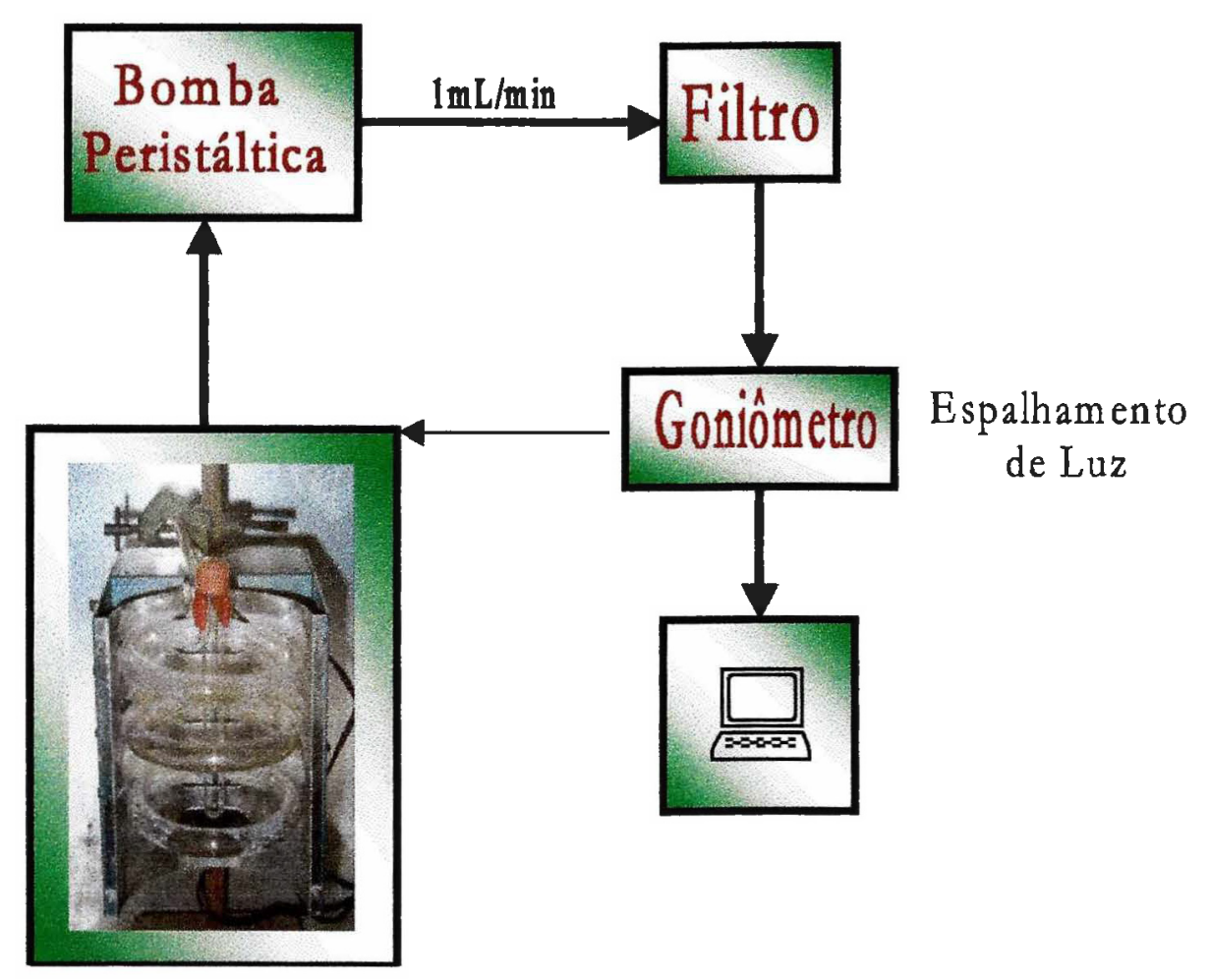

Figura 38: Sistema de irradiação em fluxo-contínuo. 


\section{Anexos}

\subsection{Espectros}

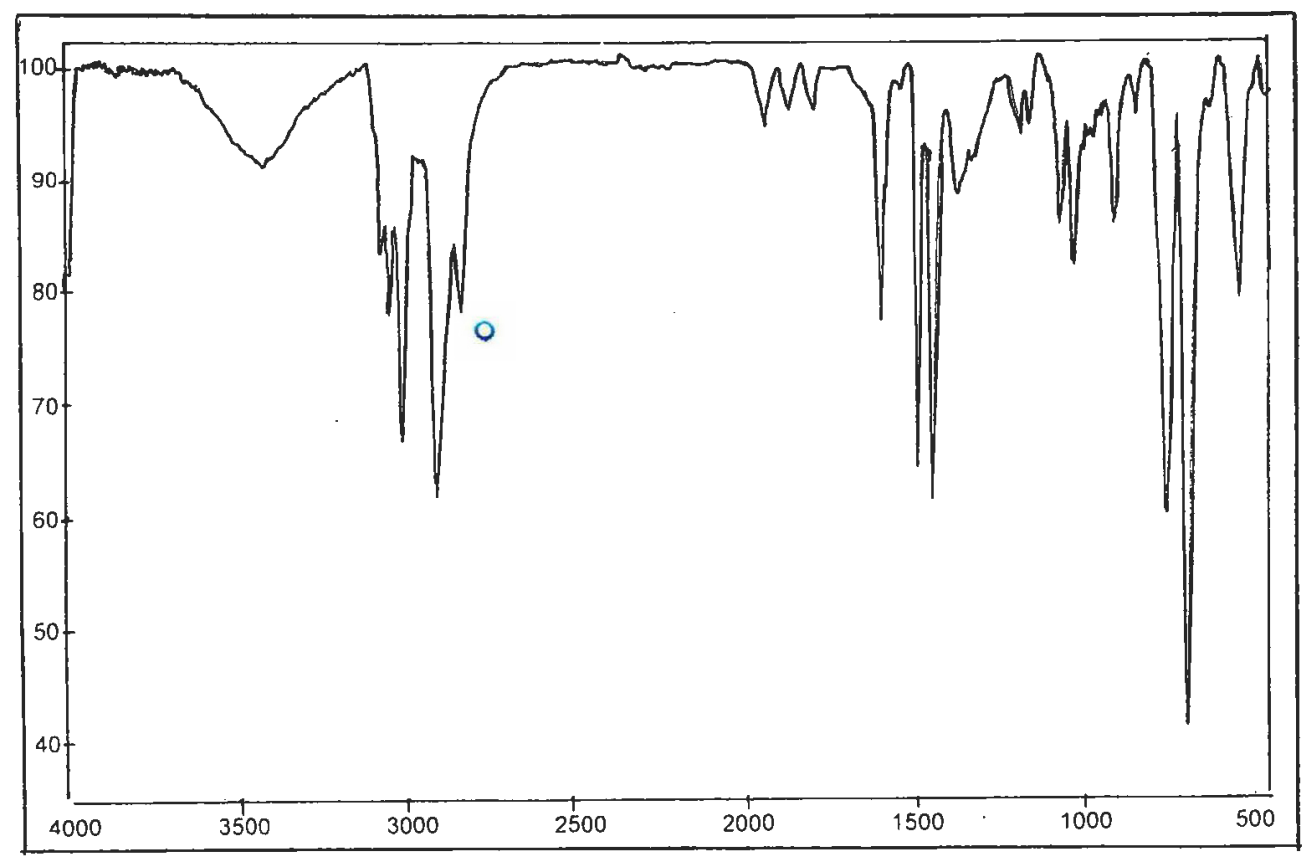

Espectro 1: Espectro de infravermelho do PS homopolimero em pastilha de $\mathrm{KBr}$.

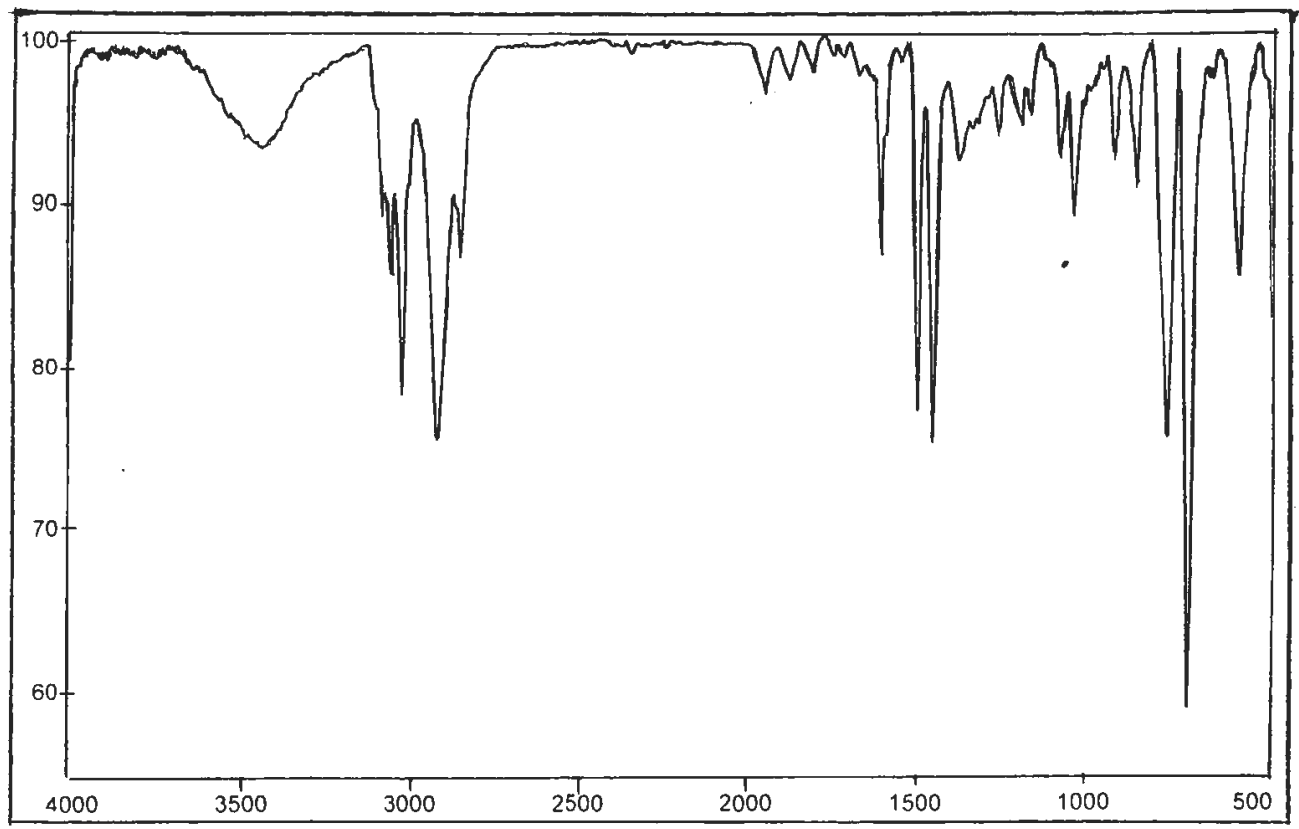

Espectro 2: Espectro de infravermelho do copolímero TSB5 não hidrolisado em pastilha de $\mathrm{KBr}$. 


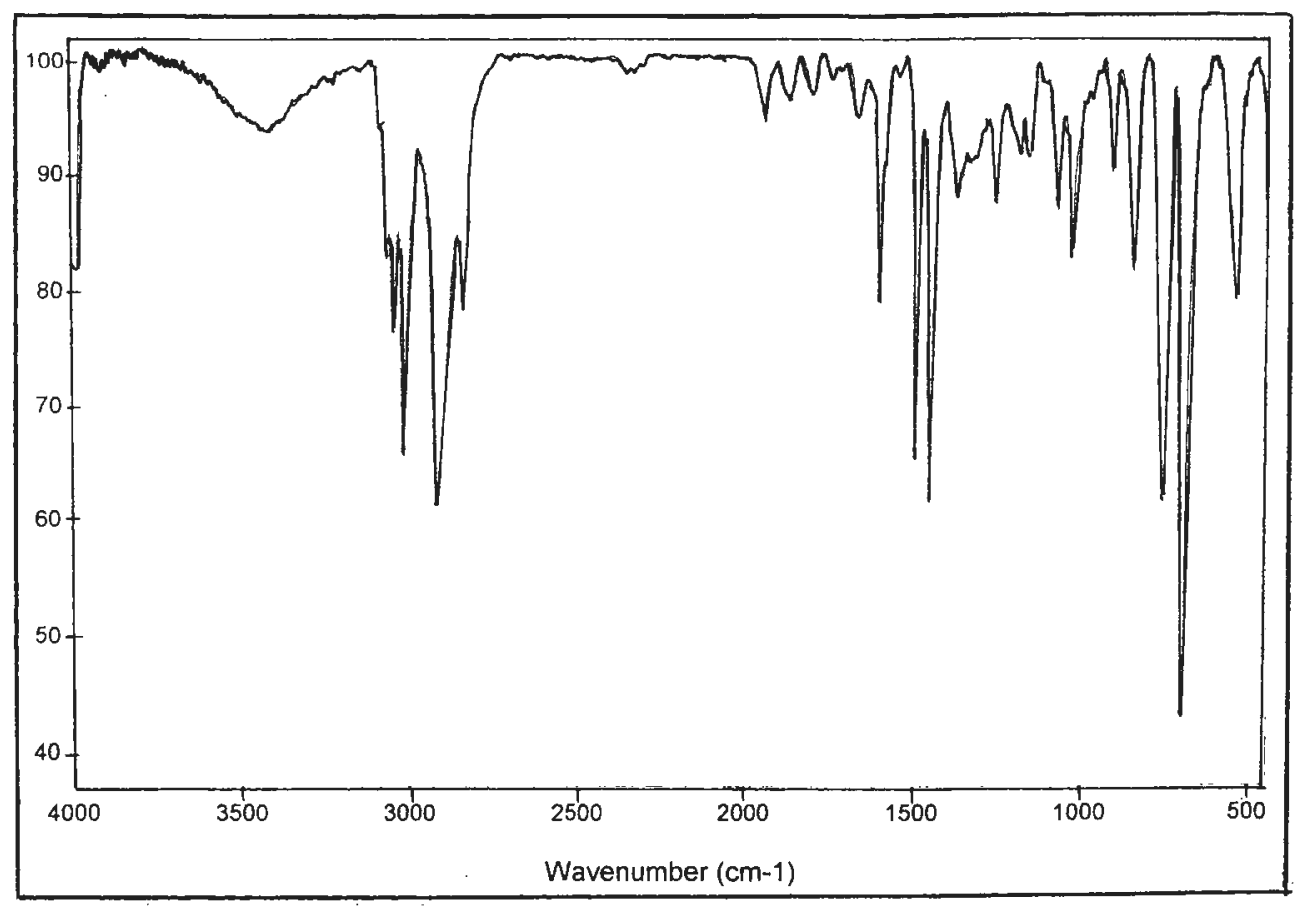

Espectro 3: Espectro de infravermelho do copolímero TSB10 não hidrolisado em pastilha de $\mathrm{KBr}$.

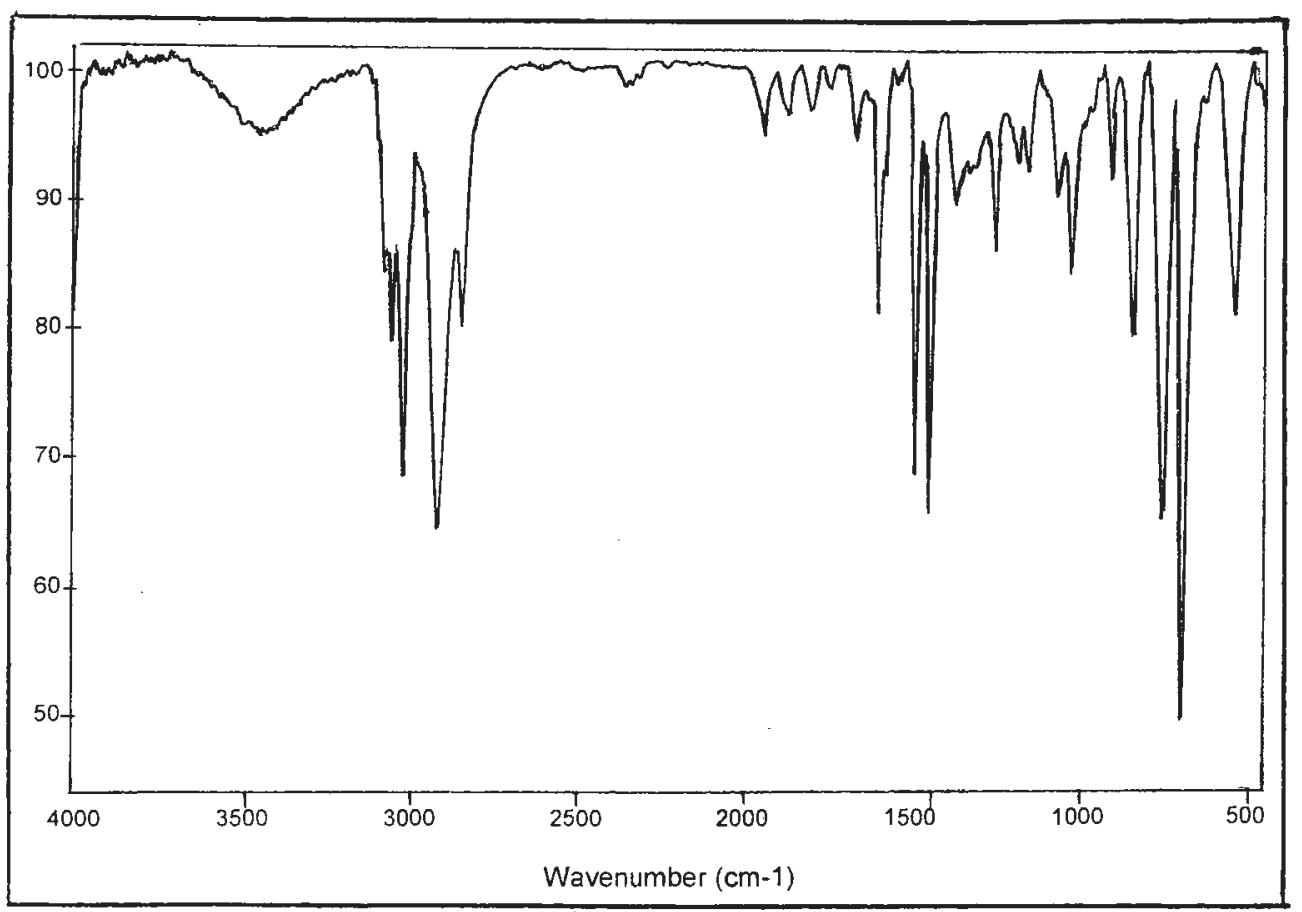

Espectro 4: Espectro de infravermelho do copolímero TSB15 não hidrolisado em pastilha de $\mathrm{KBr}$. 


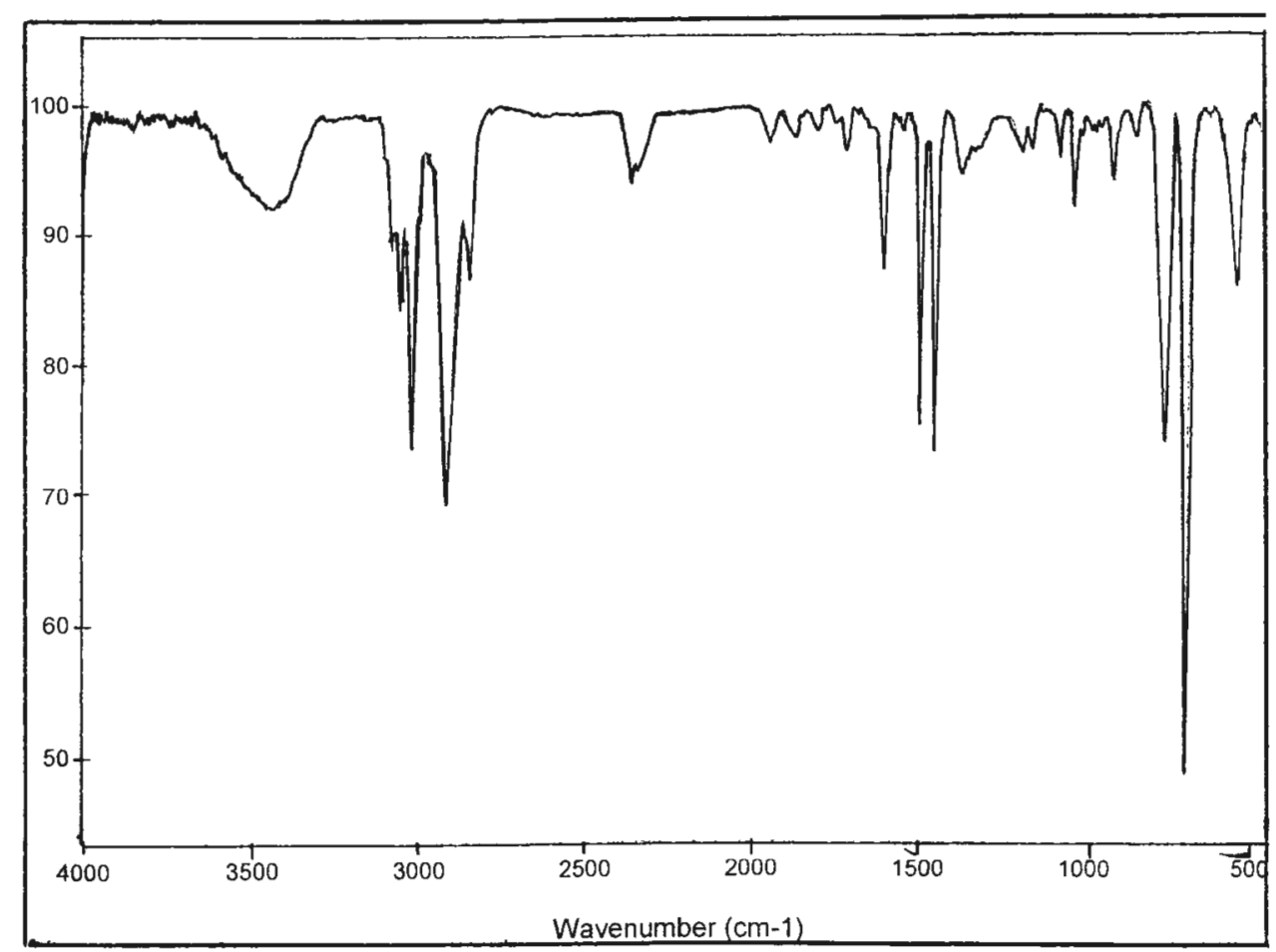

Espectro 5: Espectro de infravermelho do copolímero TSB5 hidrolisado em pastilha de $\mathrm{KBr}$.

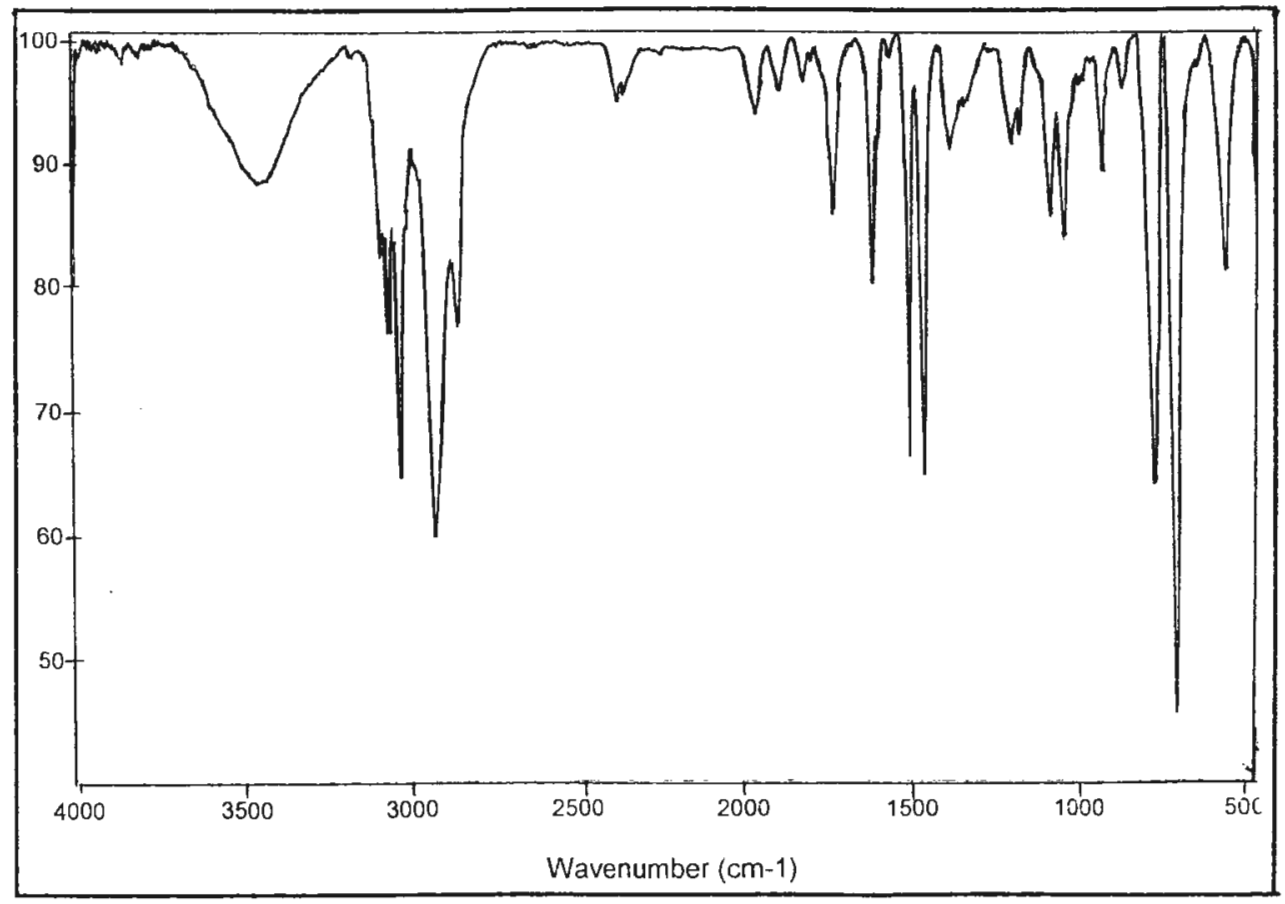

Espectro 6: Espectro de infravermelho do copolímero TSB10 hidrolisado em pastilha de $\mathrm{KBr}$. 


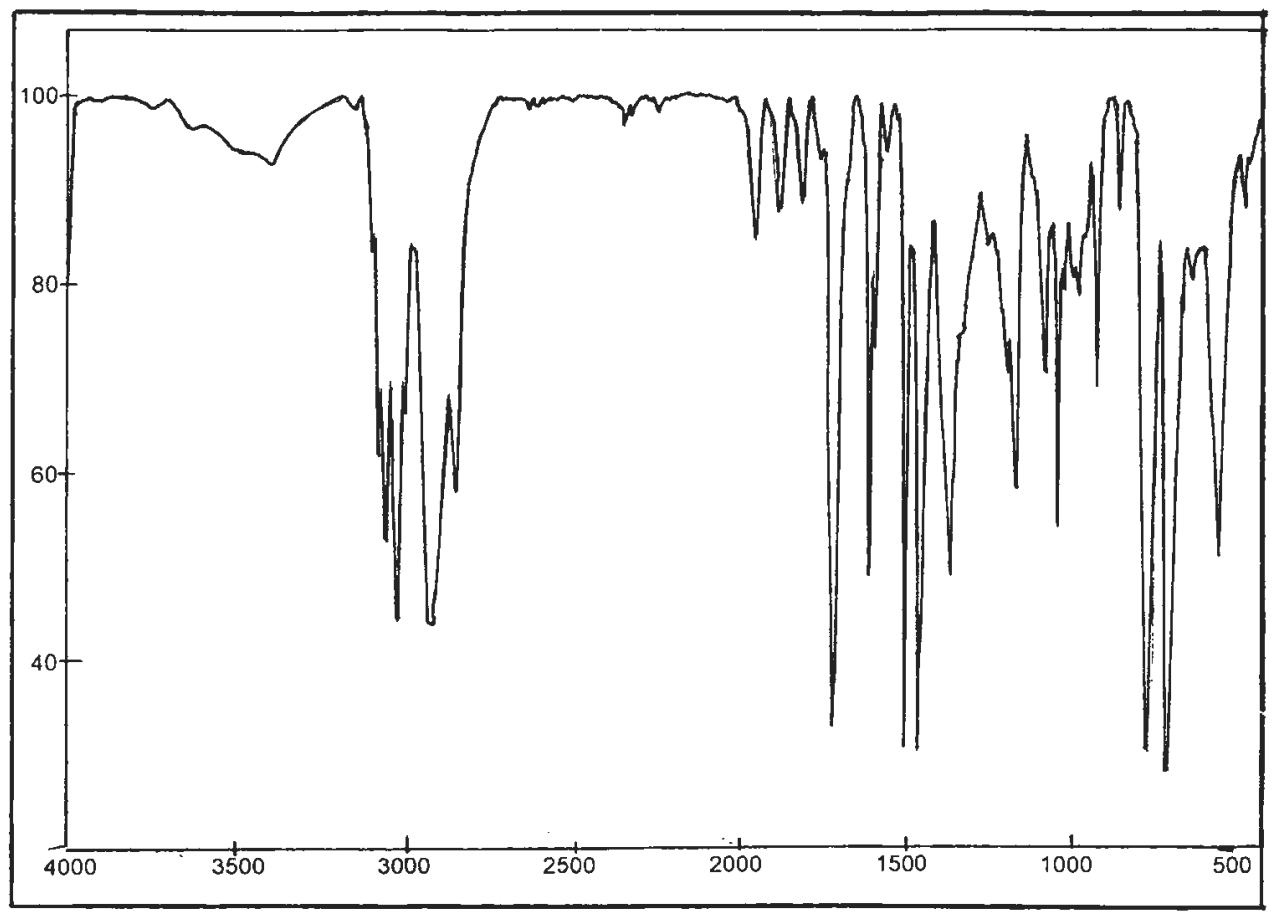

Espectro 7: Espectro de infravermelho do copolímero TSB15 hidrolisado em pastilha de $\mathrm{KBr}$.

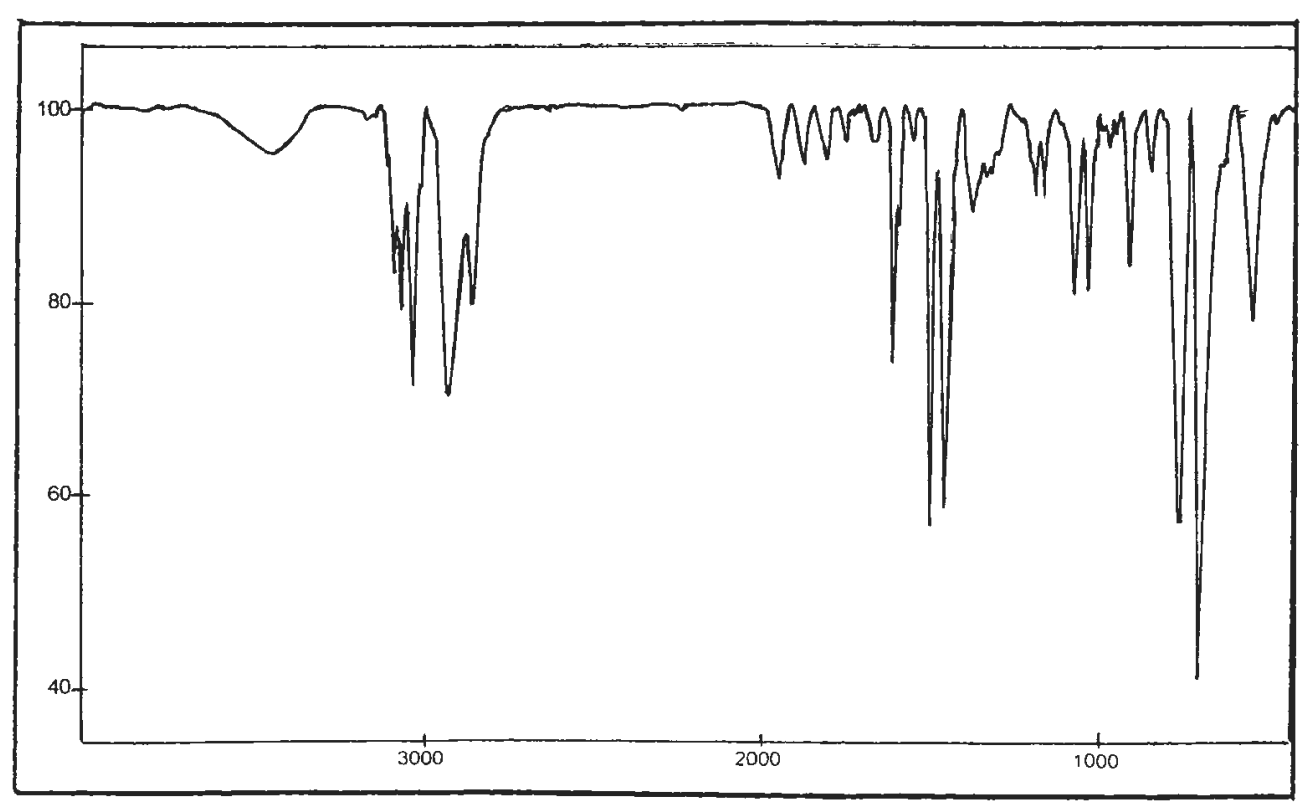

Espectro 8: Espectro de infravermelho do copolímero MEB5 hidrolisado em pastilha de $\mathrm{KBr}$. 


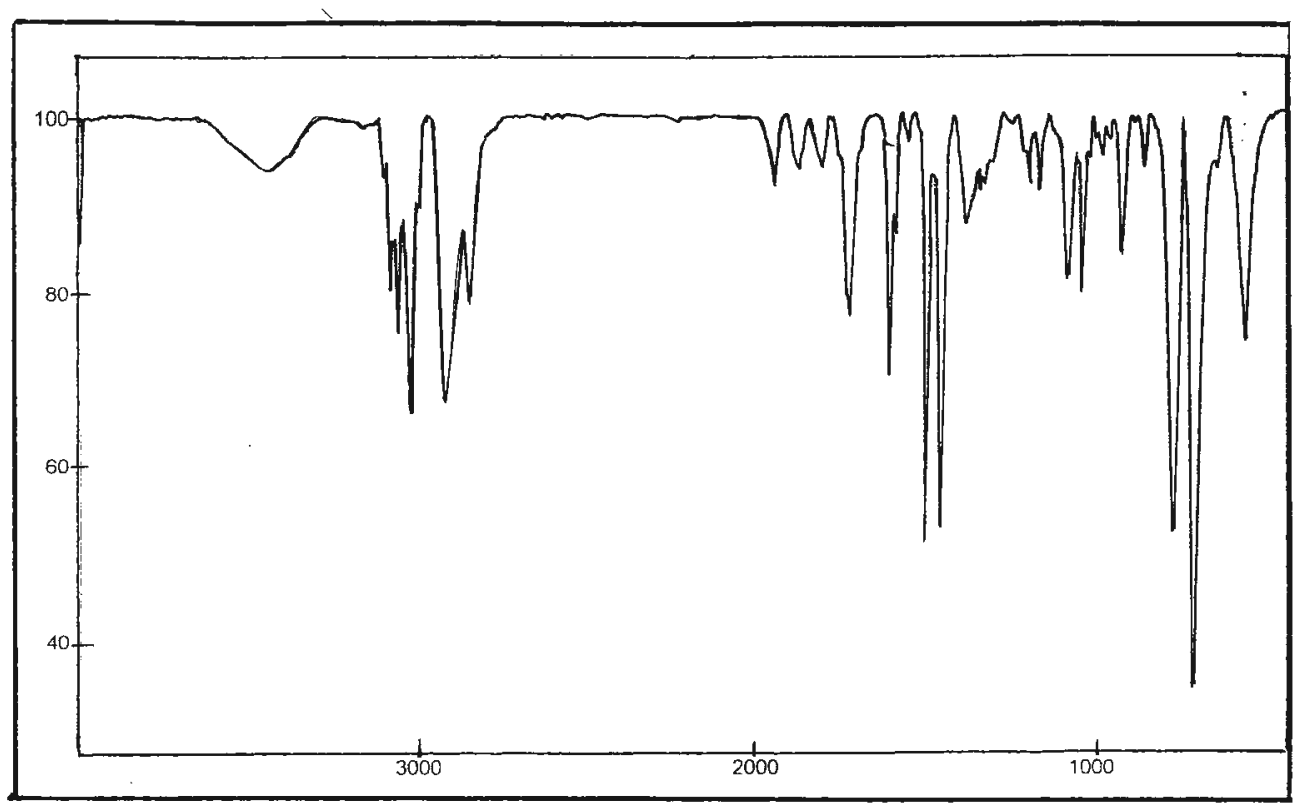

Espectro 9: Espectro de infravermelho do copolímero MEB10 hidrolisado em pastilha de $\mathrm{KBr}$.

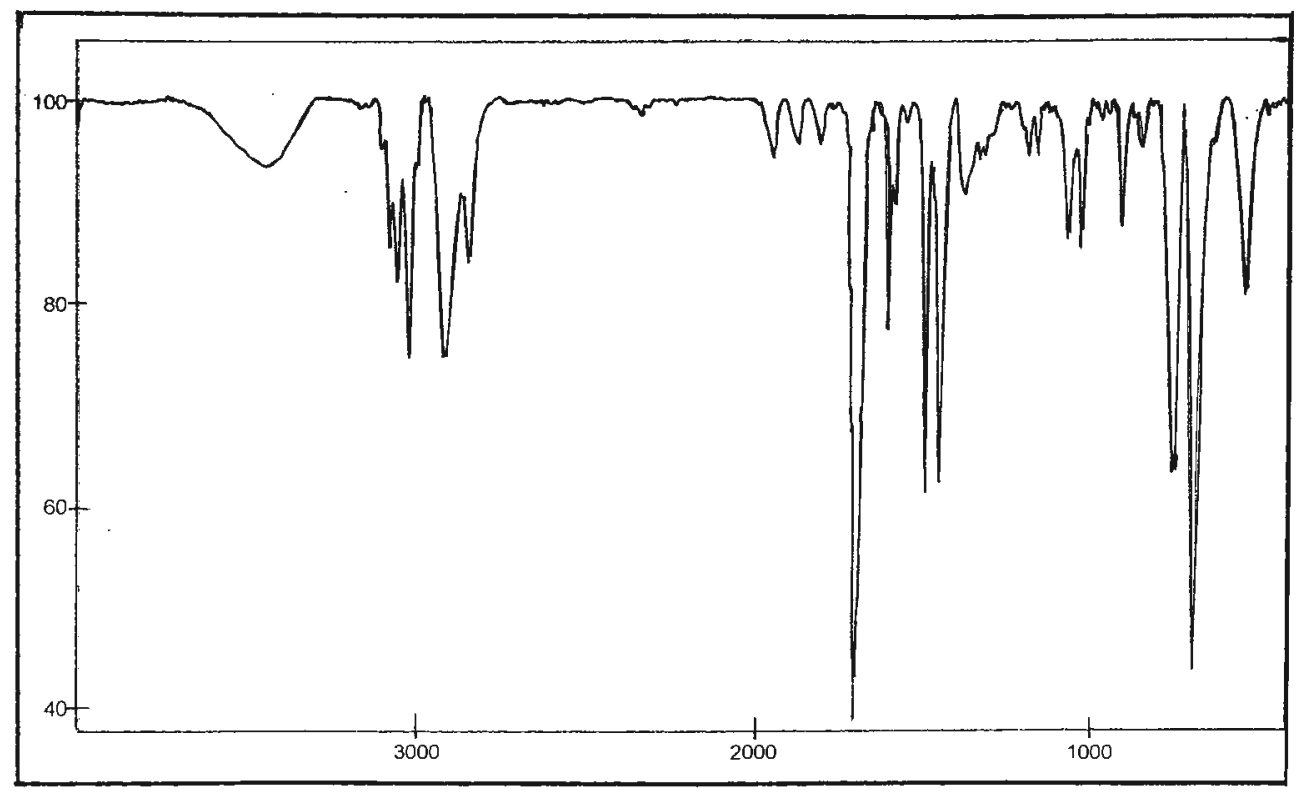

Espectro 10: Espectro de infravermelho do copolímero MEB15 hidrolisado em pastilha de $\mathrm{KBr}$. 


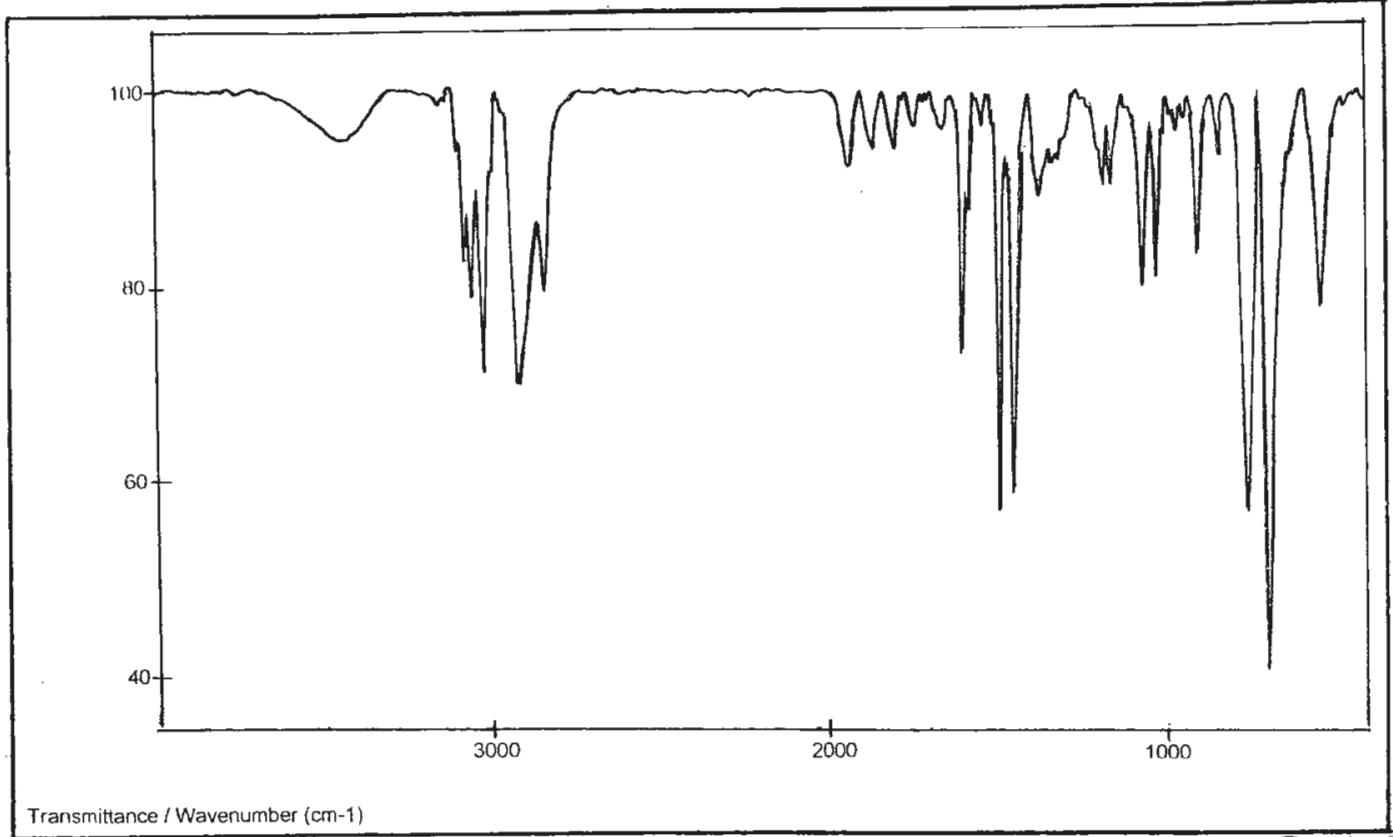

Espectro 11: Espectro de infravermelho do copolimero ETB5 hidrolisado em pastilha de $\mathrm{KBr}$.

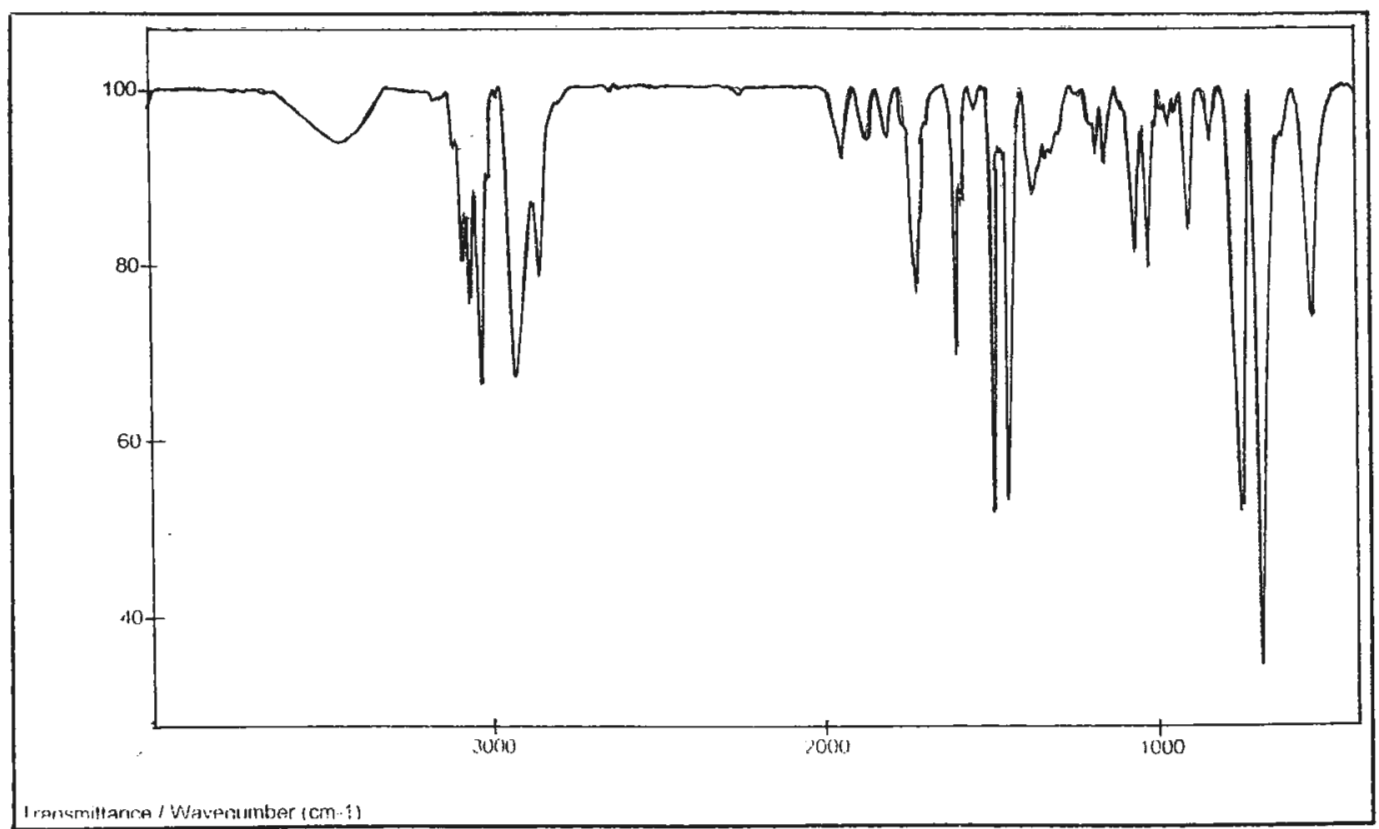

Espectro 12: Espectro de infravermelho do copolimero ETB10 hidrolisado em pastilha de $\mathrm{KBr}$. 


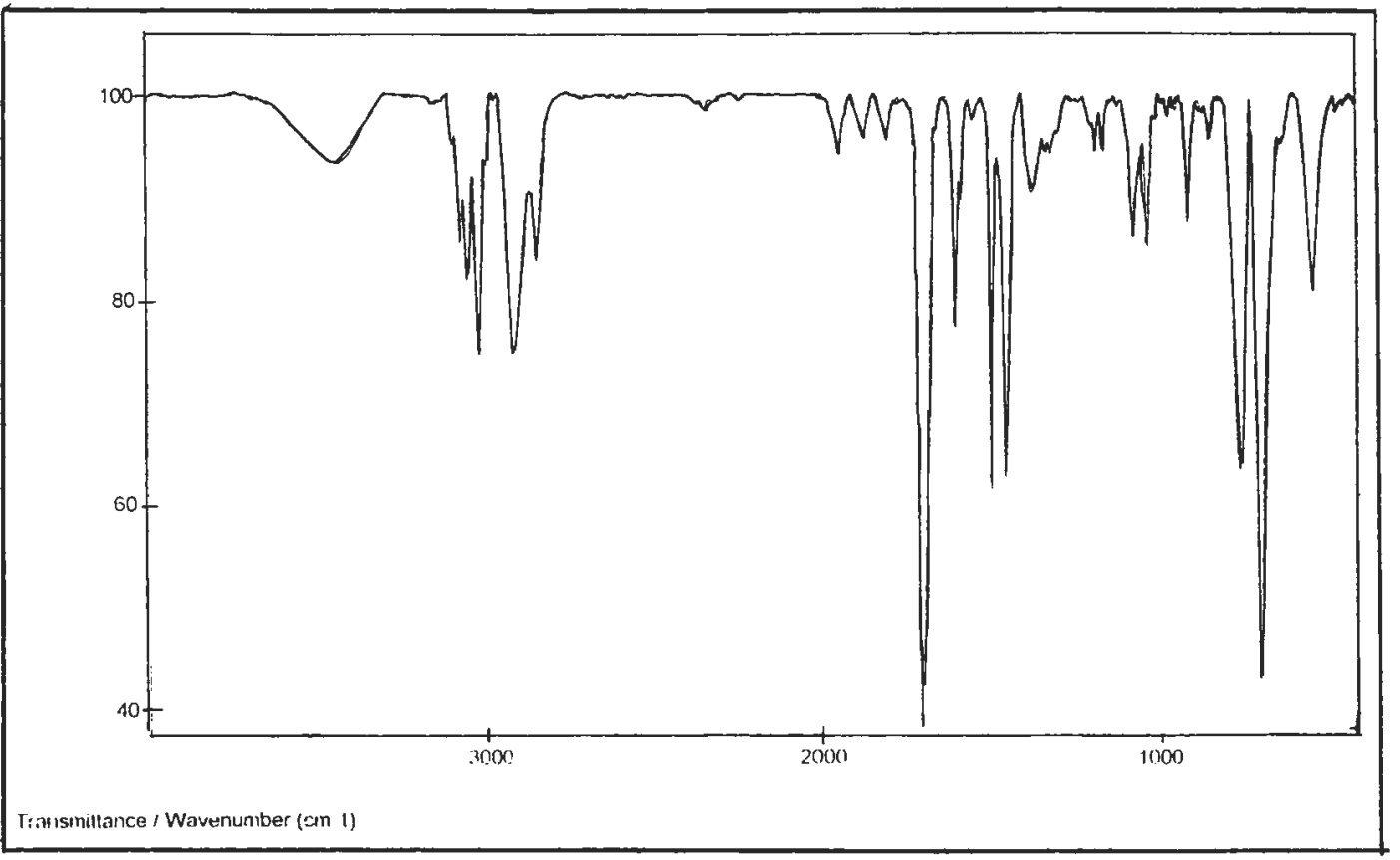

Espectro 13: Espectro de infravermelho do copolímero ETB15 hidrolisado em pastilha de $\mathrm{KBr}$.

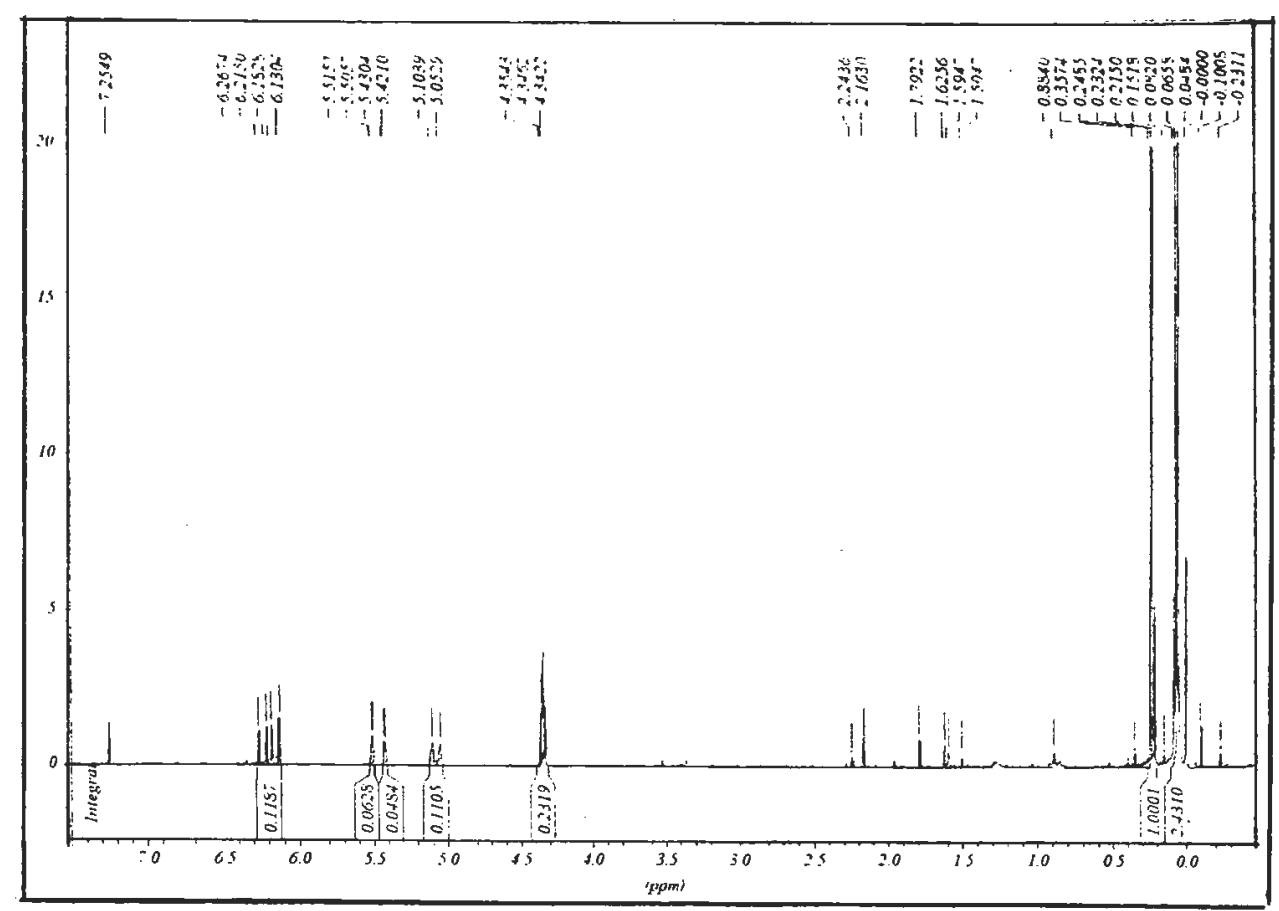

Espectro 14: Espectro de ${ }^{1} \mathrm{H}-\mathrm{NMR}$ do 2-trimetilsililóxi-1,3-butadieno (TSB). 


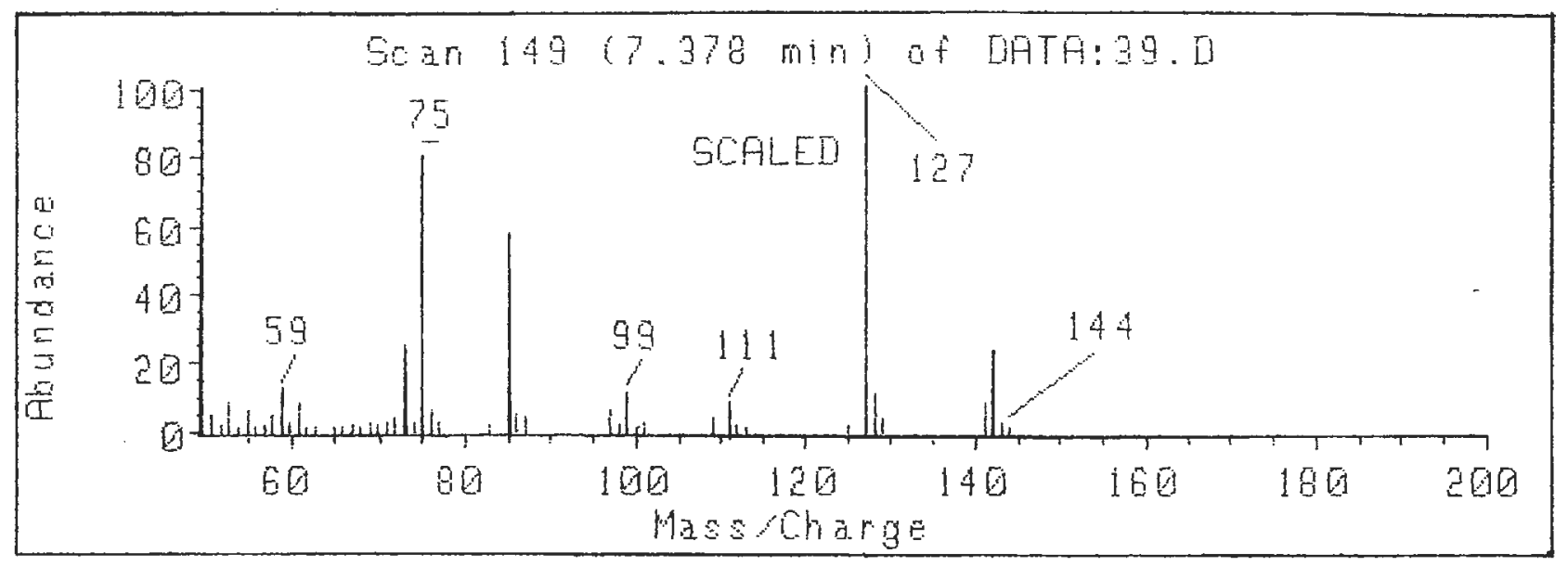

Espectro 15: Espectro de massa do 2-trimetilsililóxi-1,3-butadieno (TSB).

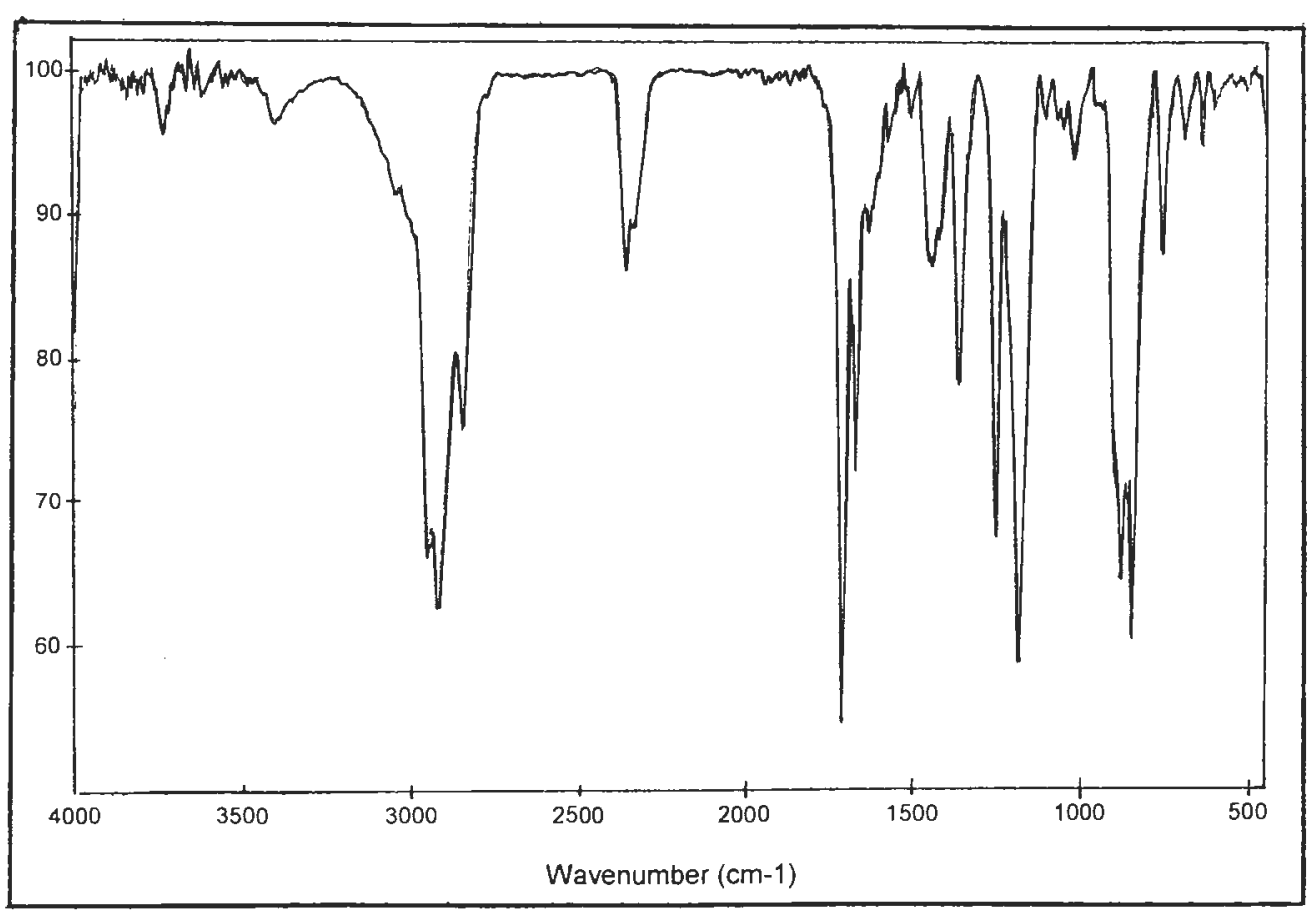

Espectro 16: Espectro de infravermelho do 2-trimetilsililóxi-1,3-butadieno (TSB) sobre cristal de $\mathrm{NaCl}$. 


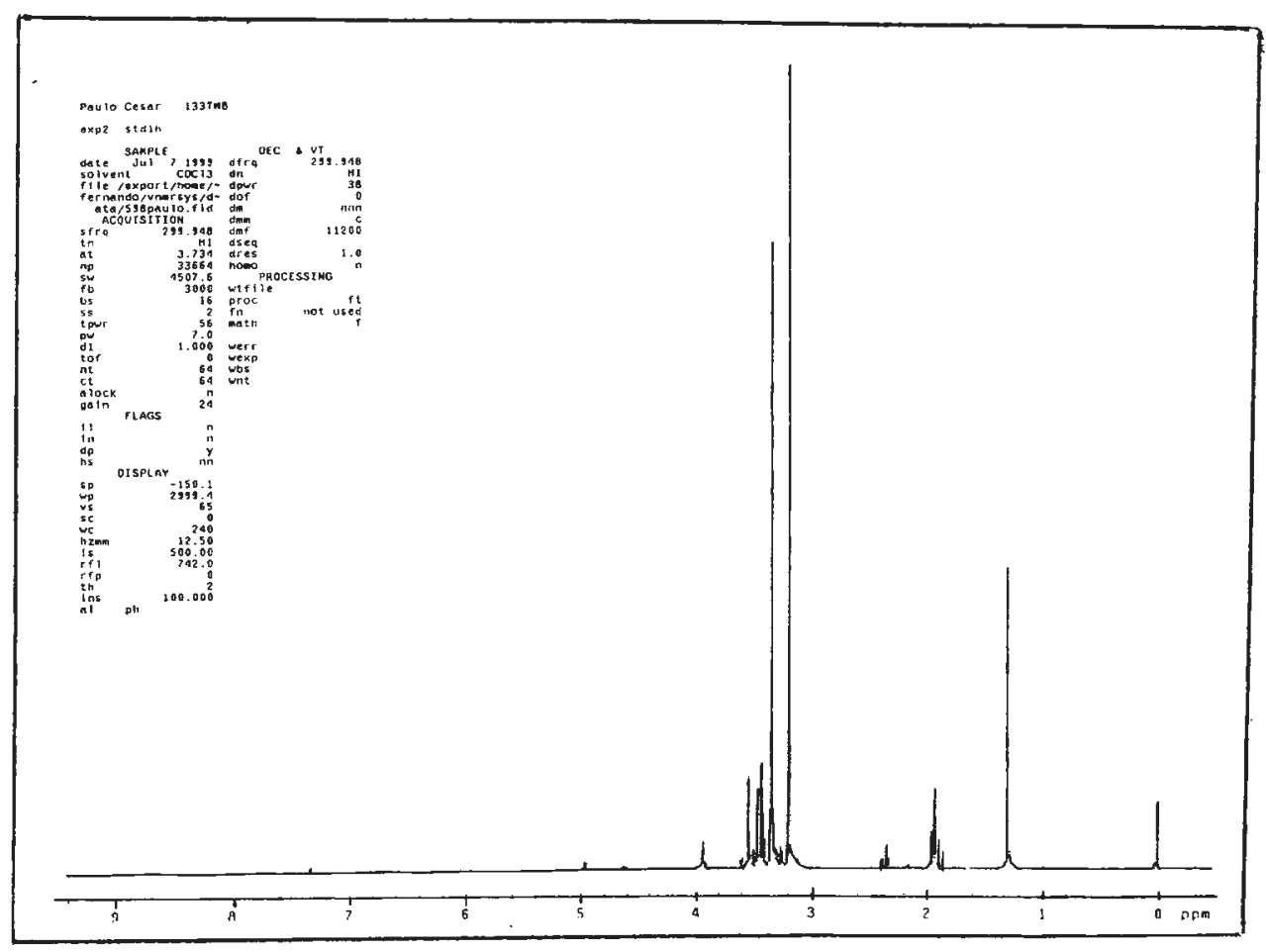

Espectro 17: Espectro de ${ }^{1} \mathrm{H}-\mathrm{NMR}$ do 1,3,3-trimetóxibutano.

\section{Scan \# : 440}

Mass Peak \#: 11 Ret. Time : 4.758

Base Peak : 47.00 ( 11152670)

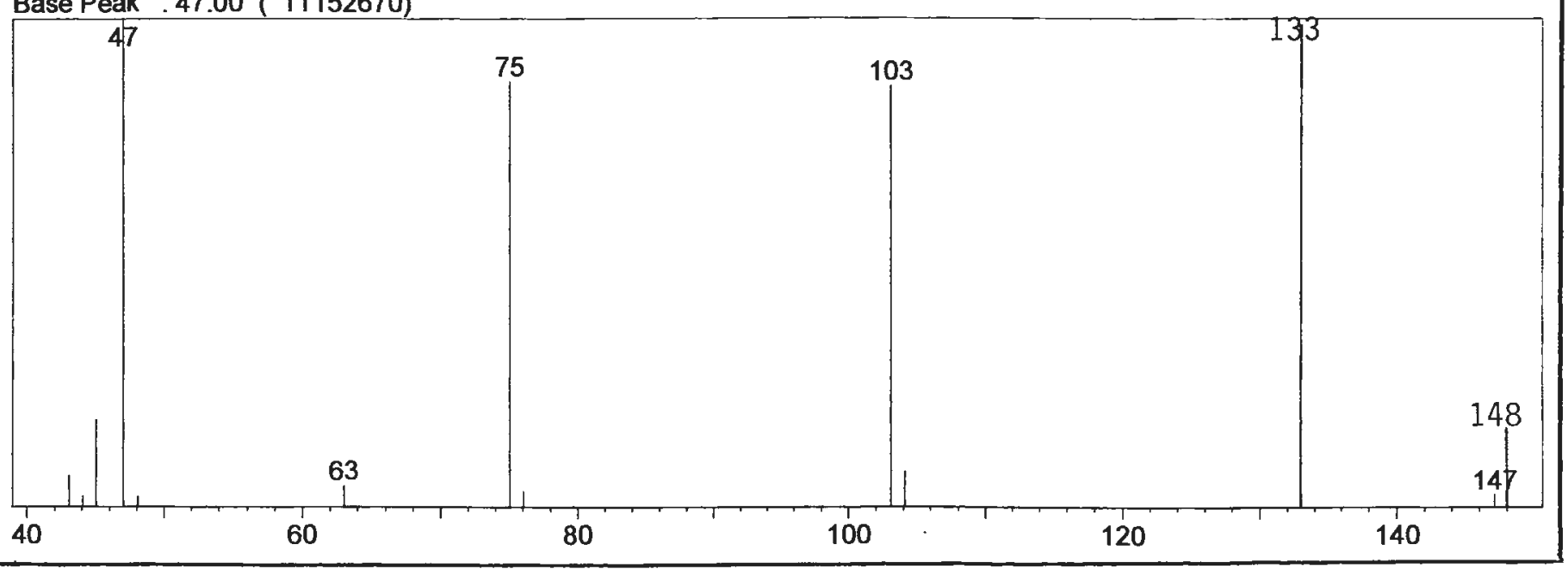

Espectro 18: Espectro de massa do 1,3,3-trimetóxibutano. 


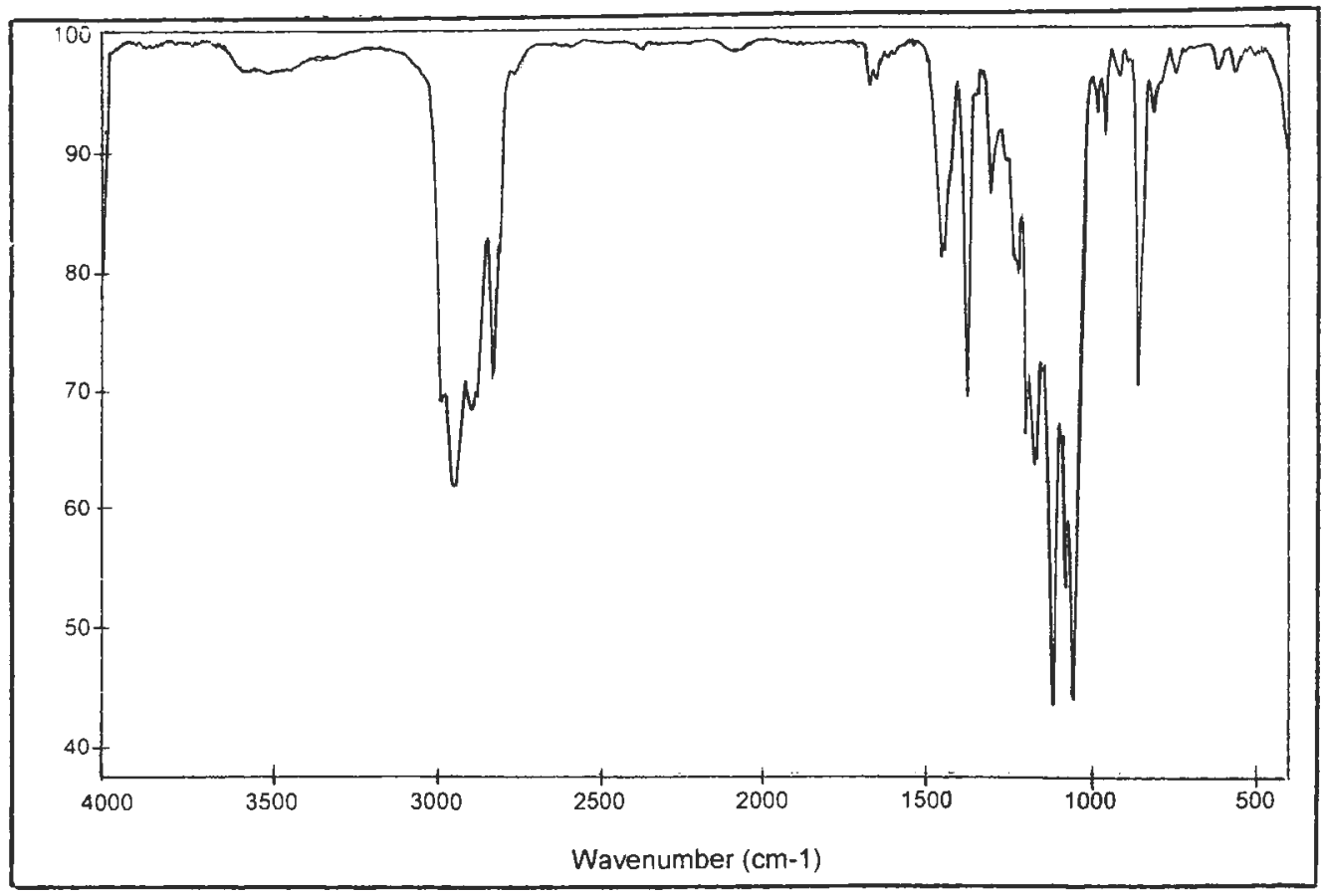

Espectro 19: Espectro de infravermelho do 1,3,3-trimetóxibutano sobre cristal de $\mathrm{NaCl}$.

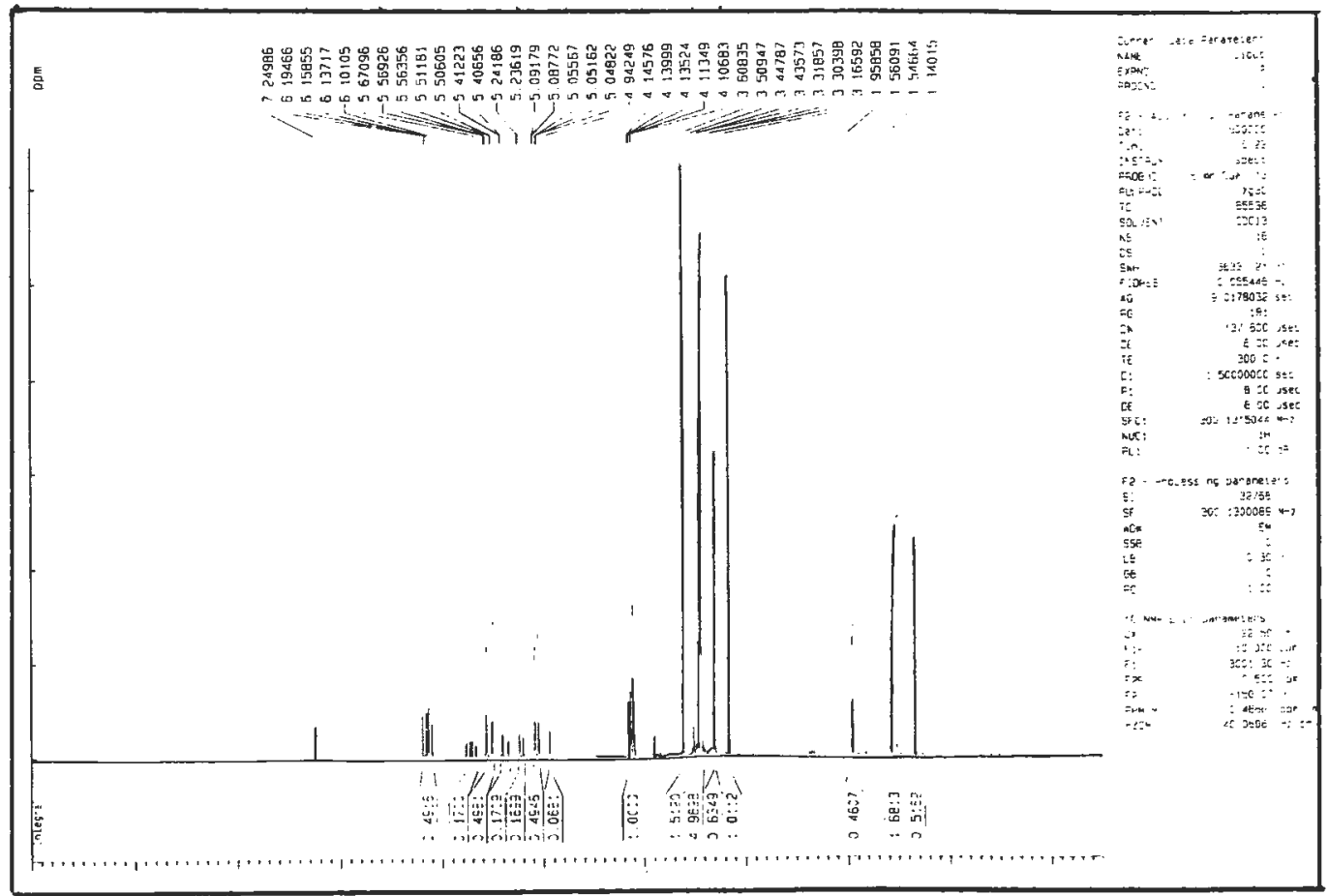

Espectro 20: Espectro de ${ }^{1} \mathrm{H}-\mathrm{NMR}$ do 2-metóxi-1,3-butadieno (MEB). 


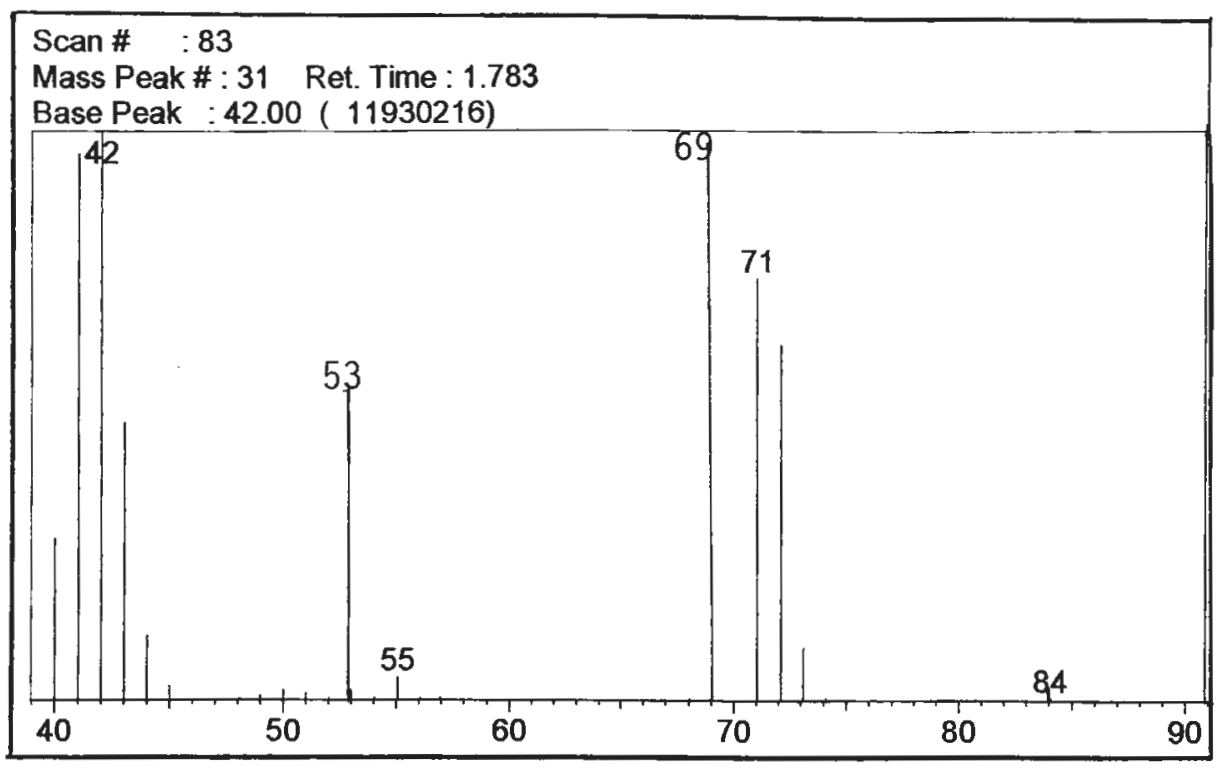

Espectro 21: Espectro de massa do 2-metóxi-1,3-butadieno (MEB).

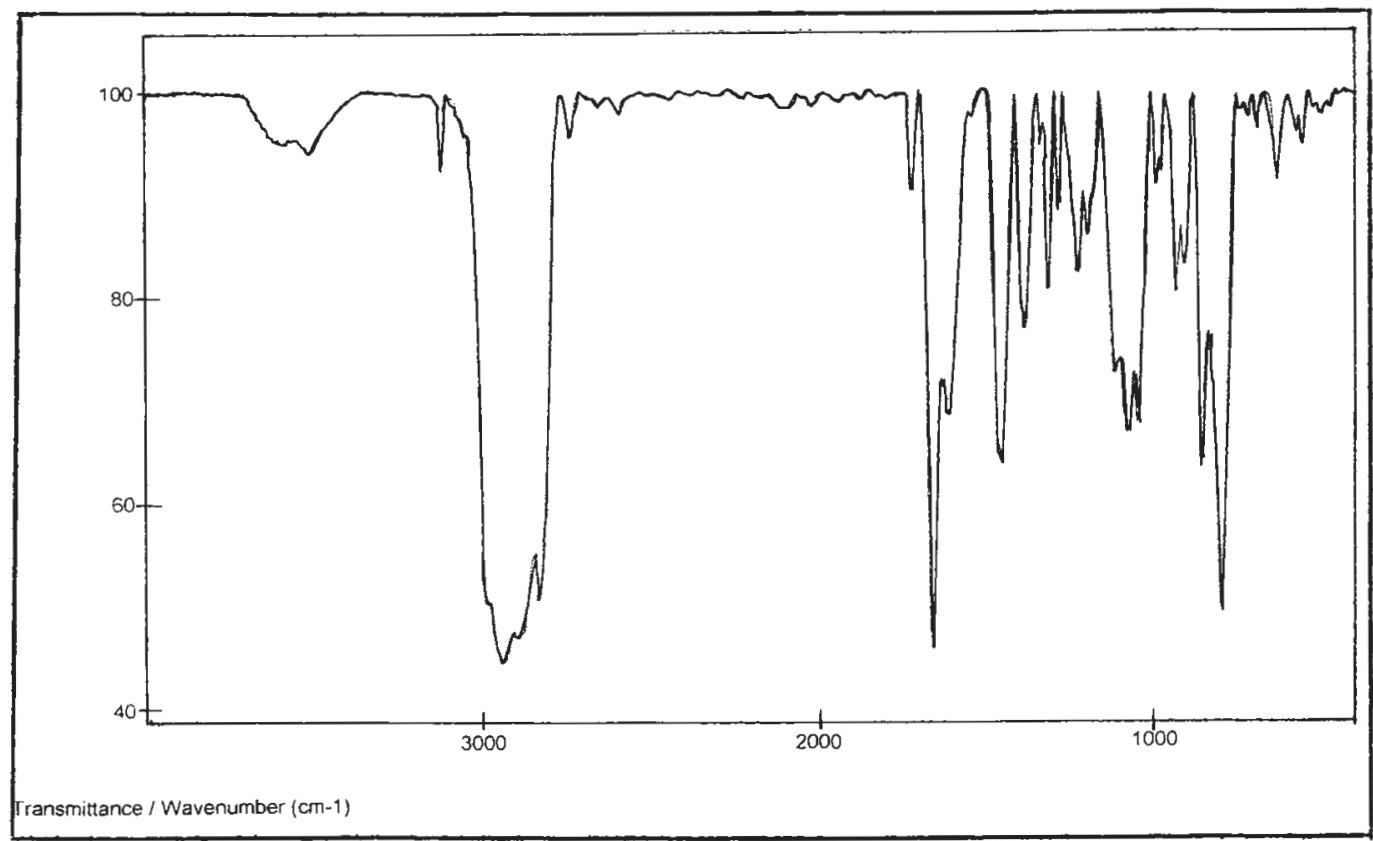

Espectro 22: Espectro de infravermelho do 2-metóxi-1,3-butadieno sobre cristal de $\mathrm{NaCl}$. 


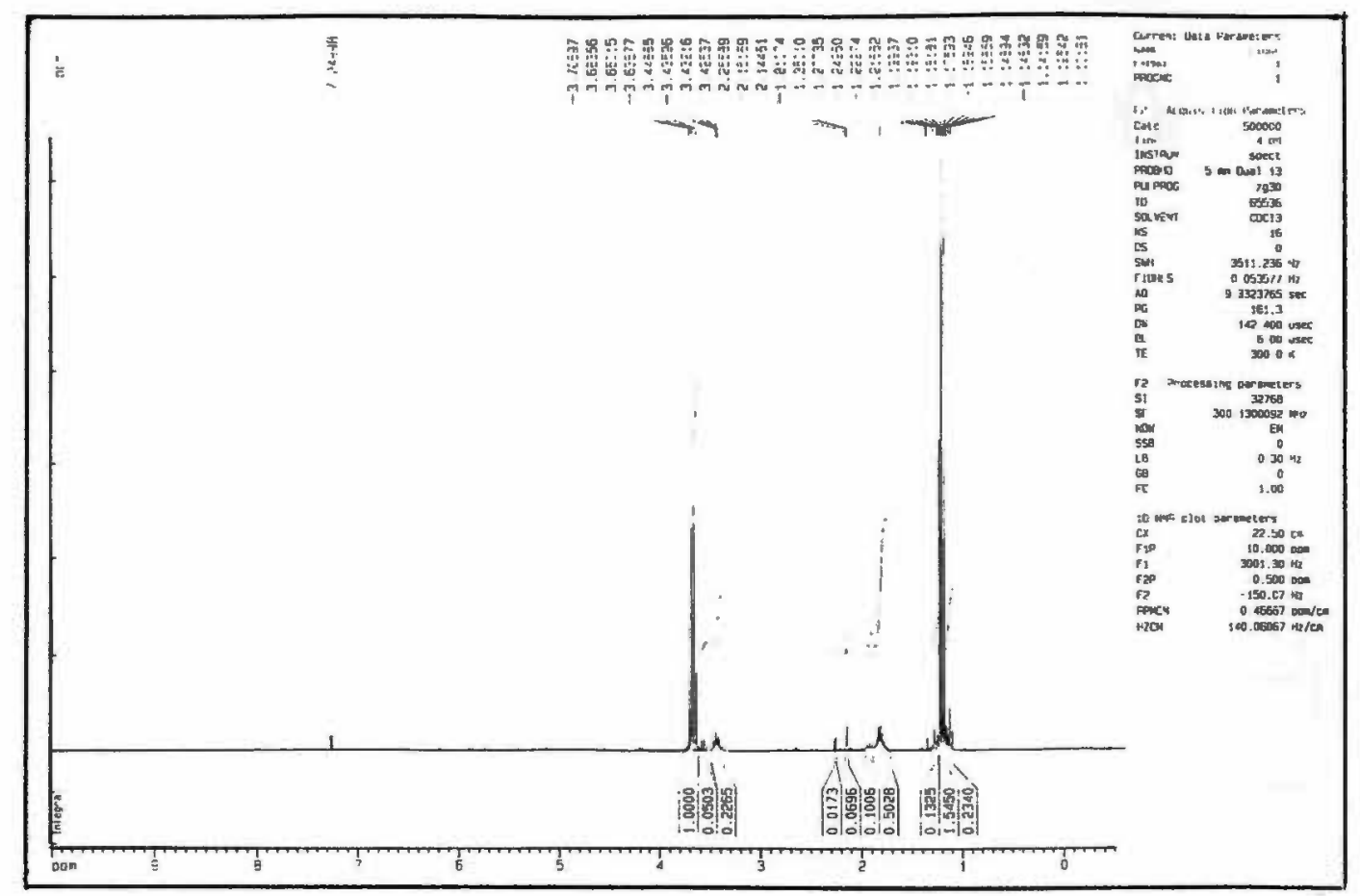

Espectro 23: Espectro de ${ }^{1} \mathrm{H}-\mathrm{NMR}$ do 2-etóxi-1,3-butadieno (ETB).

Scan \# : 120

Mass Peak \#: 28 Ret. Time : 2.092

Base Peak : 75.00 ( 15549531)

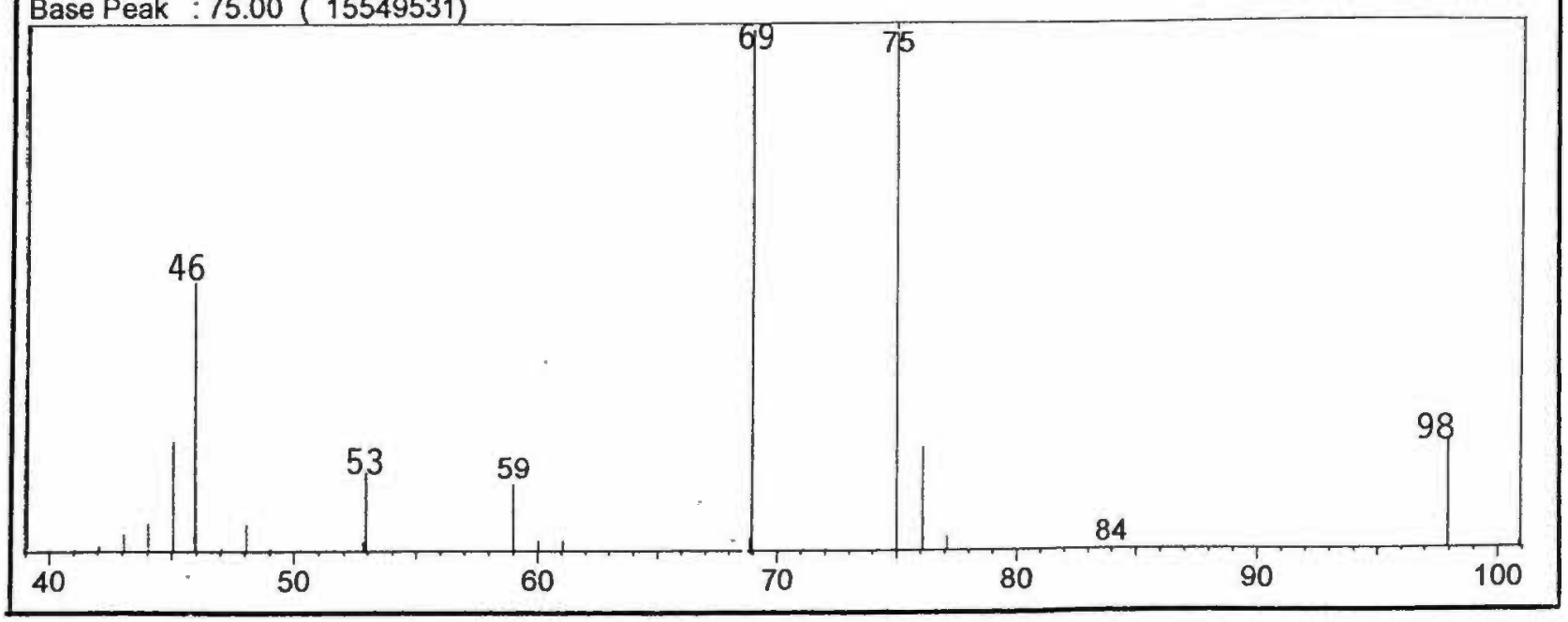

Espectro 24: Espectro de massa do 2-etóxi-1,3-butadieno (ETB). 


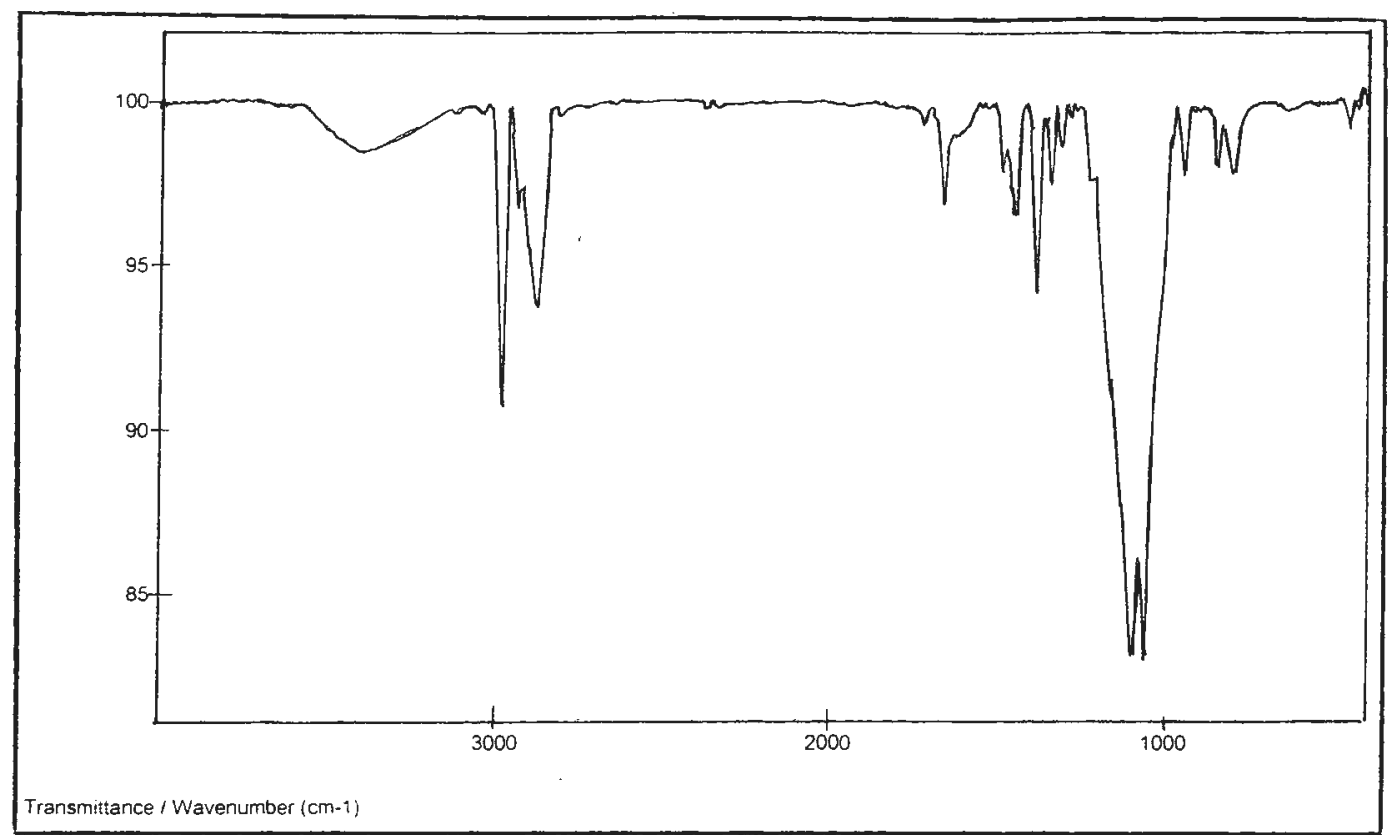

Espectro 25: Espectro de infravermelho do 2-etóxi-1,3-butadieno sobre cristal de $\mathrm{NaCl}$. 